\author{
SANDIA REPORT \\ SAND2012-6350 \\ Unlimited Release \\ August 2012
}

\title{
Inherently Safer Technology Gaps Analysis Study
}

\author{
Mitchell R. Anstey \\ Greg W. Foltz \\ Scott M. Paap \\ Margaret E. Ochs \\ Trisha M. Hoette \\ Calvin D. Jaeger \\ Amy C.-T. Sun
}

Prepared by

Sandia National Laboratories

Albuquerque, New Mexico 87185 and Livermore, California 94550

Sandia National Laboratories is a multi-program laboratory managed and operated by Sandia Corporation, a wholly owned subsidiary of Lockheed Martin Corporation, for the U.S. Department of Energy's

National Nuclear Security Administration under contract DE-AC04-94AL85000.

Approved for public release; further dissemination unlimited. 
Issued by Sandia National Laboratories, operated for the United States Department of Energy by Sandia Corporation.

NOTICE: This report was prepared as an account of work sponsored by an agency of the United States Government. Neither the United States Government, nor any agency thereof, nor any of their employees, nor any of their contractors, subcontractors, or their employees, make any warranty, express or implied, or assume any legal liability or responsibility for the accuracy, completeness, or usefulness of any information, apparatus, product, or process disclosed, or represent that its use would not infringe privately owned rights. Reference herein to any specific commercial product, process, or service by trade name, trademark, manufacturer, or otherwise, does not necessarily constitute or imply its endorsement, recommendation, or favoring by the United States Government, any agency thereof, or any of their contractors or subcontractors. The views and opinions expressed herein do not necessarily state or reflect those of the United States Government, any agency thereof, or any of their contractors.

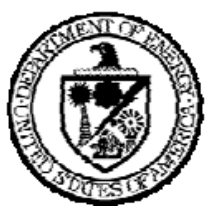


SAND2012-6350

Unlimited Release

August 2012

\title{
Inherently Safer Technology Gaps Analysis Study
}

\author{
Mitchell R. Anstey, Greg W. Foltz, Scott M. Paap, Margaret E. Ochs, Trisha M. Hoette, Calvin \\ D. Jaeger, Amy C.-T. Sun \\ 8125, 8114, 6124, 6833, 1814 \\ Sandia National Laboratories \\ 7011 East Avenue \\ Livermore, California 94550-MS9291
}

\begin{abstract}
This project consisted of an analysis of the current state of knowledge for improving safety regarding toxic industrial chemicals, including an examination of current and state-of-the-art techniques and technologies capable of increasing safety and security in production, transportation, storage, and use of hazardous chemicals. The primary goal was to improve national security through improved safety by providing a foundation for a comprehensive evaluation of the current state of knowledge surrounding the source and production methods of the "Release - Toxic" chemicals in DHS CFATS Appendix A list of chemicals of interest. Additionally, this project assisted in the data gathering and development of the CSAC IST Metrics. This involved an in-depth effort to understand specific chemical processes followed by a conceptual effort to redefine the Chemical Release Reduction Modifier that was included in the original Index.
\end{abstract}




\section{ACKNOWLEDGMENTS}

This work was performed under the programmatic direction and funding received from DHS/Science \& Technology Directorate, Chemical Security and Analysis Center. 


\section{CONTENTS}

Inherently Safer Technology Gaps Analysis Study .......................................................................... 3

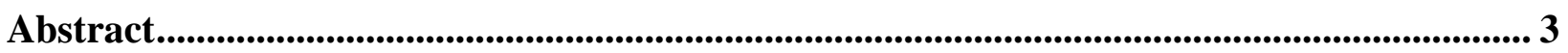

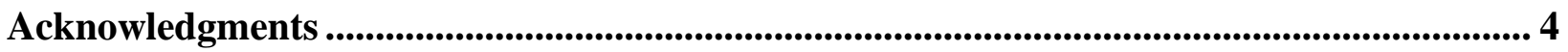

Nomenclature ........................................................................................................................ 8

1. Introduction to Gaps Study for Increasing Safety of Hazardous Chemicals.................... 9

1.1. Introduction ..................................................................................................................................... 9

1.2. Definition of Inherently Safer Technology ……………......................................................................9

1.3. Original Gaps Study Scope..............................................................................................................10

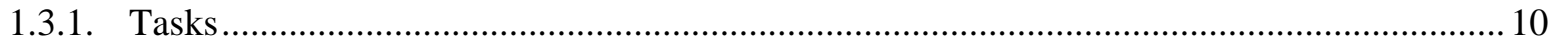

1.4. Rescoping to Support CSAC IST Metrics ....................................................................................12

1.4.1. Data Acquisition for Metrics ………………………………………………………...... 12

1.4.2. Development of a Detailed Chemical Release Reduction Modifier .......................................12

1.5. Project Conclusion............................................................................................................................... 13

1.6. References....................................................................................................................... 13

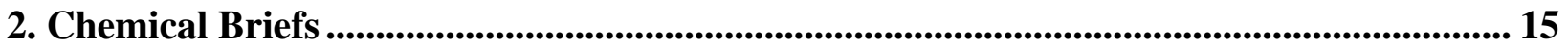

2.1. Introduction ............................................................................................................................ 15

2.2. Completed Chemical Briefs ...............................................................................................................16

2.2.1. 2-Methyl Aziridine …………………………………………………………………... 16

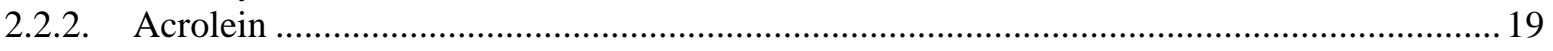

2.2.3. Allyl Alcohol ............................................................................................................. 23

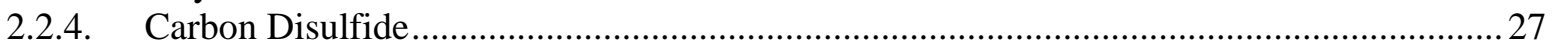

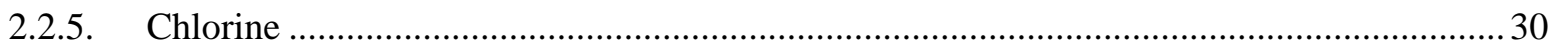

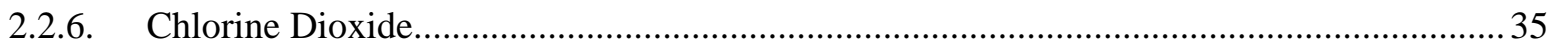

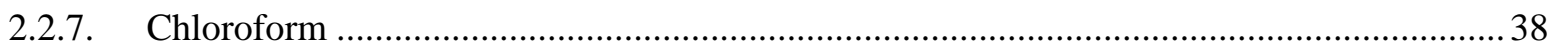

2.2.8. Chloromethyl Methyl Ether ......................................................................................... 41

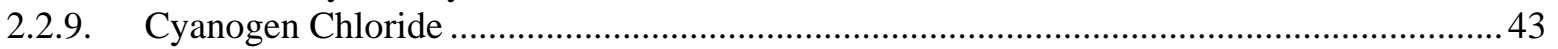

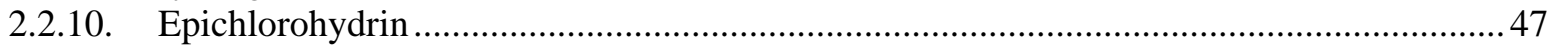

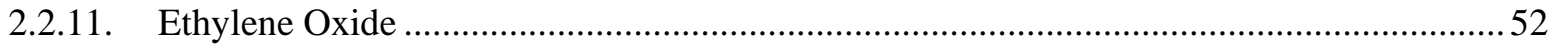

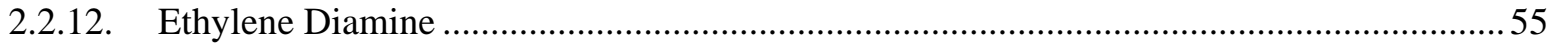

2.2.13. Hydrogen Sulfide................................................................................................... 57

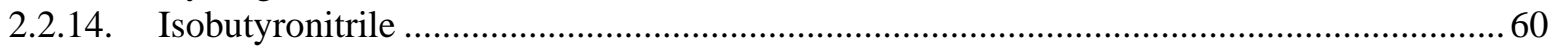

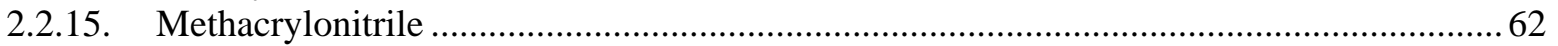

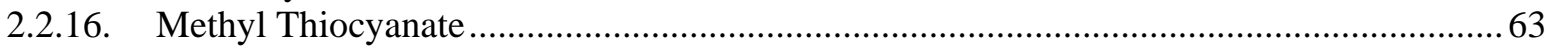

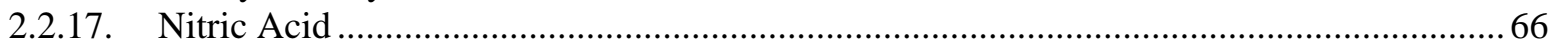

2.2.18. Phosphorus Oxychloride................................................................................................69

2.2.19. Phosphorus Trichloride............................................................................................. 71

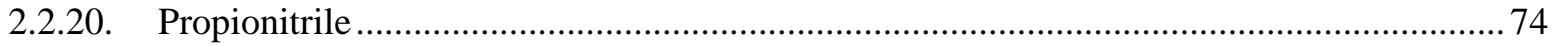

2.3. Miscellaneous Chemical Supply Chain Trees .............................................................................77

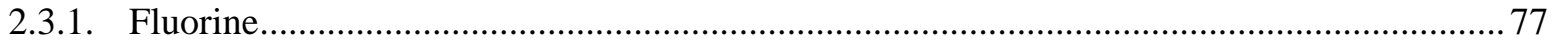

2.4. IST Data Sheet Form........................................................................................................................ 77

3. Categorization of DHS CFATS Appendix A "Release - Toxic" Chemicals ..................... 80

3.1. Introduction ..................................................................................................................................... 81

3.2. Elemental Composition ....................................................................................................................... 81

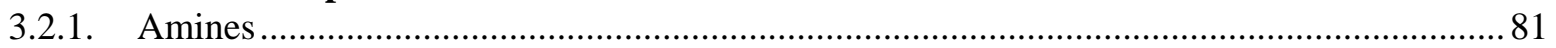

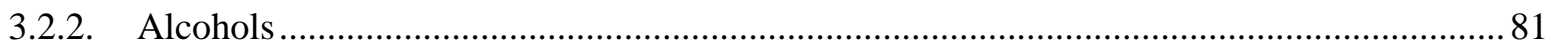

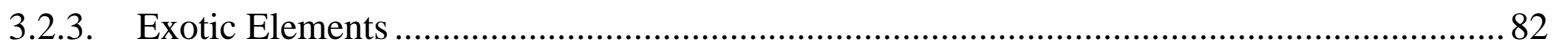




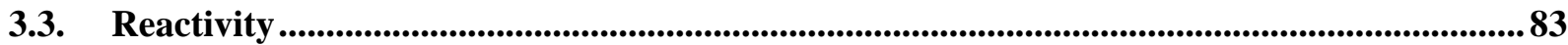

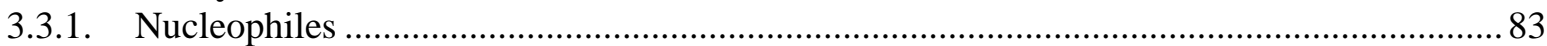

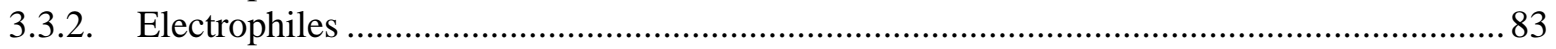

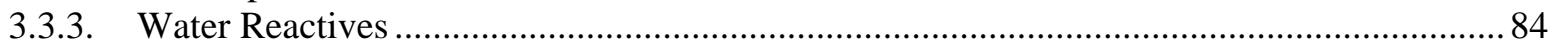

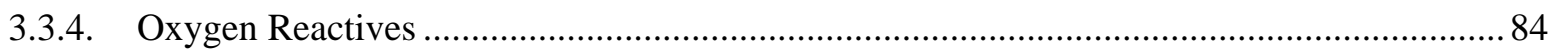

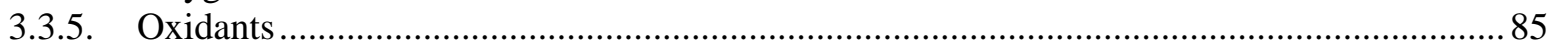

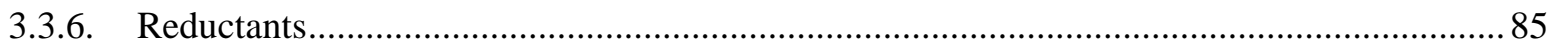

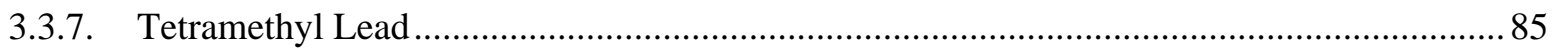

3.4. Top Priority Candidates........................................................................................................................ 86

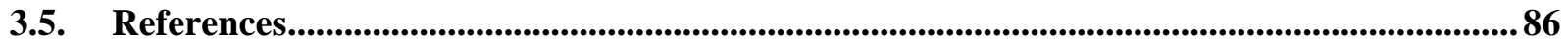

4. Acid-Catalyzed Alkylation Process Analysis.................................................................................. 87

4.1. Introduction ...................................................................................................................................... 87

4.2. Industry Overview and Process Design .........................................................................................8

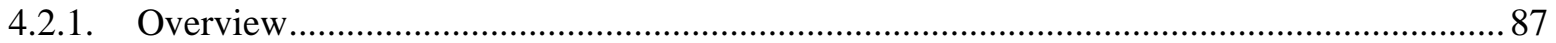

4.2.2. Alkylate Production Process Design..................................................................................... 89

4.2.3. Process Volumes.................................................................................................... 90

4.2.4. Catalyst Regeneration Processes ......................................................................................... 91

4.3. Transportation and Storage of Acid Inventories ......................................................................94

4.4. CSAC Metrics Charts......................................................................................................99

4.5. Conclusions.......................................................................................................................................95

4.6. References........................................................................................................................96

5. Epichlorohydrin Production and IST Alternatives...............................................................97

5.1. Introduction ..................................................................................................................................97

5.2. Production Volume and Use ......................................................................................................97

5.3. Modern Production Methods.......................................................................................................97

5.3.1. Propylene-based Epichlorohydrin......................................................................................97

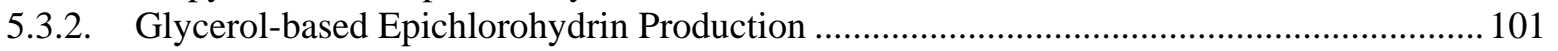

5.4. Comparison of Technologies............................................................................................................. 103

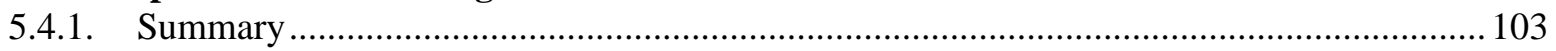

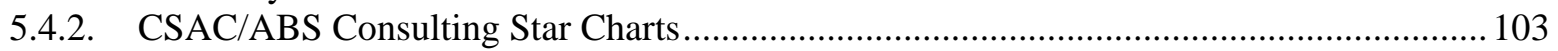

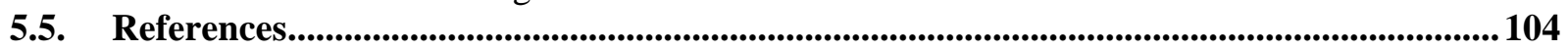

6. IST Search in Hydrogen Cyanide-Derived Chemicals......................................................... 107

6.1. Introduction ........................................................................................................................................ 107

6.2. Hydrogen Cyanide Classical Production...................................................................................107

6.3. Methyl Methacrylate Classical Production ..................................................................................... 108

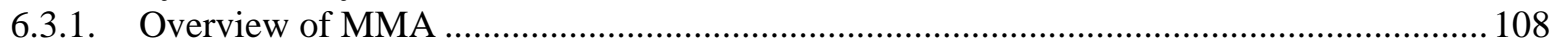

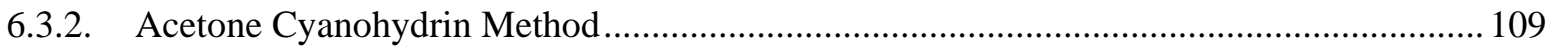

6.3.3. Mitsubishi Gas Company Method ............................................................................... 110

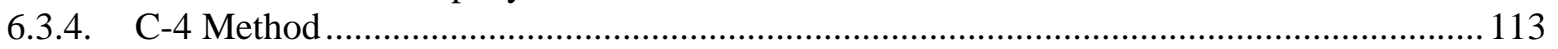

6.3.5. Final Comments on MMA Processes .......................................................................... 114

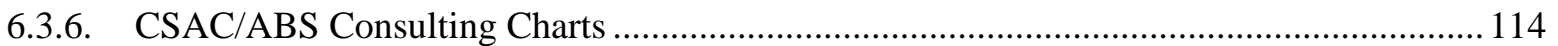

6.4. Methionine Production Processes ...............................................................................................117

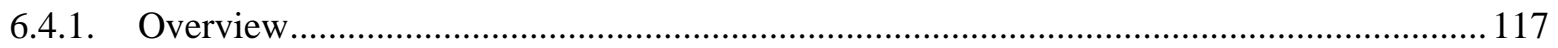

6.4.2. Petrochemical Methionine Production.............................................................................. 118

6.4.3. Biochemical Production of Methionine ……………….............................................. 121

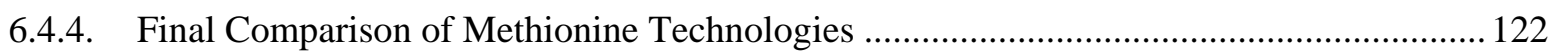

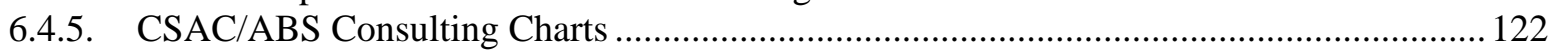

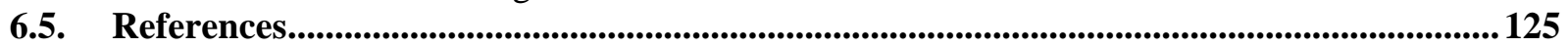


7. Chemical Release Prevention and Mitigation, Metrics Effort.............................................. 127

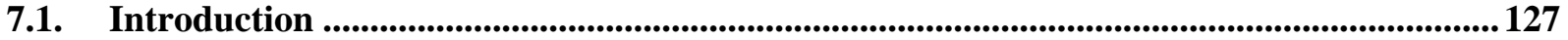

7.2. Chemical Release Prevention and Mitigation Countermeasures .......................................... 127

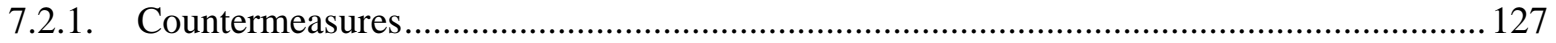

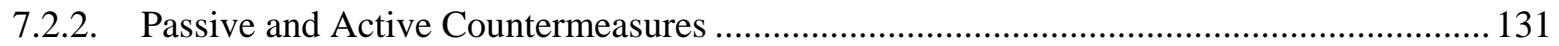

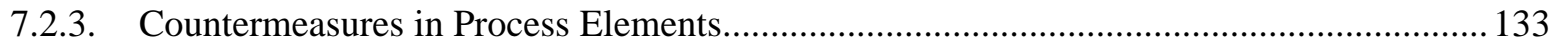

7.2.4. Countermeasures on a Timeline of a Release Event....................................................... 134

7.3. Chemical Release Countermeasures Reduction Modifier Architecture.............................136

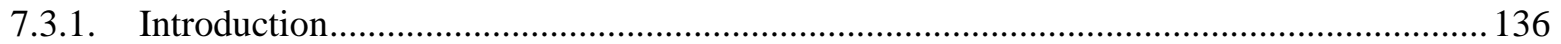

7.3.2. Sandia Countermeasure Reduction Modifier Development ............................................. 137

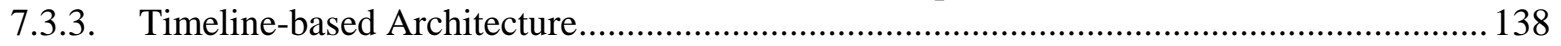

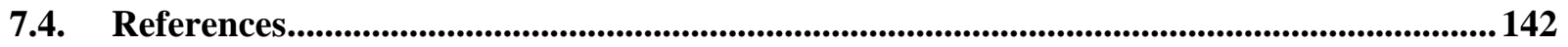

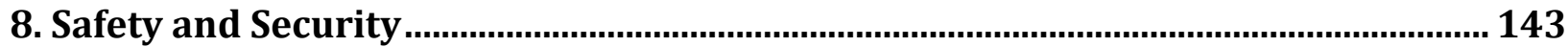

8.1. Risk Triplets for Accidental vs. Intentional Scenarios .................................................144

8.2. Assessing difficulty of CSC versus traditional chemical scenarios...............................145

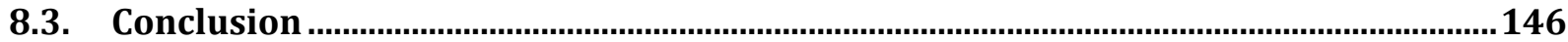

Distribution .......................................................................... Error! Bookmark not defined.147 


\section{NOMENCLATURE}

$\begin{array}{ll}\text { DHS } & \text { Department of Homeland Security } \\ \text { DOE } & \text { Department of Energy } \\ \text { DOT } & \text { Department of Transportation } \\ \text { CSAC } & \text { Chemical Security and Analysis Center } \\ \text { SNL } & \text { Sandia National Laboratories } \\ \text { OSHA } & \text { Occupational Safety and Health Administration } \\ \text { EPA } & \text { Environmental Protection Agency } \\ \text { IST } & \text { Inherently Safer Technology } \\ \text { ISD } & \text { Inherently Safer Design } \\ \text { ISHC } & \text { Increasing Safety of Hazardous Chemicals } \\ \text { SRIC } & \text { Stanford Research Institute Consulting } \\ \text { CEH } & \text { Chemical Economics Handbook } \\ \text { CDM } & \text { Chemical Data Model } \\ \text { CFATS } & \text { Chemical Facility Anti-Terrorism Standards } \\ \text { TIH } & \text { Toxic Inhalation Hazard } \\ \text { CSTR } & \text { Continuously Stirred Tank Reactor }\end{array}$




\section{INTRODUCTION TO GAPS STUDY FOR INCREASING SAFETY OF HAZARDOUS CHEMICALS}

\subsection{Introduction}

Inherently Safer Technology (IST) or Inherently Safer Design (ISD) is a wide-ranging field centered on industrial safety. Typically, it has been used by industry during the design and planning stages for facilities to manage risks associated with hazardous materials and conditions. In the context of this project, we will be focusing on chemical and chemical process hazards. Because of its success and trusted reputation, IST has been adopted in one version or another by most chemical manufacturing facilities, and attempts to incorporate IST into chemical security regulations have been proposed.

The Department of Homeland Security (DHS) and the Chemical Security and Analysis Center (CSAC) have begun a study to define IST and understand the extent to which it can assist in regulation. Literature ${ }^{1}$ exists that supports the idea that IST principles can increase safety and reduce the risk that the U.S. chemical industry poses to the public, but there is no agreement on the magnitude of the benefit.

This specific project originally consisted of an analysis of the current state of knowledge for improving safety regarding toxic industrial chemicals, including an examination of current and state-of-the-art techniques and technologies capable of increasing safety and security in production, transportation, storage, and use of hazardous chemicals. The primary goal was to improve security through improved safety by providing a foundation for conducting a comprehensive evaluation of the current state of knowledge surrounding the source and production methods of the "Release - Toxic" chemicals in DHS CFATS Appendix A list of chemicals of interest.

As the needs of CSAC changed over the life of the project, our team has been directed to assist in the data gathering and development of the CSAC IST Metrics headed by ABS Consulting. This involved an in-depth effort to understand specific chemical processes, followed by a conceptual effort to redefine the Chemical Release Reduction Modifier that was included in the original Index.

\subsection{Definition of Inherently Safer Technology ${ }^{2}$}

A project was recently completed by the Center for Chemical Process Safety for CSAC to provide a definition of Inherently Safer Technology that was technically sound and complete. While the literature in this field was mostly in agreement on the tenets of IST, this task was necessary to provide a firm foundation for future work by CSAC and others.

“Inherently Safer Technology (IST), also known as Inherently Safer Design (ISD), permanently eliminates or reduces hazards to avoid or reduce the consequences of incidents. IST is a philosophy, applied to the design and operation life cycle, including manufacture, transport, storage, use, and disposal. IST is an iterative process that considers such options, including eliminating a hazard, reducing a hazard, substituting a 
less hazardous material, using less hazardous process conditions, and designing a process to reduce the potential for, or consequences of, human error, equipment failure, or intentional harm. Overall safe design and operation options cover a spectrum from inherent through passive, active and procedural risk management strategies. There is no clear boundary between IST and other strategies.

ISTs are relative: A technology can only be described as inherently safer when compared to a different technology, including a description of the hazard or set of hazards being considered, their location, and the potentially affected population. A technology may be inherently safer than another with respect to some hazards but inherently less safe with respect to others, and may not be safe enough to meet societal expectations.

ISTs are based on an informed decision process: Because an option may be inherently safer with regard to some hazards and inherently less safe with regard to others, decisions about the optimum strategy for managing risks from all hazards are required. The decision process must consider the entire life cycle, the full spectrum of hazards and risks, and the potential for transfer of risk from one impacted population to another. Technical and economic feasibility of options must also be considered.”

\subsection{Original Gaps Study Scope}

The study was a technology assessment consisting of an examination of current technologies and alternate technologies for improving safety and included identification of knowledge gaps. Implications for present and future policy and regulatory practices were not considered. Specifically, the strategies of IST were of primary importance and opportunities for their employment were objectively assessed. Only acute airborne inhalation hazard situations were investigated. No consideration was given to chronic adverse health effects or to environmental effects. Emphasis was placed on the mitigating high-consequence events that led to adverse health effects in the surrounding (off-site) civilian population. Economic issues, supply chain resiliency, and national security concerns were not considered. Only the U.S. domestic chemical industry was considered but new technologies were drawn from international efforts. Theft was considered only in cases where the chemical was later employed at a target venue. The focus of the study was on the DHS CFATS Appendix A "Release - Toxic" chemicals, a set of 49 toxic inhalation hazard (TIH) compounds.

The intended audience for this study is principally government personnel tasked with science and engineering decision-making regarding the chemical process industry (CPI) programs.

\subsubsection{Tasks}

The initial top-level project tasks were:

- Acquire supply-chain data and process information on chemicals of interest

- Conduct an IST/safety evaluation as it pertains to security and identify knowledge gaps

- Conduct two SME/stakeholder workshops for information elicitation and vetting

- Report results

$\underline{\text { Data acquisition }}$ 
The initial focus of this project was to gather data on and understand aspects of the supply chain for each of the $49 \mathrm{TIH}$ chemicals. Important data included:

- Production amounts - aggregated capacities across the domestic CPI

- Use data - identify downstream consumer and/or derivative uses

- Storage data

- Transportation data

In addition, information on the production processes currently in use in industry for each TIH was needed. Such information included:

- overall reaction mechanisms

- process steps and conditions including pressures, temperatures, catalysts, solvents, etc.

- process toxic waste streams

Finally, industrial production process information for each derivative use of a TIH was also required and included:

- overall applications (e.g., etchants) and subsequent reaction mechanisms

- process steps and conditions including pressures, temperatures, catalysts, solvents, etc.

- process toxic waste streams

\section{$\underline{\text { IST assessment }}$}

Much work has been reported in the literature on the general application of IST strategies (minimize, substitute, moderate, and simplify) and several case studies exist. While making use of this literature base, the emphasis in this project was on considering IST alternatives across the supply chain for the specific TIH chemicals. These chemicals were grouped according to function and unit operations/chemical conversions involved in their production and use in order to investigate whatever commonalities may exist. At the most basic level, each TIH was to be examined separately, on a chemical-by-chemical basis.

The search for possible IST alternatives proceeded by first identifying the hazards associated with producing and using each chemical. For potential impacts of TIH materials on public health, loss of containment was the principal concern. Hazard discovery included consideration of:

- material properties, e.g., volatility, toxicity

- process conditions, e.g., pressure, temperature

- interaction matrices between the chemical and other process components

- likely on-site inventories, e.g., used from storage, made as needed

- amounts transported

- existing industry hazard assessments

- past safety history

- existing IST studies (as applicable)

This information was used to focus the IST alternative search. IST alternatives were considered for the process steps used in the production of each TIH that have the potential to reduce hazards. IST alternatives were also considered for TIH derivative uses. Due to the fact that the number of uses taken across all 49 TIH chemicals is very large, prioritization of this effort was needed. The initial approach was to limit initial investigations principally to substitution of the TIH in the derivative process. The overall intent was to examine ways of improving the safety of the 
production process of each TIH itself, as well as to reduce the demand for the chemical in the first place by finding substitutes for the chemical or by requiring less of it in downstream processes and applications. (Considering IST strategies beyond those that have been mentioned in connection to the derivative production process was expected to greatly enlarge the scope of the project.) Identification of potential near-term safety/security "fixes" had the most immediate value. Nevertheless, emerging technologies and synthesis chemistries were canvassed.

\subsection{Rescoping to Support CSAC IST Metrics}

\subsubsection{Data Acquisition for Metrics}

The goal of the CSAC IST Metrics program was to develop a framework for comparing and assessing the relative hazards posed by a range of chemicals throughout the supply chain from production to use. The eventual index would allow analysts to systematically compare chemical production processes to determine the "safer" alternative and give recommendations. Because this index spans the supply chain of a chemical process, it was meant to tackle a significant problem in risk management: risk transfer.

After a budgetary issue forced the Gaps Study to conclude after the 2011 fiscal year, it was determined that the best use of Sandia's resources would be to provide the data needed to demonstrate the IST Metrics. The initial Gaps Study identified potential leads for IST alternatives, and we repurposed those efforts for a focused data gathering and demonstration of the Index. Specifically, those chemicals processes were 1) acid-catalyzed alkylation using sulfuric acid or hydrofluoric acid, 2) alternative production of methyl methacrylate and methionine, and 3) alternative production of epichlorohydrin from glycerol.

\subsubsection{Development of a Detailed Chemical Release Reduction Modifier}

CSAC has invested in IST/ISHC by seeking to develop a set of metrics that can guide decisionmaking at various levels of government and industry. The result has been an innovative effort that spans the supply chain from chemical precursor production to final usage and storage. However, this methodology was meant for a direct comparison of chemical processes that produce the same final product and were not strictly developed to assess countermeasure effectiveness on the release scenarios that are commonly accounted for at chemical production facilities. This focus on chemical properties and process and storage conditions meant that there could theoretically be instances where a chemical process might be ruled less safe despite a robust safety net of release prevention and mitigation countermeasures.

A reduction factor for a potential chemical release was initially included in the Metrics as a value that would reduce the overall hazard rating when mitigation and prevention measures were put in place. However, it was determined that this reduction factor did not adequately account for the benefits. Because of these concerns, Sandia was asked to contribute to this IST Metrics effort by fleshing out the methodology for a more detailed countermeasure reduction modifier. The result of this effort, which lasted approximately one quarter of the fiscal year, was a conceptual design of a release event timeline layered with scenarios and countermeasures which would result in a more descriptive but still accessible tool for assessing a chemical process hazard. 


\subsection{Project Conclusion}

Based on budgetary concerns, the project was halted effective January $26^{\text {th }}$, 2012. No additional work was done to fill in data gaps or otherwise polish the final product. Enough funding was supplied to write this final report. It was noted by the sponsor that future work involving the continuation of similar efforts or the completion of this specific project was a possibility, and so all relevant information that might be needed to complete this work should be transferred to CSAC.

\subsection{References}

1. Center for Chemical Process Safety. Inherently Safer Chemical Processes. New York: Wiley, 2009.

2. "Final Report: Definition for Inherently Safer Technology in Production, Transportation, Storage, and Use." Center for Chemical Process Safety, The American Institute of Chemical Engineers. July 2010. 
[Blank page following section.] 


\section{CHEMICAL BRIEFS}

\subsection{Introduction}

The Chemical Security and Analysis Center (CSAC) and the Sandia team members agreed upon investigations of 49 toxic inhalation hazards. Each investigation of a chemical involved a detailed analysis of the current domestic chemical supply chain and included all known efforts to incorporate Inherently Safer Technology (IST). With the current state of technology known, a search was then performed for new or promising IST alternatives that have not yet been widely implemented. This subsequent search was not limited to domestic markets due to the propensity of new technologies being adopted in emerging markets. This search has generated a considerable amount of data that needed to be captured, organized, and distributed amongst the team members.

Living documents for each of the 49 chemicals were determined to be an appropriate solution to the problem of data storage and handling. These living documents, also known as chemical briefs, allowed the team members to pool data in a single location while maintaining homogeneity in formatting.

The chemical briefs include but are not limited to these data: physical properties, toxicity, major industrial uses, industrial producers, current production methodologies, alternative or promising production methodologies, chemical feedstocks, domestic production volumes, and distribution and transportation information. Figure 1 shows a representative chemical brief. 

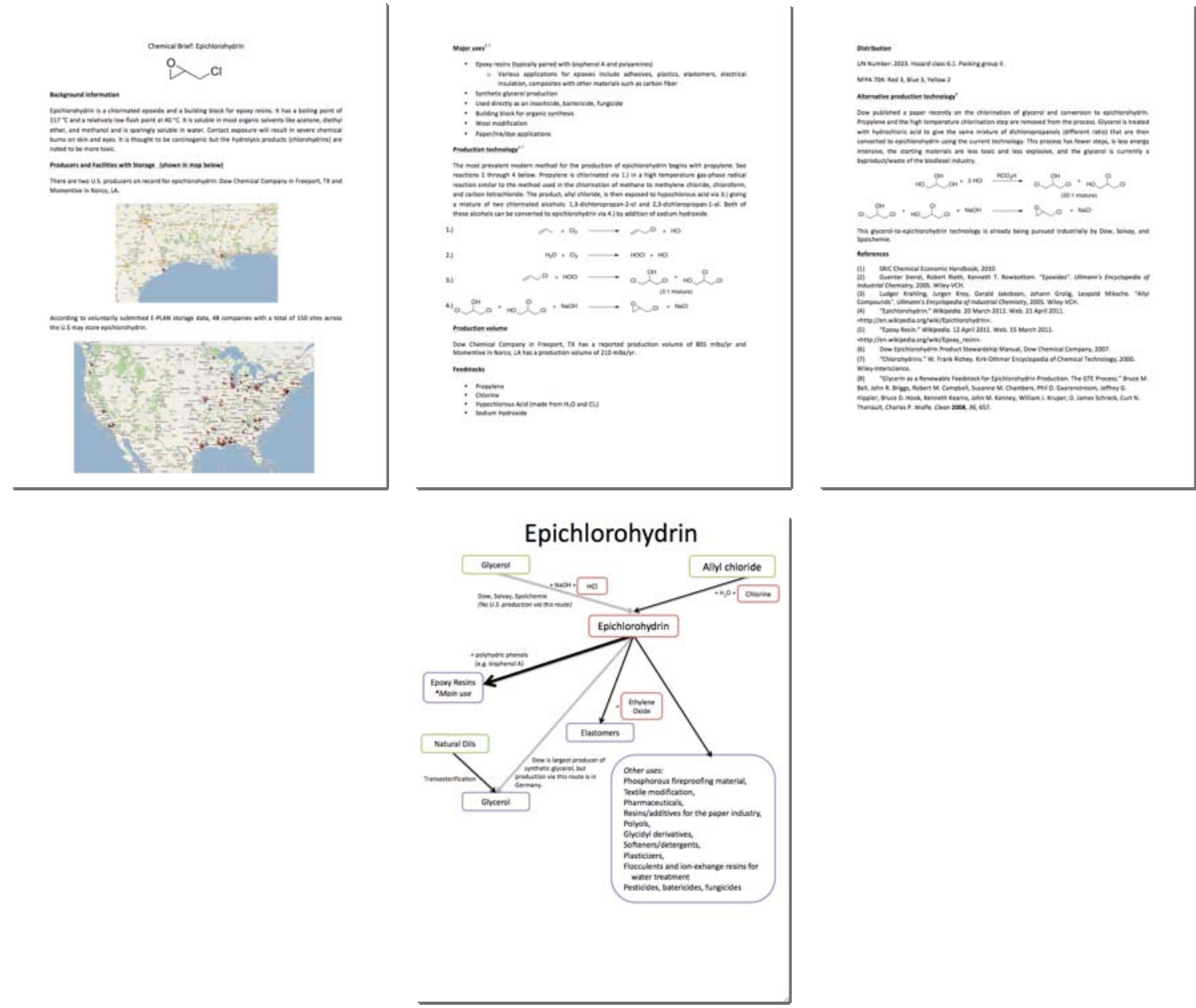

Figure 1. Representative Chemical Brief (Epichlorohydrin)

Specific sources of this data ranged from textbooks to company press releases. What follows are the general information resources that our team relied upon during these investigations: Sandia's Chemical Data Model (CDM), Kirk-Othmer Encyclopedia of Chemical Technology, Ullmann's Encyclopedia of Industrial Chemistry, and Stanford Research Institute Consulting Chemical Economics Handbook (SRIC-CEH). Additional sources for each chemical are cited within each document and will not be cited at the end of this chapter.

\subsection{Completed Chemical Briefs}

\subsubsection{2-Methyl Aziridine}

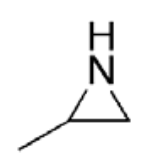

\subsubsection{Background Information}


Propyleneimine (2-methylaziridine, CAS: 75-55-8) is a strained nitrogen heterocycle commonly used as an intermediate in industrial processes for their ability to form and/or bind to hydrophilic materials. It is a volatile liquid at room temperature and boils at $66{ }^{\circ} \mathrm{C}$. 2-methylaziridine can be stored pure without incident but will fume in air, reacts with water to make propanolamine, and can polymerize explosively. Several studies have indicated that aziridines in general cause cancer, and propyleneimine was specifically linked to the formation of intestinal and mammary adenocarcinomas and leukemia. Short-term exposure can cause chemical burns and lung and eye damage with death at much higher concentrations.

\subsubsection{Major Uses ${ }^{3,4,7,8,12,13}$}

Most major uses stem from a need to bind coatings to cellulose (paper, wood, etc.)

- Binders for surface coatings (latex resins, paints) and other polymers

- Textiles (fixatives for dyes)

- Paper applications (fixatives for brighteners, coatings to allow better adhesion)

- Pharmaceuticals

\subsubsection{Production Technology $\mathrm{y}^{2-6,9,11-13}$}

Aziridines are typically formed from an ethylamine moiety that is cyclized upon itself with the utilization of a leaving group or catalyst. Previous methods such as the Dow Process and the $\beta$ Chloroethylamine Process made use of chlorine as a leaving group (Scheme 1), but these are no longer widely applied in parent aziridine production. The current dominant method is the cyclization of amino alcohols by the Wenker Process (Scheme 2).

(a)

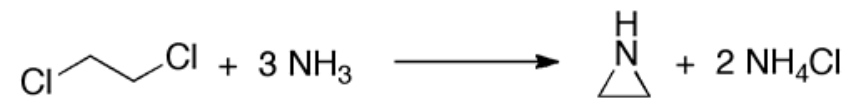

(b)

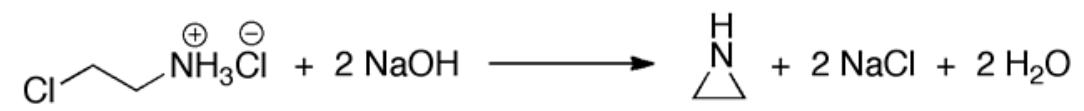

Scheme 1. Aziridine production using chlorinated alkylamines;

(a) Dow Process, (b) $\beta$-Chloroethylamine Process

The aminoalcohol is sulfonated using a dehydration process with sulfuric acid to generate the aminohydrogensulfate. This is done to allow for a more facile elimination of water from the compound and cyclization of the amine. This compound is then cyclized using aqueous sodium hydroxide to give the aziridine, sodium sulfate, and water. This second step is typically carried out at elevated temperatures $\left(250{ }^{\circ} \mathrm{C}\right)$ and pressures with residence times in heated pipeline reactors of only 4-10 seconds. 


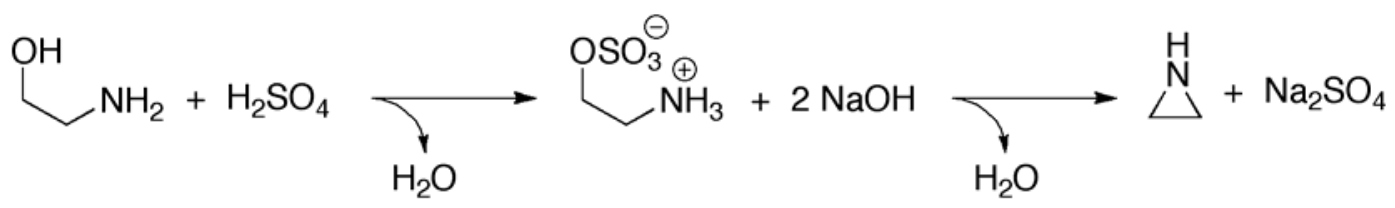

Scheme 2. Wenker Process for Aziridine Production

Propyleneimine is made in a manner similar to the $\beta$-Chloroethylamine Process once the 1amino-2-propanol has been converted to 1-amino-2-chloropropane (Scheme 3).

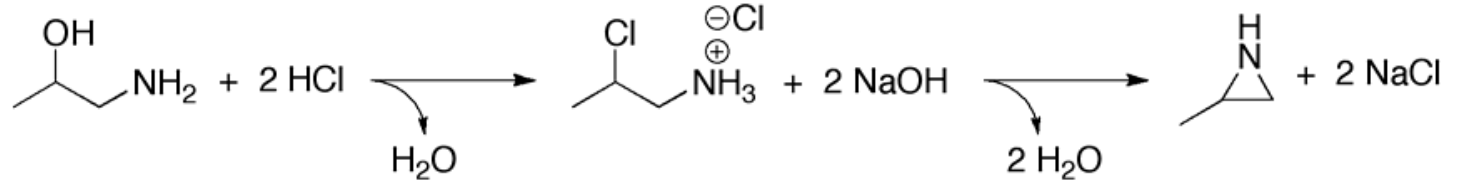

Scheme 3. Modified Chloro-amine Process

\subsubsection{Feedstocks}

- 1-amino-2-propanol or 2-amino-1-propanol

- Hydrochloric Acid

- $\quad$ Sodium Hydroxide

\subsubsection{Alternative Production Technology ${ }^{10}$}

Some methods currently exist that use a catalyst or stoichiometric additive to cyclize the amino alcohol without modification to a sulfate or chloride. This seems like the most promising method to reduce waste, maintain atom economy, and reduce the operating conditions of the industrial processes.

\subsubsection{References}

1. SRIC Chemical Economic Handbook, 2010.

2. Scherr, G.; Steuerle, U.; Fikentscher, R. "Imines, Cyclic." Kirk-Othmer Encyclopedia of Chemical Technology, 2000. Wiley-Interscience.

3. Steuerle, U.; Feuerhake, R. "Aziridines." Ullmann's Encyclopedia of Industrial Chemistry, 2007. Wiley-VCH.

4. “Aziridine.” Wikipedia. 3 March 2011. Web. 6 May 2011. $<$ http://en.wikipedia.org/wiki/Aziridine>.

5. Kindler, H.; Sanne, W.; Sinn, R.; Wittwer, A. “Technische Verwirklichung einer Kurzzeitreaktion in flüssiger Phase.” Chem. Ing. Tech. 1965, 37, 400.

6. Minoura, Y.; Takebayashi, M.; Price, C. C. "Preparation and Polymerization of D- and LPropylenimine and N-Methylpropylenimine.” J. Am. Chem. Soc. 1959, 81, 4689.

7. Xu. Z.; Ford, W. T. "Polystyrene Latices Containing Dodecanamide-Modified Poly(propyleneimine) Dendrimers.” J. Polym. Sci., Part A: Polym. Chem. 2003, 41, 597.

8. Singh, B.; Chang, L. W.; DiLeone, R. R.; Siesel, D. R. "Novel Wet Adhesion Monomers for Use in Latex Paints.” Prog. Org. Coat. 1998, 34, 214. 
9. Union Carbide Chemicals \& Plastics Technology Corporation, US 5739196, 1998 (Jenkins, R. D.; Kaminski, III, V. V.; Arney, Jr., W. C.; Bassett, D. R.).

10. Kelly, J. W.; Eskew, N. L.; Evans, Jr., S. A. "Cyclodehydration of N- and C-Substituted $\alpha$-Amino Alcohols to the Corresponding Aziridines with Diethoxytriphenylphosphorane.” J. Org. Chem. 1986, 51. 95.

11. Li, X.; Chen, N.; Xu, J. "An Improved and Mild Wenker Synthesis of Aziridines." Synthesis 2010, 20, 3423.

12. "2-Methylaziridine (Propyleneimine)." Report on Carcinogens, Eleventh Edition; U.S. Department of Health and Human Services, Public Health Service, National Toxicology Program.

13. Potential Industrial Carcinogens and Mutagens. Elseveir Scientific Publishing Company, Fishbein, L. Ed., 1979.

\subsubsection{Acrolein}

\subsubsection{Background Information ${ }^{1}$}

Acrolein is a colorless liquid with a sharp acrid odor that can yellow with age owing to decomposition products. It is severely irritating to mucous membranes and is a lachrymator, as well as being poisonous and flammable in both liquid and vapor form. Due to its tendency to polymerize, acrolein is stored with inhibitors (hydroquinone and acetic acid).

\subsubsection{Producers ${ }^{1,2}$}

- Arkema, Inc.

- Degussa

- Dow Chemical Company

- Baker Performance Chemicals

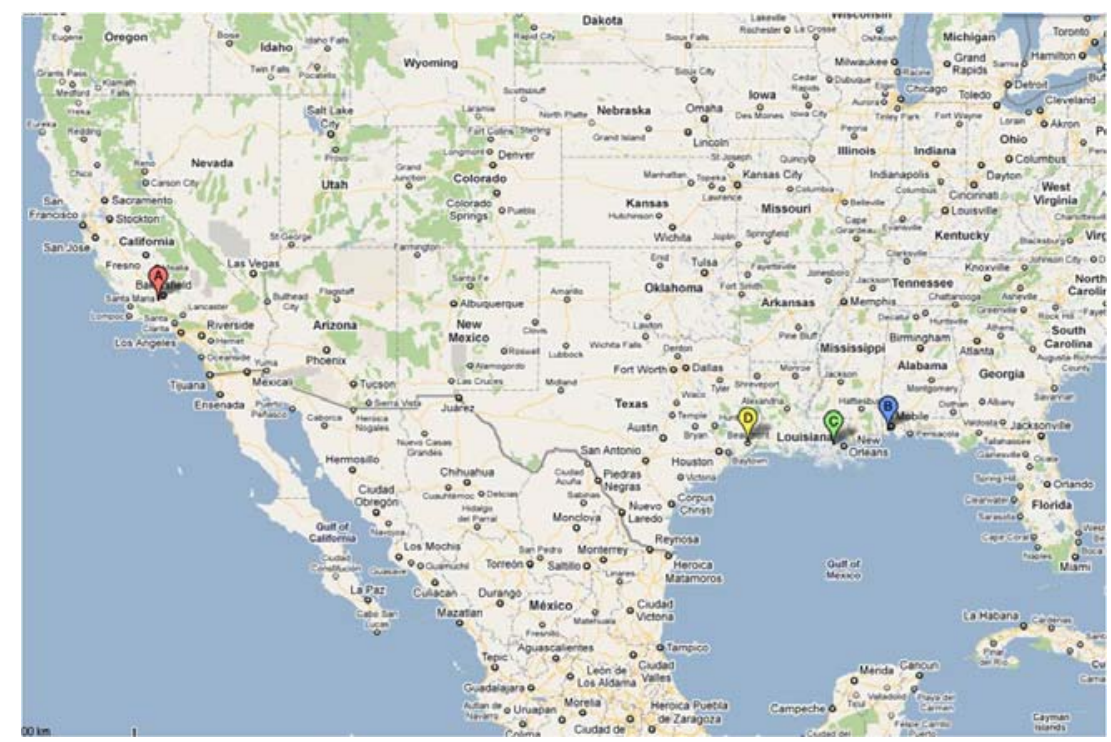

Figure 1. Domestic Producers 


\subsubsection{Major uses ${ }^{1,3,4}$}

- Methionine

- Methionine hydroxy analog

- Acrylic acid

- 1,3 propanediol - composites, adhesives, laminates, powder, solvents, moldings, antifreeze

- Glutaraldehyde - leather tanning

- Direct use

Commercially, when isolated, the largest use of acrolein is in the production of Methionine - an amino acid used as a feed supplement. Methionine hydroxyl analog is also a feed supplement. Acrylic acid is the other major use for acrolein, however, the acrolein is an intermediate and is not isolated during acrylic acid production; instead it is oxidized further. Acrolein is also used directly in solutions of ppm levels of acrolein as a broad spectrum biocide, especially for the growth of aquatic weeds, algae, and mollusks.

\subsubsection{Production Technology ${ }^{1}$}

Acrolein is synthesized by the vapor phase catalytic oxidation of propylene. The catalyst is typically a mixed metal oxide that may include $\mathrm{Bi}$, Mo, Fe, Ni, Co, K with $\mathrm{P}, \mathrm{B}$, W, or Sb. Further detail on catalyst composition is available from the SRIC Chemical Economics Handbook $^{4}$ on the two step formation of acrylic acid with acrolein as an intermediate:

"The most commonly used processes are based on Nippon Shokubai, BASF, BP (Sohio) and Mitsubishi catalysts or technologies. In the Nippon Shokubai route, the first-stage, vapor-phase oxidation is catalyzed by a cobalt-iron-bismuth-molybdenum complex at $325^{\circ} \mathrm{C}$ and 2.5-3.0 atmospheres of pressure.”

The following reaction details of propylene to acrolein are from the Kirk-Othmer Encyclopedia ${ }^{1}$.

"The catalytic vapor-phase oxidation of propylene generally is carried out in a fixed-bed multitube reactor at near atmospheric pressures and elevated temperatures $\left(\sim 330^{\circ} \mathrm{C}\right)$; molten salt or other heat exchange media is used for temperature control. Air is commonly used as the oxygen source, and steam is added to suppress the formation of flammable gas mixtures. Propylene feed concentrations are typically 7 to $10 \mathrm{~mol} \%$ with propylene space velocity of 100 to $250 \mathrm{~h}-1$. Reactor feed pressures are generally 20 to 30 psig, and temperatures of 85 to $250^{\circ} \mathrm{C}$ are typical. Operation can be single pass, or a recycle stream may be employed. As catalyst technology matured, interest focused on improving process efficiency and minimizing process wastes by defining process improvements that recycle process gas streams and/or use new reaction diluents such as nitrogen, carbon dioxide, or propane.

The reactor effluent gases are cooled to condense and separate the acrolein from the unreacted propylene, oxygen, and other low-boiling components (predominantly 
nitrogen). This process commonly is accomplished in two absorption steps in which, first, aqueous acrylic acid is condensed from the reaction effluent and absorbed in a waterbased stream, and then acrolein is condensed and absorbed in water to separate it from the propylene, nitrogen, oxygen, and carbon oxides."

Acrolein is then separated from the aqueous phase using a desorption column and distilled from other organics. The reaction is exothermic. Side reactions produce aldehydes and acids including mainly acrylic acid, acetaldehyde, acetic acid, carbon monoxide, and carbon dioxide.

\subsubsection{Production Volume}

Worldwide capacity (including captive use) is reported at 350,000 t/year from Kirk-Othmer; Ullman's reports 425 t/year. Of the seven facilities listed in Kirk Othmer that produce acrolein, four are located in the US - Arkema, Degussa, Dow Chemical Company, and Baker Performance Chemicals. The SRIC DCP lists three US producers: Degussa, Dow Chemical Company, and Baker Performance Chemicals, with no listing for Arkema, and Ullman's list doesn't include Baker. The SRIC PEP describes one U.S. facility with a capacity of 40,000 t/yr. E-plan lists acrolein storage capacity at Arkema, Baker, Degussa, Union Carbide - which is now Dow, and two smaller companies: DynaChem Inc., and Millenium Petrochemicals. Our best estimate of U.S. capacity, based on the above literature is 190,000 t/yr.

\subsubsection{Feedstocks}

- $\quad$ Propene (propylene)

- $\quad$ Oxygen (from air, typically)

\subsubsection{Distribution}

From Ullmann's ${ }^{5}$ : Acrolein is classified as a dangerous, flammable, and poisonous substance in various international and regional regulations. For the transportation of inhibited acrolein, the following regulations are mandatory:

- Proper shipping name: Acrolein, inhibited.

- National regulations: United States (CFR 49): § 172.101 Toxic liquid, flammable.

- Germany (GGVS): Special permission required for road transport of $1000 \mathrm{~kg}$ or more if transported in tanks with a capacity exceeding $3000 \mathrm{~L}$.

- International sea transport (IMDG Code): Class 6.1, UN no. 1092, PG I.

- International air transport (IATA-DGR): forbidden.

- European road (ADR) and rail (RID) transport: Classes 6.1, 8a).

\subsubsection{Alternative Production Technology}

No other production technologies are currently in use industrially, to the best of our knowledge. Technologies that are currently in an exploratory phase are propane oxidation, methanol-topropene with subsequent oxidation to acrolein, and glycerol decomposition into acrolein. ${ }^{1,5}$ 


\subsubsection{References}

1. Etzkorn, W. G. 2009. Acrolein and Derivatives. Kirk-Othmer Encyclopedia of Chemical Technology. 1-29.

2. SRIC Directory of Chemical Producers 2008

3. SRIC Chemical Economics Handbook 2010

4. SRIC Chemical Economics Handbook 2010, Acrylic Acid and Esters, pg 24.

5. Arntz, D., Fischer, A., Höpp, M., Jacobi, S., Sauer, J., Ohara, T., Sato, T., Shimizu, N. and Schwind, H. 2007. Acrolein and Methacrolein. Ullmann's Encyclopedia of Industrial Chemistry.

\subsubsection{Chemical Supply Chain Tree}

\section{Acrolein}

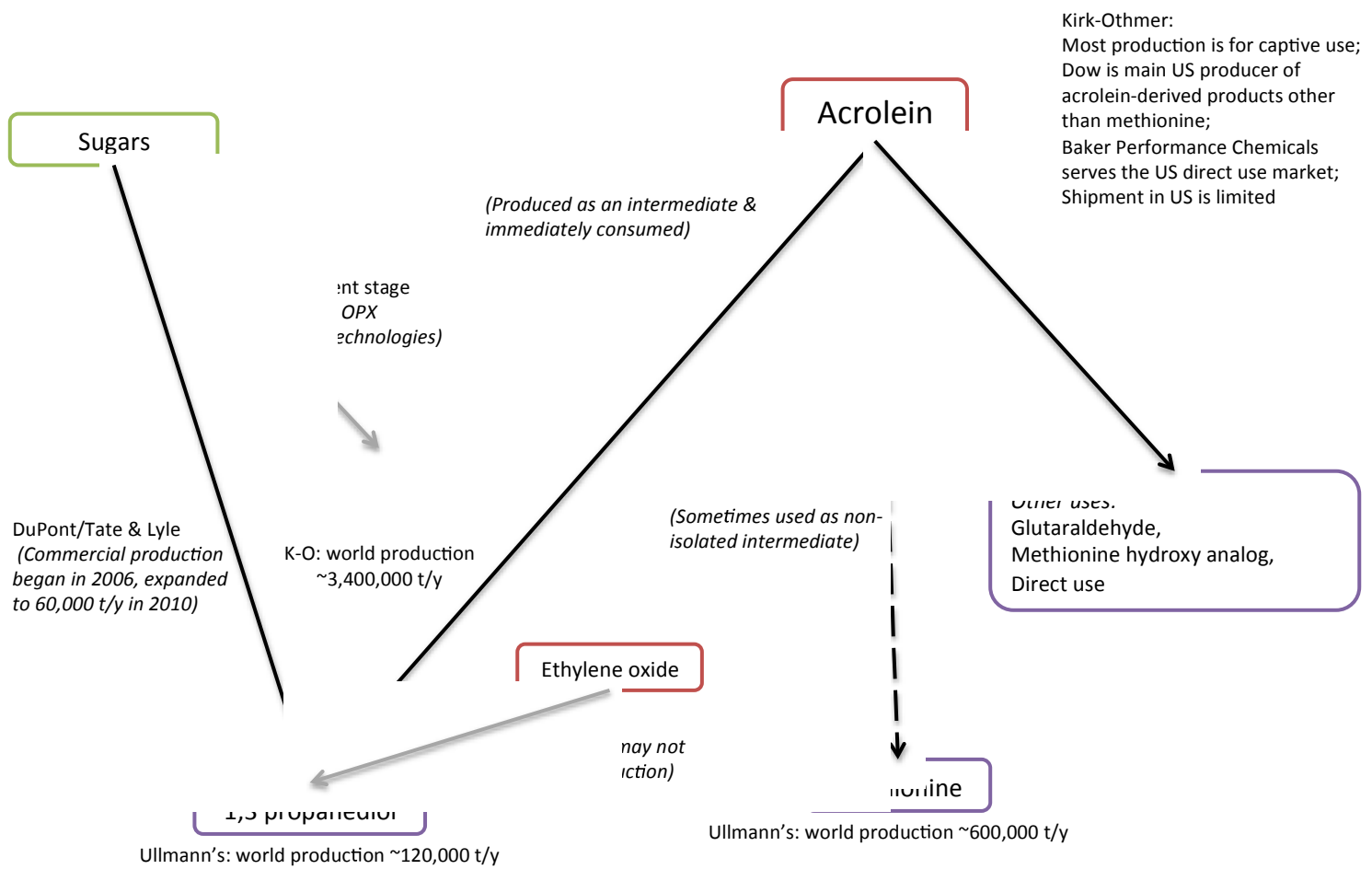




\section{Chemical Tree: Olefin Derivatives}

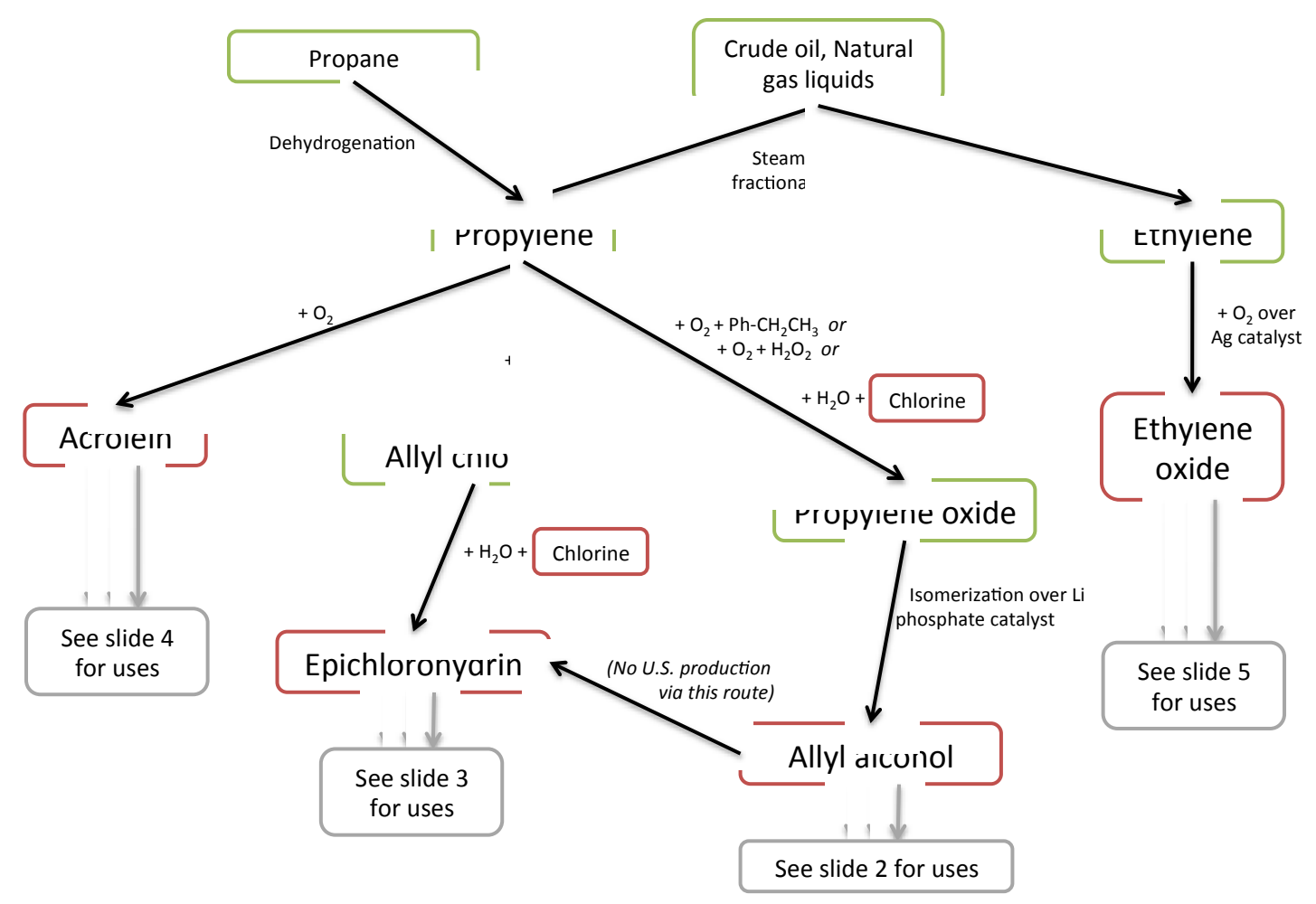

2.2.3. Allyl Alcohol<smiles>C=CCO</smiles>

\subsubsection{Background Information}

Allyl alcohol (CAS: 107-18-6) is a clear and colorless liquid at room temperature and pressure. It is the simplest unsaturated alcohol but its reactivity does not follow the typical profile of an allyl moiety due to competing side-reactions. Allyl alcohol is highly irritating to the eyes and respiratory system at concentrations as low as 2-5 ppm. Higher concentrations will cause lacrimation, blurred vision, and eventually blindness. Oral and topical doses have been shown to cause liver damage due to the ability for the body to metabolize allyl alcohol into acrolein.

\subsubsection{Major Uses}

LyondellBasell is the only US producer of allyl alcohol ${ }^{1}$. The following numbers correspond to their reported consumption:

- 1,4-butanediol ${ }^{1-3}$

o Tetrahydrofuran (45\% internal consumption)

o Butyrolactone (22\% internal consumption)

o Butylene Terephthalate (external merchant consumption)

o Polyurethanes (external merchant consumption) 
Additional known uses that might be operating domestically ${ }^{1-3}$ :

- Allyl Diglycol Carbonate (lenses and CRT screens)

- Diallyl Phthalate (plasticizer)

- Allyl Diglycidyl Ether (silane coupling agents)

- Allyl Methacrylate \& Triallyl Cyanurate (polymer cross-linking agents)

- Allyl Isoamyl Glycolate (fragrance)

- Styrene Allyl Alcohol (resin for coatings)

- Epichlorohydrin (no US production)

\subsubsection{Production Technology ${ }^{1-9}$}

Allyl alcohol can be made in four different processes, but in the United States, only one is relevant (LyondellBasell). All four are derived from propylene as a main feedstock, but new methods are focused on reducing waste streams (salts, chlorinated byproducts, etc.). The three processes that are currently being used but not in the United States are:

1) Hydrolysis of allyl chloride using sodium hydroxide

2) Catalytic conversion of propylene to allyl acetate with subsequent hydrolysis

3) Hydrogenation of acrolein using hydrogen or alcohol (ethanol, isopropanol)

The process used by LyondellBasell is the isomerization of propylene oxide. At this point, it is unknown whether propylene oxide is made on-site or imported to the site, but reviews of propylene oxide can be found in Ullmann's and Kirk-Othmer. The Ethylene Oxide Chemical Brief also contains analogous process data to extrapolate to the propylene oxide production.

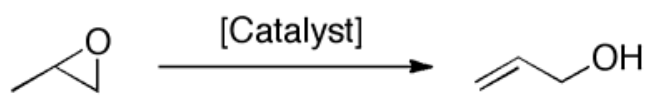

Scheme 1. Isomerization of Propylene Oxide.

Once propylene oxide has been obtained, it can be fed into the isomerization process. Two such processes exist: gas phase and liquid phase. According to patents by LyondellBasell, it is likely that they operate their modern facilities using the liquid phase process, but both will be covered here for completeness. The liquid phase method is also sometimes referred to as a slurry method due to the use of an insoluble catalyst suspended in the liquid medium. The propylene oxide is fed into the slurry as a gas $\left(280^{\circ} \mathrm{C}\right)$ using nozzles to allow the propylene oxide to mix efficiently with the catalyst. The liquid phase is a high-boiling inert hydrocarbon fluid like terphenyl. The catalysts are usually based on lithium phosphate, but some patents have identified additives such as boron that aid in product yield and selectivity. The gas product flow usually shows a conversion of $30-60 \%$ to allyl alcohol. Unreacted material is redirected back into the reactor.

\subsubsection{Feedstocks}

- $\quad$ Propylene Oxide 


\subsubsection{Distribution ${ }^{1-3}$}

LyondellBasell uses the majority of their allyl alcohol on-site for 1,4-butanediol production, but the remainder is shipped in tank cars (DOT 105J), tank trucks (DOT MC-412, 6000 gallons), and intermodal bulk transport tanks (IM 101). It is forbidden to be transported by a passenger carrying aircraft, railcar, or cargo aircraft.

Allyl alcohol is designated as a hazardous material for transportation purposes. It is classified as a Toxic Material (6.1) and a packaging group of I (PG I). It is also classified as a Toxic Inhalation Hazard, Zone B and a flammable hazard (Class 3). Identification number is UN 1098.

\subsubsection{Alternative Production Technology}

No additional commercialized technologies have been found.

\subsubsection{7. $\quad$ References}

1. SRIC Chemical Economic Handbook, 2010.

2. Krahling, L.; Krey, J.; Jakobson, G.; Grolig, J.; Miksche, L. "Allyl Compounds." Ullmann's Encyclopedia of Industrial Chemistry, 2005. Wiley-VCH.

3. Nagato, N. “Allyl Alcohol and Monoallyl Derivatives.” Kirk-Othmer Encyclopedia of Chemical Technology, 2004. Wiley-Interscience.

4. “Allyl Alcohol.” Wikipedia. 08 March 2011. Web. 19 May 2011. $<$ http://en.wikipedia.org/wiki/Allyl_alcohol>.

5. “1,4-Butanediol.” Wikipedia. 03 May 2011. Web. 19 May 2011. $<$ http://en.wikipedia.org/wiki/1,4-Butanediol>.

6. “Propylene Oxide.” Wikipedia. 10 February 2011. Web. 19 May 2011. $<$ http://en.wikipedia.org/wiki/Propylene_oxide>.

7. White, D. F. U.S. Patent 7,847,135, 2010.

8. “Allyl Alcohol Product Safety Bulletin.” Lyondell. 2006. Internal Publication.

9. “Allyl Alcohol Application Data.” Lyondell. 2006. Internal Publication.

\subsubsection{Chemical Supply Chain Tree}




\section{Allyl Alcohol}

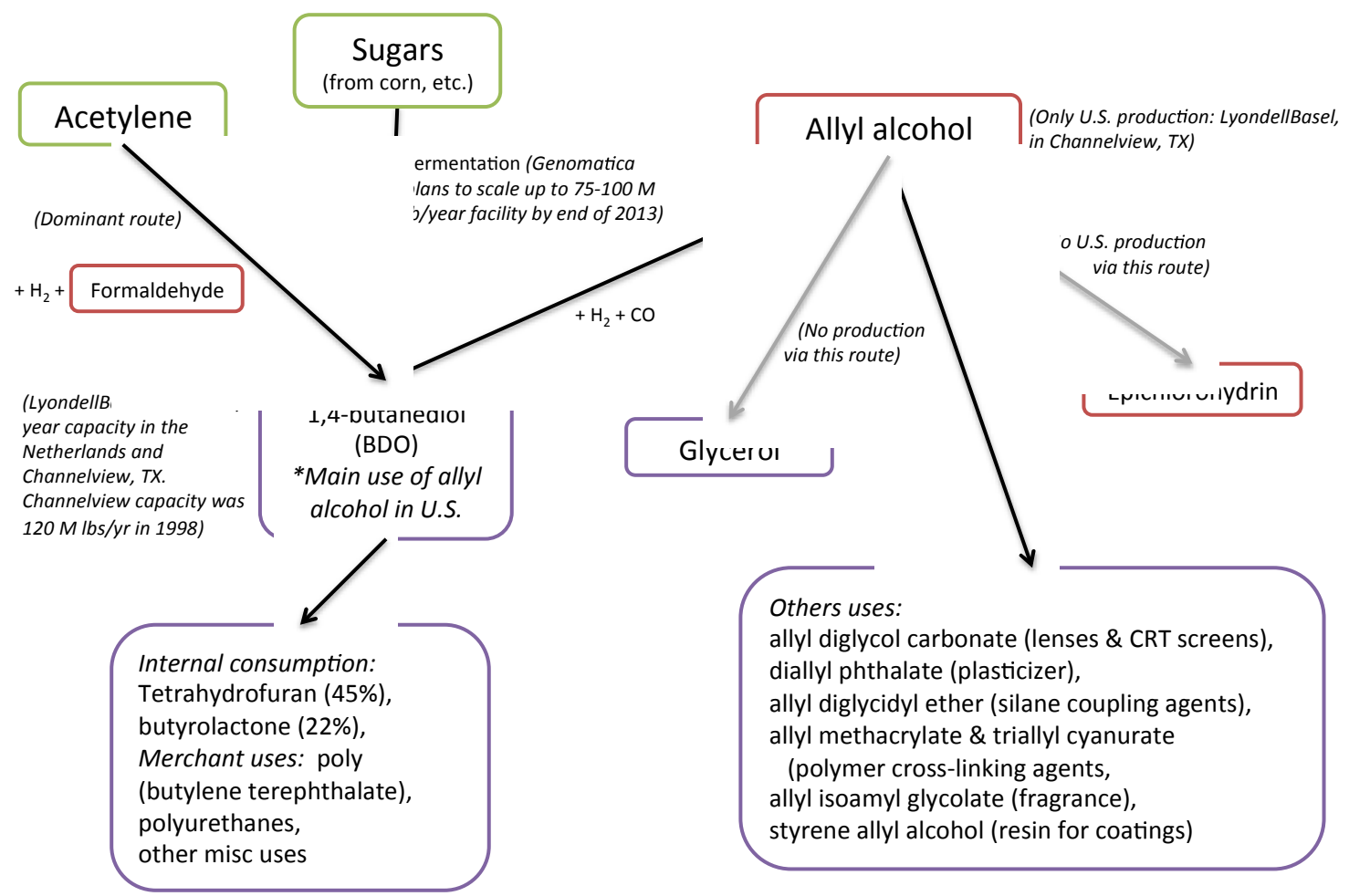

\section{Chemical Tree: Olefin Derivatives}

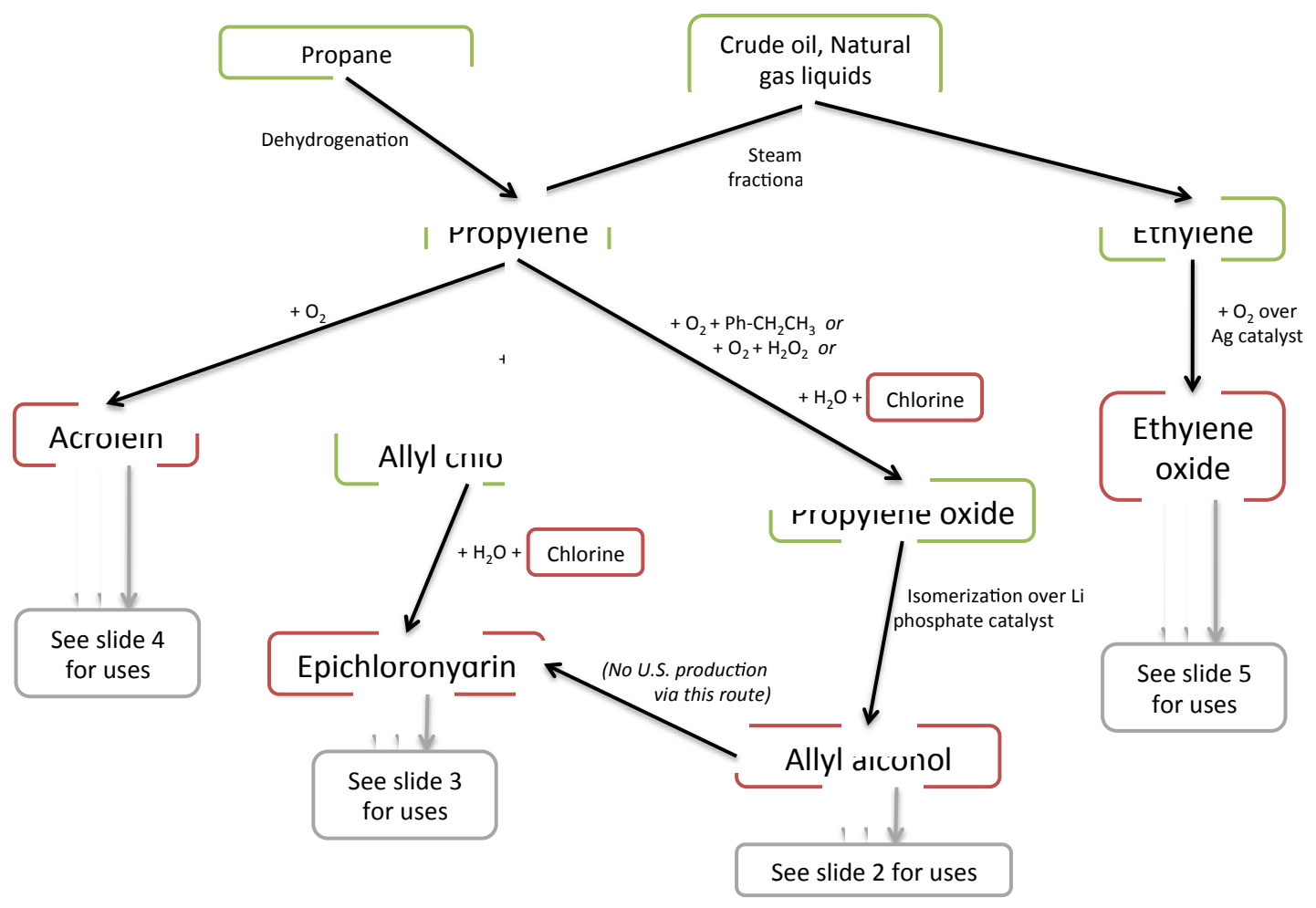




\subsubsection{Background Information ${ }^{2-3,5}$}

Carbon disulfide is a clear colorless liquid at STP. It has a pungent odor, and is highly volatile. In addition, it is highly flammable with a low autoignition temperature $\left(100^{\circ} \mathrm{C}\right)$. It is flammable in air over a range of 1-50 vol\%. Carbon disulfide is an excellent non-polar solvent for a variety of substances, from fats and resins to phosphorus, sulfur, selenium, and iodine. Carbon disulfide is toxic, impinging the central nervous system.

\subsubsection{Producers ${ }^{1,4}$}

There are two U.S. producers of carbon disulfide in SRIC's CEH and DCP. PPG, listed in KirkOthmer as a producer, discontinued production at their West Virginia plant in 2005.

- Akzo Nobel Functional Chemicals LLC

- Arkema

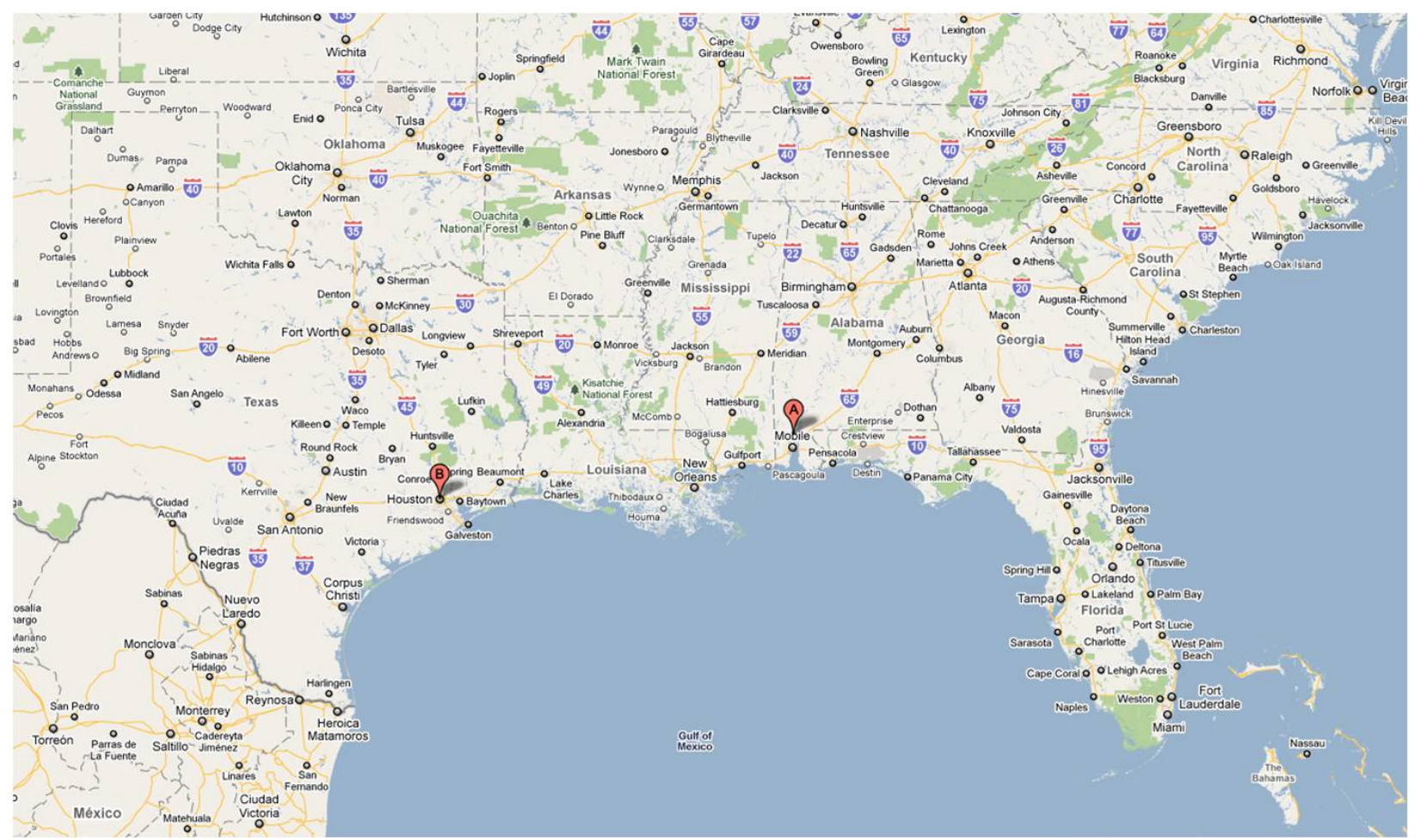

Figure 1. Domestic Producers.

\subsubsection{Major Uses ${ }^{1-5}$}

- Rayon used to be a major consumer of carbon disulfide, but U.S. rayon fiber production was halted in 2005 owing to unfavorable economic competition.

- Agricultural chemicals:

o metam-sodium (sodium N-methyl dithiocarbamate) - a soil fumigant pesticide 
o Dazomet (tetrahydro-3,5-dimethyl-1,3,5-thiadiazine-2-thione) - a soil fumigant pesticide

- Rubber chemicals - vulcanization accelerators

- Cellophane

- Carbon tetrachloride

- Other

0 xanthates

o resins and plywood adhesives;

o vinyl chloride polymerization inhibition

o hydrocarbon processing

o thiocyanates - brightening of precious metals in electroplating;

o rust removal

o industrial solvent (e.g., in petroleum-well cleaning).

o pharmaceuticals

\subsubsection{Production Technology $y^{2-3,5-13}$}

In the U.S., carbon disulfide is produced from a catalyzed reaction of methane and sulfur using a natural gas feedstock. In a furnace, the incoming flow of natural gas is preheated to $250^{\circ} \mathrm{C}$ then mixed with liquid sulfur (in slight excess of $5 \%$ ) and heated to $550-600^{\circ} \mathrm{C}$ to vaporize the mixture. The gas mixture then flows over a catalyst bed of silica, bauxite, alumina or clay to effect the reaction. Product gas includes sulfur, hydrogen sulfide, carbonyl sulfide with the carbon disulfide. A sulfur condenser removes the excess sulfur, and then the gas passes through scrubbers and a mineral oil adsorber to selectively remove the carbon disulfide. The carbon disulfide is obtained by reheating the oil.

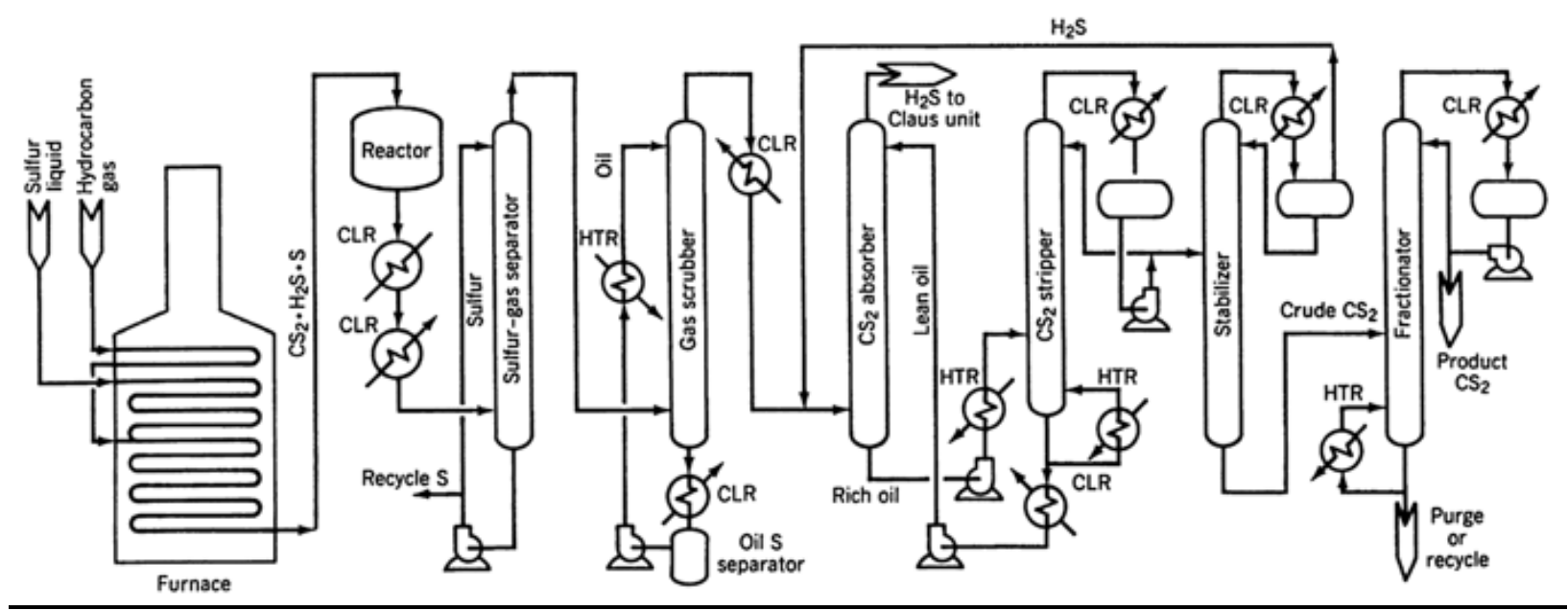

Figure 1: Hydrocarbon Sulfur Process

\subsubsection{Production Volume ${ }^{4}$}


Azko Nobel produces the larger share of carbon disulfide in the U.S. with $86 \%$ of the total capacity. The total U.S. Production capacity was $131 \mathrm{tmt}$ in 2007, with actual production in 2008 estimated to be $43 \mathrm{tmt}$ annually.

\subsubsection{Feedstocks ${ }^{2}$}

- $\quad$ Natural Gas

- $\quad$ Sulfur

\subsubsection{Distribution ${ }^{2}$}

Carbon disulfide is a Class 1 flammable liquid as determined by DOT. Carbon disulfide may be shipped via ground - rail, truck, tank trucks, etc. Air transport is not allowed. Containers are steel; lead may be used, but copper or copper alloys must be avoided. All containers of carbon disulfide are blanketed and filled to capacity by an inert, typically nitrogen or water. The U.S. exports approximately 7 tmt carbon disulfide to Mexico, Brazil, and Peru.

\subsubsection{Alternative Production Technology $y^{2-3,5}$}

The retort process, the first developed production method, is still used in Western Europe and other areas that do not have an adequate source of natural gas. In the retort process, sulfur vapor flows over heated charcoal in a furnace. The sulfur is superheated to $700{ }^{\circ} \mathrm{C}$, and fed to the bottom of the retort filled with calcined charcoal at 850 to $900{ }^{\circ} \mathrm{C}$. The retort may be kept at a slightly elevated pressure. As the heated sulfur vapor rises through the charcoal bed, carbon disulfide along with byproducts of sulfur, hydrogen sulfide, and carbonyl sulfide are formed. The carbon disulfide is separated from the product gas either by condensation followed by distillation, or condensations and selective absorption by mineral oil followed by stripping.

Even though they suffer from poor yield or by-product formation, other feedstocks may be used: Hydrogen sulfide or sulfur dioxide instead of sulfur with coke or coal, liquid hydrocarbons, chlorinated hydrocarbons or carbon monoxide as the carbon source.

\subsubsection{References}

1. Milen Blagoev and Chiyo Funada, "CARBON DISULFIDE,” SRIC Chemical Economic Handbook, 2008

2. Lay, M. D. S., Sauerhoff, M. W. and Saunders, D. R. 2000. Carbon Disulfide. Ullmann's Encyclopedia of Industrial Chemistry.

3. “Carbon Disulfide.” Wikipedia. 10 February 2011. Web. 25 March 2011. $<$ http://en.wikipedia.org/wiki/Carbon_disulfide>

4. SRIC Directory of Chemical Producers 2008 and SRIC 2009 World Petroleum.

5. Smith, D. E. and Timmerman, R. W. 2003. Carbon Disulfide. Kirk-Othmer Encyclopedia of Chemical Technology.

6. "Thermodynamics of carbon disulphide synthesis. Equilibrium in some reactions involving hydrogen sulphide, sulphur dioxide, carbon dioxide and carbon.” A. J. Owen, K. W. Sykes and D. J. D. Thomas; Trans. Faraday Soc., 1951, 47, 419-428. 
7. "The reactions of carbon with sulphur compounds. Part 2.-The reaction of hydrogen sulphide with various types of carbon.” A. J. Owen, K. W. Sykes, D. J. D. Thomas and P. White; Trans. Faraday Soc., 1953, 49, 1198-1206.

8. "Carbon Disulfide from Sulfur Dioxide and Anthracite." C. W. Siller; Ind. Eng. Chem., 1948, 40 (7), 1227-1233.

9. "Spectrophotometric studies of electrolytic dissociation. Part 2. Some thiosulphates in 50\% ethanol.” G. O. Thomas and C. B. Monk; Trans. Faraday Soc., 1956, 52, 685-689.

10. W. J. Thomas, S. C. Naik, Trans. Inst. Chem. Eng., 1970, 48, (4 - 6), 129.

11. C. M. Thacker, Hydrocarbon Process. 1970, 49, 137.

12. "Kinetics and Catalysis of Reaction Between Sulphur and Hydrocarbons." Thomas, W. J.; John, B. Transactions of the Institution of Chemical Engineers and the Chemical Engineer. 1967, 45, (3), T119.

13. "The reaction between paraffin hydrocarbons and sulphur vapour.” W. A. Bryce and Cyril Hinshelwood; J. Chem. Soc., 1949, 3379-3387.

\subsubsection{Chlorine}

\subsubsection{Background Information}

Elemental chlorine $\left(\mathrm{Cl}_{2}\right)$ exists as a heavier-than-air diatomic gas at standard atmospheric pressure and temperature. The gas is greenish yellow in appearance. Chlorine is a powerful oxidizer making it a potent disinfectant. This feature also makes it highly toxic to human life. Inhalation is the typical route of accidental exposure and can cause severe damage to the respiratory system.

\subsubsection{Major Uses ${ }^{2-3}$}

- 1,2-dichloroethane (a precursor to vinyl chloride and polyvinylchloride)

- Hydrochloric Acid

- Phosgene

- Chlorinated and halogenated solvents (chloroform, methylene chloride, some fluorocarbons, etc.)

- Allyl chloride (precursor to epichlorohydrin)

- Aromatic chlorides (precursors to important isocyanates, dyes, pesticides, etc.)

- Polycarbonates

- Inorganic chlorides (titanium tetrachloride, phosphorus trichloride and pentachloride, aluminum chloride, etc.)

- Intermediates for pharmaceuticals and cosmetics

- Water treatment

- Pulp and paper bleaching

- Refrigerants (precursors to fluorinated compounds)

- Silicones 
- Chlorinated paraffins (plasticisers, detergents, additives for lubricants, flame retardants, etc.)

- Other disinfectants

\subsubsection{Production Technology $y^{2-5}$}

Modern industrial-scale chlorine production is an energy-intensive electrochemical process commonly called the Chlor-Alkali process. Three different electrochemical techniques are currently in use: mercury cell process, diaphragm cell process, and membrane cell process. These three processes all generate gaseous chlorine and hydrogen and aqueous sodium hydroxide (caustic soda), but they differ on several aspects such as the anode and separation between the two cells. The overall reaction is written below.

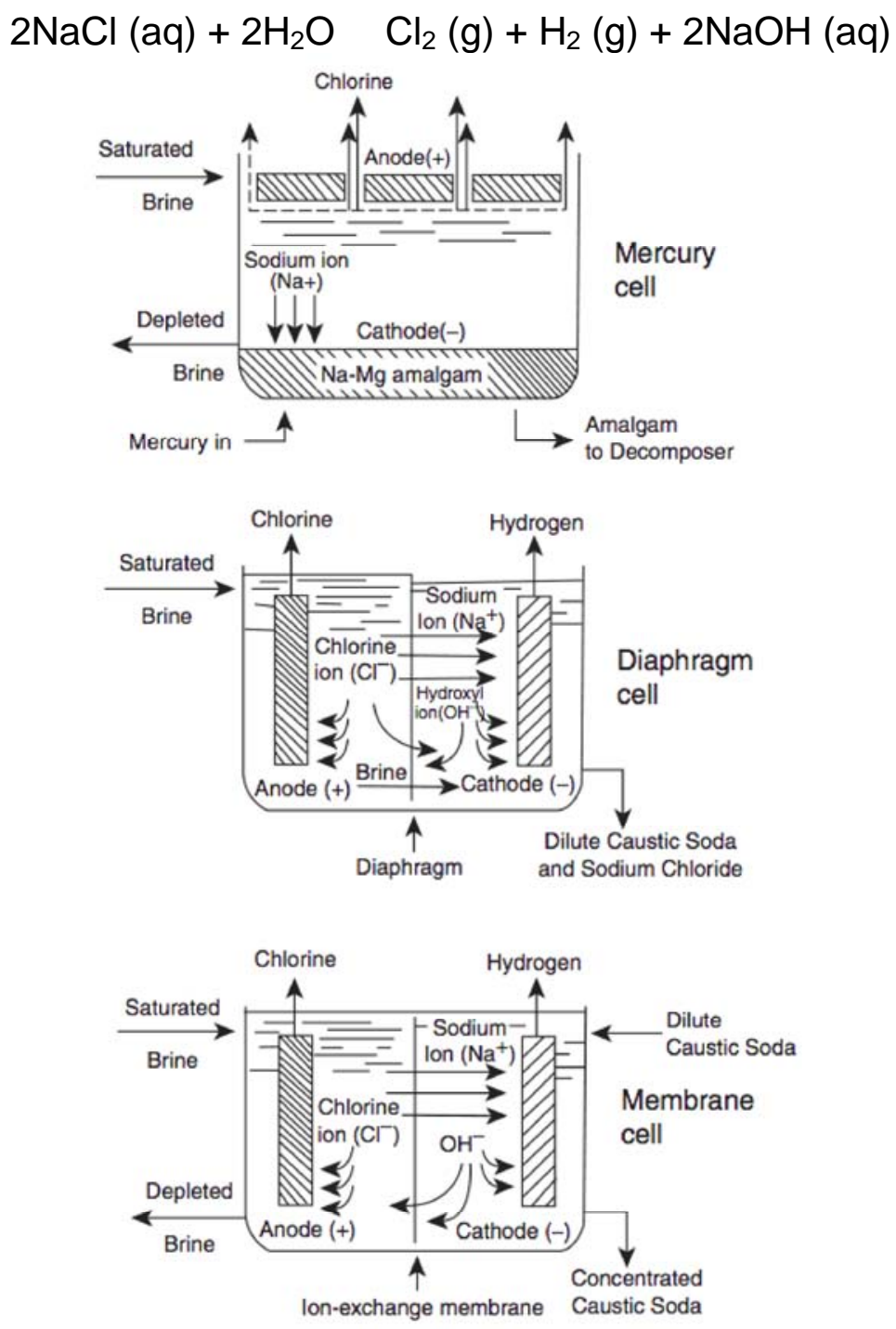

Figure 1. Three cell types from top to bottom: Mercury Cell, Diaphragm Cell, Membrane Cell. (From Kirk-Othmer) 
The mercury cell process is the oldest and until recently, the most prevalent technology in use. This process uses mercury as the cathode and a titanium-based anode. A brine solution $(\mathrm{NaCl})$ is cycled through the electrochemical cell where the chloride ion is oxidized to form chlorine, which bubbles out of the cell as a gas to be collected. The sodium is reduced to sodium metal, which combines with the mercury to form a sodium amalgam. This amalgam is then exposed to water and a catalyst yielding hydrogen gas and sodium hydroxide. This method is now in decline due to concerns over mercury poisoning in areas surrounding production facilities. At present, there are only four facilities in the United States currently using this process with one slated for conversion to the membrane cell process and another to be shutdown (both are operated by Olin Corporation). The other two facilities are operated by Ashta Chemicals (Ashtabula, $\mathrm{OH}$ ) and PPG Industries (Natrium, WV).

The diaphragm cell process uses a two-cell configuration separated by an asbestos diaphragm, which allows brine solution to flow from the anode to the cathode. The anode is still a titaniumbased material but the cathode is made from steel and sometimes activated nickel. As chloride is oxidized to chlorine gas, water is reduced to give hydrogen gas and hydroxide ions. The diaphragm is necessary to separate the hydroxide from the dissolved $\mathrm{Cl}_{2}$ and prevent hydrolysis of the chlorine. The aqueous sodium chloride is never fully consumed in this process and must be separated from the desirable sodium hydroxide by an evaporative process. This step is costly since significant amounts of water must be converted to steam, and this reduces the energy efficiency of the entire process. Even so, this process is cheaper to operate over the long term than the mercury cell process $(\sim 15 \%)$.

The membrane cell process is the most cost-efficient process ( 25\%) and is the favored technology for all new chlorine and caustic soda facilities. The cell configuration is similar to that of the diaphragm process but with the substitution of a sulfonate-based ion exchange membrane in place of the diaphragm. This allows sodium ions to travel from the anode to the cathode and while preventing hydroxide from reacting with the chlorine. The anode is made from oxides of titanium, iridium, and ruthenium and the cathode is nickel with a nickel or noble metal high surface area coating. In this case, the brine solution is only cycled through the anode cell preventing cross-contamination of the sodium hydroxide that is generated at the cathode. This in turn allows this process to be more energy efficient and removes the concerns of mercury poisoning.

In all of these processes, the cell temperatures vary from $40{ }^{\circ} \mathrm{C}$ to $120{ }^{\circ} \mathrm{C}$ and the pressures remain near atmospheric inside the cell. During purification and storage of the chlorine, it is necessary to compress the chlorine into a liquid state. This is either done at room temperature or active cooling to $-34{ }^{\circ} \mathrm{C}$ and large pressures can be generated (up to $1.6 \mathrm{MPa}$ )

\subsubsection{Feedstocks}

- Sodium Chloride

- Water

\subsubsection{Distribution ${ }^{2}$}


"Chlorine is transported in cylinders and ISO (International Standards Organization) containers and by rail and road tankers. It is classified as a non- flammable compressed gas. U.S. Department of Transportation regulations call for a green label. Repackagers of chlorine supply it in small cylinders containing 45.4 or $68 \mathrm{~kg}$. They also, along with some producers, supply ton lots in cylinders. These are pressurized and protected with fusible-plug relief devices. Quantities between 15 and 90 short tons are transported in tankers with covered manholes fitted with special angle valves. In the United States, shipping containers are fitted with special relief devices comprising a diaphragm-protected conventional relief valve mounted above a breakingpin assembly. Thinking on the matter of relief of transport containers is divided, and in Europe chlorine is shipped with- out relief devices (106)."

Also, it is noted by several sources that a pipeline can transport chlorine if the distance is only a few kilometers. This is most likely done within a single industrial facility.

IMDG (International Maritime Dangerous Goods) Code, class 2.3

RID/ADR (Rail), class 2, 2TC

\subsubsection{Alternative Production Technology ${ }^{2-3,6}$}

The electrolysis of hydrochloric acid to generate chlorine and hydrogen gas is one of the more successful methods. Several plants are operating in the United States and abroad where very pure gases are needed. Because caustic soda is not produced in this process, commercial viability is limited.

Catalytic oxidation of hydrochloric acid by oxygen is another process that has received some attention but has mostly been limited by the need for more efficient catalysts. Three processes have been explored on an industrial scale: KEL-Chlor Process, Shell-Chlor Process, and Mitsui MT-Chlor Process.

\subsubsection{References}

1. SRIC Chemical Economic Handbook, 2010.

2. Peter Schmittinger, Thomas Florkiewicz, L. Calvert Curlin, Benno Lüke, Robert Scannell, Thomas Navin, Erich Zelfel, Rüdiger Bartsch. "Chlorine.” Ullmann's Encyclopedia of Industrial Chemistry, 2006.

3. Tilak V. Bommaraju, Benno Lüke, Thomas F. O'Brien, Mary C. Blackburn. "Chlorine.” Kirk-Othmer Encyclopedia of Chemical Technology, 2002.

4. "Chloralkali Process." Wikipedia. 14 March 2011. Web. 14 March 2011. $<$ http://en.wikipedia.org/wiki/Chloralkali_process $>$.

5. Oceana Foundation. "Olin's Corporation Two Dinosaur Olin Corporation's Two Dinosaur Mercury Plants Will End Mercury Use and Releases." Oceana. 10 December 2010. Web. 14 March 2011. <http://na.oceana.org/en/our-work/stop-oceanpollution/mercury/overview>.

6. "Deacon Process." Wikipedia. 14 March 2011. Web. 14 March 2011. $<$ http://en.wikipedia.org/wiki/Deacon_process>. 


\subsubsection{Chemical Supply Chain Trees}

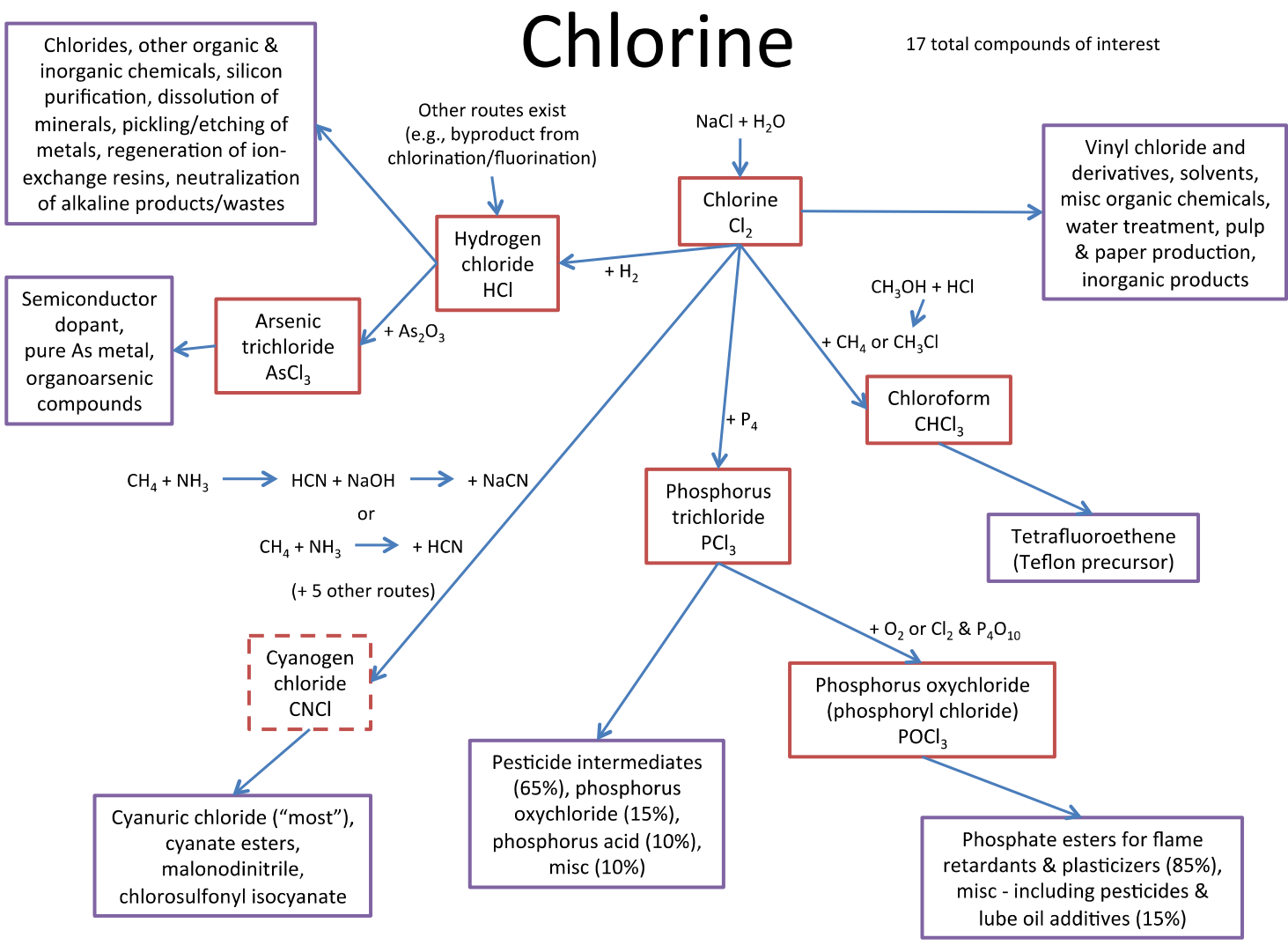




\section{Chlorine (continued)}

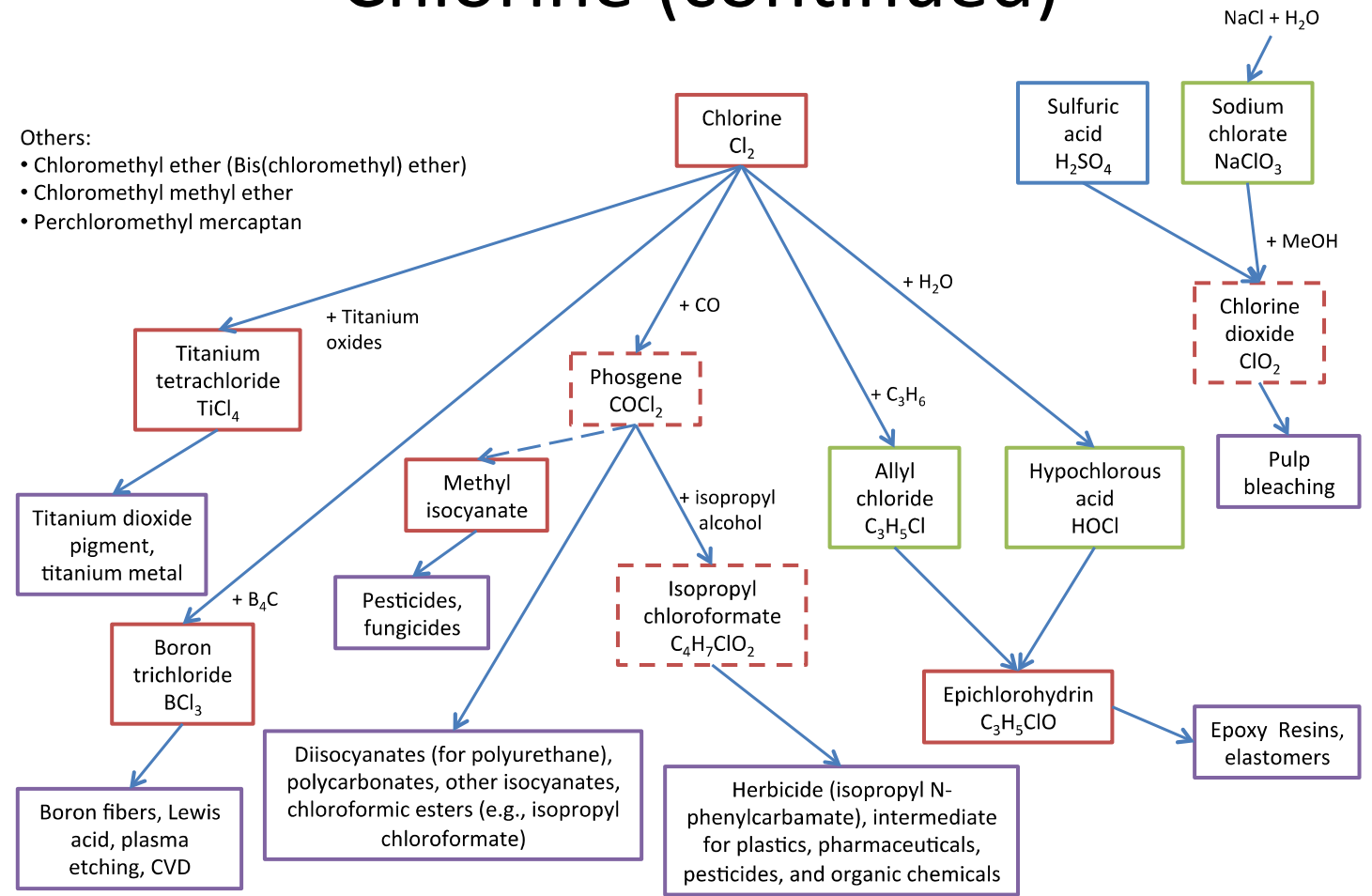

\subsubsection{Chlorine Dioxide}

\subsubsection{Background Information ${ }^{2-3}$}

Chlorine dioxide is a triatomic molecule of greenish yellow color and is a gas at Standard Temperature and Pressure. It is a powerful oxidizing agent and its chemical reactivity is similar to single-electron radical species. It will decompose thermally, often explosively, in an autocatalytic process to generate chlorine and oxygen gas. This reaction is initiated by light.

$$
2 \mathrm{ClO}_{2} \rightarrow \mathrm{Cl}_{2}+\mathrm{O}_{2}
$$

Chlorine dioxide will also hydrolyze in alkaline solutions. Therefore, most applications call for buffered acidic solutions $(<\mathrm{pH} 6.0)$.

$$
2 \mathrm{ClO}_{2}+2{ }^{-} \mathrm{OH} \rightarrow \mathrm{ClO}_{2}^{-}+\mathrm{ClO}_{3}^{-}+\mathrm{H}_{2} \mathrm{O}
$$

Due to the explosive potential and tendency toward decomposition, it is always made at the point of use. In the United States, it is illegal to transport chlorine dioxide, even in solutions. There are "stabilized" forms of chlorine dioxide that can be shipped, but this is a misnomer since the compound in question is a chemical precursor that must be activated with acid to produce gaseous chlorine dioxide. 
Because of its oxidizing power, chlorine dioxide is a dangerous inhalation and contact hazard. Nausea and general irritation are common symptoms of exposure. Respiratory problems such as coughing, bronchitis, and pulmonary edema are possible. There is no evidence thus far to suggest it is carcinogenic.

\subsubsection{Major Uses ${ }^{2-5}$}

- Pulp and paper bleaching

- Water treatment

- Textile bleaching (wool, cotton)

- Oil field applications (odor control, removal of biofilms, neutralization of $\mathrm{H}_{2} \mathrm{~S}$ and ferrous sulfide)

- $\mathrm{NO}_{\mathrm{x}}$ neutralization for incinerators

\subsubsection{Production Technology $y^{2-5}$}

\section{Chlorate Reduction}

The production of chlorine dioxide is dominated by one process: the reduction of sodium chlorate. There are several variants within this one process, but the general scheme is the same. This method is almost exclusively applied in the pulp and paper industry for bleaching. It has been chosen for its cost effectiveness and because of the availability of starting materials compared to other production methods. Chlorine dioxide was chosen as the bleaching agent because it does not generate chlorinated organic compounds during use.

$$
\mathrm{NaClO}_{3}+\text { reducing agent }+ \text { acid } \Rightarrow \mathrm{ClO}_{2}+\text { byproducts }
$$

The reduction of chlorate is commonly performed under a vacuum or at atmospheric pressure to avoid concentrating the chlorine dioxide product and risking an explosion. As the reactants are fed into the reactor, chlorine dioxide is generated and a carrier gas moves it into an absorption tower where it dissolves into water and can be pumped into storage. The concentration of this aqueous chlorine dioxide solution is kept at or below 10 grams/liter (1 weight \%). The solution is normally cooled to $10-12{ }^{\circ} \mathrm{C}$ to reduce the vapor pressure and prevent decomposition.

Methanol is the most common of the reductants used in industry because it forms only small concentrations of $\mathrm{Cl}_{2}$ in the product stream, and the formic acid byproduct does not interfere with bleaching. Sulfate byproducts are removed or recycled.

Hydrogen peroxide as a reductant also yields a low $\mathrm{Cl}_{2}$ content with oxygen, water, and sulfate as byproducts. This process can also performed on smaller scales using a cartridge system containing premixed chlorate and hydrogen peroxide. The mixture, called Purate, is subjected to sulfuric acid in a computer-controlled and on-demand process to generate the aqueous chlorine dioxide product. 
Sulfur Dioxide had been a popular reductant for paper mills due to the synergy of sulfur production. There are several side reactions present in this technology that decompose the $\mathrm{Cl}_{2} \mathrm{O}$ to form $\mathrm{Cl}_{2}$, and while solutions have been put in place, the technology is being phased out.

Chloride ions can also function as reductants in this process, but this produces a sizable quantity of chlorine gas along with the chlorine dioxide (2:1 ratio of $\mathrm{ClO}_{2}$ to $\mathrm{Cl}_{2}$ ). Integrated facilities that produce hydrochloric acid, chlorine, sodium hydroxide, and chlorine dioxide typically employ this version of the process.

\section{Chemical Chlorite Oxidation}

Because sodium chlorite is produced from chlorine dioxide, using $\mathrm{NaClO}_{2}$ as the reductant is only cost-effective on smaller scales like water treatment facilities. Two main processes exist for this method: chlorine activation and acid activation.

$$
\begin{gathered}
2 \mathrm{NaClO}_{2}+\mathrm{Cl}_{2} \Rightarrow 2 \mathrm{ClO}_{2}+2 \mathrm{NaCl} \\
5 \mathrm{NaClO}_{2}+4 \mathrm{HCl} \Rightarrow 4 \mathrm{ClO}_{2}+5 \mathrm{NaCl}+2 \mathrm{H}_{2} \mathrm{O}
\end{gathered}
$$

The chlorine activation process will typically have a chlorine-contaminated product stream, but in applications where chlorine is permissible, this is an advantageous route due to the speed of reaction.

\section{Electrochemical Chlorite Oxidation}

There are several electrochemical methods beginning from chlorate, chlorite, or chloric acid that are used on small scales for water treatment (food processing, etc). Chlorite oxidation is the most common commercialized form. Hydrogen, water, oxygen, and $\mathrm{NaOH}$ are common byproducts in these reactions and can be vented or disposed of easily. Additionally, noble metal coatings on the electrodes play a role in the catalysis of some of these processes.

\subsubsection{Feedstocks ${ }^{2-5}$}

Chlorate Reducing Processes

- $\quad$ Sodium Chlorate

- $\quad$ Reducing Agent (Methanol, Sulfur Dioxide, Chloride, or Hydrogen Peroxide)

- $\quad$ Acid (Sulfuric Acid or Hydrochloric Acid)

Chlorite Oxidation Processes

- Sodium Chlorite

- $\mathrm{HCl}$ or $\mathrm{Cl}_{2}$

- $\quad$ Additional oxidants (bleach) might be employed

Electrochemical Processes

- Sodium Chlorite, Sodium Chlorate, or Chloric Acid

- $\quad$ Acid (hydrochloric or sulfuric) 


\subsubsection{Distribution ${ }^{2}$}

Chlorine dioxide cannot be transported in any quantity in the United States. It is always made at the point of use from premixed precursors or by one of the processes listed above.

\subsubsection{Alternative Production Technology}

No additional commercialized technologies have been found.

\subsubsection{7. $\quad$ References}

1. SRIC Chemical Economic Handbook, 2010.

2. Helmut Vogt, Jan Balej, John E. Bennett, Peter Wintzer, Saeed Akbar Sheikh, Patrizio Gallone, Subramanyan Vasudevan, Kalle Pelin. "Chlorine Oxides and Chlorine Oxygen Acids". Ullmann's Encyclopedia of Industrial Chemistry, 2010. Wiley-VCH.

3. Jerry J. Kaczur and David W. Cawlfield. "Chlorine Oxygen Acids and Salts, Chlorous Acid, Chlorites, and Chlorine Dioxide.” Kirk-Othmer Encyclopedia of Chemical Technology, 2000. Wiley-Interscience.

4. “Chlorine Dioxide.” Wikipedia. 15 March 2011. Web. 15 March 2011. $<$ http://en.wikipedia.org/wiki/Chlorine_dioxide>.

5. "Chlorine Dioxide Generation | How Chlorine Dioxide is Generated | ClO2 Chemistry." Clearwater Technology. Web. 15 March 2011.

<http://www.clearwater.eu.com/chlorine_dioxide/how_it_works.html>

\subsubsection{Chloroform}

\subsubsection{Background Information ${ }^{3-4}$}

Chloroform is a nonflammable colorless liquid at Standard Temperature and Pressure. It is not especially reactive and is typically used as a solvent in laboratory applications. Chloroform has been implicated as a carcinogen and targets the liver and central nervous system. Contact exposure can cause sores. Left unstabilized in air, it will decompose to phosgene and hydrochloric acid. As of 2003, 70\% of chloroform went into the production of HCFCs for refrigerants, but chloroform's importance will decrease as the Montreal Protocol puts further restrictions on HCFCs and CFCs.

\subsubsection{2. $\quad$ Producers ${ }^{2}$}

- Dow Chemical Company

- Occidental Chemical Corporation 


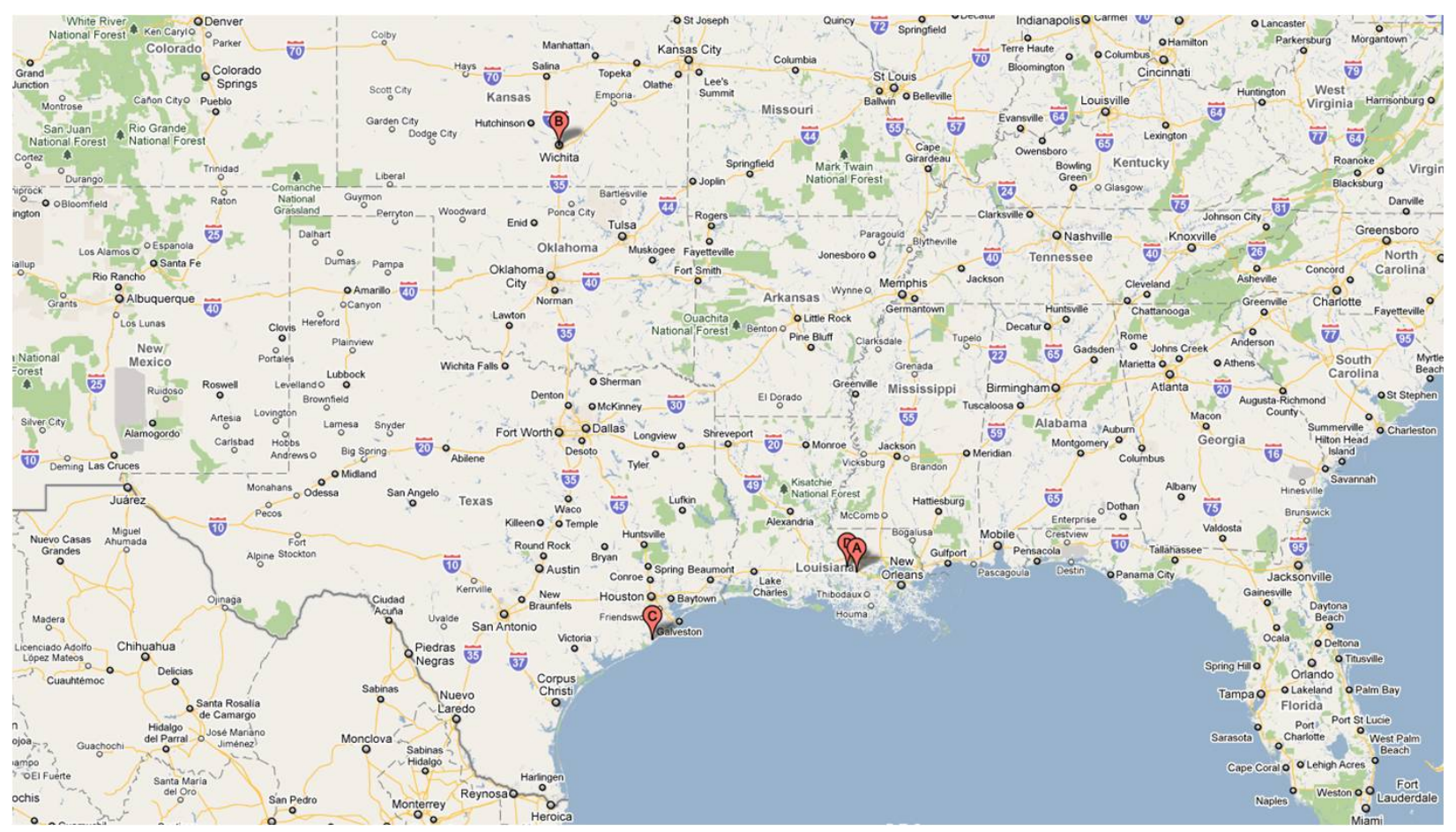

Figure 1. Domestic Producers

\subsubsection{Major Uses ${ }^{3-4}$}

- Monochlorodifluoromethane (HCFC-22 or R-22), a refrigerant and precursor to tetrafluoroethylene and Teflon

- Solvent in laboratory and pharmaceutical chemistry

- Minor miscellaneous uses as a chemical reagent

\subsubsection{Production Technology $y^{3-5}$}

The production of chloroform is typically tied to the production of the related chlorinated methanes $\left(\mathrm{CH}_{3} \mathrm{Cl}, \mathrm{CH}_{2} \mathrm{Cl}_{2}\right.$, and $\left.\mathrm{CCl}_{4}\right)$. All of these processes are performed in much the same way: high temperature gas-phase chlorination. It is a radical chain reaction initiated by the cleavage of $\mathrm{Cl}_{2}$.

(Initiation)

(Propagation Steps)

Chloromethane

Dichloromethane

Chloroform
$\mathrm{Cl}_{2} \rightarrow 2 \mathrm{Cl} \bullet$

$\mathrm{Cl} \bullet+\mathrm{CH}_{4} \rightarrow \mathrm{CH}_{3} \bullet+\mathrm{HCl}$

$\mathrm{CH}_{3} \bullet+\mathrm{Cl}_{2} \rightarrow \mathrm{CH}_{3} \mathrm{Cl}+\mathrm{Cl} \bullet$

$\mathrm{Cl} \bullet+\mathrm{CH}_{3} \mathrm{Cl} \rightarrow \mathrm{CH}_{2} \mathrm{Cl} \bullet+\mathrm{HCl}$

$\mathrm{CH}_{2} \mathrm{Cl} \bullet+\mathrm{Cl}_{2} \rightarrow \mathrm{CH}_{2} \mathrm{Cl}_{2}+\mathrm{Cl} \bullet$

$\mathrm{Cl} \bullet+\mathrm{CH}_{2} \mathrm{Cl}_{2} \rightarrow \mathrm{CHCl}_{2} \bullet+\mathrm{HCl}$

$\mathrm{CHCl}_{2} \bullet+\mathrm{Cl}_{2} \rightarrow \mathrm{CHCl}_{3}+\mathrm{Cl} \bullet$ 


$$
\text { Carbon Tetrachloride } \quad \mathrm{CCl}_{3} \bullet+\mathrm{Cl}_{2} \rightarrow \mathrm{CCl}_{4}+\mathrm{Cl} \bullet
$$

Because this reaction mechanism could potentially lead all products to carbon tetrachloride, the concentration of $\mathrm{Cl}_{2}$ and methane (and more recently chloromethane) are carefully monitored to afford only the desired product. The reactor, typically of a flow-through or loop design, is charged with the reactant gases and heated to $350-500{ }^{\circ} \mathrm{C}$ to initiate and maintain the reaction. In the case of $\mathrm{CHCl}_{3}$, lower chlorinated methanes are recycled back into the reactor to continue the chlorination. Any carbon tetrachloride is condensed away from the product gas.

The hydrochloric acid generated in this reaction has been recycled to effect the monochlorination of methanol to yield chloromethane. In this way, a substantial amount of $\mathrm{HCl}$ is removed from the process waste stream, and the chloromethane can be further chlorinated using the radical chlorination method.

The Tokuyama Soda Company developed a liquid-phase form of this chlorination in the 1980s. A radical initiator, AIBN (azobisisobutyronitrile), allows this reaction to proceed at lower temperatures, however, high pressures are still needed.

\subsubsection{Production Volume ${ }^{2}$}

Kirk-Othmer and SRIC estimate the U.S. production capacity of chloroform to be 720 mlbs and 620 mlbs respectively, with the Occidental Chemical Corporation production being $80 \%$ of that at Dow Chemical Company.

\subsubsection{Feedstocks}

- $\quad$ Chlorine

- Methane

- $\quad$ Chloromethane

\subsubsection{Distribution ${ }^{3}$}

The shipment and storage of chloroform is widely performed. Precautions are taken to avoid aluminum and its alloys because of unintended reactions between the two compounds. Storage containers are commonly made from stainless steel. Chloroform is shipped in drums, rail cars, barges, and ships.

\subsubsection{Alternative Production Technology}

No additional commercialized technologies have been found.

\subsubsection{References}


1. "The Montreal Protocol on Substances that Deplete the O-Zone Layer." United Nations Environment Programme. Web. $16 \quad$ March, 2011. $<$ http://ozone.unep.org/publications/mp_handbook/section_1.1_the_montreal_protocol/>

2. SRIC Chemical Economic Handbook, 2010.

3. Manfred Rossberg, Wilhelm Lendle, Gerhard Pfleiderer, Adolf Tögel, Eberhard-Ludwig Dreher, Ernst Langer, Heinz Rassaerts, Peter Kleinschmidt, Heinz Strack, Richard Cook, Uwe Beck, Karl-August Lipper, Theodore R. Torkelson, Eckhard Löser, Klaus K. Beutel, Trevor Mann. "Chlorinated Hydrocarbons." Ullmann's Encyclopedia of Industrial Chemistry, 2006. Wiley-VCH.

4. Michael T. Holbrook. "Chloroform.” Kirk-Othmer Encyclopedia of Chemical Technology, 2003. Wiley-Interscience.

5. “Chloroform.” Wikipedia. 11 March 2011. Web. 16 March 2011. $<$ http://en.wikipedia.org/wiki/Chloroform>.

6. “Chlorodifluoromethane.” Wikipedia. 16 March 2011. Web. 16 March 2011. $<$ http://en.wikipedia.org/wiki/Chlorodifluoromethane>.

\subsubsection{Chloromethyl Methyl Ether}

\subsubsection{Background Information ${ }^{2-4,9}$}

Chloromethyl methyl ether (CAS: 107-30-2) is a $\alpha$-chlorohydrocarbon with a boiling point of 55 ${ }^{\circ} \mathrm{C}$. It is commonly referred to as $\mathrm{MOMCl}$ (methyl-oxygen-methyl-chloride) and is typically a "protecting group" in synthetic laboratory chemistry. Alternatively, it can be used to install chloromethyl groups as is the case with polymers for ion exchange resins. Chloromethyl methyl ether is a known animal carcinogen, and several studies have examined lung cancer death rates in workers at $\mathrm{MOMCl}$ manufacturing facilities. Acute exposure is typically through inhalation and results in pulmonary edema, suffocation, and chemical burns. It has been banned in Canada along with the related halohydrocarbon bis(chloromethyl) ether, and domestic production of both chemicals has been curtailed. Bis(chloromethyl) ether is no longer made in the United States, and only a few thousand pounds of chloromethyl methyl ether was produced in 2003. It is important to note that commercial samples of chloromethyl methyl ether are typically contaminated with bis(chloromethyl) ether (process dependent).

\subsubsection{Major Uses ${ }^{2}$}

Alkylation and chloromethylation to synthesize:

- Water repellents

- Ion-Exchange Membranes/Resins

- Polymers

\subsubsection{Production Technology}

Chloromethyl methyl ether is made from the condensation of formaldehyde and methanol using hydrochloric acid as the chloride source. A thorough literature search has not yielded the conditions used in industrial syntheses, and there may be no current domestic production. 


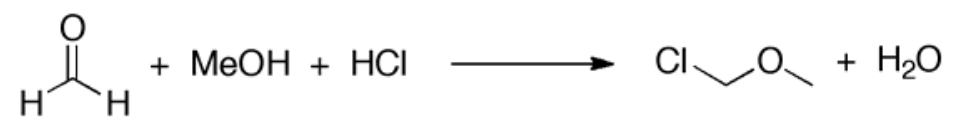

Scheme 1. Synthesis of Chloromethyl Methyl Ether

\subsubsection{Feedstocks}

- Formaldehyde

- Methanol

- Hydrochloric Acid

\subsubsection{Distribution ${ }^{2}$}

Chloromethyl methyl ether is regulated by OSHA as a carcinogen (29 CFR 1910.1006) and is listed in IARC Group 1 ("carcinogenic to humans").

\subsubsection{Alternative Production Technology ${ }^{7}$}

There are several methods based around the need for more substituted chloromethyl ethers, but most of these methods use complex starting materials that are broken down into the desired ethers. These are not "atom economical” but catalysts might offer lower the temperature/pressure to create a safer alternative. None have been developed so far.

\subsubsection{7. $\quad$ References}

1. SRIC Chemical Economic Handbook, 2010.

2. Michael Sakuth, Thomas Mensing, Joachim Schuler, Wilhelm Heitmann, Gunther Strehlke, Dieter Mayer. "Ethers, Aliphatic". Ullmann's Encyclopedia of Industrial Chemistry, 2005. Wiley-VCH.

3. “Chloromethyl Methyl Ether.” Wikipedia. 4 May 2011. Web. 5 May 2011. <http://en.wikipedia.org/wiki/Chloromethyl_methyl_ether>.

4. “Chloroalkyl Ether.” Wikipedia. 11 April 2011. Web. 5 May 2011. $<$ http://en.wikipedia.org/wiki/Chloroalkyl_ether>.

5. McCallum, R.; Woolley, V.; Petrie, A. "Lung Cancer Associated with Chloromethyl Methyl Ether Manufacture: an Investigation at Two Factories in the United Kingdom.” Brit. J. Ind. Med. 1983, 40, 384.

6. Suzuki, H. "Chloromethylation with Chloromethyl Methyl Ether and 60\% Fuming Sulfuric Acid. A Simple Synthesis of Some Nitropolymethylbenzyl Chlorides and Dihalopolymethylbenzyl Chlorides.” Bull. Chem. Soc. Jpn. 1970, 43, 3299.

7. Chong, J. M.; Shen, L. "Preparation of Chloromethyl Methyl Ether Revisited." Synth. Commun. 1998, 28, 2801.

8. Marvel, C. S.; Porter, P. K., Org. Synth., Coll. Vol. 1941, 1, 377.

9. Wuts, P. G. M. “Encyclopedia of Reagents for Organic Synthesis.” Paquette, L. A., Ed.; Wiley: New York, 1995. 
10. "Bis(chloromethyl) Ether and Technical Grade Chloromethyl Methyl Ether.” Report on Carcinogens, Eleventh Edition; U.S. Department of Health and Human Services, Public Health Service, National Toxicology Program.

\subsubsection{Background Information ${ }^{4}$}

Cyanogen chloride, $(\mathrm{CNCl})$, is a colorless gas that can be condensed to a clear liquid at low (13 ${ }^{\circ} \mathrm{C}$ ) temperatures. It is also known as CK. It is a toxic blood agent that is harmful by inhalation and skin contact as well as ingestion and injection. Cyanogen chloride can polymerize explosively. Cyanogen chloride is listed in schedule 3 of the Chemical Weapons Convention: it can be used as a chemical weapon itself and it can be used in the manufacture of chemical weapons but it also has "legitimate large-scale industrial uses."

\subsubsection{Producers $^{1-3}$}

While production data on cyanogen chloride is not available through SRIC DCP, production locations can be determined through the production of cyanuric acid, which uses cyanogen chloride as a precursor.

- Syngenta Crop Protection

- Specialty Gases of America

- Monsanto Co.

- Clearon Corp.

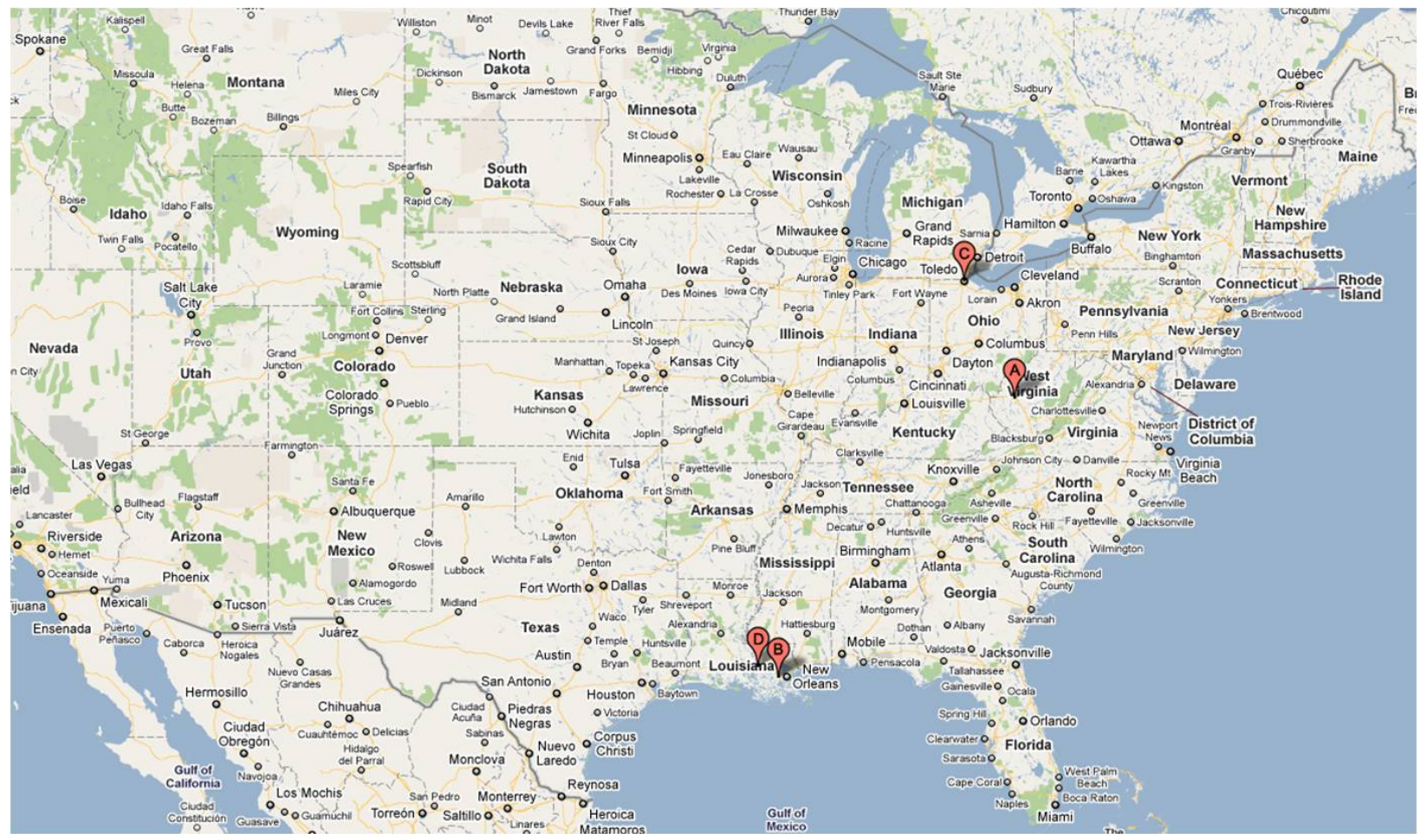




\section{Figure 1. Domestic Producers}

\subsubsection{Major Uses ${ }^{4}$}

- For cyanuric acid production, in the manufacture or herbicides (atrazine, simiazine, cyanizine), dyestuffs, and optical brighteners

\subsubsection{Production Technology ${ }^{4-17}$}

As most cyanogens chloride is produced in the manufacture of cyanuric acid, the most often employed route involves hydrogen cyanide and chlorine as starting materials; the reaction can be carried out in aqueous solution, in organic and inorganic solvents, and in the gas phase, as shown in patents from Degussa and Bayer. The $\mathrm{HCl}$ can be re-oxidized to chlorine with oxygen and hydrogen peroxide in catalyzed reactions in order to avoid producing $\mathrm{HCl}$ as a by-product. Cyanogen chloride may also be made in the following ways, as taken from Ullmann's. None of these processes are employed industrially to the best of our knowledge:

1. Electrolysis of an aqueous solution of $\mathrm{HCN}$ and $\mathrm{NH}_{4} \mathrm{Cl}$

2. Reaction of complex cyanide salts (e.g., $\mathrm{Na}_{2}\left[\mathrm{Zn}(\mathrm{CN})_{4}\right]$ ) with chlorine below $20^{\circ} \mathrm{C}$

3. Formation of $\mathrm{ClCN}$ from cyanide salts (mostly $\mathrm{NaCN}$ ) and chlorine in an exothermic reaction; in a continuous process, sprayed aqueous NaCN solution is contacted with chlorine, and the reaction heat evaporates the ClCN .

4. Chlorinolysis of cyanogen in the gas phase at $300-600{ }^{\circ} \mathrm{C}$ in the presence of a catalyst.

5. Pyrolysis of cyanuric chloride at $600-900{ }^{\circ} \mathrm{C}$ in the presence of a charcoal catalyst.

6. High-temperature syntheses based on elemental chlorine, nitrogen, and carbon.

\subsubsection{Production Volume P $^{1-4}$}

Again, using the information in SRIC's CEH the production volume can be calculated from the amount of HCN used to produce it, and verified by the amount of cyanuric acid produced. In both cases, the U.S. production level of cyanogen chloride was calculated to be $11 \mathrm{tmt}$.

\subsubsection{Feedstocks}

- $\mathrm{HCN}$

- $\mathrm{Cl}_{2}$

\subsubsection{Distribution ${ }^{4}$}

From Ullman's: “In most cases, ClCN is used in the gas phase immediately after preparation. Relatively small amounts are condensed and stored in gas containers as liquids. Steel cylinders, which must meet specific requirements in each country, can be used for shipment. The condensed and bottled ClCN must be very pure; moreover, it must be mixed with a stabilizing agent (generally sodium pyrophosphate) to inhibit exothermic polymerization caused by impurities.” 
Specialty Gases of America will ship it under the following regulations:

DOT (US only)

Proper shipping name: Cyanogen Chloride, Stabilized

Class : 2.3

UN/ID No. : UN1589

Labeling : Poison Gas; Corrosive

Additional shipping description: Toxic-Inhalation Hazard Zone A

\subsubsection{Alternative Production Technology}

No other production technologies are currently in use industrially, to the best of our knowledge.

\subsubsection{References}

1. SRIC Directory of Chemical Producers 2008 and SRIC 2009 World Petroleum.

2. E-PLAN, Department of Homeland Security's Emergency Response Information System: https://erplan.net/eplan

3. SRIC Chemical Economic Handbook, 2010, Hydrogen Cyanide.

4. Gail, E., Gos, S., Kulzer, R., Lorösch, J., Rubo, A. and Sauer, M. 2004. “Cyano Compounds, Inorganic.” Ullmann's Encyclopedia of Industrial Chemistry.

5. Patents involving cyanogen chloride production from Ullmann's article:

6. DEGUSSA, DE 833 490, 1949 (H. Huemer).

7. DEGUSSA, DE 842 067, 1950 (H. Huemer, H. Schulz).

8. DEGUSSA, DE 827 358, 1949 (1952) (H. Huemer, H. Schulz, W. Pohl).

9. DEGUSSA, DE-OS 2521 580, 1976 (L. Devlies, R. Hendricx, K. Henkel, N. Kriebitzsch, M. Petzold).

10. Ciba-Geigy Corp., US 4100 263, 1978 (R. Miller).

11. Bayer, DE-OS 3117 054, 1982 (H. Königshofen, D. Bruck, A. Nierth, M. Zlokarnik, H. J. Uhlmann).

12. Agripat SS.A, DE-OS 1801 311, 1969 (W. S. Durrell, R. J. Eckert, Jr. ).

13. SKW Trostberg, DE-OS 2838 016, 1980 (G. Buchreiter, P. Kniep, K. Scheinost, H. R. Vollbrecht).

14. DEGUSSA, DE-OS 2154 721, 1973 (F. Geiger, W. Weigert).

15. Bayer, DE-OS 2157 973, 1973 (Z. Kricsfalussy, K. Blöcker, J. Pawlowski, B. Scherhag, R. Weiler).

16. DEGUSSA, DE-AS 2521 581, 1977 (W. Heimberger, G. Schreyer).

17. DEGUSSA, DE-AS 2521 582, 1979 (W. Heimberger, G. Schreyer).

18. Specialty Gases of America Website; $<$ http://www.specialtygasesofamerica.com/msds/material-safety-data-sheets.html $>$

\subsubsection{Chemical Supply Chain Tree}




\section{Cyanogen Chloride}

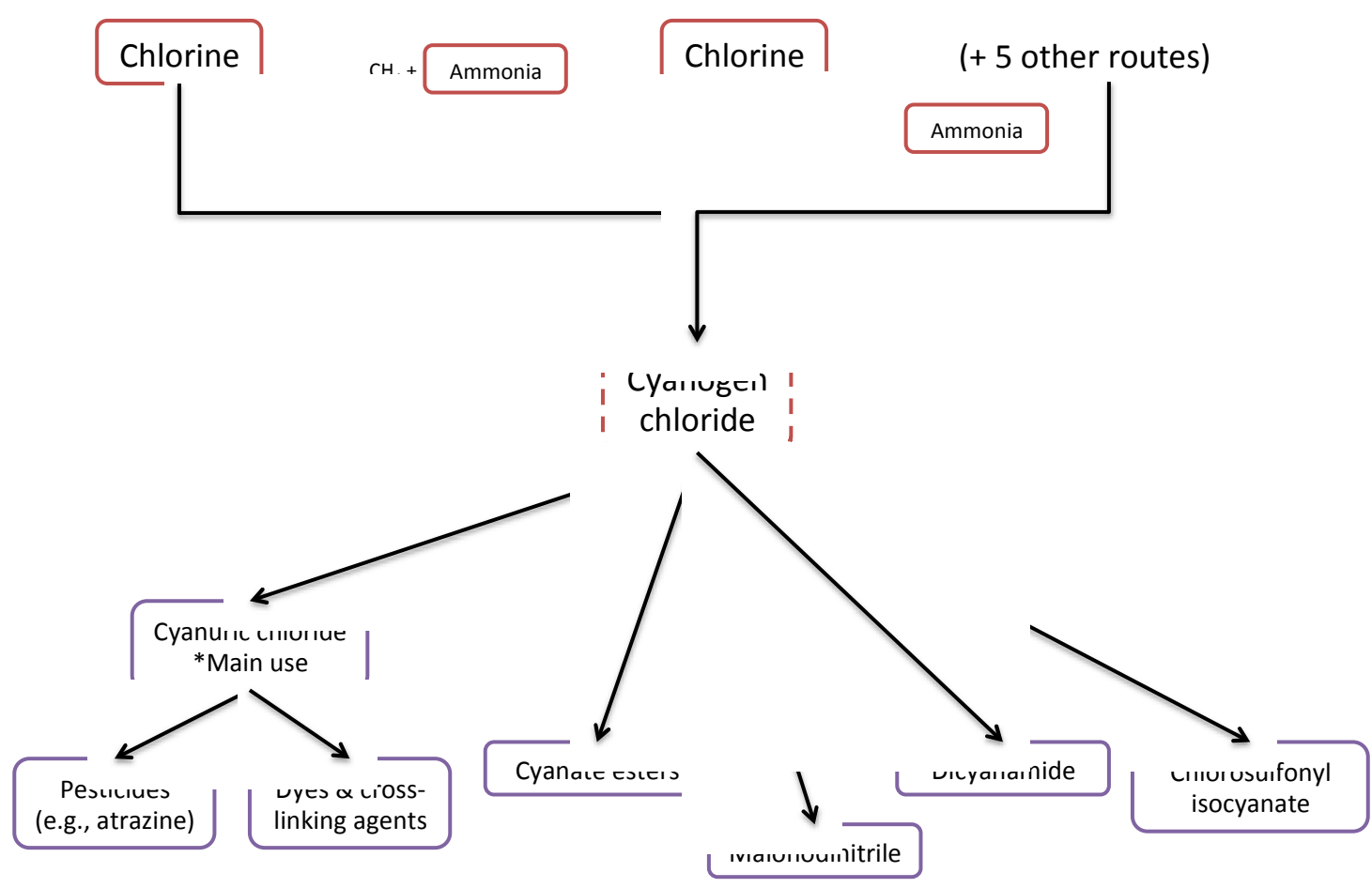

\section{HCN Production}

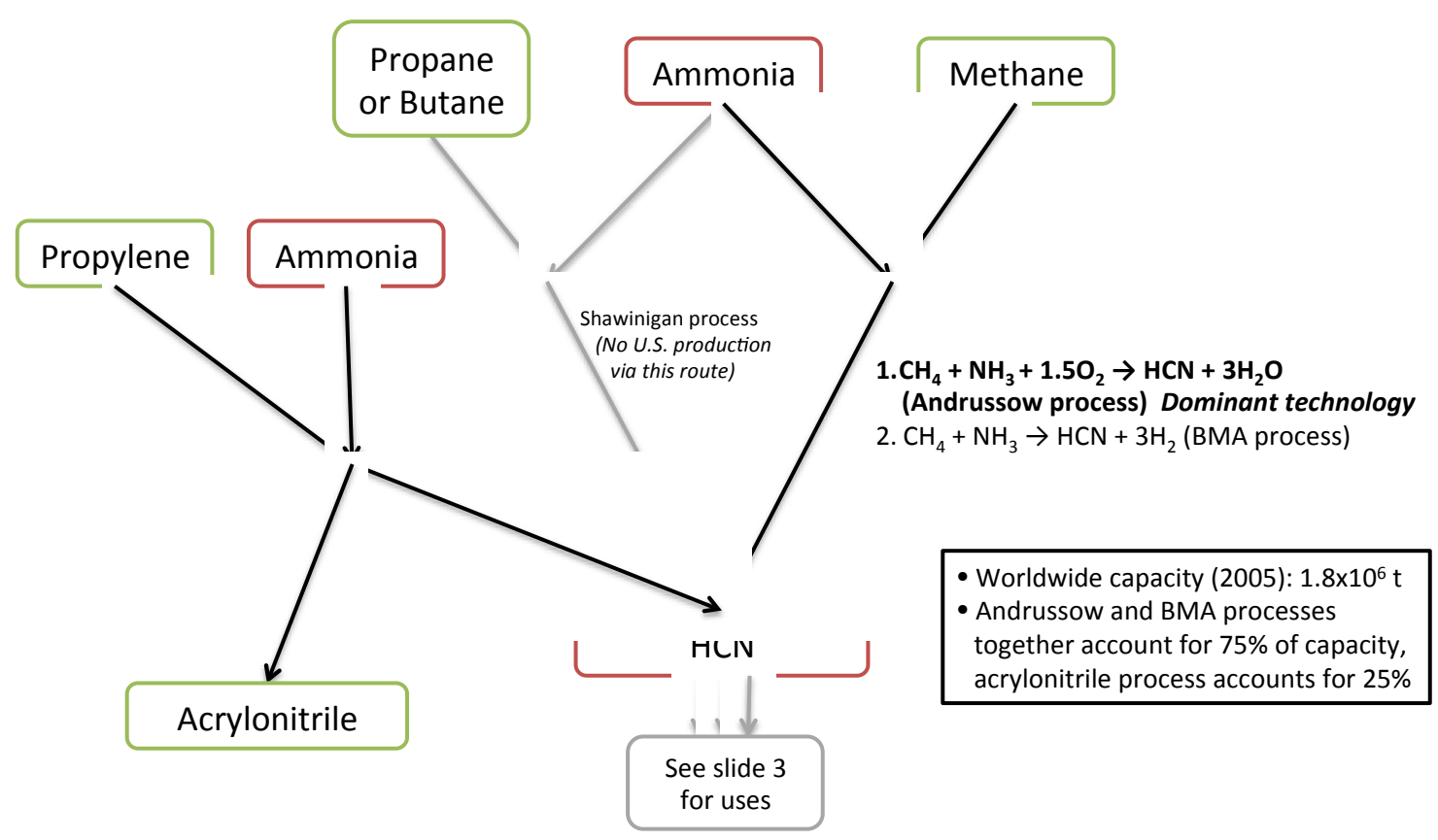




\section{HCN Derivatives}

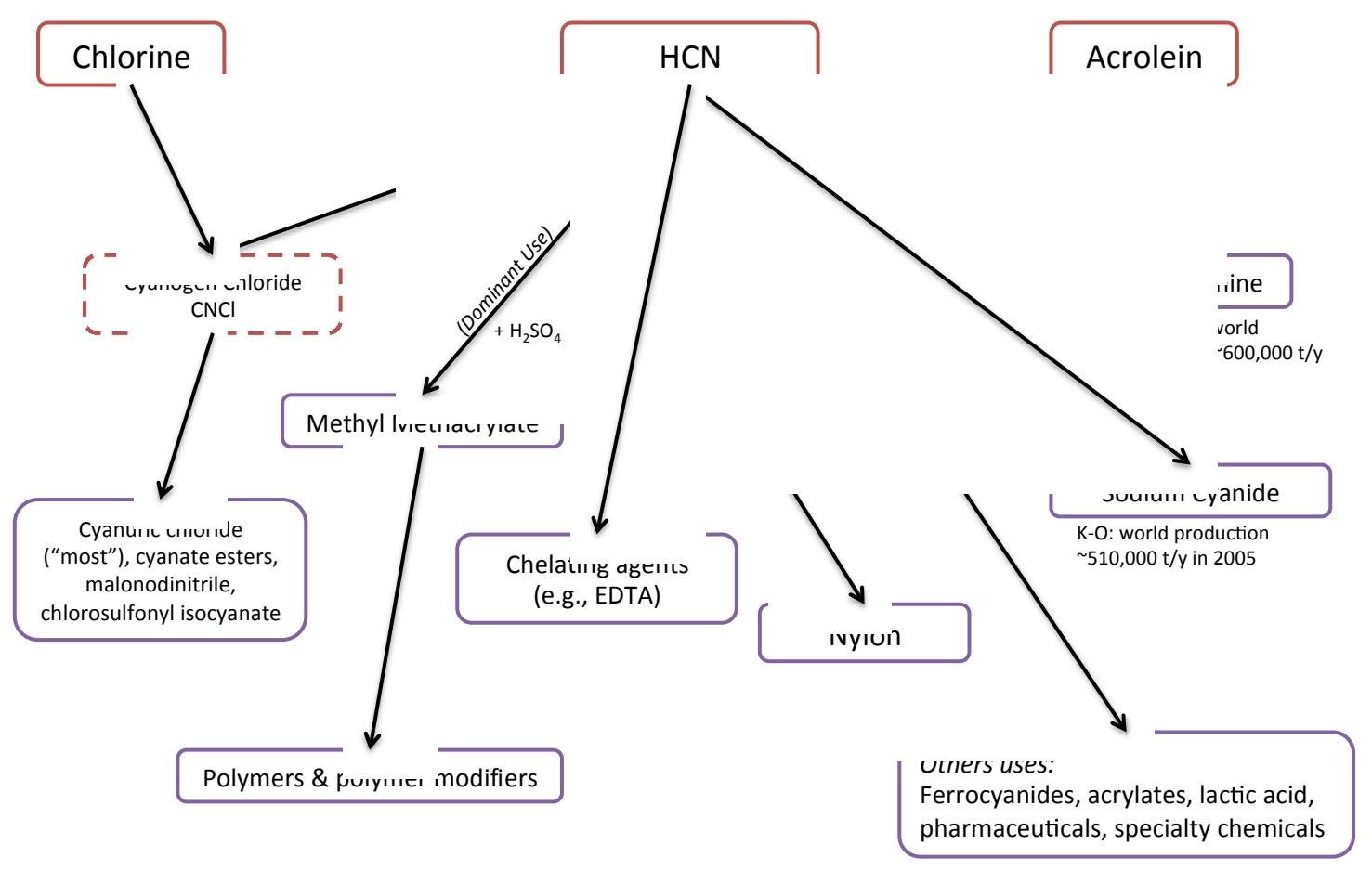

\subsubsection{Epichlorohydrin}

\subsubsection{Background Information}

Epichlorohydrin is a chlorinated epoxide and a building block for epoxy resins. It has a boiling point of $117^{\circ} \mathrm{C}$ and a relatively low flash point at $40^{\circ} \mathrm{C}$. It is soluble in most organic solvents like acetone, diethyl ether, and methanol and is sparingly soluble in water. Contact exposure will result in severe chemical burns on skin and eyes. It is thought to be carcinogenic but the hydrolysis products (chlorohydrins) are noted to be more toxic.

\subsubsection{Producers ${ }^{1}$}

There are two U.S. producers on record for epichlorohydrin: Dow Chemical Company in Freeport, TX and Momentive in Norco, LA. 


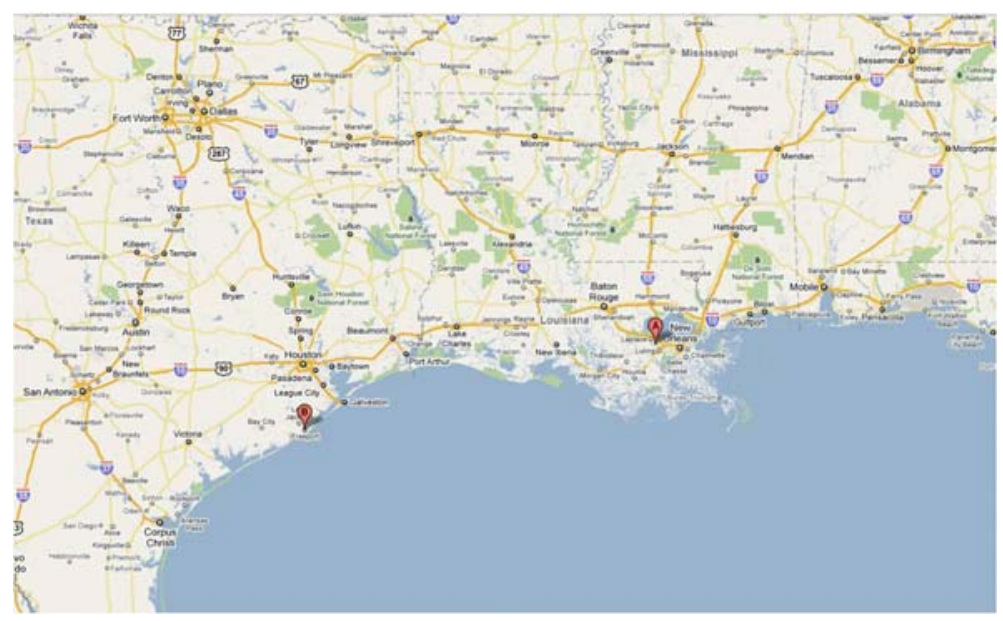

Figure 1. Domestic Producers.

According to voluntarily submitted E-PLAN storage data, 48 companies with a total of 150 sites across the U.S may store epichlorohydrin.

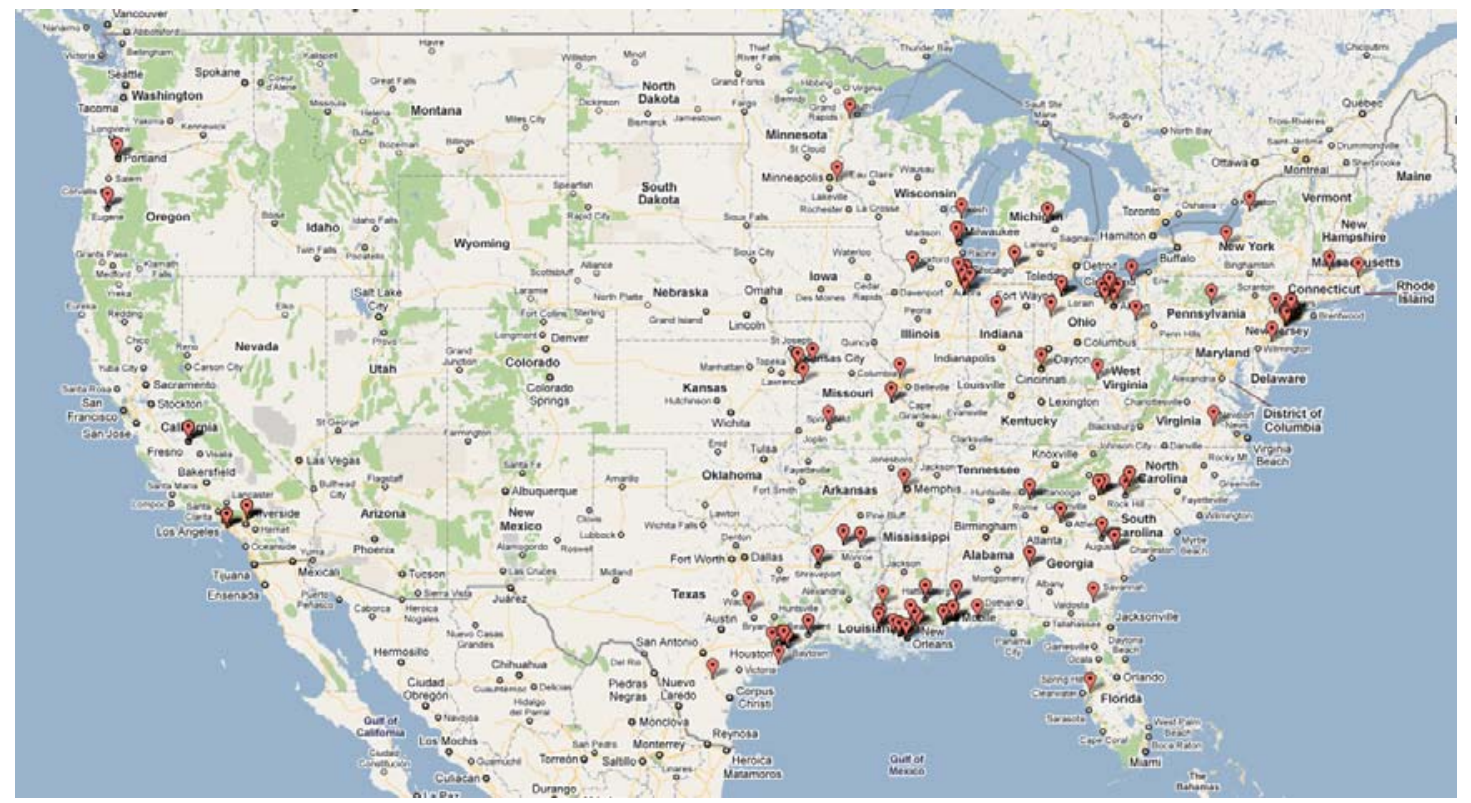

Figure 2. Domestic Storage.

\subsubsection{Major Uses ${ }^{2-4}$}

- $\quad$ Epoxy resins (typically paired with bisphenol A and polyamines)

o Various applications for epoxies include adhesives, plastics, elastomers, electrical insulation, composites with other materials such as carbon fiber

- Synthetic glycerol production

- Used directly as an insecticide, bactericide, fungicide

- Building block for organic synthesis

- Wool modification 
- $\quad$ Paper/ink/dye applications

\subsubsection{Production Technology ${ }^{2-4}$}

The most prevalent modern method for the production of epichlorohydrin begins with propylene. See reactions 1 through 4 below (Scheme 1). Propylene is chlorinated via 1.) in a high temperature gas-phase radical reaction similar to the method used in the chlorination of methane to methylene chloride, chloroform, and carbon tetrachloride. The product, allyl chloride, is then exposed to hypochlorous acid via 3.) giving a mixture of two chlorinated alcohols: 1,3dichloropropan-2-ol and 2,3-dichloropropan-1-ol. Both of these alcohols can be converted to epichlorohydrin via 4.) by addition of sodium hydroxide.

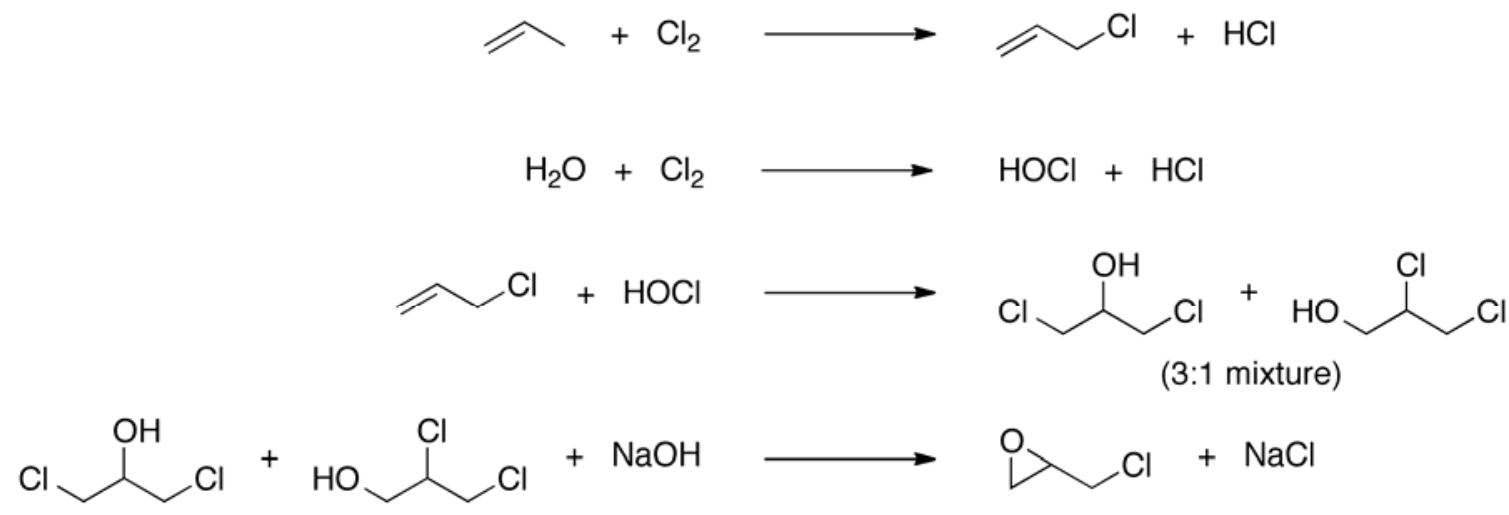

Scheme 1. Propylene Chlorination Production.

\subsubsection{Production Volume ${ }^{1}$}

Dow Chemical Company in Freeport, TX has a reported production volume of $805 \mathrm{mlbs} / \mathrm{yr}$ and Momentive in Norco, LA has a production volume of $210 \mathrm{mlbs} / \mathrm{yr}$.

\subsubsection{Feedstocks}

- $\quad$ Propylene

- $\quad$ Chlorine

- $\quad$ Hypochlorous Acid (made from $\mathrm{H}_{2} \mathrm{O}$ and $\mathrm{Cl}_{2}$ )

- $\quad$ Sodium Hydroxide

\subsubsection{Distribution ${ }^{1}$}

UN Number: 2023. Hazard class 6.1. Packing group II. NFPA 704: Red 3, Blue 3, Yellow 2

\subsubsection{Alternative Production Technology ${ }^{8}$}

Dow published a paper recently on the chlorination of glycerol and conversion to epichlorohydrin. Propylene and the high temperature chlorination step are removed from the 
process. Glycerol is treated with hydrochloric acid to give the same mixture of dichloropropanols (different ratio) that are then converted to epichlorohydrin using the current technology. This process has fewer steps, is less energy intensive, the starting materials are less toxic and less explosive, and the glycerol is currently a byproduct/waste of the biodiesel industry.

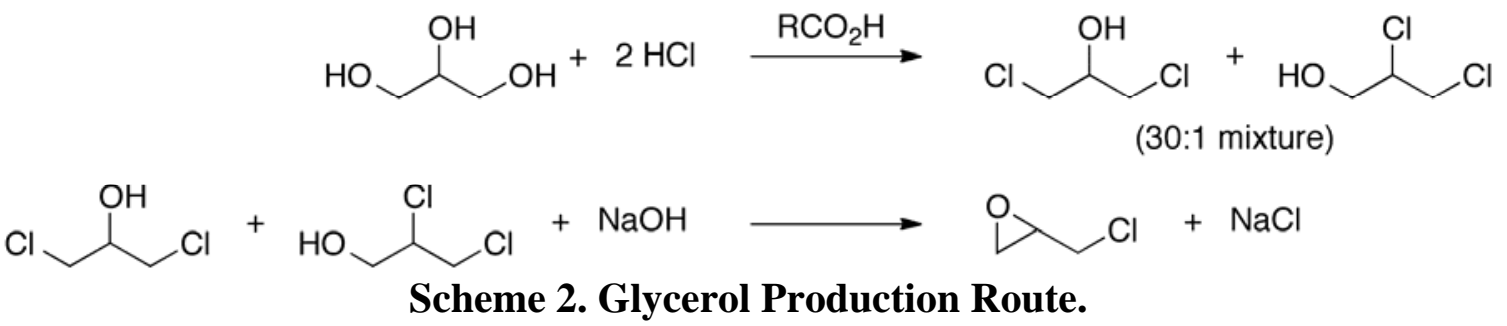

This glycerol-to-epichlorohydrin technology is already being pursued industrially by Dow, Solvay, and Spolchemie.

\subsubsection{References}

1. SRIC Chemical Economic Handbook, 2010.

2. Guenter Sienel, Robert Rieth, Kenneth T. Rowbottom. "Epoxides". Ullmann's Encyclopedia of Industrial Chemistry, 2005. Wiley-VCH.

3. Ludger Krahling, Jurgen Krey, Gerald Jakobson, Johann Grolig, Leopold Miksche. "Allyl Compounds". Ullmann's Encyclopedia of Industrial Chemistry, 2005. Wiley-VCH.

4. “Epichlorohydrin.” Wikipedia. 20 March 2011. Web. 21 April 2011. $<$ http://en.wikipedia.org/wiki/Epichlorohydrin>.

5. “Epoxy Resin.” Wikipedia. 12 April 2011. Web. 15 March 2011. $<$ http://en.wikipedia.org/wiki/Epoxy_resin>.

6. Dow Epichlorohydrin Product Stewardship Manual, Dow Chemical Company, 2007.

7. “Chlorohydrins.” W. Frank Richey. Kirk-Othmer Encyclopedia of Chemical Technology, 2000. Wiley-Interscience.

8. "Glycerin as a Renewable Feedstock for Epichlorohydrin Production. The GTE Process." Bruce M. Bell, John R. Briggs, Robert M. Campbell, Susanne M. Chambers, Phil D. Gaarenstroom, Jeffrey G. Hippler, Bruce D. Hook, Kenneth Kearns, John M. Kenney, William J. Kruper, D. James Schreck, Curt N. Theriault, Charles P. Wolfe. Clean 2008, 36, 657.

\subsubsection{Chemical Supply Chain Tree}




\section{Epichlorohydrin}
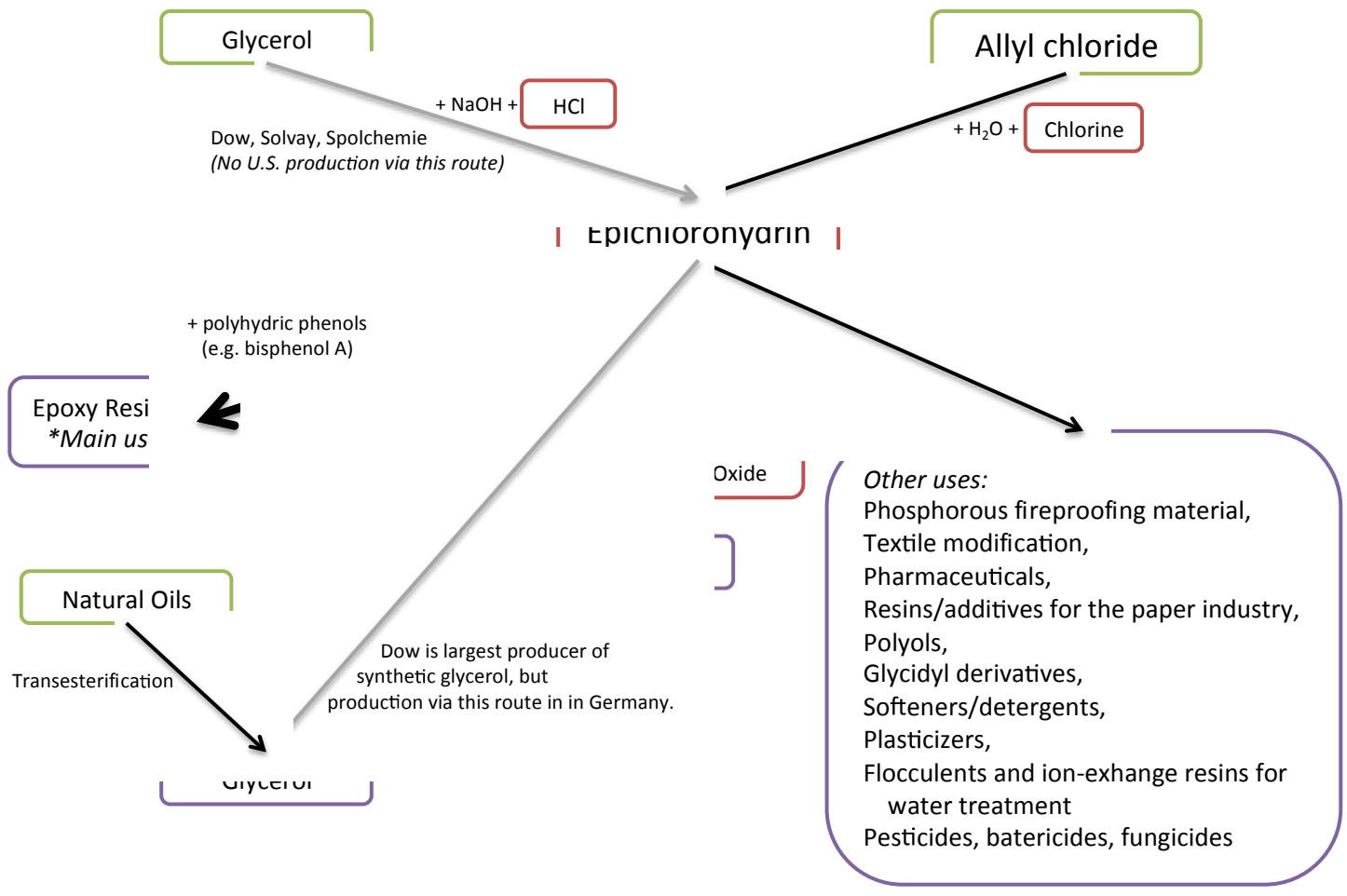

\section{Chemical Tree: Olefin Derivatives}

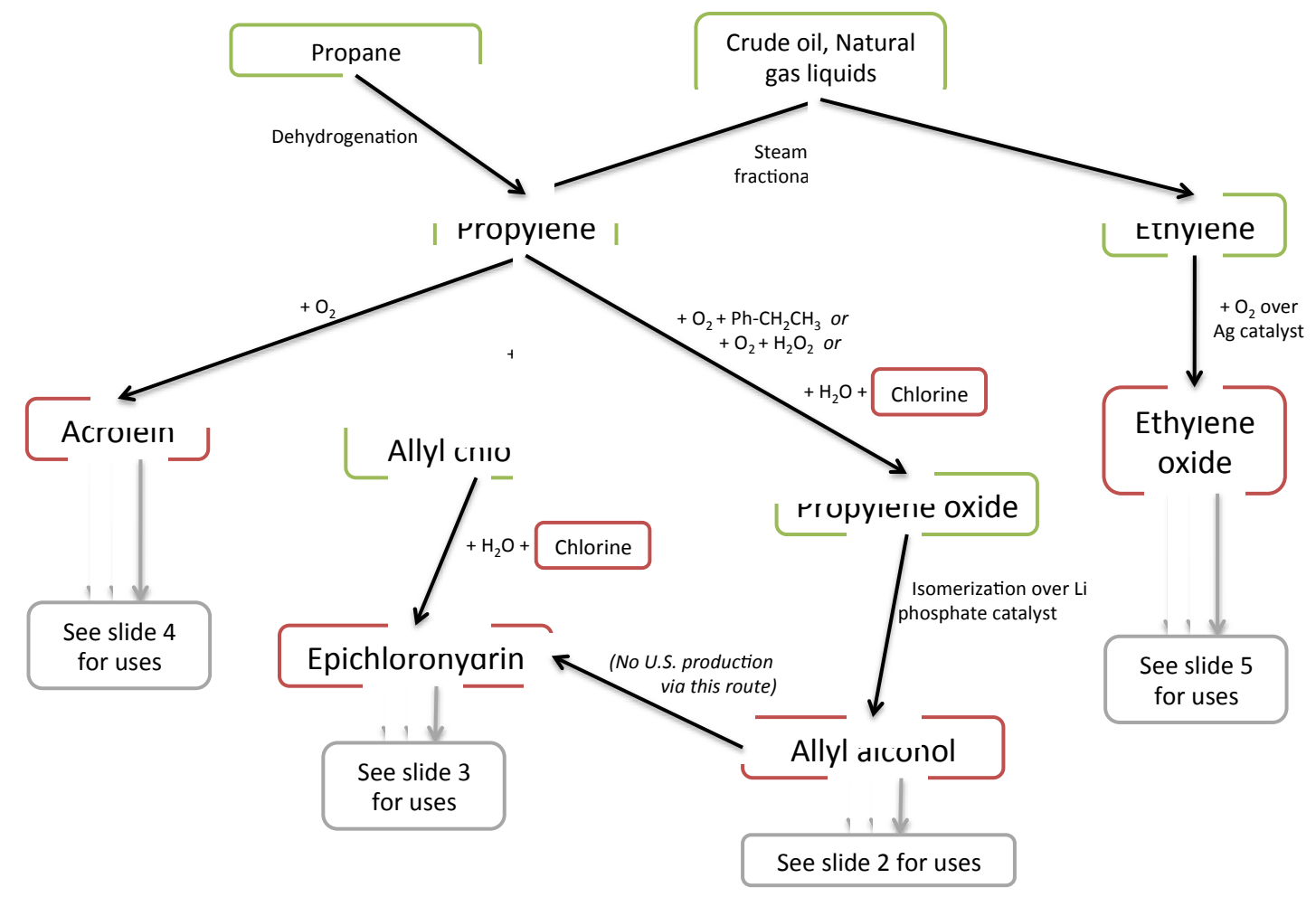




\subsubsection{Ethylene Oxide}

\subsubsection{Background Information ${ }^{2-4}$}

Ethylene Oxide (CAS: 75-21-8) is a strained 3-membered ring composed of two carbon atoms and one oxygen atom. This strained ring system is the primary reason for this molecule's utility but when this strain is released, a significant amount of energy is generated leading to explosions and runaway reactions. Ethylene oxide is a toxic gas with a 4-hour $\mathrm{LC}_{50}$ (rat) of $1460 \mathrm{ppm}$. Inhalation exposure leads to many respiratory problems such as irritation, shortness of breath, coughing, and eventually pulmonary edema and death. Convulsions, headache, nausea and vomiting, dizziness, and coma are other more severe effects of exposure. There is also evidence to suggest that low-level but long-term exposure causes neurological and mutagenic effects.

\subsubsection{Major Uses ${ }^{2-4}$}

- Ethylene Glycol

- Ethoxylates

- Diethylene and Triethylene Glycol

- Ethanol Amines

- Ethylene Glycol Ethers

- Polyols

- Polyethylene Glycols

- Direct use as an agricultural fumigant and sterilization agent for medical equipment

\subsubsection{Production Technology ${ }^{2-4}$}

The production of ethylene oxide in the United States after 1975 has been completely dominated by one general class of technology: direct oxidation of ethylene. There are two subclasses of this direct oxidation method based on pure oxygen or air-oxygen. Newer facilities favor the pure oxygen oxidation method, and some existing air-oxygen plants have been converted over to pure oxygen.

$$
\begin{aligned}
& \text { a) } \quad 2 \mathrm{C}_{2} \mathrm{H}_{4}+\mathrm{O}_{2} \stackrel{\text { Catalyst }}{\longrightarrow} 2 \mathrm{O} \\
& \text { b) } 4 \mathrm{C}_{2} \mathrm{H}_{4}+5 \mathrm{O}_{2} \longrightarrow 4 \mathrm{CO}_{2}+4 \mathrm{H}_{2} \mathrm{O}
\end{aligned}
$$

Scheme 1. a) oxidation of ethylene with oxygen gas and, b) combustion of ethylene to give carbon dioxide and water

The direct oxidation of ethylene by oxygen is a simpler process than air-oxygen due to the exclusion of carrier gases and the reduction in side products. Ethylene and oxygen along with a combustion inhibitor (1,2-dichloroethane or other halogenated hydrocarbons) are mixed in the 
gas phase and fed into a tubular packed bed reactor at 220 C and 20-30 atmospheres. This reactor can be 6-12 meters in length. It is filled with a solid-supported silver catalyst doped with promoters such as calcium, barium, rubidium, potassium, and cesium. This process achieves 70$80 \%$ selectivity for ethylene oxide at a yield of $8-12 \%$. The unreacted material is fed back into the reactor and the ethylene oxide is captured in water scrubbers and fractionally distilled.

\subsubsection{Feedstocks ${ }^{2-4}$}

- $\quad$ Ethylene

- $\quad$ Oxygen (pure or air-mixture)

- $\quad$ Combustion Inhibitors (ethylenedichloride)

\subsubsection{Distribution ${ }^{2}$}

Ethylene oxide can be shipped by barge, rail, or road. However, the containers that are used must be free from any deposits that could promote the polymerization of ethylene oxide. Specifically, iron oxide is known to initiate the polymerization of ethylene oxide and stainless steel is typically used to avoid this. Most tanker cars are pressure rated to 10 atmospheres or greater to withstand a potential explosion.

UN Number: 1040

NFPA 704: 3, 4, 3

\subsubsection{Alternative Production Technology}

No additional commercialized technologies have been found.

\subsubsection{References}

1. SRIC Chemical Economic Handbook, 2010.

2. Rebsdat, S.; Mayer, D. "Ethylene Oxide." Ullmann's Encyclopedia of Industrial Chemistry, 2005. Wiley-VCH.

3. Dever, J. P.; George, K. F.; Hoffman, W. C.; Soo, H. "Ethylene Oxide.” Kirk-Othmer Encyclopedia of Chemical Technology, 2004. Wiley-Interscience.

4. “Ethylene Oxide.” Wikipedia. 11 May 2011. Web. 17 May 2011. <http://en.wikipedia.org/wiki/ethylene_oxide>

\subsubsection{Chemical Supply Chain Tree}




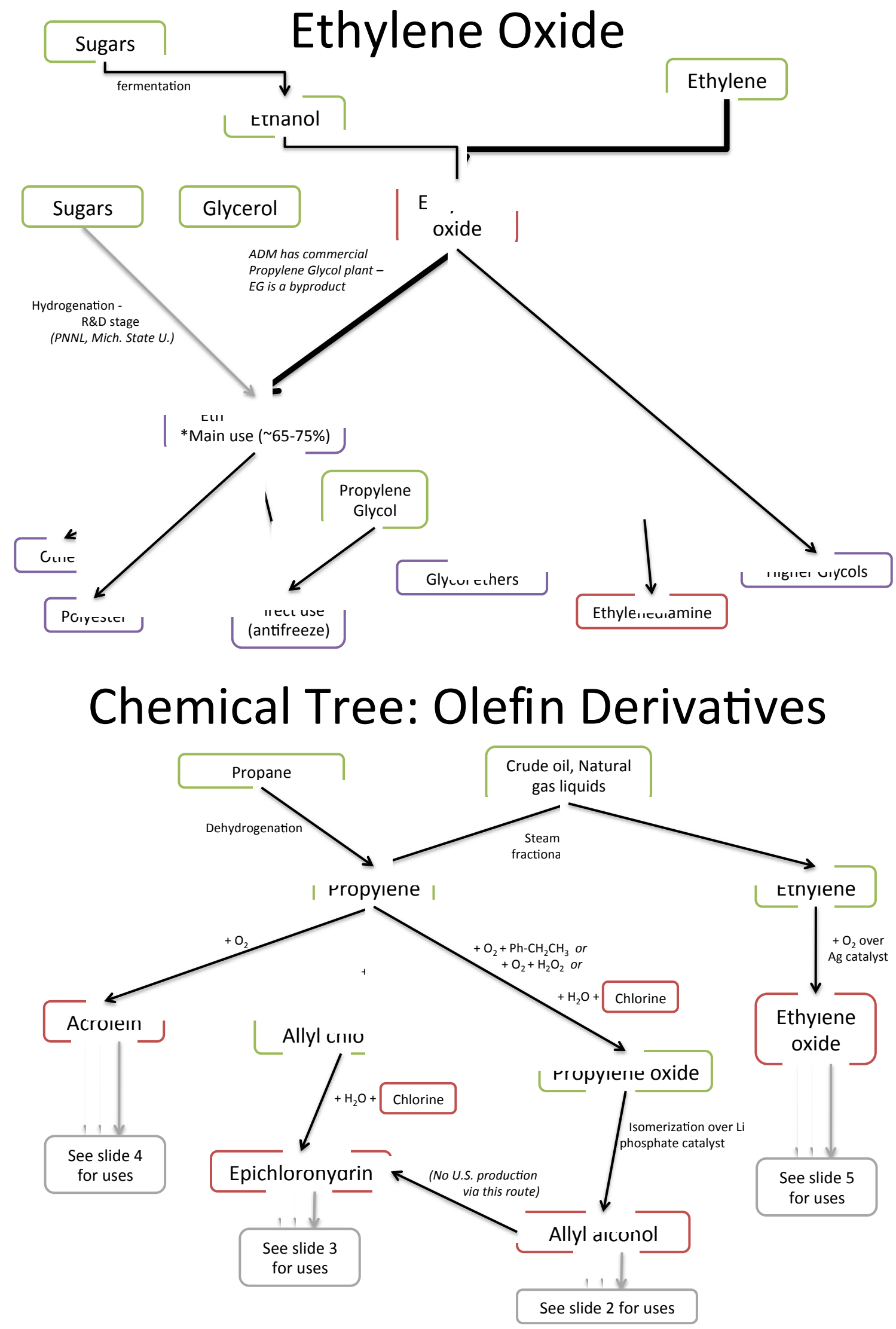




\subsubsection{Ethylene Diamine}

\subsubsection{Background Information}

Ethylenediamine (1,2-diaminoethane, EDA, CAS: 107-15-3) is one of the most common diamines by production volume both domestically and internationally. EDA has a relatively high boiling point $\left(117^{\circ} \mathrm{C}\right)$ for a compound with a molecular weight of only 60.10 grams $/ \mathrm{mol}$. It is not as harmful as the monoamines but can still cause skin irritation on direct contact and kidney damage from chronic oral exposure. There is no evidence to suggest that it has teratogenic or mutagenic properties.

\subsubsection{Major Uses ${ }^{2-13}$}

- Fungicides based on ethylenebisdithiocarbamates (Maneb, Zineb, Mancozeb, Metiram)

- Chelating Agents (Ethylenediaminetetraacetic Acid)

- Bleach Activator (Tetraacetyleneethylenediamine)

- Polyamides, Epoxy Curing Agents (N,N-ethylenebis(stearamide))

- Petroleum/Fuel Additives

- Higher Polyamines

\subsubsection{Production Technology ${ }^{2-4}$}

a)
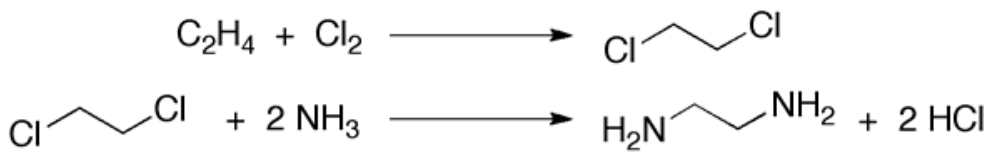

b)

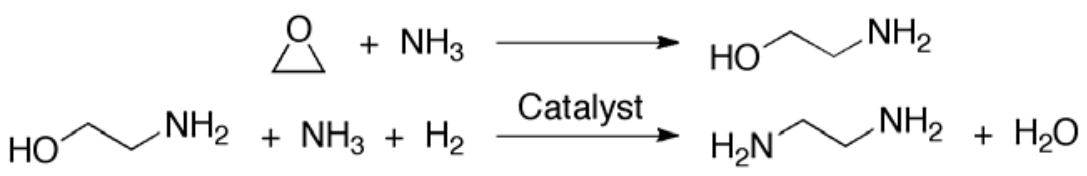

Scheme 1. a) Ethylenedichloride condensation with ammonia; b) Ethanolamine reduction with ammonia and hydrogen

Two processes dominate the production of ethylenediamine. The most common method is the conversion of ethylenedichloride into ethylenediamine via condensation with ammonia in an aqueous solution. Temperatures from $100-180{ }^{\circ} \mathrm{C}$ are used in this process with moderately high pressures. The hydrochloride salt that is obtained is neutralized using a caustic aqueous solution, separated by a number of different methods such as crystallization and solvent extraction, and distilled to purify from the other amine products. The ratios of reactants, $\mathrm{pH}$, and reactor type are all methods used to control the formation of amine byproducts. A major drawback to this method 
is the use of chlorine in forming the ethylenedichloride and the eventual disposal of unneeded chlorine salts after condensation with ammonia.

A major alternative method is also a workaround for the use of ethylenedichloride. Ethylene oxide is reacted with anhydrous ammonia to generate the monoethanolamine product (MEA). MEA is then reacted in a separate step with supercritical ammonia (500 ${ }^{\circ} \mathrm{C}$ and 200 atmospheres) over a solid supported-transition metal catalyst composed of various combinations of rhenium, nickel, cobalt, copper, tungsten, boron, and zirconium. This reductive amination takes place in the gas phase in the presence of hydrogen. These two steps have been integrated into a single process directly from ethylene oxide.

\subsubsection{Feedstocks}

- $\quad$ Ethylene/Ethylene Oxide, Ammonia, Hydrogen

- $\quad$ Ethylene/Ethylenedichloride, Ammonia

\subsubsection{Distribution ${ }^{2}$}

Storage of ethylenediamine is typically done in 300 series stainless steel or aluminum. Other alloys including carbon steel will react with EDA to leech iron out of the container and into solution. EDA is stored above room temperature to prevent solidification and increase viscosity, but storage in this way necessitates scrubbers to prevent significant quantities of EDA from escaping.

\subsubsection{Alternative Production Technology ${ }^{2-4}$}

Some alternative small-scale processes have been developed. Catalytic condensation of formaldehyde, hydrocyanic acid, and ammonia under reducing conditions. Condensation of chloroacetyl chloride and ammonia. Hydrogenation of aminoacetonitrile. None are significant improvements over current technology from an IST standpoint.

\subsubsection{References}

1. SRIC Chemical Economic Handbook, 2010.

2. Eller, K.; Henkes, E.; Rossbacher, R.; Höke, H. "Amines, Aliphatic." Ullmann's Encyclopedia of Industrial Chemistry, 2005 Wiley-VCH Verlag, Weinheim.

3. Sridhar, S.; Carter, R. G. "Diamines and Higher Amines, Aliphatic." Kirk-Othmer Encyclopedia of Chemical Technology, 2001, Wiley-Interscience.

4. Edens, M. R.; Lochary, J. F. "Alkanolamines From Olefin Oxides and Ammonia.” KirkOthmer Encyclopedia of Chemical Technology, 2004, Wiley-Interscience.

5. "Ethylenediamine." Wikipedia. 20 April 2011. Web. 16 May 2011. $<$ http://en.wikipedia.org/wiki/Ethylenediamine>.

6. "Patented Production Process - AkzoNobel Ethylene Amines.” AkzoNobel. Web. 12 May 2011.

$<$ https://www.akzonobel.com/ea/our_products/ethanolamines/patented_production_proce ss $>$. 
7. "Ethylenediamine (EDA)." Dow Specialty Amines. Web. 16 May 2011. $<$ http://www.dow.com/amines/prod/ethyl-eda.htm>.

8. “Ethylene diamine (CASRN 107-15-3).” US EPA. 07 March 2011. Web. 16 May 2011. $<$ http://www.epa.gov/iris/subst/0528.htm>.

9. “Zineb.” Wikipedia. 18 October 2010. Web. 16 May 2011. $<$ http://en.wikipedia.org/wiki/Zineb>.

10. "Maneb." Wikipedia. 13 May 2011. Web. 16 May 2011. $<$ http://en.wikipedia.org/wiki/Maneb>.

11. "Ethylenediaminetetraacetic Acid.” Wikipedia. 11 May 2011. Web. 16 May 2011. $<$ http://en.wikipedia.org/wiki/EDTA>.

12. “Tetraacetyleneethylenediamine.” Wikipedia. 1 May 2011. Web. 16 May 2011. $<$ http://en.wikipedia.org/wiki/Tetraacetyleneethylenediamine>.

13. "Ethylene bis stearamide." Wikipedia. 13 December 2010. Web. 16 May 2011. <http://en.wikipedia.org/wiki/Ethylene_bis_stearamide>.

\subsubsection{Chemical Supply Chain Tree}

\section{Ethylenediamine}

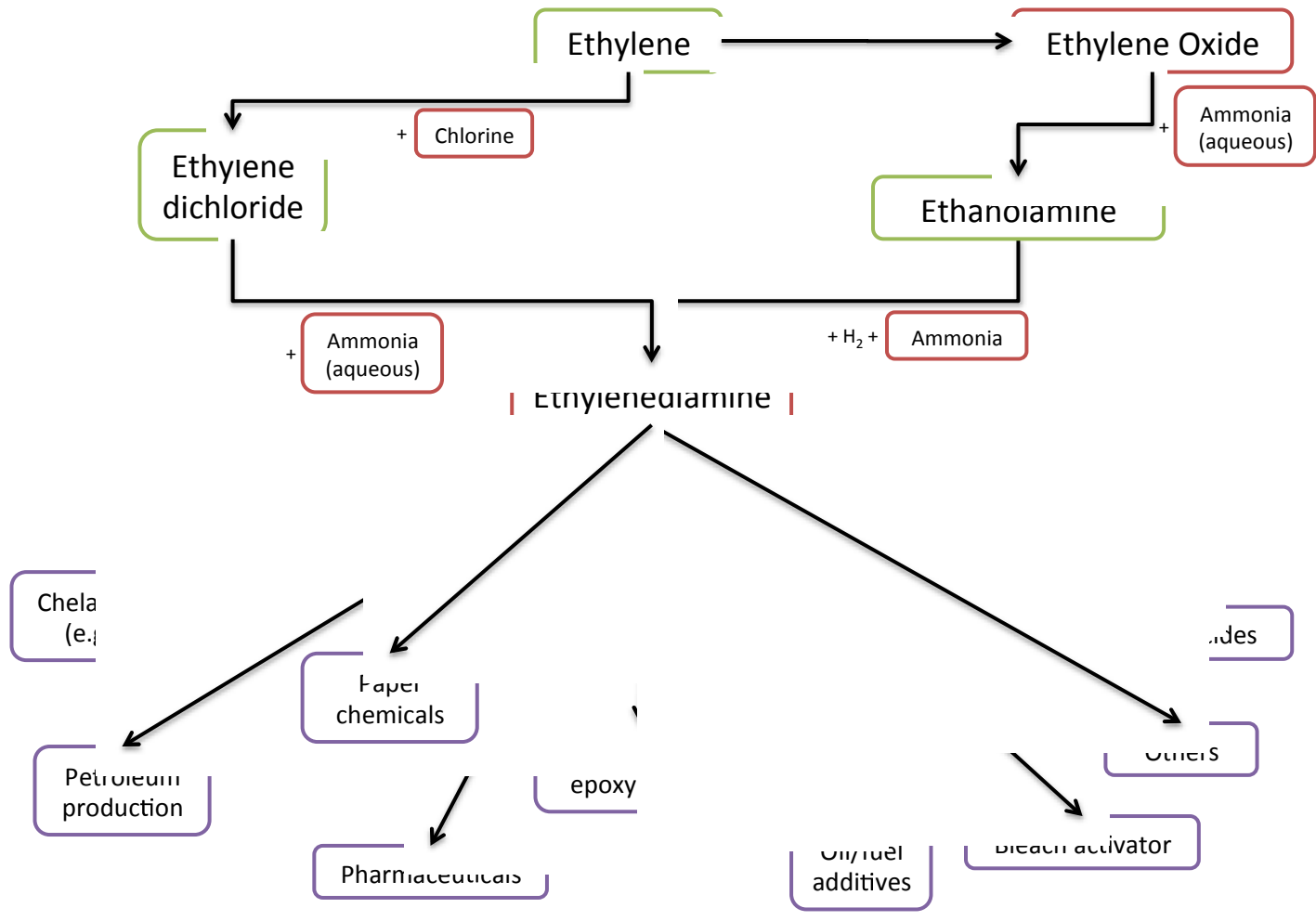

2.2.13. Hydrogen Sulfide

\subsubsection{Background Information}


Hydrogen sulfide $\left(\mathrm{H}_{2} \mathrm{~S}\right)$ is a colorless, flammable, extremely hazardous gas with a "rotten-egg" smell. As such, its quantity in a confined space is monitored. Pre-existing amounts of hydrogen sulfide in natural gas, petroleum, and coke must be removed during fossil fuel processing to ensure no release. Intentional breakdown to either sulfur dioxide or elemental sulfur reduces the overall US production of hydrogen sulfide via the following processes:

$$
\begin{aligned}
& \mathrm{H}_{2} \mathrm{~S}+\frac{3}{2} \mathrm{O}_{2} \rightarrow \mathrm{H}_{2} \mathrm{O}+\mathrm{SO}_{2} \\
& 3 \mathrm{H}_{2} \mathrm{~S}+\mathrm{SO}_{2} \rightarrow 2 \mathrm{H}_{2} \mathrm{O}+3 \mathrm{~S}
\end{aligned}
$$

Reaction (1) is an oxidation step that results in sulfur dioxide, which can then participate in production of sulfuric acid. Reaction (2) is used in the Claus process, which recovers sulfur from hydrogen sulfide.

\subsubsection{Producers ${ }^{2-3}$}

- Arkema

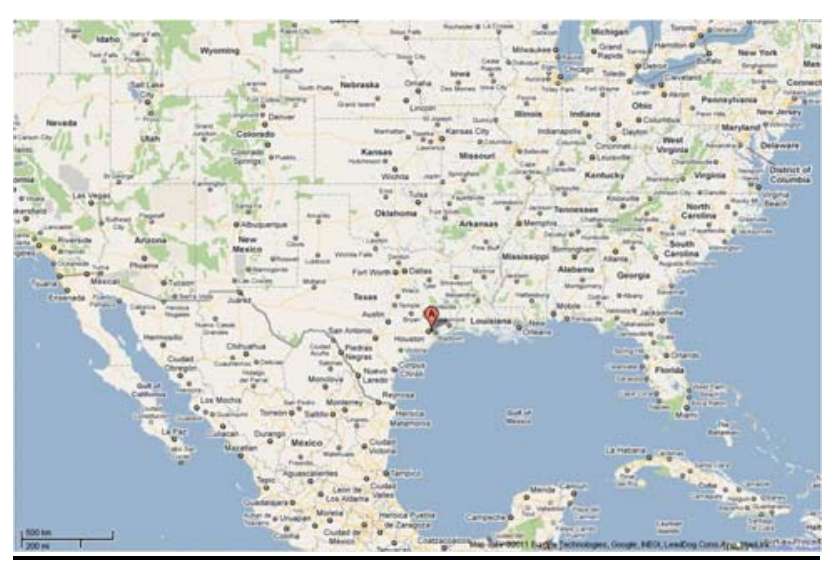

Figure 1. Domestic Producers.

There is one recorded hydrogen sulfide producer in the United States based on chemical producer information. Nonetheless, approximately 67 sulfuric acid producers and 190 elemental sulfur producers are recorded in Sandia's Chemical Data Model. It is uncertain what percentages of sulfuric acid and elemental sulfur are derived from hydrogen sulfide, but it is noted by several sources that it is a majority. EPA's chemical storage information shows over 1,900 registered storage sites for hydrogen sulfide. These are inclusive of the producers listed for sulfuric acid and elemental sulfur; hence, existence of hydrogen sulfide is consistent with reactions (1) and (2).

\subsubsection{Major Uses ${ }^{5-6}$}

- Elemental sulfur

- Sulfuric acid 
- Inorganic sulfides

- Thiols

- Dyes

- Rubber chemicals

- Pesticides

- Polymers

- Plastics additives

- Leather

- Pharmaceuticals

\subsubsection{Production Technology $y^{4-6}$}

As stated above, $\mathrm{H}_{2} \mathrm{~S}$ occurs naturally in natural gas and petroleum reserves and can be recovered as opposed to produced. Natural gas can contain anywhere from trace amounts to $90 \%$ by wt $\mathrm{H}_{2} \mathrm{~S}$ (Alberta, Canada) and usually a substantial amount of $\mathrm{CO}_{2}$. Similarly, refinery gases produced in hydrodesulfurization or cracking units also have a very high ratio of hydrogen sulfide to carbon dioxide. In humid or aqueous conditions, hydrogen sulfide is extremely corrosive to most metal components making its removal from gas streams necessary. This process is typically referred to as "sweetening." The extracted $\mathrm{H}_{2} \mathrm{~S}$ is mostly diverted to elemental sulfur production by the Claus process (above - reaction 2) but can be refined to serve as a direct source of hydrogen sulfide.

From Ullmann's:

"Hydrogen sulfide is obtained from the gas

1. directly if the hydrogen sulfide - carbon dioxide ratio is high enough to give an acid gas with the desired hydrogen sulfide content ( $80-90 \mathrm{vol} \%)$ or if a selective sweetening process is used;

2. after additional treatment, consisting of selective reprocessing (desired purity, 90 - 95\%) or compression and subsequent distillation (minimum purity $99.5 \%$ ).

Hydrogen sulfide can be recovered from gas containing sufficiently high quantities of it by (selectively) sweetening the gas with respect to carbon dioxide by chemical or physical absorption. Absorption by a chemical solvent (amines or potassium carbonate) is a function of pressure and temperature. Absorption by a physical solvent is primarily a function of pressure."

\subsubsection{Production Volume ${ }^{2-3}$}

US capacity (Jan. 2006): 1.1 Million tons/yr

From Ullmann’s (2000) 2.3-2.5 million metric tons/yr

\subsubsection{Feedstocks ${ }^{5-6}$}

Natural gas 
Petroleum and coke processing by-product

\subsubsection{Distribution ${ }^{2}$}

Small containers of less than 1 ton or small bottles are generally used for road and rail transportation. In the United States, liquid hydrogen sulfide is transported in specially designed tankers. Hazard classifications for hydrogen sulfide are as follows:

IMDG (International Maritime Dangerous Goods) Code, class 2.1, label $2.1+6$

RID/ADR (Rail), class 2, label $3+6.1$

United States, CFR (Code of Federal Regulations) 49: 172.02, flammable

UN no. 1053

\subsubsection{Alternative Production Technology}

No other production technologies are currently in use industrially, to the best of our knowledge.

\subsubsection{References}

1. OSHA FactSheet: Hydrogen Sulfide, 2005.

2. SRIC Chemical Economic Handbook, 2010.

3. SRIC Directory of Chemical Producers 2008 and SRIC 2009 World Petroleum.

4. Eow, John S. (2002). "Recovery of sulfur from sour acid gas: A review of the technology". Environmental Progress 21: 143.

5. Weil, E. D., Sandler, S. R. and Gernon, M. 2006. "Sulfur Compounds.” Kirk-Othmer Encyclopedia of Chemical Technology.

6. Pouliquen, F., Blanc, C., Arretz, E., Labat, I., Tournier-Lasserve, J., Ladousse, A., Nougayrede, J., Savin, G., Ivaldi, R., Nicolas, M., Fialaire, J., Millischer, R., Azema, C., Espagno, L., Hemmer, H. and Perrot, J. 2000. “Hydrogen Sulfide.” Ullmann's Encyclopedia of Industrial Chemistry.

\subsubsection{Isobutyronitrile}

\subsubsection{Background Information}

Isobutyronitrile is a colorless liquid at Standard Temperature and Pressure. It is a fairly high boiling $\left(107^{\circ} \mathrm{C}\right)$ liquid but with a low flash point $\left(8^{\circ} \mathrm{C}\right)$. This nitrile, as compared to others (acetonitrile, propionitrile, acrylonitrile, etc.), is particularly toxic because of a structural predisposition toward metabolic decomposition and release of cyanide. Isobutyronitrile can affect the gastrointestinal tract, cause respiratory irritation, and even lead to coma.

\subsubsection{Major Uses ${ }^{2-6}$}

- Feedstock for Diazinon, an organophosphate-based insecticide recently restricted to nonresidential agricultural use, (O,O-Diethyl-O-[4-methyl-6-(propan-2-yl)pyrimidin-2-yl] phosphorothioate) 
- Additional industrial-scale uses have not been uncovered, but based on the data found for more common aliphatic nitriles, it is safe to assume that this chemical might also have applicability as an extraction or reaction solvent and starting material for pharmaceuticals, and/or for pesticides and insecticides.

\subsubsection{Production Technology $y^{2-5}$}

As with many saturated aliphatic nitriles, isobutyronitrile is made using the ammoxidation (Sohio) process. The corresponding alcohol (isobutanol) or aldehyde (isobutyraldehyde) is reacted with ammonia and oxygen using a catalyst. The catalysts are typically transition metal oxides of vanadium and molybdenum.

It is noted that while the Sohio process is performed in the presence of air for oxidation purposes, this is only explicitly needed when the starting material is not already oxidized. In the case of isobutanol and isobutyraldehyde, it is possible to perform the transformation to isobutyronitrile under anaerobic conditions.

$$
\left(\mathrm{H}_{3} \mathrm{C}\right)_{2}-\mathrm{CH}-\mathrm{CH}_{2} \mathrm{OH}+\mathrm{NH}_{3} \rightarrow\left(\mathrm{H}_{3} \mathrm{C}\right)_{2}-\mathrm{CH}_{2}-\mathrm{CN}+\mathrm{H}_{2} \mathrm{O}+2 \mathrm{H}_{2}
$$

\subsubsection{Feedstocks ${ }^{2-5}$}

- Isobutanol/Isobutyraldehyde

- Ammonia

- $\quad$ Oxygen

\subsubsection{Distribution ${ }^{1}$}

Transport Classification: RID/ADR: 3 no. 11B, UN: 2284, IMO: 3.2

\subsubsection{Alternative Production Technology}

No additional commercialized technologies have been found.

\subsubsection{References}

1. SRIC Chemical Economic Handbook, 2010.

2. Peter Pollak, Gérard Romeder, Ferdinand Hagedorn, Heinz-Peter Gelbke. "Nitriles." Ullmann's Encyclopedia of Industrial Chemistry, 2005. Wiley-VCH.

3. Stephen C. DeVito. "Nitriles." Kirk-Othmer Encyclopedia of Chemical Technology, 2007. Wiley-Interscience.

4. "2-Methylpropanenitrile." National Library of Medicine HSDB Database. 14 February 2003. Web. 23 March 2011. <http://toxnet.nlm.nih.gov/cgibin/sis/search/a?dbs+hsdb:@term+@DOCNO+5221>.

5. “Ammoxidation.” Wikipedia. 14 August 2010. Web. 23 March 2011. $<$ http://en.wikipedia.org/wiki/ammoxidation>. 
6. “Diazinon.” Wikipedia. 18 February 2011. Web. 23 March 2011. $<$ http://en.wikipedia.org/wiki/Diazinon>.

\subsubsection{Methacrylonitrile}

\subsubsection{Background Information}

Methacrylonitrile is a colorless liquid at Standard Temperature and Pressure. As with most nitriles, cyanide is a potential metabolic decomposition product, and exposure to methacrylonitrile results in symptoms related to cyanide poisoning. It is highly flammable and with the potential for inhalation, ingestion, and contact hazards, which lead to nausea, headache, vomiting, and asphyxiation.

\subsubsection{Producers ${ }^{1}$}

There are no U.S. producers of methacrylonitrile. E-Plan data lists only distributors and waste disposal companies.

\subsubsection{Major Uses ${ }^{2-5}$}

- Polymers such as polymethacrylimide

- Intermediate in the synthesis of methyl methacrylate and methacrylic acid

\subsubsection{Production Technology ${ }^{2-8}$}

Methacrylonitrile is made using the ammoxidation (Sohio) process. Isobutene is the starting material for this process and is reacted in the gas-phase with ammonia and air (oxygen source) to very selectively form the desired product. This reaction is typically performed in a fluidized bed reactor with residence times of only a few seconds, temperatures of $300-400{ }^{\circ} \mathrm{C}$, and pressures of 0.3-3 bar. There have been many catalyst formulations patented for the ammoxidation process and almost all use some type of transition metal (e.g. vanadium, molybdenum).

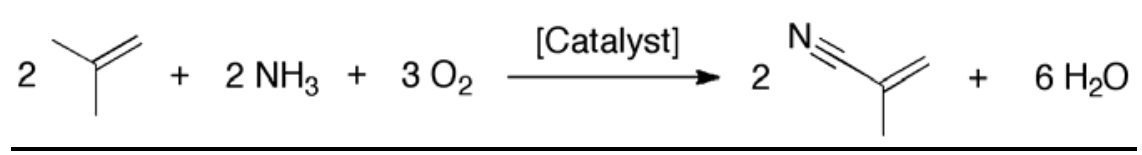

Scheme 1. Chemical Production Route.

There is the potential for cleavage of the cyano group from the product making HCN a typical waste byproduct.

\subsubsection{Production Volume ${ }^{1}$}

There is no reported production in the U.S.

\subsubsection{Feedstocks ${ }^{2-4}$}


- $\quad$ Isobutene

- Ammonia

- Oxygen

\subsubsection{Distribution ${ }^{2}$}

Transport Classification: UN3079, Class 3

\subsubsection{Alternative Production Technology $y^{2-8}$}

Decomposition of acetone cyanohydrin was a potential method that has since been abandoned. Other ammoxidation processes are possible when using isobutene-related oxidized starting materials (methacrolein, 2-methyl-2-propen-1-ol), but none have been commercialized.

\subsubsection{References}

1. SRIC Chemical Economic Handbook, 2010; SRIC Directory of Chemical Producers 2008; and SRIC 2009 World Petroleum.

2. Peter Pollak, Gérard Romeder, Ferdinand Hagedorn, Heinz-Peter Gelbke. "Nitriles." Ullmann's Encyclopedia of Industrial Chemistry, 2005. Wiley-VCH.

3. Patrick W. Langvardt. “Acrylonitrile.” Ullmann's Encyclopedia of Industrial Chemistry, 2005. Wiley-VCH.

4. William Bauer. "Methacrylic Acid and Derivatives." Ullmann's Encyclopedia of Industrial Chemistry, 2005. Wiley-VCH.

5. Stephen C. DeVito. "Nitriles.” Kirk-Othmer Encyclopedia of Chemical Technology, 2007. Wiley-Interscience.

6. Robert Wilczynski, Jamie Jerrick Juliette. "Methacrylic Acid and Derivatives.” KirkOthmer Encyclopedia of Chemical Technology, 2003. Wiley-Interscience.

7. “Acetone Cyanohydrin.” Wikipedia. 11 February 2011. Web. 23 March 2011. $<$ http://en.wikipedia.org/wiki/Acetone_cyanohydrin>.

8. “Ammoxidation.” Wikipedia. 14 August 2010. Web. 23 March 2011. $<$ http://en.wikipedia.org/wiki/ammoxidation>.

9. “Rohacell.” Evonik Industries. Web. 23 March 2011. $<$ http://www.rohacell.com/product/rohacell/en/Pages/default.aspx>.

10. “List of UN numbers 3001 to 3100.” Wikipedia. 10 March 2011. Web. 23 March 2011. <http://en.wikipedia.org/wiki/List_of_UN_numbers_3001_to_3100>.

11. E-PLAN, Department of Homeland Security’s Emergency Response Information System: https://erplan.net/eplan

\subsubsection{Background Information ${ }^{6}$}

Methyl thiocyanate ( $\mathrm{CH}_{3} \mathrm{SCN}$, CAS\# 556-64-9) is a moderately toxic, flammable liquid. Violent, possibly explosive oxidation reactions can occur when mixed with chlorates, nitrates, nitric acid, organic or inorganic peroxides, or perchlorates. On contact with mineral acids or acid fumes, 
deadly toxic hydrogen cyanide gas is produced. When heated to decomposition or on contact with mineral acids it emits highly toxic fumes of nitriles, oxides of sulfur and nitrogen.

Methyl thiocyanate isomerizes to methyl isothiocyanate (MITC, CAS\# 556-61-6) upon heating. The latter is referenced more frequently as an active ingredient in fumigants and nematicides. The chemical constitutes a very small percentage of the overall fumigants market. Only $1.2 \%$ of all fumigants is made up of MITC.

$\mathrm{CH}_{3} \mathrm{~S}-\mathrm{C}=\mathrm{N} \rightarrow \mathrm{CH}_{3} \mathrm{~N}=\mathrm{C}=\mathrm{S}$

\subsubsection{Producers ${ }^{2-3}$}

There are no U.S. producers on record for methyl thiocyanate nor MITC in Sandia's database; however, there are two U.S. producers of wood preservatives and two EPLAN storage sites. Osmose, Inc owns three of four locations and markets a preservative under the trade name MITC-FUME. Bonneville Power Administration in The Dalles, Oregon stores MITC-FUME. Chemical Economic Handbook indicates Bayer CropScience markets a MITC based fumigant under the trade name Di-Trapex, but its production is likely overseas for non-US market. In particular, Japan has the strongest demand for MITC.

According to EPA storage data, Osmose, Inc in Buffalo NY (location A on the map) has an annual storage of methyl isothiocyanate of approximately 21,726 lb (8,109 kg) with a maximum capacity of 33,300 lb (12,429 kg). The two Osmose producers addresses are located in Millington, Tennessee (B) and Rock Hill, South Carolina (C) with no recorded capacities.

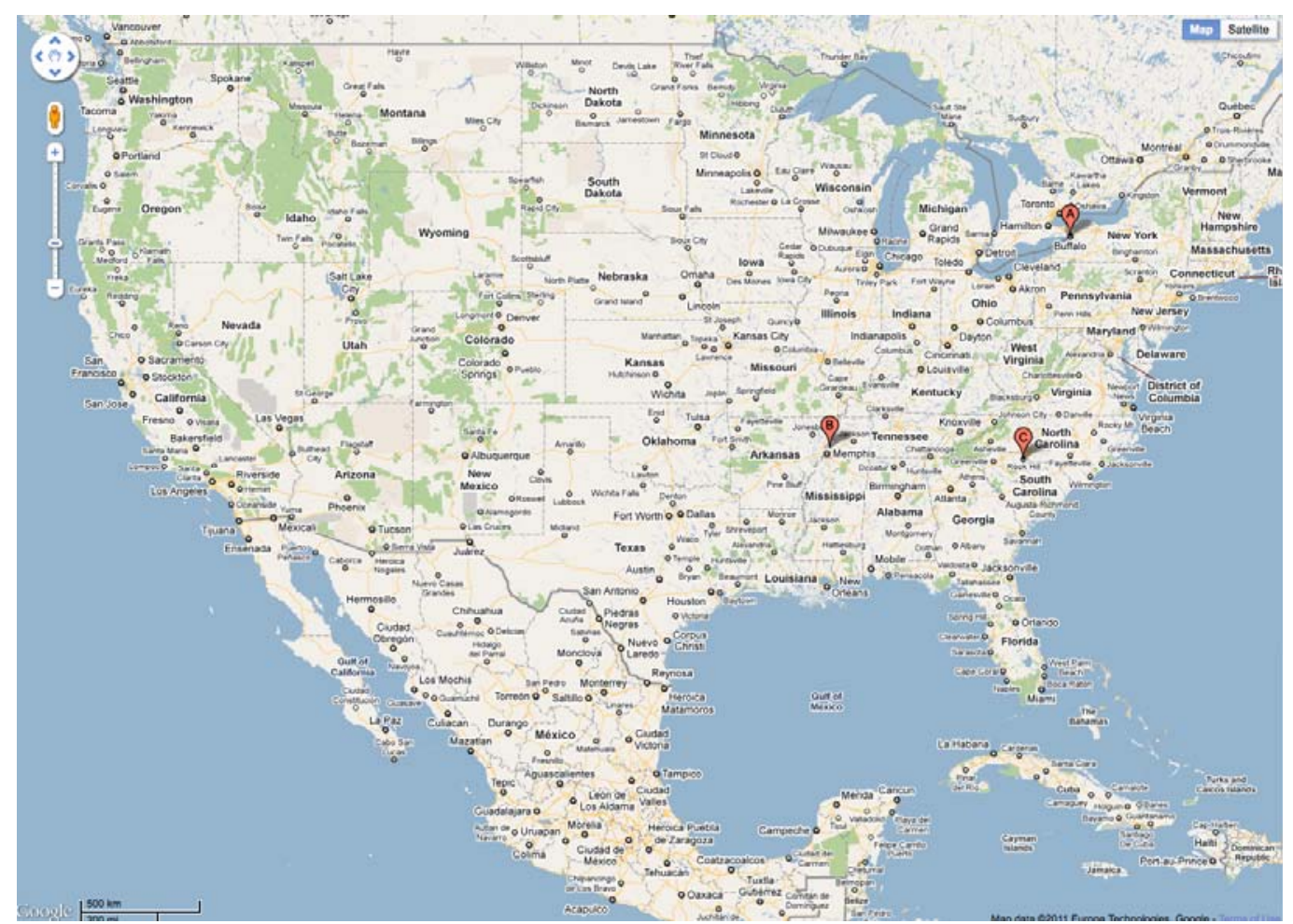

Figure 1. Domestic Producers. 


\subsubsection{Major Uses ${ }^{6}$}

This chemical is no longer used in United States for agricultural purposes but registered as a wood preservative due to its biocidal and fungicidal properties. Contrary to the lack of usage, methyl thiocyanate can be purchased through eight U.S. suppliers while MITC has no U.S. suppliers.

\subsubsection{Production Technology ${ }^{6}$}

There are three different production pathways that have been found thus far. One pathway is by substitution of a halogen $(\mathrm{X})$ in an alkyl halide $(\mathrm{R}-\mathrm{X})$ by the thiocyanate anion. The thiocyanate anion is ambidentate. Such reaction can yield a mixture of thiocyanates and isothiocyanates.

$$
\mathrm{R}-\mathrm{X}+\mathrm{SCN}^{-} \rightarrow \mathrm{R}-\mathrm{SCN}
$$

A second pathway to form thiocyanate is by reacting thiols with cyanogen chloride.

$$
\mathrm{R}-\mathrm{SH}+\mathrm{ClCN} \rightarrow \mathrm{R}-\mathrm{SCN}+\mathrm{HCl}
$$

Another pathway to produce methyl isothiocyanate originates from methylamine and carbon disulfide via production of dithiocarbamate.

$$
\mathrm{CH}_{3} \mathrm{NH}_{2}+\mathrm{CS}_{2} \underset{\text { aq. } \mathrm{NaOH}}{\rightarrow} \mathrm{CH}_{3}-\mathrm{NCS}+\mathrm{H}_{2} \mathrm{~S}
$$

It is unclear which one of the three methods is the dominant pathway.

\subsubsection{Feedstocks ${ }^{6}$}

- $\quad$ Methylamine

- $\quad$ Carbon disulfide

- $\quad$ Potassium thiocyanate

- Cyanogen chloride

- Thiols

\subsubsection{Distribution ${ }^{2-3}$}

Information on transportation or storage is absent for methyl thiocyanate. Methyl isothiocyanate is generally stored in tanks or in 200-kg steel drums and must be stored free of water and tightly closed at normal temperature in a well-ventilated, dry area.

Methyl isothiocyanate (UN No 2477).

Major hazard class 6.1: Toxic substance

Packing group I: Great danger. 


\subsubsection{Alternative Production Technology}

No other production technologies are currently in use industrially, to the best of our knowledge.

\subsubsection{References}

1. Lewis, 3rd ed., 1993, p. 879, 1234

2. SRIC Chemical Economic Handbook, 2010.

3. SRIC Directory of Chemical Producers, 2008.

4. EPA E-Plan Chemical and Facility Hazards Data $<$ https://erplan.net/eplan/login.htm $>$

5. Chemical Book Supplier list - <http://www.chemicalbook.com/ProductIndex_EN.aspx>

6. Ulmann's Encyclopedia of Industrial Chemistry, vol. A26, "Thiocyanates and Isothiocyanates, Organic."

7. Organic Syntheses, Coll. Vol. 3, p.599 (1955); Vol. 21, p.81 (1941)

\subsubsection{Nitric Acid}

\subsubsection{Background Information}

Nitric acid $\left(\mathrm{HNO}_{3}\right)$ is a colorless to clear yellow liquid that is highly corrosive and toxic. The decomposition products, $\mathrm{NO}_{2}$ and other nitrogen oxides, color the initially clear liquid to yellow. Formulations of anhydrous nitric acid with nitrogen dioxide concentrations of $13 \%$ or higher are identified as red fuming nitric acid. The pure anhydrous acid is called white fuming nitric acid.

\subsubsection{Producers ${ }^{1-2}$}

From the SRIC CEH in 2007: "The United States is the world's third-largest producer and consumer of nitric acid, following Western Europe and the former USSR. The impact of imports and exports on the domestic balance is minimal. Terra, with plants at four different locations, accounts for $22 \%$ of U.S. capacity and PCS and LSB, each with plants at three locations, account for $17 \%$, and $13 \%$, respectively. Several other companies also have significant shares. In addition to the plants listed above, the U.S. government has seven idle ammunition plants with a total capacity of about 1,350 thousand metric tons per year."

- Agrium

- Air Products and Chemicals, Inc.

- Angus Chemical Company

- Apache Nitrogen Products, Inc.

- CF Industries, Inc.

- Cherokee Nitrogen Company

- Coffeyville Resources

- Dyno Nobel, Inc.

- E. I. Du Pont

- El Dorado Chemical Company 
- First Chemical Corp.

- Geneva Nitrogen

- Invista, Inc.

- J. R. Simplot Co.

- Koch Nitrogen Company

- PCS Nitrogen Fertilizer

- Rentech Energy

- Solutia Inc.

- Terra Industries, Inc.

- Trademark Nitrogen Corp.

- Lyondell Chemical

- Orica

- Rubicon

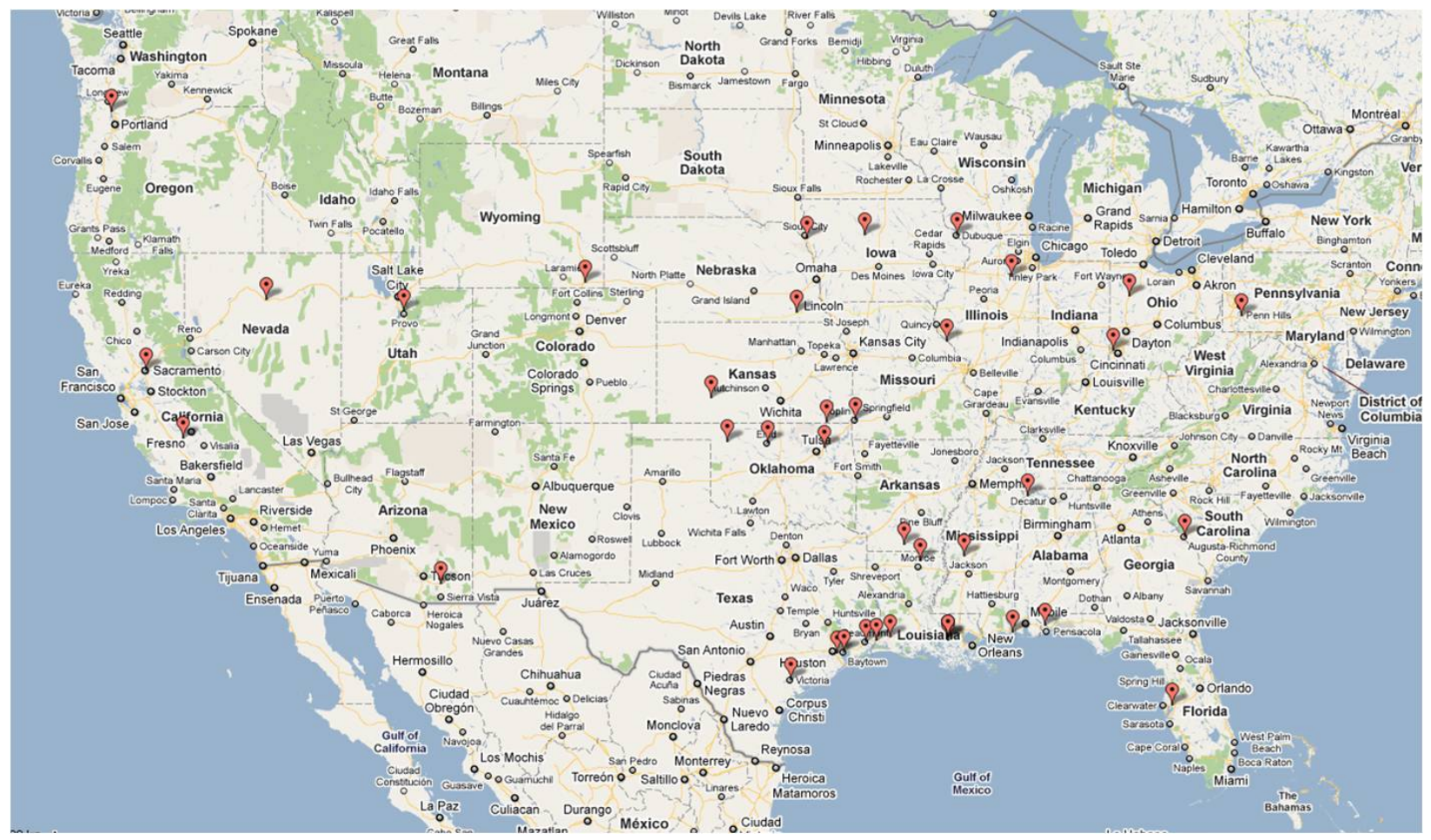

Figure 1. Domestic Producers.

\subsubsection{Major Uses ${ }^{3-4}$}

- Ammonium Nitrate - fertilizer, explosives

- Adipic Acid - used to make nylon 66 fibers, other plastics and plasticizers

- Nitrobenzene - used to make aniline whose end product is polyurethane foams and rubber chemicals

- Toluene Diisocyanate - used to make polyurethane foams, coatings, and sealants

- Electronics industry - used in wafer cleaning in semiconductor manufacturing 
- $\quad$ Metal Nitrates - for fertilizers

- Metal etching/treatment - pickling

- Organic syntheses (nitrochlorobenzene, cellulose nitrate, nitroparaffins)

- Explosives

- Uranium processing

- Other fertilizers

\subsubsection{Production Technology ${ }^{3-4}$}

Nitric acid is produced by the Ostwald process by oxidizing $\mathrm{NH}_{3}$ first to $\mathrm{NO}$, then to $\mathrm{NO}_{2}$, and then finally reacting/absorbing the $\mathrm{NO}_{2}$ with water to make $\mathrm{HNO}_{3}$. While the reactions depend on the operating conditions of the plant, the primary reactions are the following:

Ammonia Combustion/Oxidation:

$$
4 \mathrm{NH}_{3}+5 \mathrm{O}_{2} \rightarrow 4 \mathrm{NO}+6 \mathrm{H}_{2} \mathrm{O}
$$$$
2 \mathrm{NO}+\mathrm{O}_{2} \rightarrow 2 \mathrm{NO}_{2} \leftarrow \rightarrow \mathrm{N}_{2} \mathrm{O}_{4}
$$

Absorption Reaction:

$$
3 \mathrm{NO}_{2}+\mathrm{H}_{2} \mathrm{O} \rightarrow 2 \mathrm{HNO}_{3}+\mathrm{NO}
$$

Overall Reaction:

$$
\mathrm{NH}_{3}+2 \mathrm{O}_{2} \rightarrow \mathrm{HNO}_{3}+\mathrm{H}_{2} \mathrm{O}
$$

Operating temperatures, pressures, and the concentration of the final acid product represent the largest difference between plants, with some differences in catalysts as well. The entire reaction can be run at a single pressure (monopressure) anywhere from 200 to $600 \mathrm{kPa}$. A dual pressure plant will run the absorption step as a higher pressure (900 to $1400 \mathrm{kPa}$ ) than the combustion pressure (400-600 $\mathrm{kPa})$. In North America, the catalyst is typically a woven wire pad with a composition of $90 \%$ platinum, 5\% rhodium and 5\% palladium, with some variation between plants in the composition. Once spent, the catalyst is reprocessed. Ullmann's contains detailed process information on concentrated acid production (98 to 100\%) as well as industrial acid production (50-70\%). The absorption process yields the weak acid, which may be used to make the strong acid through extractive distillation with a dehydrating agent. A dehydrating agent like sulfuric acid or magnesium nitrate is used to increase the volatility of the nitric acid, ensuring that the distillation will overcome the azeotropic concentration (69\%) of nitric acid.

\subsubsection{Production Volume ${ }^{1-2}$}

SRIC Chemical Economic Handbook, with data from 2006, puts capacity at 8,800 tmt and production at 8,559 tmt $\left(100 \% \mathrm{HNO}_{3}\right.$ basis). Kirk-Othmer puts capacity at 10,225 tmt (100\% $\mathrm{HNO}_{3}$ basis).

\subsubsection{Feedstocks ${ }^{3-4}$}
- Ammonia
- Air (oxygen source) 
- Water

\subsubsection{Distribution ${ }^{1-4}$}

From Kirk Othmer and verified through DOT Hazardous Materials CFR title 49:

“The Department of Transportation (DOT) classifies nitric acid as a hazardous material requiring proper packaging, labeling, and shipping documentation for transportation. The DOT defines three categories of nitric acid: (1) nonfuming, more than $70 \mathrm{wt} \%$ acid; (2) nonfuming, less than 70 wt \% acid; and (3) red fuming nitric acid. All are in Hazards Class 8, meaning corrosive material, and must be labeled "corrosive." Red fuming nitric acid must also be labeled "oxidizer" and "poison." Each category of nitric acid has its own packaging authorization number (ie, packaging requirements) for both bulk and nonbulk shipping. Depending on these packaging requirements, nitric acid may be shipped in either stainless steel or aluminum. Bulk nitric acid can be shipped by railcar, tank truck, or portable tank. Nonbulk packaging includes drums. For other than red fuming acid, a variety of smaller containers are permitted, all of which require various forms of individual packaging, depending on acid strength and mode of transportation. Packages are mostly glass or earthenware containers ranging in size from 0.5 to 2.51 . Transportation on passenger aircraft or railcar is forbidden for all categories of nitric acid. Red fuming acid is forbidden on cargo aircraft.”

\subsubsection{Alternative Production Technology}

No other production technologies are currently in use industrially, to the best of our knowledge.

\subsubsection{References}

1. SRIC Directory of Chemical Producers 2008 and SRIC 2009 World Petroleum.

2. SRIC Chemical Economic Handbook, 2007, Nitric Acid.

3. Thiemann, M., Scheibler, E. and Wiegand, K. W. 2000. Nitric Acid, Nitrous Acid, and Nitrogen Oxides. Ullmann's Encyclopedia of Industrial Chemistry.

4. Clarke, S. I., Mazzafro, W. J. and Updated by Staff 2005. Nitric Acid. Kirk-Othmer Encyclopedia of Chemical Technology.

\subsubsection{Phosphorus Oxychloride}

\subsubsection{Background Information}

Phosphorus Oxychloride, $\left(\mathrm{POCl}_{3}\right)$ also known as phosphoryl trichloride, is a clear colorless liquid that fumes in humid air, producing phosphoric acid and hydrogen chloride. It is corrosive and non-flammable, but reacts violently with water and therefore poses a risk of explosion. Skin contact causes burns, and inhalation of fumes may be fatal.

\subsubsection{Producers $^{1-2}$}

- Rhodia, Inc. 
- Supresta, US.

- Strem Chemical, Inc.

- Air Products, Inc.

- Porex Technologies

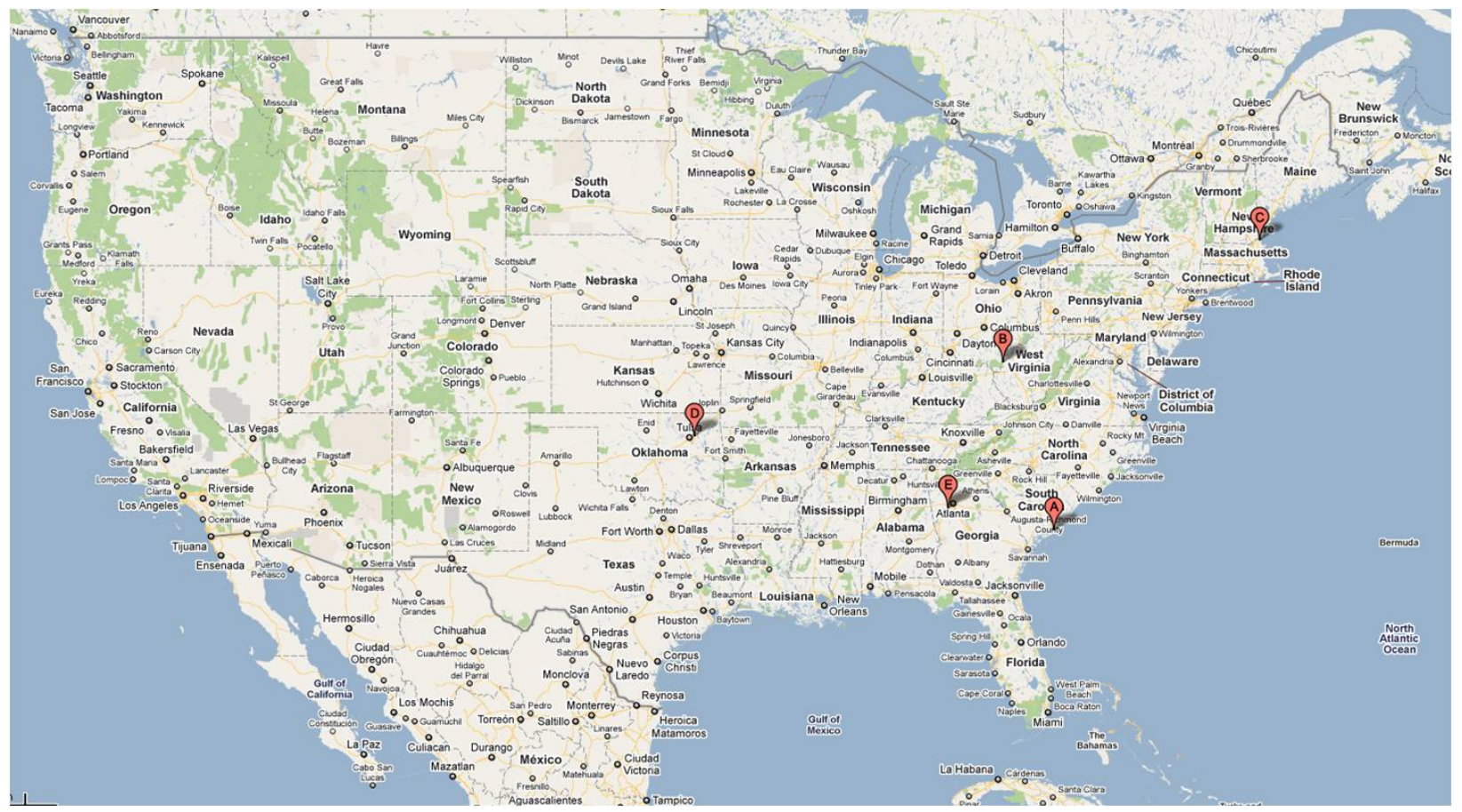

Figure 1. Domestic Producers.

\subsubsection{Major Uses ${ }^{2-3}$}

- Phosphate esters for flame retardants, hydraulic fluids, oil stabilizers, pesticides, and plasticizers for PVC

- Semiconductor wafer fabrication

- Dehydrating agent

- Solvent for nitrates, esp. in uranium processing

\subsubsection{Production Technology}

Phosphorus oxychloride has been manufactured by oxidizing phosphorus trichloride. When oxygen is bubbled through liquid phosphorus trichloride, complete absorption of pure oxygen is effected in a 1-m depth. When there is good heat exchange, the rate of oxygen absorption remains practically constant until only 3-5 wt \% of phosphorus trichloride remains in the oxychloride. The reaction is inhibited by impurities, especially iron and copper, sulfur compounds, or certain impurities from $\mathrm{Cl}_{2}$ production process. If these impurities are present, the reaction rate between phosphorus trichloride and oxygen exhibits an induction period and then increases to a maximum, after which it falls steadily as the reaction proceeds. A small amount of dissolved elemental phosphorus in the phosphorus trichloride does not influence the reaction. 
Heating a mixture of anhydrous phosphorus pentoxide [1314-56-3] and phosphorus pentachloride produces phosphorus oxychloride. Use of expensive phosphorus pentachloride is obviated by using a mixture of the trichloride and chlorine. Thus, a manufacturing method consists of the chlorination reaction of the trichloride with the pentoxide:

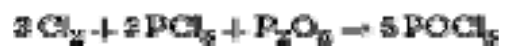

\subsubsection{Production Volume ${ }^{1-3}$}

US capacity (Jan. 2006): 30 tst (thousand short tons)/yr

\subsubsection{Feedstocks}

Phosphorus trichloride and oxygen (air) Phosphorus pentoxide and phosphorus pentachloride Phosphorus pentoxide and chlorine and phosphorus trichloride

\subsubsection{Distribution ${ }^{3}$}

From Kirk-Othmer: "Phosphorus oxychloride is classified by the ICC as a corrosive liquid and a poisonous inhalation hazard. Shipment of $\mathrm{POCl}_{3}$ must be in conformance with ICC regulations, and individual containers must be affixed with the DOT white acid label and red poison label: DOT UN No. 1810. Phosphorus oxychloride is stored and shipped in 3.8-L (1-gal) or smaller glass containers and DOT-specification wooden overpacking. Bulk $\mathrm{POCl}_{3}$ shipments are in nickel-clad tank cars of 15,000-30,000 L (4000-8000 gal) each. Glass and glass-lined steel equipment frequently is used for storage, as well as for reaction vessels.

\subsubsection{Alternative Production Technology}

No other production technologies are currently in use industrially, to the best of our knowledge.

\subsubsection{References}

1. SRIC Directory of Chemical Producers 2008 and SRIC 2009 World Petroleum.

2. E-PLAN, Department of Homeland Security's Emergency Response Information System: https://erplan.net/eplan

3. Fee, D. C., Gard, D. R. and Yang, C.-H. 2006. “Phosphorus Compounds.” Kirk-Othmer Encyclopedia of Chemical Technology.

\subsubsection{Phosphorus Trichloride}

\subsubsection{Background Information}

Phosphorus trichloride $\left(\mathrm{PCl}_{3}\right)$ is a clear liquid at room temperature with an irritating odor. It is insoluble in water, but does hydrolyze rapidly. Its boiling point is $76^{\circ} \mathrm{C}$. 


\subsubsection{Producers $^{1-2}$}

- Monsanto Company

- Rhodia Inc. (formerly Albright and Wilson)

- Israel Chemicals Ltd. (formerly Supresta, formerly Azko Nobel)

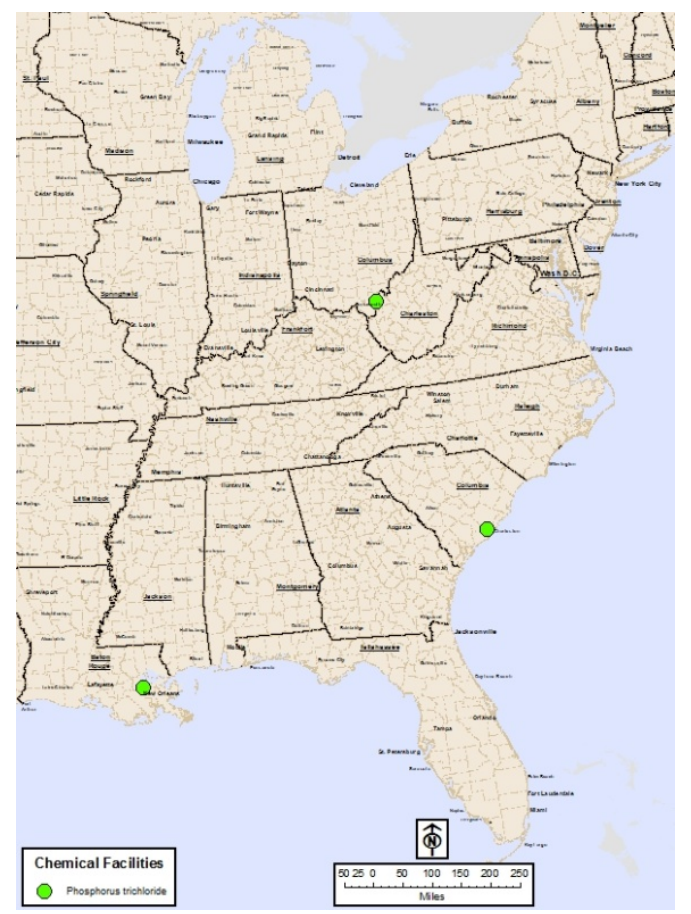

Figure 1. Domestic Producers.

\subsubsection{Major Uses ${ }^{3-4}$}

- $\quad$ Pesticides - $72 \%$

- Surfactants and sequestrants - $13 \%$

- Phosphorus oxychloride - 8\%

- $\quad$ Plastic and Elastomers - 5\%

- Lube Oil additives - $0.4 \%$

- Other $-1.6 \%$

Phosphorus trichloride is an important starting material for many phosphorus containing chemicals. $\mathrm{PCl}_{3}$ is used directly for the production of phosphoryl chloride, phosphorus pentachloride, thiophosphoryl chloride, phosphonic acid and other organophosphorus compounds. Phosphite esters are formed by $\mathrm{PCl}_{3}$ reacting with alcohols and phenols. In organic chemistry, phosphorus trichloride is also used as a chlorinating agent and catalyst. 


\subsubsection{Production Technology $y^{3-4}$}

Phosphorus trichloride is formed by the combustion of phosphorus in a dry stream of chlorine.

\section{$\mathrm{P}_{1}+\mathrm{SCl}_{2} \rightarrow\left\{\mathrm{PCG}_{2} \mathrm{AB}=-12 \mathrm{FeI} / \mathrm{mod}\right.$}

In a Hoechst continuous process, molten white phosphorus and gaseous chlorine react in previously produced phosphorus trichloride. The formation of phosphorus pentachloride is prevented by the presence of a small excess of phosphorus. The heat of reaction, ca. 10 times the heat of evaporation, keeps the system at its boiling point, and the phosphorus trichloride distills off. The vapors are fractionated as reflux takes place, and the $\mathrm{PCl}_{3}$ condenses in air-cooled condensers. The rate of removal of $\mathrm{PCl}_{3}$ (i.e. the production rate) is equivalent to the feed rate of phosphorus and chlorine. The process is controlled by the boiling temperature, which is determined by the phosphorus content. The rate of chlorine flow is fixed, and the phosphorus feed rate is adjusted manually. The phosphorus trichloride produced contains no free phosphorus and needs no further treatment. The impurities from the phosphorus remain in the reactor, and are removed periodically, i.e., the phosphorus trichloride is completely driven off by distillation, and the tarry mass remaining is removed and can be burnt.

There exists a Bayer patent (\#1767949) for another similar process: liquid phosphorus and gaseous chlorine are reacted in a combustion chamber to form phosphorus trichloride. The product is then distilled.

\subsubsection{Production Volume ${ }^{1-2}$}

US capacity (Jan. 2009): 295 thousand short tons (CEH report asserts that industry reports the capacity is somewhat higher)

\subsubsection{Feedstocks}

- $\quad$ Phosphorus $\left(\mathrm{P}_{4}\right)$

- Chlorine

\subsubsection{Distribution ${ }^{4}$}

From Kirk-Othmer Encyclopedia of Chemical Technology: $\mathrm{PCl}_{3}$ is an inhalation hazard as well as corrosive, therefore requires a Department of Transportation (DOT) white acid label and red poison label. Alloy or glass-lined vessels are used for storage and reactors. One gallon quantities of $\mathrm{PCl}_{3}$ are stored and shipped in glass containers using specified wooden overpacking. Heresitelined steel drums are for $208 \mathrm{~L}$ (55 gal) volume. Bulk $\mathrm{PCl}_{3}$ shipments are made in Heresite-lined tank cars of 15000-30000 L each, and tank trucks of 15,000 -19,000-L volume. The industrial trend is toward closed-loop loading and unloading operations.

\subsubsection{Alternative Production Technology}

No other production technologies are currently in use industrially, to the best of our knowledge. 


\subsubsection{References}

1. SRIC Directory of Chemical Producers 2008

2. SRIC Chemical Economics Handbook 2010

3. Ullmann's Encyclopedia of Industrial Chemistry, 2003

4. Kirk-Othmer Encyclopedia of Chemical Technology, $4^{\text {th }}$ edition.

\subsubsection{Propionitrile}

\subsubsection{Background Information}

Propionitrile is a saturated aliphatic nitrile with a boiling point of $97^{\circ} \mathrm{C}$ and is a colorless liquid at standard temperature and pressure. It is not as toxic as the other more branched and functionalized nitriles. Its metabolic products include cyanide, which can cause neural trauma, respiratory distress, convulsions, and gastrointestinal problems.

\subsubsection{Producers ${ }^{1,8}$}

There are no United States producers of propionitrile in SRIC's CEH or DCP. ${ }^{1}$ E-Plan ${ }^{8}$ data lists seven producing plants at six companies as well as other users and waste disposal companies.

- (RY 2006) GFS Chemicals, Inc

- Angus Chemical Co.

- Creanova, Inc.

- Ineos USA, LLC

- Lucite International, Inc.

- Rhodia, Inc.

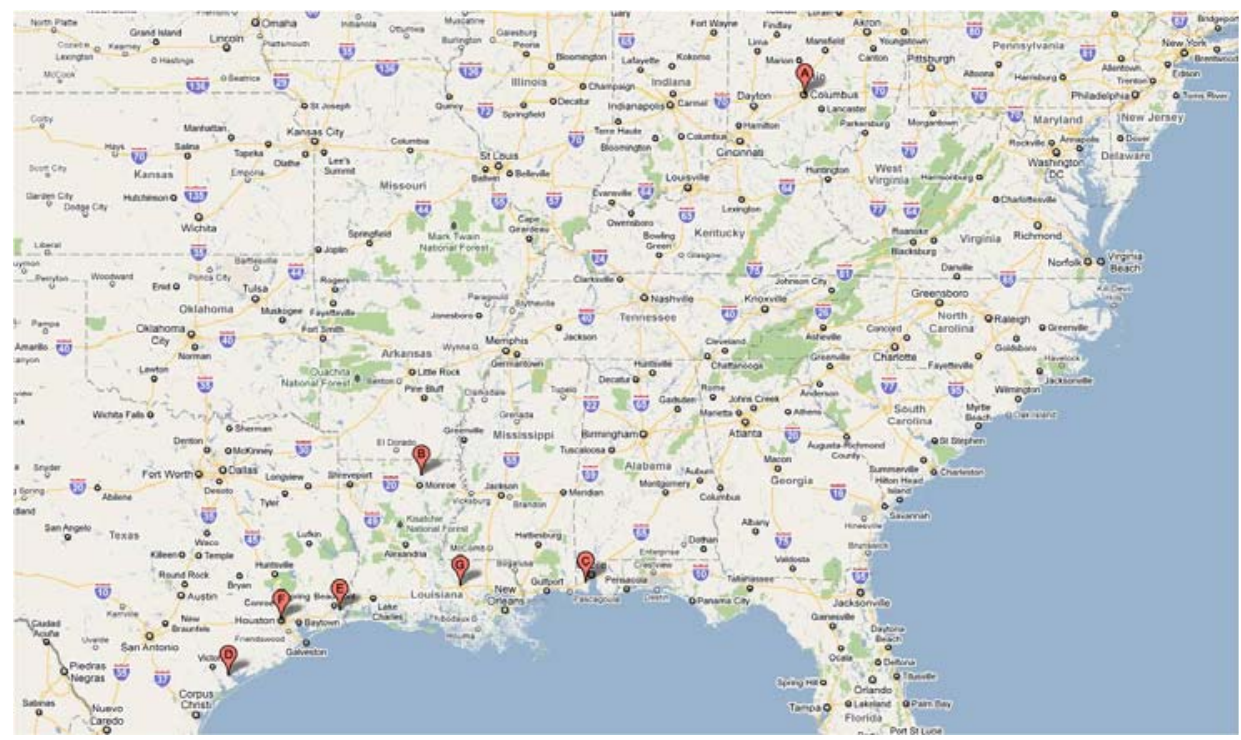

Figure 1. Domestic Producers. 


\subsubsection{Major Uses ${ }^{2-6}$}

- $\quad$ Pharmaceuticals (Flopropione, Ketoprofen)

- Additional industrial-scale uses have not been uncovered, but based on the data found for more common aliphatic nitriles, it is safe to assume that this chemical might also have applicability as an extraction or reaction solvent and starting material for pharmaceuticals, and/or for pesticides and insecticides.

\subsubsection{Production Technology ${ }^{2-6}$}

Propionitrile is made in much the same way as other nitriles. The ammoxidation process and the hydrogenation of acrylonitrile are currently the dominant processes in production today. In the ammoxidation process, 1-propanol and ammonia are passed over a transition metal catalyst (typically a mixture of vanadium, molybdenum, and various oxides) to yield the product nitrile. Raney nickel is the preferred catalyst in the reduction of acrylonitrile to propanenitrile.

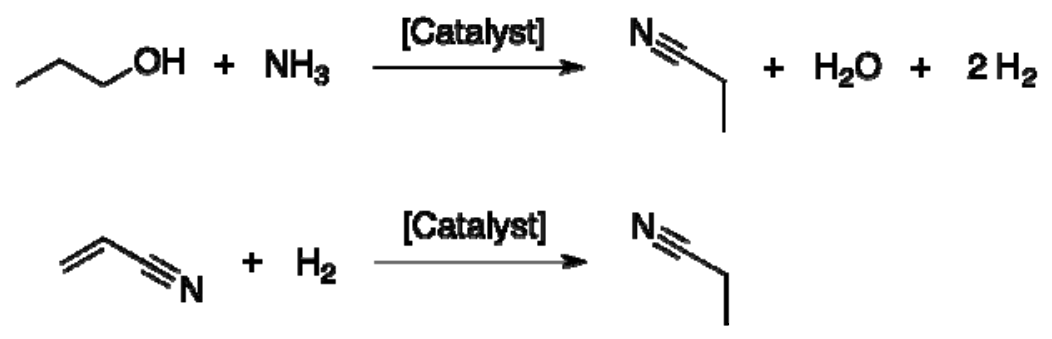

\subsubsection{Production Volume ${ }^{8}$}

There is no reported production in the United States. Data from E-Plan suggests that the 7 producing plants can store up to 608 tmt of propionitrile.

\subsubsection{Feedstocks ${ }^{2-6}$}

- 1-Propanol and Ammonia

- $\quad$ Acrylonitrile and Hydrogen

\subsubsection{Distribution ${ }^{2}$}

UN Number 2404, Hazard Class 3 (Flammable), 6.1 (Poisonous), Packing Group II. NFPA 704: Red 3, Blue 4, Yellow 1

\subsubsection{Alternative Production Technology ${ }^{2}$}

There are comments made about obtaining propanenitrile as a byproduct from the production of adiponitrile by electrohydrodimerization of acrylonitrile. This is not the dominant method of making adiponitrile, but it might still fill a significant need for propanenitrile. 


\subsubsection{References}

1. SRIC Chemical Economic Handbook, 2010; SRIC Directory of Chemical Producers 2008; and SRIC 2009 World Petroleum.

2. Peter Pollak, Gérard Romeder, Ferdinand Hagedorn, Heinz-Peter Gelbke. "Nitriles." Ullmann's Encyclopedia of Industrial Chemistry, 2005. Wiley-VCH.

3. Stephen C. DeVito. "Nitriles.” Kirk-Othmer Encyclopedia of Chemical Technology, 2007. Wiley-Interscience.

4. Patrick W. Langvardt. “Acrylonitrile.” Ullmann's Encyclopedia of Industrial Chemistry, 2005. Wiley-VCH.

5. “Propanenitrile.” Wikipedia. 11 March 2011. Web. 20 April 2011. $<$ http://en.wikipedia.org/wiki/Propanenitrile>.

6. “Ammoxidation.” Wikipedia. 14 August 2010. Web. 20 April 2011. $<$ http://en.wikipedia.org/wiki/Ammoxidation>.

7. “List of UN numbers 2401 to 2500.” Wikipedia. 14 August 2008. Web. 20 April 2011. $<$ http://en.wikipedia.org/wiki/List_of_UN_numbers_2401_to_2500>.

8. E-PLAN, Department of Homeland Security's Emergency Response Information System: $<$ https://erplan.net/eplan>.

\subsubsection{Chemical Supply Chain Tree}

\section{Propionitrile}

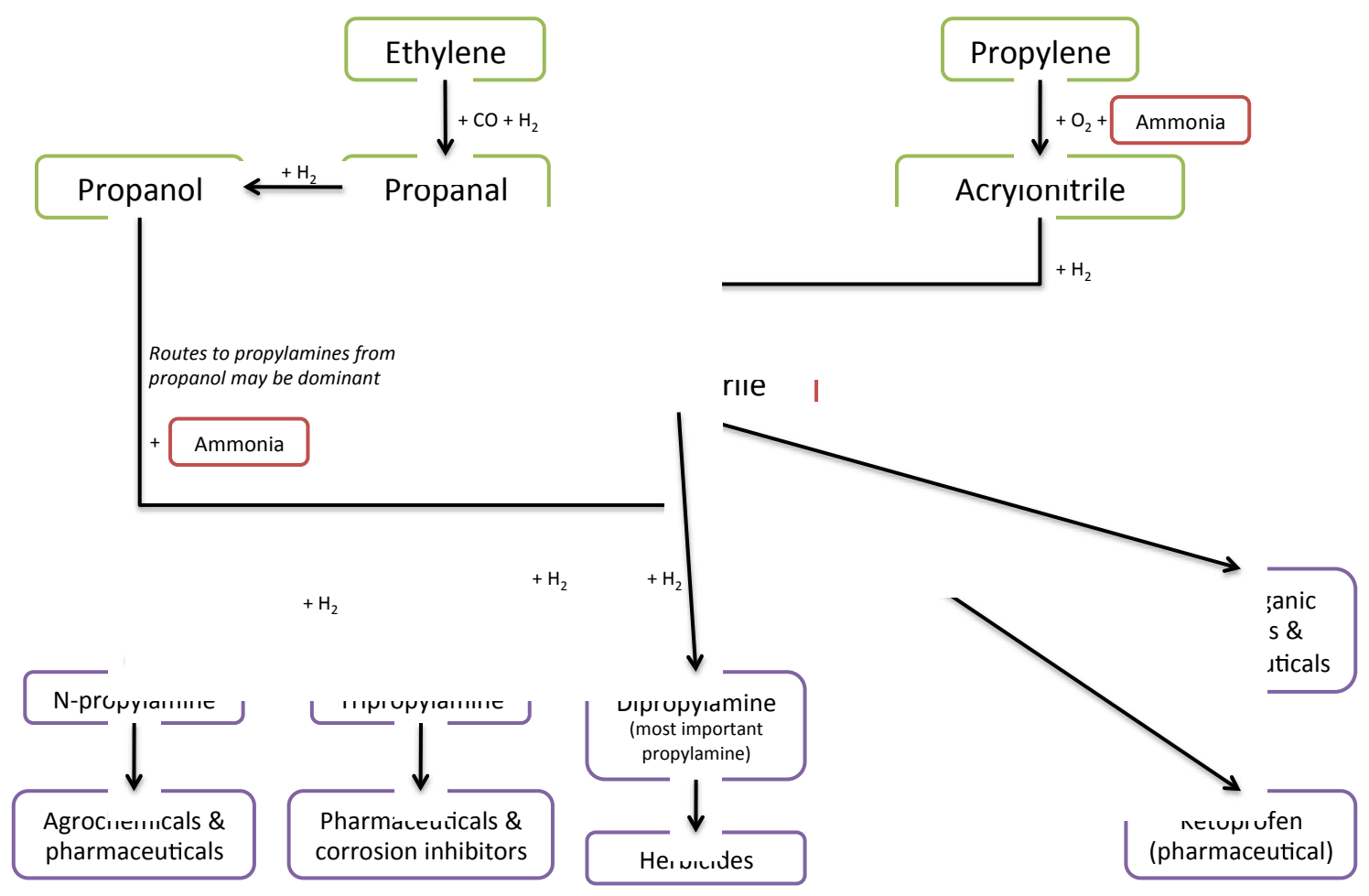




\subsection{Miscellaneous Chemical Supply Chain Trees}

\subsubsection{Fluorine}

\section{Fluorine}

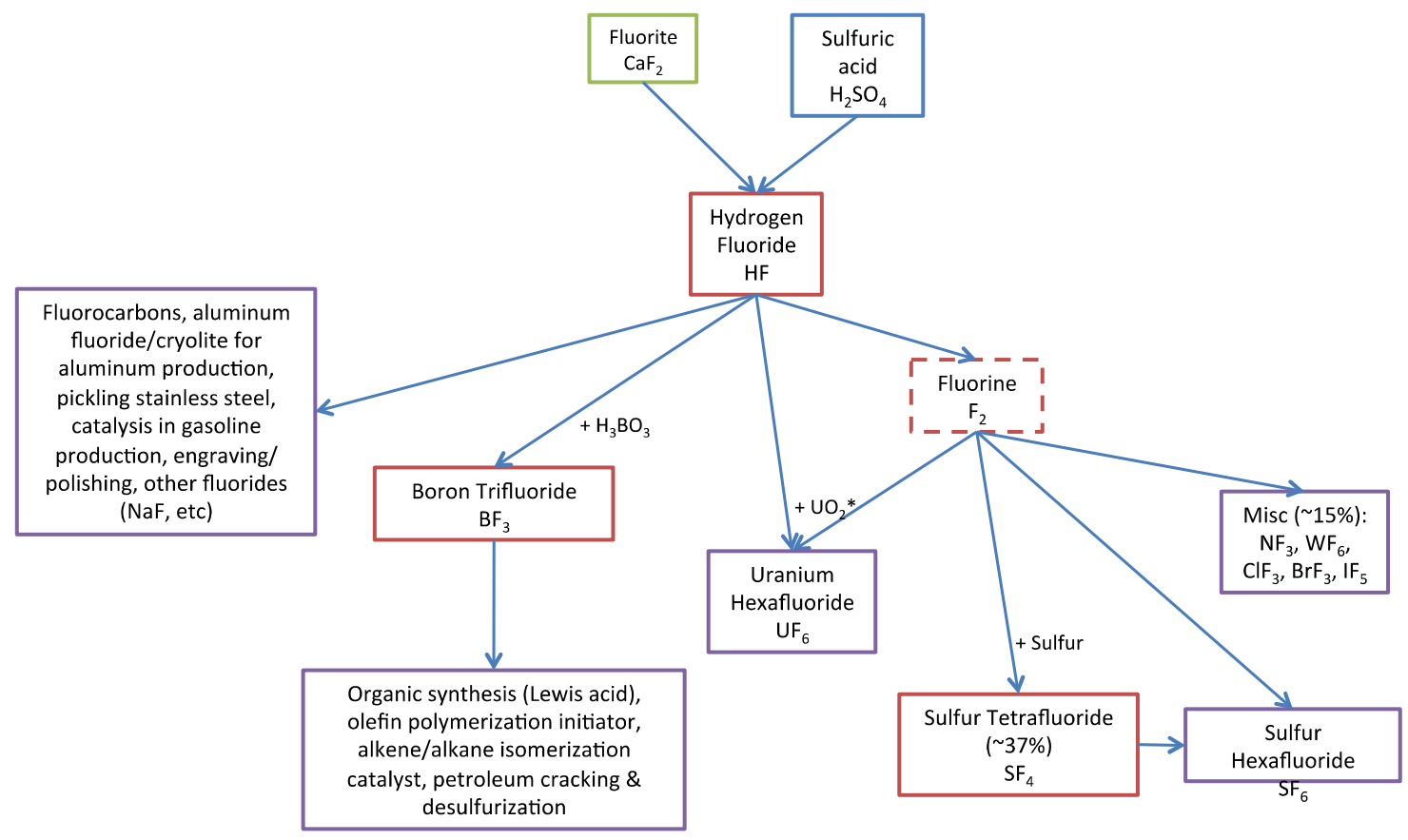

*Nitric acid and ammonia are also used in $\mathrm{UO}_{2}$ production

\subsection{IST Data Sheet Form}

The IST Data Sheet was a component of our chemical brief IST search methodology. We intended to use this to probe further the areas within IST that have and have not been explored for each chemical supply chain. The idea was not pursued once the first redirection occurred.

\section{IST Data Sheets}

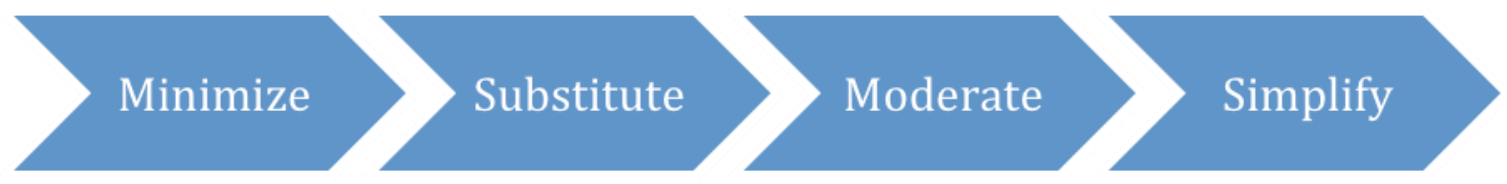

If the answer to a question is Yes, proceed to the sub-questions. If the answer to a question is No, proceed to the next top-level question. 
TABLE 1. TO BE COMPLETED FOR EACH CHEMICAL

\begin{tabular}{|c|c|c|c|}
\hline \multicolumn{2}{|r|}{ Question } & $\mathbf{Y} / \mathbf{N}$ & Comments \\
\hline \multirow{4}{*}{ 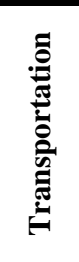 } & Is the chemical transported in significant quantities? & & $\begin{array}{l}\text { (If yes, list transportation methods; if no, note } \\
\text { any minor transportation requirements) }\end{array}$ \\
\hline & Can the chemical be generated on-site at point of use? & & (If yes, list available options and issues) \\
\hline & $\begin{array}{l}\text { Can the chemical be shipped in a less hazardous form } \\
\text { (e.g., dilute, refrigerated, as a chemical compound, on a } \\
\text { low-P adsorbent) }\end{array}$ & & (If yes, list available options and issues) \\
\hline & Can the compound be shipped via pipeline? & & \\
\hline \multirow{2}{*}{ 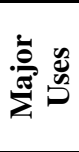 } & $\begin{array}{l}\text { Does the chemical have a large (e.g., >5) number of major } \\
\text { uses? }\end{array}$ & & (List major uses and \% of total) \\
\hline & $\begin{array}{l}\text { Can uses for the chemical be binned in a manageable } \\
\text { number of major categories? }\end{array}$ & & (List major use categories and \% of total) \\
\hline
\end{tabular}

TABLE 2. TO BE COMPLETED FOR EACH MAJOR USE OF EACH CHEMICAL \begin{tabular}{|l|l|l|l}
\hline Question & Y/N & Comments \\
\hline
\end{tabular}

\begin{tabular}{|c|c|c|c|}
\hline & Question & $\mathbf{Y} / \mathbf{N}$ & Comments \\
\hline \multirow{9}{*}{ 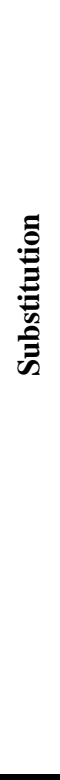 } & $\begin{array}{l}\text { Can a less hazardous chemical be directly substituted into } \\
\text { the existing process? }\end{array}$ & & (If yes, list available options and issues) \\
\hline & $\begin{array}{l}\text { Does the substitute material utilize any of the } 49 \\
\text { Appendix A chemicals in their supply chain? }\end{array}$ & & \\
\hline & $\begin{array}{l}\text { Does the substitute material introduce other hazards (e.g. } \\
\text { flammable/explosive materials, environmental hazards) } \\
\text { in their supply chain? }\end{array}$ & & \\
\hline & $\begin{array}{l}\text { Do commercially competitive alternatives to the process } \\
\text { exist which use different raw materials? }\end{array}$ & & (If yes, list available options and issues) \\
\hline & $\begin{array}{l}\text { Do the alternative processes utilize any of the } 49 \\
\text { Appendix A chemicals in their supply chain? }\end{array}$ & & \\
\hline & $\begin{array}{l}\text { Do the alternative processes introduce other hazards (e.g. } \\
\text { flammable/explosive materials, environmental hazards) } \\
\text { in their supply chain? }\end{array}$ & & \\
\hline & $\begin{array}{l}\text { Do early-stage or non-competitive alternatives to the } \\
\text { process exist? }\end{array}$ & & (If yes, list available options and issues) \\
\hline & $\begin{array}{l}\text { Do the alternative processes utilize any of the } 49 \\
\text { Appendix A chemicals in their supply chain? }\end{array}$ & & \\
\hline & $\begin{array}{l}\text { Do the alternative processes introduce other hazards (e.g. } \\
\text { flammable/explosive materials, environmental hazards) } \\
\text { in their supply chain? }\end{array}$ & & \\
\hline \multirow{11}{*}{ 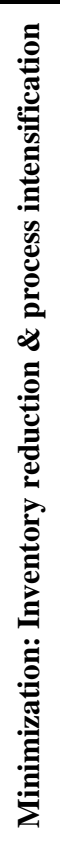 } & $\begin{array}{l}\text { Is the chemical stored in significant quantities as a raw } \\
\text { material (before being fed to the process)? }\end{array}$ & & $\begin{array}{l}\text { (If yes, describe storage conditions and } \\
\text { quantities) }\end{array}$ \\
\hline & $\begin{array}{l}\text { Can the chemical be generated on demand within the } \\
\text { plant from less hazardous raw materials? }\end{array}$ & & (If yes, list available options and issues) \\
\hline & $\begin{array}{l}\text { Can the production unit be integrated into (coupled to) } \\
\text { the process? }\end{array}$ & & (If yes, list available options and issues) \\
\hline & $\begin{array}{l}\text { Can the chemical be stored in a less hazardous form } \\
\text { within the plant (e.g., dilute, refrigerated liquid)? }\end{array}$ & & (If yes, list available options and issues) \\
\hline & $\begin{array}{l}\text { Can the storage amount be reduced through just-in-time } \\
\text { deliveries or inventory management systems? (*may shift } \\
\text { risk*) }\end{array}$ & & \\
\hline & $\begin{array}{l}\text { Is the chemical stored in significant quantities as an } \\
\text { intermediate? }\end{array}$ & & $\begin{array}{l}\text { (If yes, describe storage conditions and } \\
\text { quantities) }\end{array}$ \\
\hline & $\begin{array}{l}\text { Can intermediate storage be reduced via direct coupling } \\
\text { of process elements? }\end{array}$ & & \\
\hline & $\begin{array}{l}\text { Can intermediate storage be reduced, e.g., through } \\
\text { improved process control? }\end{array}$ & & \\
\hline & $\begin{array}{l}\text { Do significant inventories of the chemical exist within the } \\
\text { process elements (e.g., in reactors or separation } \\
\text { equipment)? }\end{array}$ & & $\begin{array}{l}\text { (If yes, describe storage conditions and } \\
\text { quantities) }\end{array}$ \\
\hline & $\begin{array}{l}\text { Do significant inventories of the chemical exist within } \\
\text { reactors? }\end{array}$ & & \\
\hline & Can alternative reactor technologies or configurations & & (If yes, list available options and issues) \\
\hline
\end{tabular}




\begin{tabular}{|c|c|c|}
\hline & & \\
\hline & be employed to reduce inventories of the chemical? & \\
\hline & $\begin{array}{l}\text { Do significant inventories of the chemical exist within } \\
\text { separation devices? }\end{array}$ & \\
\hline & $\begin{array}{l}\text { Can alternative separation technologies be employed to } \\
\text { reduce inventories? }\end{array}$ & (If yes, list available options and issues) \\
\hline & $\begin{array}{l}\text { Do significant inventories of the chemical exist within } \\
\text { other process units? }\end{array}$ & \\
\hline & $\begin{array}{l}\text { Can alternative technologies (e.g., intensive mixers) be } \\
\text { employed to reduce inventories? }\end{array}$ & (If yes, list available options and issues) \\
\hline & $\begin{array}{l}\text { Can pipeline inventory be reduced by using the } \\
\text { hazardous material as a gas? }\end{array}$ & \\
\hline \multirow{9}{*}{ 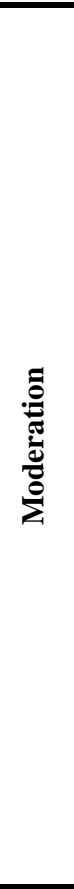 } & $\begin{array}{l}\text { Is it possible to limit the supply pressure of hazardous raw } \\
\text { materials to less than the maximum allowable working } \\
\text { pressure of the vessels to which they are delivered? }\end{array}$ & \\
\hline & $\begin{array}{l}\text { Is it possible to make reaction conditions (T, P) less severe } \\
\text { by using a catalyst, or a better catalyst (e.g., structured } \\
\text { monolithic vs. packed bed)? }\end{array}$ & (If yes, list available options and issues) \\
\hline & $\begin{array}{l}\text { Can the process be operated at less severe conditions by } \\
\text { considering improved thermodynamics and kinetics, } \\
\text { reaction phase, the order in which raw materials are added, } \\
\text { raw material recycle, or operation at lower T and P? }\end{array}$ & (If yes, list available options and issues) \\
\hline & $\begin{array}{l}\text { Are heating/cooling media, etc. compatible with process } \\
\text { materials in the event of inadvertent contamination? }\end{array}$ & \\
\hline & $\begin{array}{l}\text { Is it possible to add an ingredient to volatile hazardous } \\
\text { materials that will reduce their vapor pressure? }\end{array}$ & (If yes, list available options and issues) \\
\hline & $\begin{array}{l}\text { For equipment containing material that become unstable at } \\
\text { elevated temperature or freeze at low temperature, is it } \\
\text { possible to use heating/cooling media which limit the } \\
\text { max/min temperatures attainable? }\end{array}$ & (If yes, list available options and issues) \\
\hline & $\begin{array}{l}\text { Is equipment designed to totally contain the materials that } \\
\text { might be present inside at ambient temperature or the } \\
\text { maximum attainable process temperature? }\end{array}$ & \\
\hline & $\begin{array}{l}\text { Can process units be designed to limit the magnitude of } \\
\text { process deviations? }\end{array}$ & (If yes, list available options and issues) \\
\hline & Can passive containment designs be implemented? & (If yes, list available options and issues) \\
\hline \multirow{4}{*}{ 苞 } & & \\
\hline & & \\
\hline & & \\
\hline & & \\
\hline
\end{tabular}


[Blank page following section.] 


\section{CATEGORIZATION OF DHS CFATS APPENDIX A "RELEASE - TOXIC" CHEMICALS}

\subsection{Introduction}

At the outset of this project, chemicals agreed upon for a full Inherently Safer Technology gaps study consisted of those listed in the DHS CFATS Appendix A. Forty nine chemicals were in this appendix, but beyond their shared quality of being toxic release chemicals, the listing was quite diverse. To find a starting point and to better understand the list of 49, we began a categorization exercise.

This categorization of the 49 chemicals was based on various physical properties such as reactivity, common use, and elemental composition. This section will summarize those findings and give our conclusions. Notably, this exercise showed that there are chemicals on the list that do not need to be investigated.

\subsection{Elemental Composition}

\subsubsection{Amines}

Nitrogen-containing materials comprise a significant group of chemicals in the industrial sector from pharmaceuticals to fertilizer and pesticides. The small building blocks that are used to synthesize these products are derived from simpler compounds like ammonia and primary amines: $\mathrm{R}-\mathrm{NH}_{2}$ where $\mathrm{R}$ is an alkyl group. In the DHS CFATS Appendix A, there are three compounds that fit this definition.

Ammonia

Cyclohexylamine

Ethylenediamine

The latter two chemicals are made by the addition of ammonia to the corresponding alcohol or halogenated starting material. Ammonia itself is made using the Haber-Bosch process ${ }^{1}$. It is evident from this list that the three compounds vary greatly in industrial importance with ammonia being made on enormous scales and consuming approximately $1 \%$ of man-made power world-wide $^{1}$. The other two chemicals have niche markets as ligands for metals and synthons for pharmaceuticals and other organic compounds.

The scale of ammonia production puts this chemical high on our list of priorities for further study. The other amines would be explored during our larger study of ammonia.

\subsubsection{Alcohols}

Alcohols (R-OH) are an important group of chemicals that are surprisingly not well represented in Appendix A. Only one alcohol is present on the list.

Allyl Alcohol 
Industrially, allyl alcohol is an intermediate in the synthesis of 1,4-butanediol, glycerol, and epichlorohydrin along with a host of other small-market chemicals. 1,4-butanediol (BDO) is the main use of allyl alcohol in the United States, and is only made by LyondellBasel in Channelview, $\mathrm{TX}^{2}$. For this reason, this chemical was deemphasized in this study in favor of other chemicals.

\subsubsection{Exotic Elements}

A final category based on elemental composition was devised based on elements that are viewed as non-carbon, -hydrogen, -nitrogen, and -oxygen or more succinctly, "exotic". The compounds in this category are composed of and are used to introduce exotic elements for specific purposes. It would be difficult to circumvent the use of these chemicals because of the need to include the specific element. While other chemicals with the desired elements exist, they will most likely all be hazardous in one way or another.

This list contains 13 compounds of diverse elemental compositions.

Arsenic Trichloride

Arsine

Boron Trichloride

Boron Triflouride

Boron Trifluoride Dimethyl Ether Complex

Hydrofluoric Acid (concentration $\geq 50 \%$ )

Hydrogen Fluoride

Hydrogen Sulfide

Fluorine

Phosphorus Oxychloride

Phosphorus Trichloride

Sulfur Tetrafluoride

Titanium Tetrachloride

Due to the simplicity of these compounds, any derivative compounds would most likely have to be made from the compound in question. Sulfur Tetrafluoride is a good example of this. ${ }^{3}$ The derivative Amine: $\mathrm{SF}_{2}$ is now used to fluorinate compounds in place of Sulfur Tetrafluoride $\left(\mathrm{SF}_{4}\right)$. However, one needs to use $\mathrm{SF}_{4}$ to make Amine:SF 2 . This could be argued as a safety improvement because $\mathrm{SF}_{4}$ production has been localized into a few places, but a counterargument would be that this "improvement" has increased capacity at a smaller number of locations leading to a larger hazard. In either case, this is likely an example of risk-shifting and not necessarily an IST alternative.

Because of these factors, this category of compounds was designated as low priority. No IST alternatives would be able to sufficiently remove the hazard of a release since these chemicals are all small building blocks and contain necessary elements for specific purposes. Alternatives should ideally focus on substitutions for the downstream product (i.e. substitution of fluorinated compounds to reduce the use of $\mathrm{SF}_{4}$ and any derivative compounds). 


\title{
3.3. Reactivity
}

\subsubsection{Nucleophiles}

Nucleophiles are compounds that are able to donate an electron pair to another compound and form a new chemical bond. They are also known as Lewis Bases. Typically, these compounds are not reactive in air, and can be fairly stable over long periods if handled carefully. It should be noted here that some compounds could function as both nucleophiles and electrophiles depending on reaction conditions and the identity of the other reactants. We have chosen these designations based on the way they are used in the chemical industry.

\author{
Allyl Alcohol \\ Ammonia \\ Arsine \\ Cyclohexylamine \\ Ethylenediamine \\ Isobutyronitrile \\ Methyl Hydrazine \\ Propionitrile
}

\subsubsection{Electrophiles}

Compounds that are characterized as electrophiles tend to be the more reactive counterpart to the nucleophile/electrophile pairing (from the perspective of a release event). An electrophile is a chemical species that is able to accept a pair of electrons from a chemical and form a new chemical bond. These compounds are also known as Lewis Acids. The number of electrophiles in Appendix A far outnumbers that of the nucleophiles._It should be noted here that some compounds could function as both nucleophiles and electrophiles depending on reaction conditions and the identity of the other reactants. We have chosen these designations based on the way they are used in the chemical industry.

\author{
Acrolein \\ Arsenic Trichloride \\ Boron Trichloride \\ Boron Trifluoride \\ Boron Trifluoride Ether Complex \\ Bromine \\ Carbon Disulfide \\ Chlorine \\ Chloromethyl Ether \\ Chloromethyl Methyl Ether \\ Cyanogen Chloride \\ Diborane \\ Epichlorohydrin \\ Fluorine
}




\author{
Formaldehyde \\ Isopropyl Chloroformate \\ Methyl Isocyanate \\ Methyl Thiocyanate \\ Perchloromethyl Mercaptan \\ Phosgene \\ Phosphorus Oxychloride \\ Phosphorus Trichloride \\ Propionitrile \\ Propyleneimine \\ Sulfur Dioxide \\ Sulfur Tetrafluoride \\ Sulfur Trioxide \\ Titanium Tetrachloride
}

\title{
3.3.3. Water Reactives
}

This class of compounds will react with water spontaneously at ambient conditions. We see this as an inherent danger and compounds on this list were given high priority in our gaps study. To validate this logic, many of these compounds have already been investigated for IST alternatives by the chemical industry.

Boron Trichloride
Boron Trifluoride
Boron Trifluoride Ether Complex
Cyanogen Chloride
Diborane
Fluorine
Methyl Isocyanate
Methyl Thiocyanate
Nitric Oxide
Oleum
Phosgene
Phosphorus Oxychloride
Phosphorus Trichloride
Sulfur Tetrafluoride
Sulfur Trioxide
Titanium Tetrachloride

\subsubsection{Oxygen Reactives}

These compounds will reactive with oxygen in the atmosphere. Similar to the previous section of water reactive compounds, this category was also given higher priority when selecting early candidates for study.

Arsine 


\title{
Nitric Oxide \\ Phosphorus Trichloride \\ Titanium Tetrachloride
}

\subsubsection{Oxidants}

Oxidants, or oxidizing agents, are compounds that will accept electrons from another compound inducing an increase in the formal oxidation state of that compound. The oxidant then becomes reduced. The nomenclature used here differs from that of a dangerous materials definition where the oxidizing agent is thought to generate oxygen and contribute to other combustion reactions.

\author{
Carbon Disulfide \\ Bromine \\ Chlorine \\ Fluorine \\ Nitric Oxide \\ Nitric Acid \\ Oleum \\ Phosgene \\ Chlorine Dioxide \\ Methyl Isocyanate
}

\subsubsection{Reductants}

Reducing agents are the counter to oxidants since they donate electrons to an acceptor inducing a decrease in the formal oxidation state of that compound.

\author{
Ammonia \\ Arsine \\ Diborane \\ Hydrogen Sulfide \\ Formaldehyde \\ Isopropyl Chloroformate \\ Methyl Hydrazine \\ Sulfur Dioxide \\ Sulfur Trioxide
}

\subsubsection{Tetramethyl Lead}

This compound was pulled out by itself in the categorization stage. Our team researched this chemical could not find any industrial uses domestically or globally. After speaking with the sponsor, it was determined that this chemical was either put on the list by mistake or was written incorrectly when inputted. Most likely, tetraethyl lead is the chemical of concern in this case, but | we were not asked to pursue that chemical either. 


\title{
3.4. Top Priority Candidates
}

Based on the categorization effort shown in the above sections, our final list of top candidates was determined to be the following:

\author{
Acrolein \\ Allyl Alcohol \\ Chlorine Dioxide \\ Chloroform \\ Epichlorohydrin \\ Hydrocyanic Acid \\ Isobutyronitrile \\ Methacrylonitrile \\ Oleum \\ Propionitrile
}

This list was also determined in part by efforts that were already underway in IST adoption and by the expertise of our industry contacts and contractors.

\subsection{References}

1. Appl, M. "Ammonia." Ullmann's Encyclopedia of Industrial Chemistry, 2006 WileyVCH Verlag, Weinheim.

2. SRIC Chemical Economic Handbook, 2010.

3. Aigueperse, J.; Mollard, P.; Devilliers, D.; Chemla, M.; Faron, R.; Romano, R.; Pierre Cuer, J. "Fluorine Compounds, Inorganic." Ullmann's Encyclopedia of Industrial Chemistry, 2005 Wiley-VCH Verlag, Weinheim. 


\section{ACID-CATALYZED ALKYLATION PROCESS ANALYSIS}

\subsection{Introduction}

In addition to the 49 chemicals that our team analyzed, we were directed to determine the current state of technology for the domestic acid-catalyzed alkylation process. Acid-catalyzed alkylation processes were developed in the early 1930s by Universal Oil Products (UOP), Shell Oil Company, Texaco, and Anglo-Iranian Oil Company (AIOC). This process is used chiefly to synthesize high-octane gasoline for transportation purposes, and approximately $12 \%$ of the total domestic gasoline supply is generated in this way. It was chosen because it is a high profile example of safety choices in the chemical production sector and is a good scenario for the CSAC IST Metrics to explore.

Changes in this technology stem from the acid catalyst used to produce the octane product. Historically, sulfuric acid has been the catalyst of choice, but factors such as quantity, selectivity, and recyclability are sacrificed compared to other catalysts. In the 1970s and 1980s, hydrofluoric acid (HF) alkylation units were developed as an alternative to the sulfuric acid units. HF alkylation allows for more selective formation of octane using smaller quantities of acid and with decreased catalyst degradation in process. However, HF is known to be more hazardous than sulfuric acid, and this trade off has been the focus of attention by safety experts around the world.

Our objective was to determine the state of the current technology as accurately as possible based on patent and scholarly literature, paying special attention to process conditions and the quantities of acid.

\subsection{Industry Overview and Process Design}

\subsubsection{Overview}

The acid-catalyzed alkylation technologies employ two main catalysts: sulfuric acid and hydrofluoric acid. Until the 1970 s, more than $75 \%$ of the alkylate that was produced in the US was made using sulfuric acid. In the 1970s and 1980s, hydrofluoric acid technology dramatically increased its market share to approximately $50 \%$ of gasoline production. However, based on the aforementioned safety hazards introduced by $\mathrm{HF}$, there is now renewed interest in the development of sulfuric acid technology. To that point, $70 \%$ of facilities built domestically in the last 10 years are sulfuric acid-catalyzed. European facilities still favor hydrofluoric acid with $60 \%$ of gasoline produced in this way.

The alkylation process can be described as a biphasic reaction mixture of a hydrocarbon-rich phase and an acid-rich phase. The hydrocarbon phase consists of olefins, typically isobutene and propylene, and isobutane. Isobutane is supplied in excess and is only moderately soluble in the acid phase. Olefins are highly soluble in the acid phase based on their reactivity with the acid. 
The catalytic reaction is started via protonation of the olefin creating a reactive intermediate called a carbocation (carbon-centered positively charged organic molecule). This carbocation reacts with the available isobutene to generate a $\mathrm{C}_{8}$ carbocation. This reactive species scavenges a hydride from an isobutane moiety reforming the initiating carbocation. The cycle continues in this way consuming both isobutane and isobutylene (Figure 1 and Figure 2).
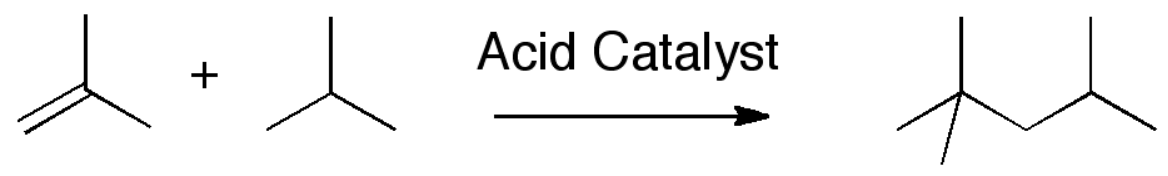

Figure 1. Representative Alkylation Reaction
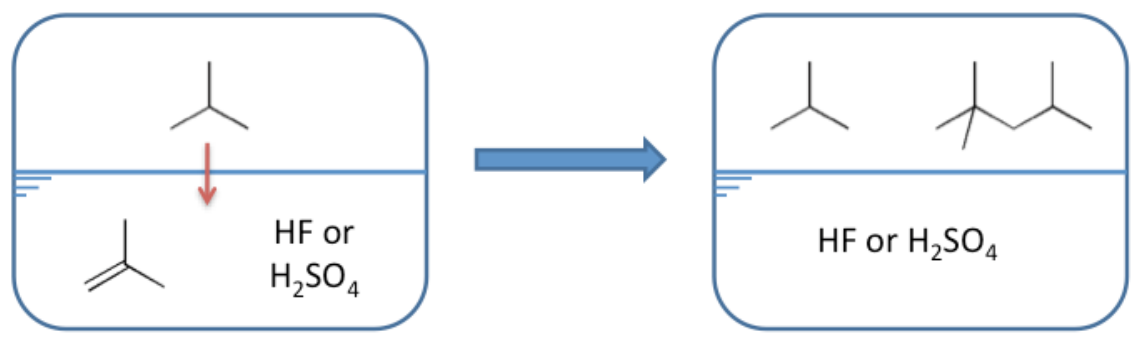

Figure 2. Representative Reactor Composition

The most common hydrofluoric acid alkylation units are the Phillips gravity flow process (31\% world-wide market) and the UOP pumped flow process (22\% world-wide market). Both processes are now owned by UOP. Sulfuric acid alkylation is performed using the Kellogg and ExxonMobil cascade reactor process (13\% of US market) and the DuPont STRATCO contactor process (34\% world-wide market). A generalized view of the reactor process is pictured in Figure 3. The dotted line outlines the process components.

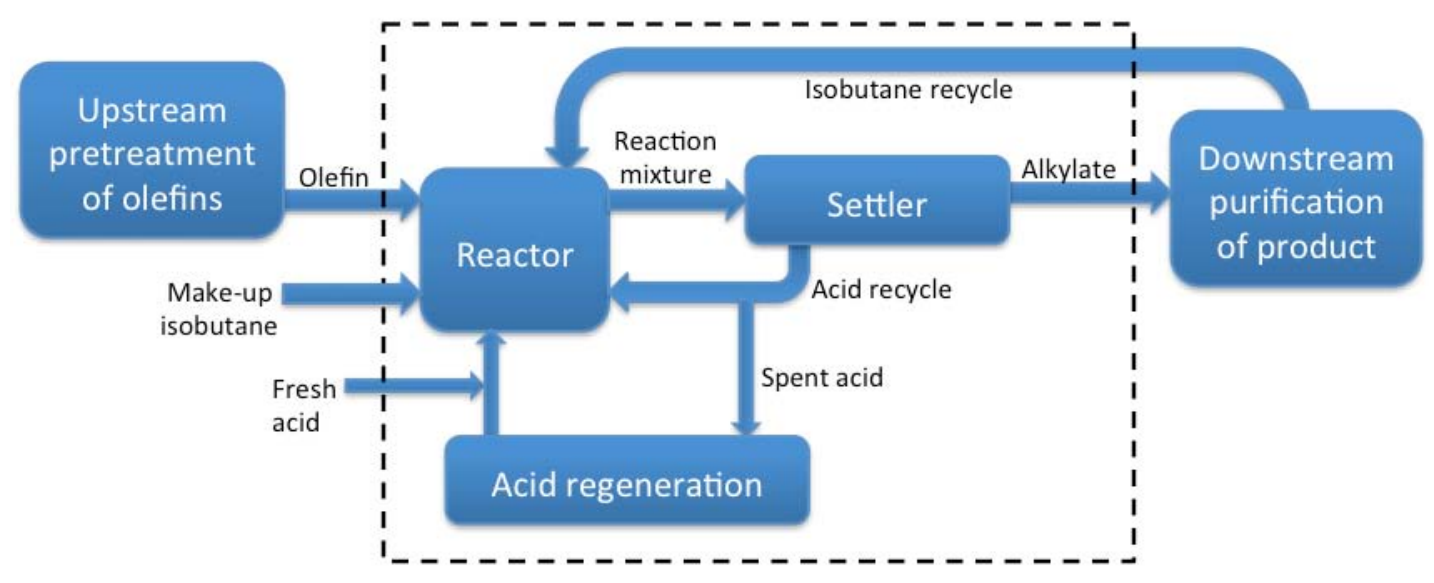

Figure 3. Diagram of Alkylation Process Components 
The reactor facilitates intimate mixing of the reactants to enhance the reaction rate. The settler tank or tanks "de-mix" the product-rich stream and acid-rich stream with the aqueous acid settling to the bottom and hydrocarbon being siphoned from the top of the tank. Acid regeneration is the continual draw off and replenishment of spent acid and is an important part of the process since decomposition of catalyst occurs for both hydrofluoric and sulfuric acid.

\subsubsection{Alkylate Production Process Design}

The reactor technology for the two acids differs in the approach to organic/aqueous mixing and the cooling methods. The HF process, and more specifically the Phillips gravity process, is a vertical tank system that uses the differences in density of acid and hydrocarbon to achieve mixing and settling (Figure 4). The reactor tank is filled with HF acid. A nozzle sprays the hydrocarbon mixture radially into the acid mixture at the bottom of the reactor. The hydrocarbon is dispersed throughout the aqueous mixture and reacts as it rises to the top of the reactor vessel. At the top of the reactor, it phase-separates and is siphoned away for further settling in the separate tank. Fresh and recycled acid is fed in through the bottom of the reactor.

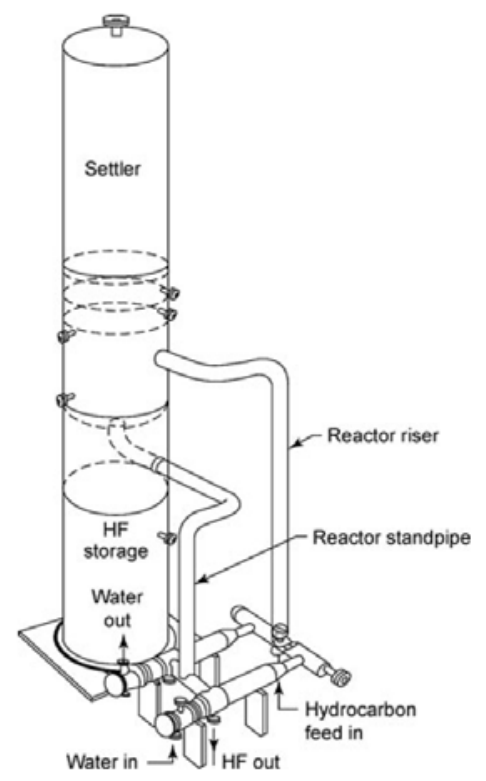

Figure 4. Phillips HF Gravity Process (graphic from Albright, L. Oil and Gas Journal, 1990, 70-77.)

The DuPont STRATCO process is one of the most popular sulfuric acid alkylation methods (Figure 5). The reactor is horizontally aligned and mixed with a propeller. Acid and hydrocarbon enter near the propeller where they mix and then travel the length of the reactor by cooling tubes to maintain the operating temperature. The mixture is siphoned away at the end of the reactor and sent to a settler tank. 


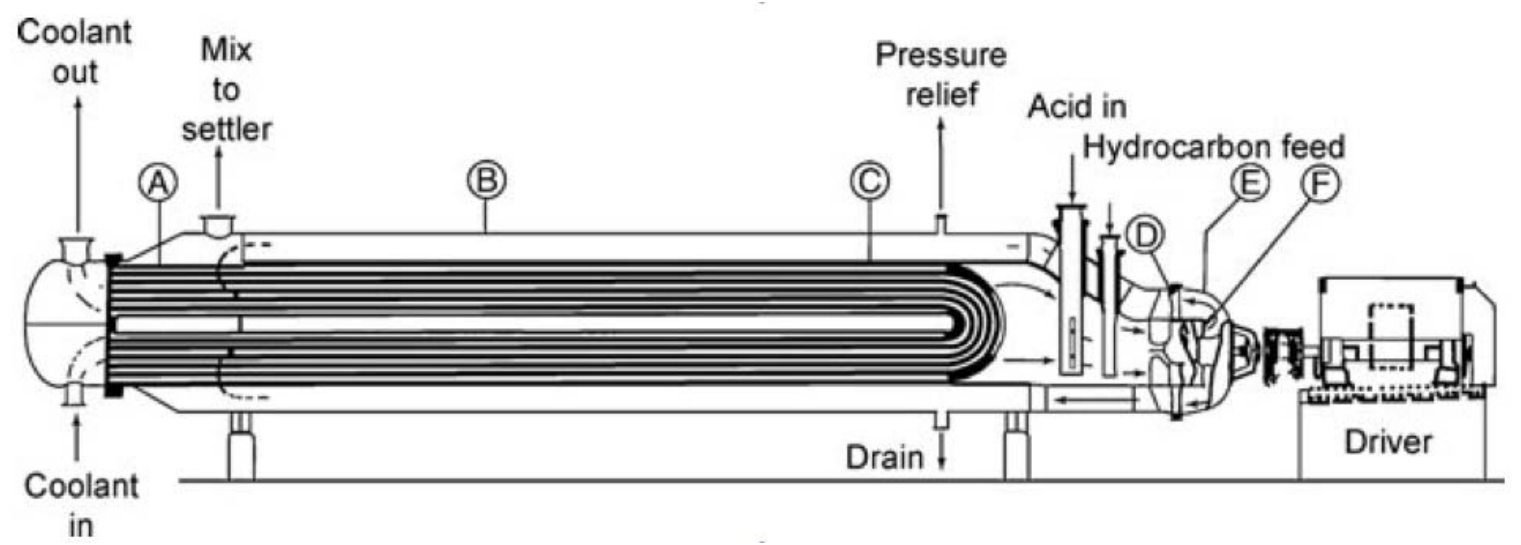

Figure 5. DuPont STRATCO Reactor (graphic from DuPont External Information Sheet, "Stratco Alkylation Technology" page 3.)

Reactor conditions are fairly uniform. The HF process runs at a temperature of $35-40{ }^{\circ} \mathrm{C}, 1$ atmosphere of pressure, a residence time of five minutes in the reactor and 15 minutes in the settler. The sulfuric acid process only differs here with a temperature of $5-10^{\circ} \mathrm{C}$.

\subsubsection{Process Volumes}

At the outset of this investigation, the sponsor asked a pointed question regarding the volumes of acid and alkylate in the alkylation unit. Based on industry and patent literature and expert opinion, we gave the following response. The specific question and response are copied below.

Question: In connection with the $\mathrm{HF}$ or $\mathrm{H}_{2} \mathrm{SO}_{4}$ catalytic alkylation process, how large (e.g., in gallons or pounds) would the alkylation reactor and/or the associated settling tank be at, for example, a 10,000 barrel/day refinery?

As one would expect, these volumes are not widely known. Most patent literature does not dictate a specific size or quantity for a given technology and usually sets boundaries through percentages and ratios. However, we have obtained some information from the literature and industry contacts to answer this question.

For each acid, there are several current and outdated reactor designs. The Phillips process (gravity flow unit) and the UOP process (pumped flow) are used for HF-catalyzed alkylation. These processes have more recently been upgraded by the use of additives to reduce the vapor pressure of HF. Sulfuric acid alkylation is performed in tank reactors (new facilities no longer use this technology), cascade reactors (Kellogg, ExxonMobil), and the STRATCO contactors. Sulfuric acid volumes are typically larger than HF volumes for a similar alkylate output. Volumes, residence times, and many other factors can change drastically within a category like "HF-catalyzed alkylation." Our numbers below are as accurate as we can find for the most common processes.

\section{HF Alkylation Process}


US Patent 5,098,668 entitled "HF Evacuation Unit with Acid Evacuation System" describes an invention where an HF alkylation unit is augmented to reduce the amount of acid in the reactor and equips it with an emergency evacuation system. They compare specific numbers for their process and current technology to show the benefits their technology offers. "Typically, the acid inventory in the unit can be reduced to about 12,000 gallons for a unit producing 18,000 bpsd [barrels per stream day] of alkylate product, as compared to an inventory of about $\mathbf{7 0 , 0 0 0}$ gallons for a gravity flow unit of the same size."

In " $\mathrm{H}_{2} \mathrm{SO}_{4}$, HF Processes Compared, and New Technologies Revealed," Lyle Albright notes that 1 million pounds of HF (120,000 gallons) is needed for a 25,000 barrel/day alkylation plant. No specific reactor technology was named.

Marathon's Texas City plant was reported to be currently operating at a capacity of 12,400 barrels/day but we could not locate current acid inventories. However, in "Analysis of Hydrogen Fluoride Release at Texas City," it was reported that their total amount of HF and Water in the alkylation unit was $158,160 \mathrm{~kg}$ in 1987 . To verify that these values are still relevant to each other, we applied Lyle Albright's rough calculation of $1 \mathrm{M}$ pounds for 25,000 barrels/day. We used the 158,160 kg as $100 \%$ HF (the HF and Water is most $98 \% \mathrm{HF}$, the authors acknowledged several sources of error in estimating this initial value) and came to an estimate of 9,000 barrels/day of alkylate. We think this is a good correlation and have confidence that they are adequate descriptors of the current plant's capacity despite the 2 decades span between these reported values.

\section{Sulfuric Acid Process}

STRATCO Process is a multi-reactor/settler installation that produces approximately 2000 barrels/day of alkylate per reactor. Contents of a reactor by volume is $50 \%$ acid and $50 \%$ hydrocarbon. Volume of a reactor is $43.5 \mathrm{~m}^{3}$ giving $21.75 \mathrm{~m}^{3}$ of sulfuric acid $(39,150 \mathrm{~kg})$. Volume of the associated settler is in a range of $8-25 \mathrm{~m}^{3}$ with $50 \%$ being acid $\left(4-13 \mathrm{~m}^{3}\right.$ and $7,200-23,400 \mathrm{~kg}$ ). Total volume of both is $46,350-62,550 \mathrm{~kg}$ of sulfuric acid. In the example we found, 8 of these were operated in parallel to achieve an output of 15,000-18,000 barrels of alkylate per day bringing the total acid in the process to approximately $370,800-500,400 \mathrm{~kg}$ of sulfuric acid.

A DuPont Process Technology Manager, Randall Peterson, has confirmed these sulfuric acid process numbers as accurate estimates. Another industry contact, Ron McGihon formerly of Mobil Technology Company, confirmed both the HF and sulfuric acid process numbers accurate estimates.

\subsubsection{Catalyst Regeneration Processes}

The acid catalyst is continually diluted with contaminants within the reactor and decomposed under the conditions present in the process. This necessitates a replenishment scheme to maintain the efficiency of the process. Hydrofluoric acid is typically recycled on site, but the enormous scale of sulfuric acid regeneration precludes this option. Both of these recycling technologies will be outlined. 
A small stream of the diluted HF-containing aqueous layer is continuously pulled from the acid recycle loop. This acid stream is stripped of water either by a stripper or distillation column. Because this can be done efficiently and immediately, no intermediate storage is necessary. The distilled HF is then piped back into the process reactor along with a small amount of virgin HF that is necessary to make up for losses.

The virgin HF is produced by the reaction of fluorspar and sulfuric acid. This is an important point to make since the use of HF coincidentally also necessitates the other acid for its formation. That process is pictured in Figure 6.

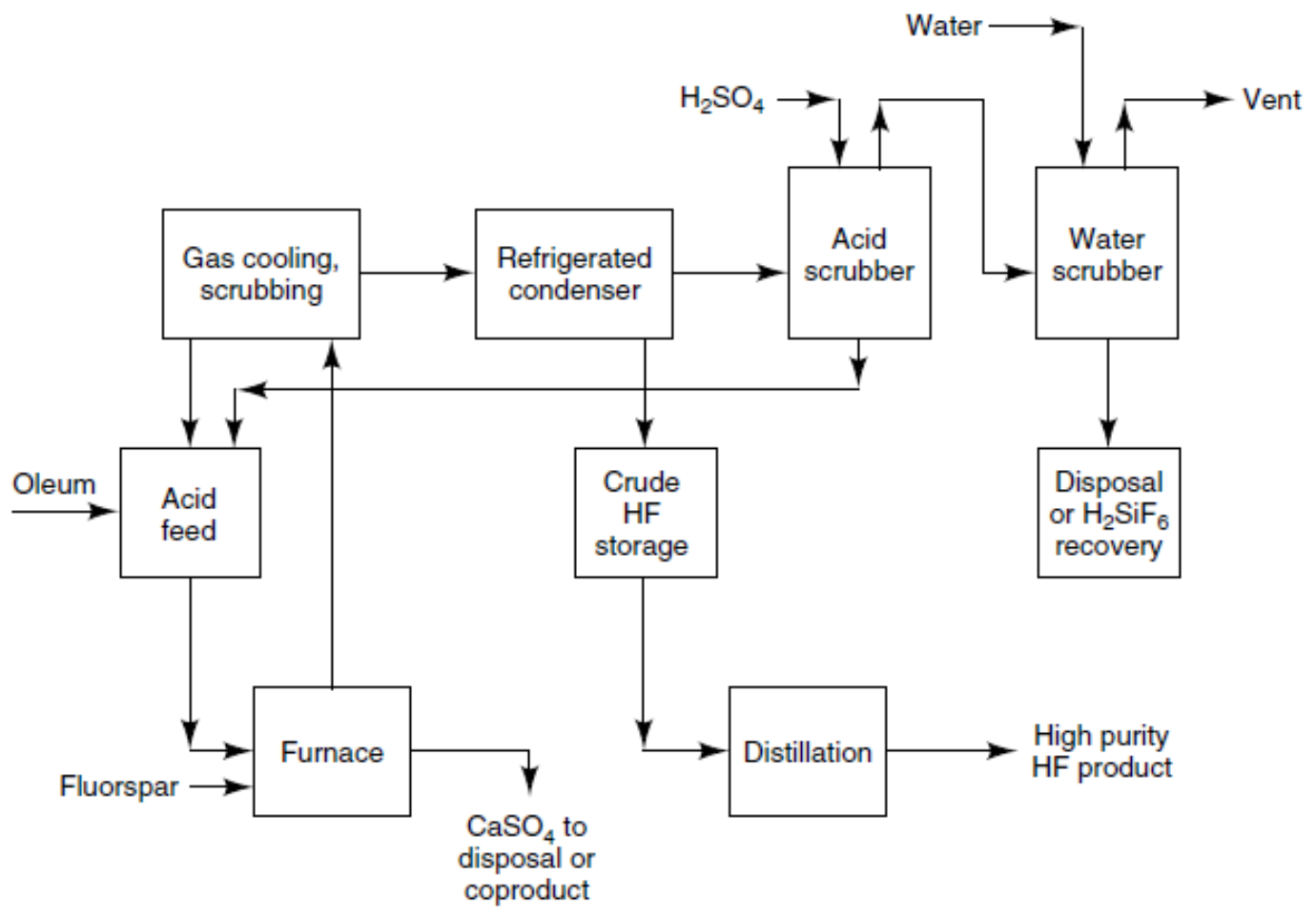

Figure 6. Production of Hydrofluoric Acid

In the sulfuric acid regeneration process, the spent acid is carried out in a separate process either on-site or in a nearby/adjacent facility. This avoids shipping costs on the large amounts of acid that need to be transported back and forth between the regeneration area and the process. Spent acid is essentially burned along with any hydrocarbons contaminants to reclaim the sulfur as $\mathrm{SO}_{2}$ and $\mathrm{SO}_{3}$ which is then converted completely to sulfuric acid. In addition, virgin acid needs to be added to offset the sizable amount of losses seen here $(0.25-0.7$ pounds of acid per gallon of alkylate).

The production of new acid from sulfur stockpiles is not too dissimilar from the aforementioned regeneration process. In its modern form, the production of sulfuric acid is a three-step process beginning from elemental sulfur or sulfur-containing compounds. This process is called the contact process, and more specifically, the double absorption contact process. 
In the United States, the main method of sulfur dioxide formation is by combustion of elemental sulfur (Figure 7, Reaction A). This elemental sulfur is obtained from either hydrogen sulfide as an impurity in natural gas (Claus Process) or from underground sulfur deposits (Frasch Process). Sulfur dioxide is also obtained by processing pyrite $\left(\mathrm{FeS}_{2}\right)$ or other sulfur-containing ores. If sulfur dioxide is obtained by combustion of elemental sulfur, it can be used as-is for the following process steps (Figure 8).

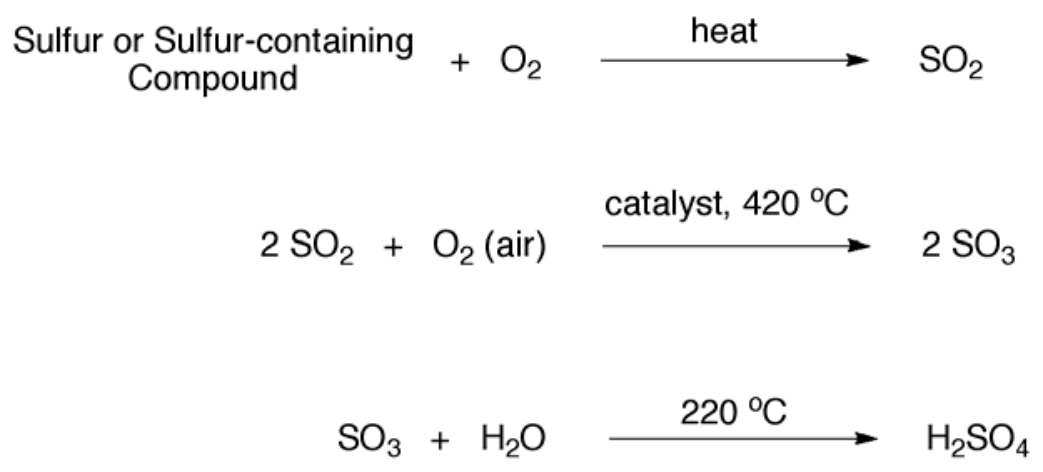

Figure 7. Sulfuric Acid Production

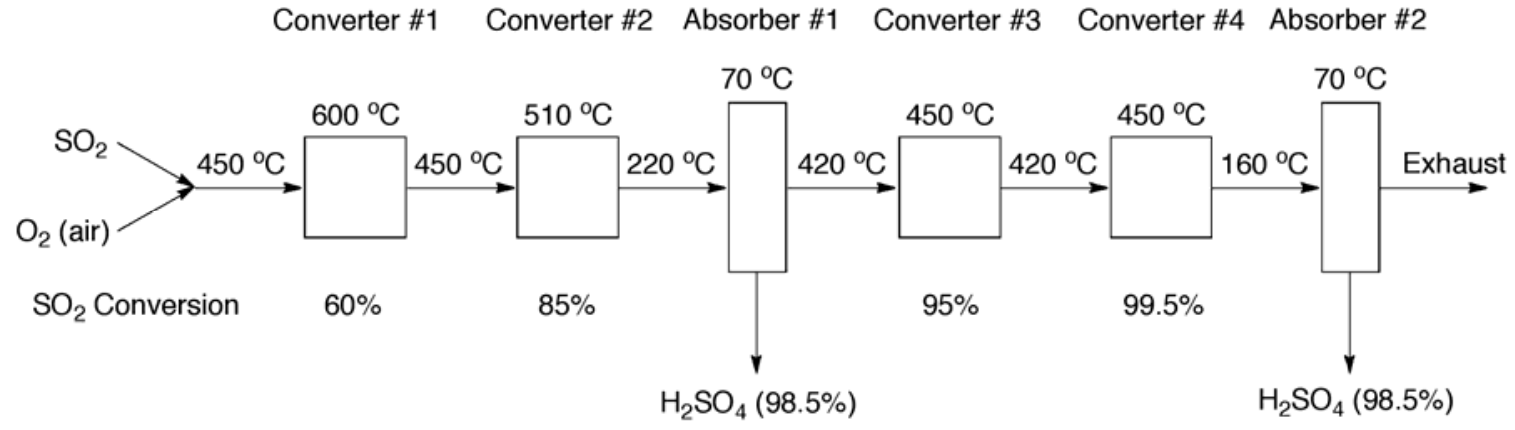

Figure 8. Process Components for Sulfuric Acid Production

The sulfur dioxide gas stream (10-12\% by volume) and dry air are the feed gases for the next step (Figure 7, Reaction B). Dry air is obtained by first filtering to remove dust and then passing through a Venturi scrubber where it is mixed with $98.5 \%$ sulfuric acid. The $98.5 \%$ sulfuric acid absorbs the water in the inlet air stream. The dry air gas is then ready for use in the converter. The sulfuric acid in this stage is eventually diluted to approximately $93-95 \%$ before it is siphoned away to be concentrated in the latter stages of this process. The dry air and sulfur dioxide are mixed in a ratio such that the $\mathrm{SO}_{2}$ and $\mathrm{O}_{2}$ are in a 1:1 molar ratio. The gases are heated to approximately $450{ }^{\circ} \mathrm{C}$ before they are sent into the converter unit (the reactors).

The converter is a series of four or more reactors each with its own catalyst bed $\left(\mathrm{V}_{2} \mathrm{O}_{5}\right.$ with additives). The inlet gases are preheated to $450{ }^{\circ} \mathrm{C}$ and maintained at roughly $1 \mathrm{~atm}$. $\mathrm{As}^{\mathrm{SO}_{2}}$ is converted to $\mathrm{SO}_{3}$, the temperature rises to $600{ }^{\circ} \mathrm{C}$ before it leaves the first reactor (at around $60 \%$ conversion of $\mathrm{SO}_{2}$ ). This $600{ }^{\circ} \mathrm{C} \mathrm{SO}_{2} / \mathrm{SO}_{3} /$ air stream is cooled back to $450{ }^{\circ} \mathrm{C}$ and put through the next reactor where it reaches $\sim 85 \%$ conversion of $\mathrm{SO}_{2}$ and rises to $510{ }^{\circ} \mathrm{C}$. 
At this point, the "first absorption" can be performed (Figure 7, Reaction C). The product gas is cooled to $220{ }^{\circ} \mathrm{C}$ and is passed into a "packed tower" which is irrigated with concentrated sulfuric acid. The $\mathrm{SO}_{3}$ reacts with residual or added water in the sulfuric acid, and the remaining $\mathrm{SO}_{2}$ and air $/ \mathrm{O}_{2}$ stream is reheated to $420{ }^{\circ} \mathrm{C}$ and routed back into the two additional converter units. After the last two converter units, $99.5-99.7 \%$ of the $\mathrm{SO}_{2}$ has been converted into $\mathrm{SO}_{3}$. A second absorption step is performed in the same manner as the first. The two absorption steps allow the equilibrium to be pushed to essentially $100 \%$ conversion, and this is why it is called the "double absorption" process.

The product obtained is $98.5 \%$ concentrated sulfuric acid. This can be used directly for the industrial alkylation process.

\subsection{Transportation and Storage of Acid Inventories}

According to subject matter experts, the transportation and storage of acid is highly dependent on the type of reactor and acid catalyst used. For a 10,000 barrel per day (420,000 gallons per day) alkylation unit, one to two truckloads of hydrofluoric acid per month are needed to replenish any losses incurred in the process. This equates to 500 kilograms of HF acid per day. This number is dwarfed by the amounts contained in the process at any one time (roughly 220,000 kilograms). Additionally, production of hydrofluoric acid will involve the transportation and storage of similar quantities of sulfuric acid based on the preferred method of production (see above).

Sulfuric acid, as stated above, suffers from considerable losses during the process. The regeneration process is not integrated into the alkylate production process, so all acid must be taken to the regeneration facility at some point. If 0.5 pounds of acid per gallon of alkylate is taken as the consumption factor, a 15,000 barrel per stream day (bpsd) alkylation unit will consume approximately 80,000 kilograms of acid per day. This is equivalent to 5-7 tanker trailer loads per day. If two days of raw materials storage is necessary, then 160,000 kilograms of sulfuric acid needs to be on site at all times. This volume can be reduced with the use of direct pipelines to the regeneration facility.

\subsection{CSAC Metrics Charts}

The Metrics charts were prepared by ABS Consulting for CSAC based on the data above. They are reproduced here for completeness. Note: only the magnitudes of the values along the axes are meaningful, and the triangular areas between each axis are a stylistic choice made by ABS Consulting/CSAC. 


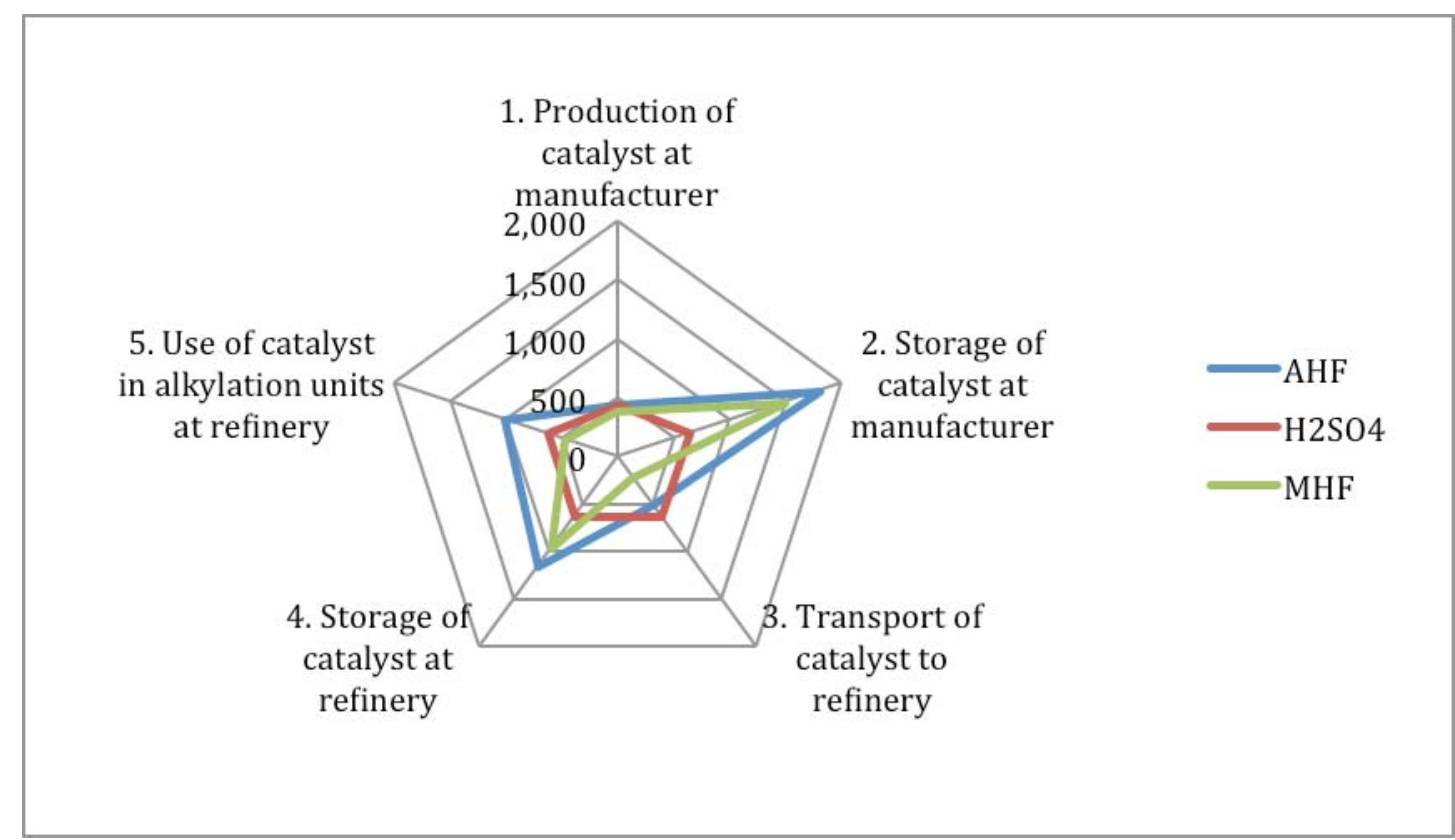

Figure 9. CSAC Metrics Star Chart for Acid Alkylation Process

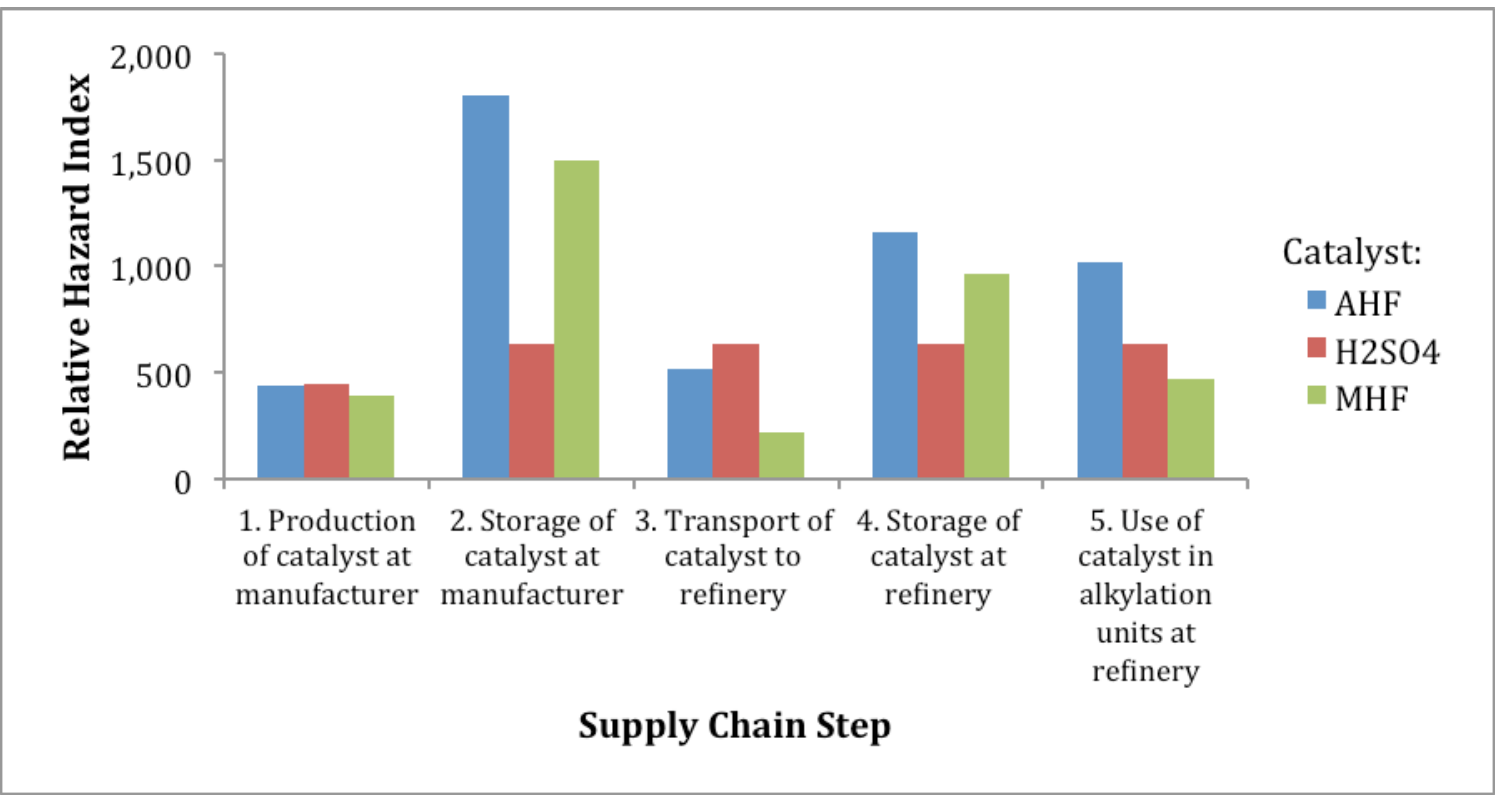

Figure 10. CSAC Metrics Values for Acid Alkylation Process

\subsection{Conclusions}

Initially, the toxic inhalation hazards (TIH) were assumed to be only hydrofluoric acid and sulfuric acid. However, when a thorough analysis of the processes was conducted, other chemicals were identified for both acid catalysts. Sulfuric acid involves the use and consumption of sulfur dioxide, sulfur trioxide, sulfur, and hydrogen sulfide. Hydrofluoric acid uses sulfuric acid as oleum in its production process, and therefore, necessitates all the starting materials noted above. 
Another interesting conclusion involved the acid inventories necessary for alkylation processes. From our "back of the envelope" calculations using figures obtained from patent literature and expert opinion, we determined that inventories of acid in the HF and sulfuric acid processes are roughly the same. The true difference is apparent when the necessary make-up acid is added to these figures with sulfuric acid needing substantially more replenishment than hydrofluoric acid.

\subsection{References}

1. Himes, J. F.; Mehlberg, R. L. "Handbook of Petroleum Processing.” Chapter 9.1, Gasoline Components, Motor fuel alkylation.

2. Aigueperse, J.; Mollard, P.; Devilliers, D.; Chemla, M.; Faron, R.; Romano, R.; Pierre Cuer, J. "Fluorine Compounds, Inorganic." Ullmann's Encyclopedia of Industrial Chemistry, 2005 Wiley-VCH Verlag, Weinheim.

3. Marathon City $<\underline{\text { http://www.petrostrategies.org/Learning Center/hf alkylation concerns.htm }>}$

4. Robinson, K. K. “Reactor Engineering”, pg 2564-2565

5. DuPont External Information Sheet, "Stratco Alkylation Technology"

6. DuPont External Information Sheet "Introduction to Sulfuric Acid Alkylation Unit Process Design"

7. DuPont External Information Sheet " $\mathrm{H}_{2} \mathrm{SO}_{4}$ Technology Comparison" pg. 3

8. Albright, $\mathrm{L}$. " $\mathrm{H}_{2} \mathrm{SO}_{4}$, HF Processes Compared, and New Technologies Revealed," Oil and Gas Journal, 1990, 70-77.

9. Woodward, J. L.; Woodward, H. Z. "Analysis of Hydrogen Fluoride Release at Texas City.” Process Safety Progress, 17, 3.

10. Industry Subject Matter Expert, DuPont Process Technology Manager, Randall Peterson.

11. Industry Subject Matter Expert, Mobil Technology Company, Ron McGihon.

12. U.S. Patent 5,284,990

13. U.S. Patent $3,956,417$

14. U.S. Patent 5,098,668 


\section{EPICHLOROHYDRIN PRODUCTION AND IST ALTERNATIVES}

\subsection{Introduction}

Based on early results from our top-level survey of the 49 chemicals, epichlorohydrin was chosen as a target for an in-depth IST search. Epichlorohydrin is a chlorinated epoxide and building block for epoxy resins, and is produced on very large scales both domestically and globally. Contact exposure will result in severe chemical burns on skin and eyes. It is thought to be carcinogenic but the hydrolysis products (chlorohydrins) are noted to be more toxic. These properties have the potential to generate a toxic release hazard should containment of any sort be compromised.

\subsection{Production Volume and Use}

The United States' domestic production of epichlorohydrin is currently dominated by two facilities: Dow Chemical in Freeport, TX and Momentive (formerly Hexion) in Norco, LA. These plants combine to produce roughly 250,000 metric tons of epichlorohydrin per year using the classical propylene-based method (vide infra). ${ }^{1}$

The current distribution of products made from epichlorohydrin in the United States is as follows: epoxy resins (63\%), polyamide-epichlorohydrin resins and water treatment chemicals (26\%), elastomers (1\%), and miscellaneous use chemicals (10\%). Synthetic glycerol was a significant percentage of the use stream until 2006 when Dow ceased production at its Freeport, TX facility due to the glut of natural/refined glycerol derived from biofuels production. ${ }^{1}$

When considering the four tenets of Inherently Safer Technology, Simplification has the greatest capacity for development. Simplification is the removal of complexity from the manufacturing process. Simplification arising from the advent of new chemistries to produce epichlorohydrin can address concerns of toxicity, waste, and inherent dangers of high temperature. Due to the current availability of byproduct glycerol from biofuels production, a new glycerol-based route to epichlorohydrin is being commercialized by Dow (Germany at pilot-scale), Solvay (France at 15,000 metric tons), and Spolchemie (Czech Republic at 15,000 metric tons). Solvay is building a 100,000-metric ton facility in Thailand, and Dow announced plans to build a 150,000-metric ton facility in Shanghai. ${ }^{4,6}$

\subsection{Modern Production Methods}

After a careful inspection of the available patent literature, open-use company literature, and interviews with subject matter experts, we have determined a most likely manufacturing scenario for the classical and glycerol-based epichlorohydrin production. This section will outline those processes and highlight the reasons why this new technology is an improvement in safety.

\subsubsection{Propylene-based Epichlorohydrin}


The classic process for producing epichlorohydrin (Figure 1) begins with a high temperature chlorination of propylene to give allyl chloride. Allyl chloride is then reacted with hypochlorous acid in an aqueous mixture yield a mixture of dichloropropanols. This mixture is then treated with base (lime or $\mathrm{NaOH}$ ) to promote an epoxidation reaction to epichlorohydrin.

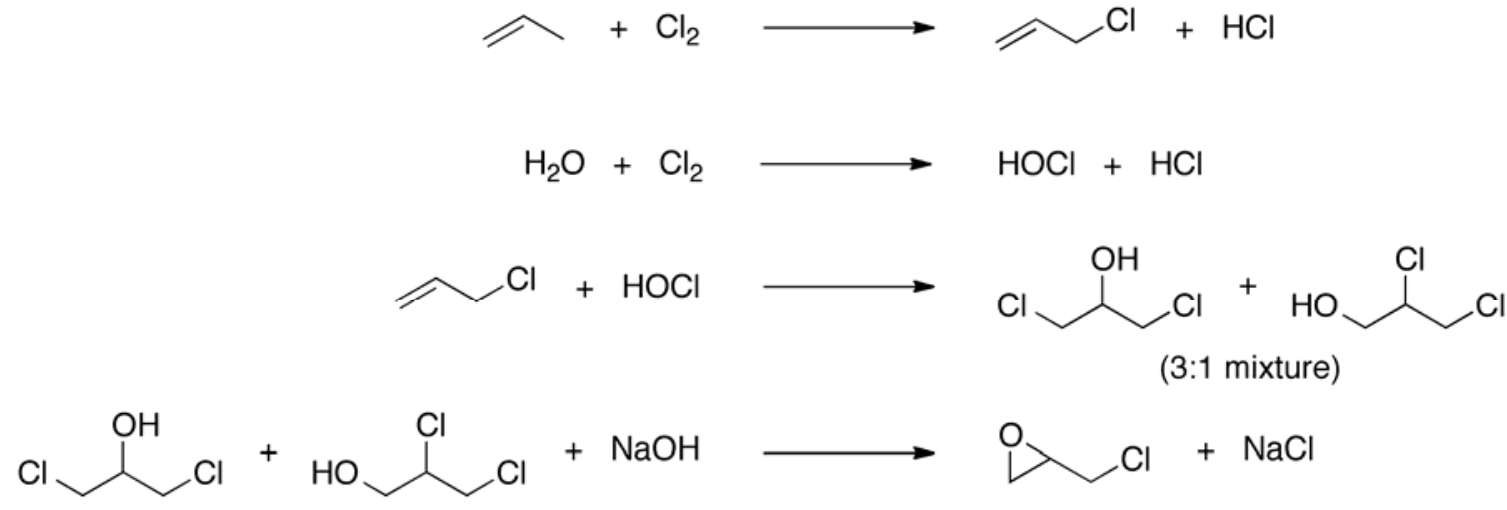

Figure 1. Classical Epichlorohydrin Production

\subsubsection{Allyl Chloride Formation}

The first step in this classical process is the most problematic. A radical-type chlorination reaction must be performed at sufficiently high temperature to activate the elemental chlorine. In this case, temperatures in the range of $500^{\circ} \mathrm{C}$ are employed in the reactor assembly. Propylene is introduced to the reactor in excess with chlorine at one atmosphere of pressure and significantly high flow rates. Access to high volumes of chlorine and propylene are key for this process to operate. Therefore, the plant is typically placed adjacent to those facilities capable of producing the starting materials.

Once the allyl chloride product has been formed, it is condensed away from the remaining propylene stream allowing the propylene to be recycled back into the reactor for further conversion. The product is taken on directly to the chlorohydrin formation step. The residence time for the starting material and products in the reaction assembly is on the order of seconds.

Concerning the reaction conditions, it was initially postulated that performing this reaction at lower temperatures and/or pressures might achieve the goals of IST. However, when this was investigated, it was determined that undesirable side reactions would outweigh the formation of allyl chloride and would not lead to industry-wide technology adoption (Figure 2). A reaction at lower temperature results in the electrophilic addition of $\mathrm{Cl}_{2}$ across the double bond of propylene. This is due to the incomplete dissociation of the $\mathrm{Cl}_{2}$ molecule into chlorine atoms. The second side reaction results at longer reaction times and consumes the allyl chloride product. Therefore, high flow rates are needed to insure product retention.

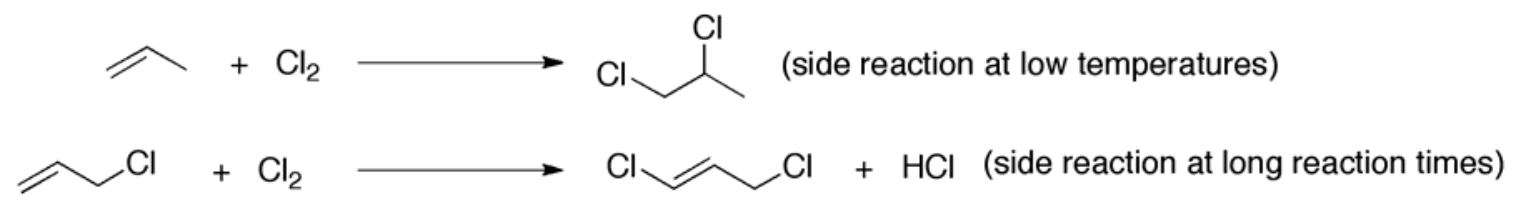


Figure 2. Side Reactions in Allyl Chloride Formation

\begin{tabular}{|c|c|}
\hline Propylene Inlet Temperature: $350-400{ }^{\circ} \mathrm{C}$ & Chlorine Storage Conditions: $-34^{\circ} \mathrm{C}, 1 \mathrm{~atm}$ \\
\hline Chlorine Inlet Temperature: Not Heated & Chlorine Transport: $-34^{\circ} \mathrm{C}, 1 \mathrm{~atm}$ \\
\hline Reactor Temperature: $510^{\circ} \mathrm{C}$ & Propylene Storage Conditions: $-47^{\circ} \mathrm{C}, 1 \mathrm{~atm}$ \\
\hline Reactor Pressure: 1 atm & Propylene Transport: $25^{\circ} \mathrm{C}, 14 \mathrm{~atm}$ \\
\hline Reactor Residence Time: 1 second & \\
\hline Propylene/ $\mathrm{Cl}_{2}$ Ratio: 3 to 1 & \\
\hline Allyl Chloride Yield (based on $\mathrm{Cl}_{2}$ ): $85 \%$ & \\
\hline
\end{tabular}

Table 1. Allyl Chloride Formation Data

\subsubsection{Hydrochlorination of Allyl Chloride}

The second step in the production of epichlorohydrin is the hydrochlorination of allyl chloride to generate dichlorohydrins. This reaction is performed in a dilute aqueous mixture, and most likely in a continuously stirred tank reactor (CSTR). The conditions are fairly mild in comparison to the previous gas-phase reaction and, with the reaction performed at $30{ }^{\circ} \mathrm{C}$, one atmosphere, and a residence time of one minute. The liquid or gas product, allyl chloride, from the previous reaction is introduced into the aqueous mixture with chlorine gas. The chlorine gas, at low dilution, will react with water preferentially to form hypochlorous acid. Hypochlorous acid then reacts with allyl chloride to generate a mixture of two isomers of dichlorohydrin (Figure 3). If a dilution of approximately 12:1:1 water to chlorine to allyl chloride is not achieved and $\mathrm{Cl}_{2}$ persists in the reaction mixture, 1,2,3-trichloropropane is formed and must be separated and disposed of as waste (Figure 4).

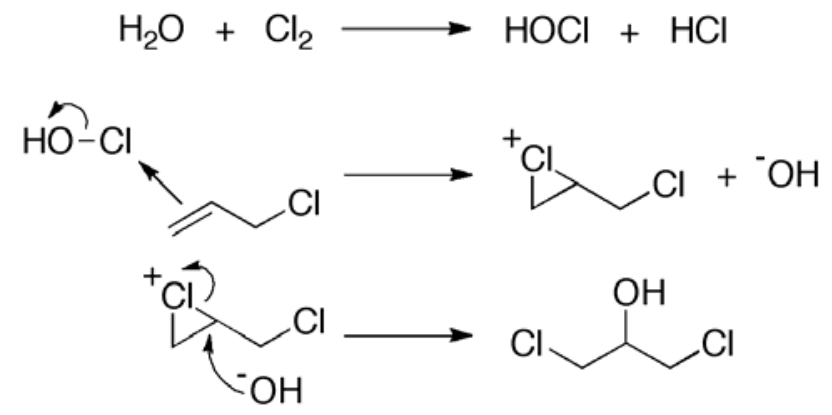

Figure 3. Hydrochlorination of Allyl Chloride (only one product pictured)<smiles>C=CCCl</smiles>

Figure 4. Side Reaction and Formation of 1,2,3-trichloropropane

The final product is not separated from this aqueous mixture. The reaction mixture is taken on directly to the next step. The assumption here is that all the chlorine-containing starting materials $\left(\mathrm{Cl}_{2}\right.$ and hypochlorous acid) have been completely consumed. The final mixture of products is a 
3:1 ratio of 1,3-dichloropropanol and 2,3-dichloropropanol.

\begin{tabular}{|l|l|}
\hline Reactor Type: Aqueous Stirred Vessel & Product Concentration in Effluent: $4 \% \mathrm{wt}$ \\
\hline Reactor Temperature: $30^{\circ} \mathrm{C}$ & Dichlorohydrin Yield: $85 \%$ \\
\hline Reactor Pressure: $1 \mathrm{~atm}$ & Chlorine Storage Conditions: $-34{ }^{\circ} \mathrm{C}, 1 \mathrm{~atm}$ \\
\hline Reactor Residence Time: 1 minute & Allyl Chloride Conditions: $20{ }^{\circ} \mathrm{C}, 1 \mathrm{~atm}$ \\
\hline Water/Allyl Chloride $/ \mathrm{Cl}_{2}$ Ratio: $12: 1: 1 \mathrm{wt}$ & \multicolumn{1}{|l}{} \\
\cline { 1 - 2 } &
\end{tabular}

\section{Table 2. Dichlorohydrin Formation Data}

\subsubsection{Epoxidation Reaction and Formation of Epichlorohydrin}

The final step in the classical production process is the base-promoted epoxidation of dichlorohydrins. The reactor is essentially a stripping column heated to approximately $100{ }^{\circ} \mathrm{C}$ (Figure 5). The aqueous effluent from the previous step enters the top of the column along with a stream of aqueous base (e.g. sodium hydroxide). The base deprotonates the available alcoholic proton allowing for a collapse of this anion by displacement of an adjacent chlorine atom (Figure 6). Steam passes upwards through the column to immediately volatilize any epichlorohydrin that is formed. This is done to prevent any unwanted side reactions between the base and product. Water, sodium chloride, and any unreacted starting materials wash down the column and are recycled or disposed of as waste.

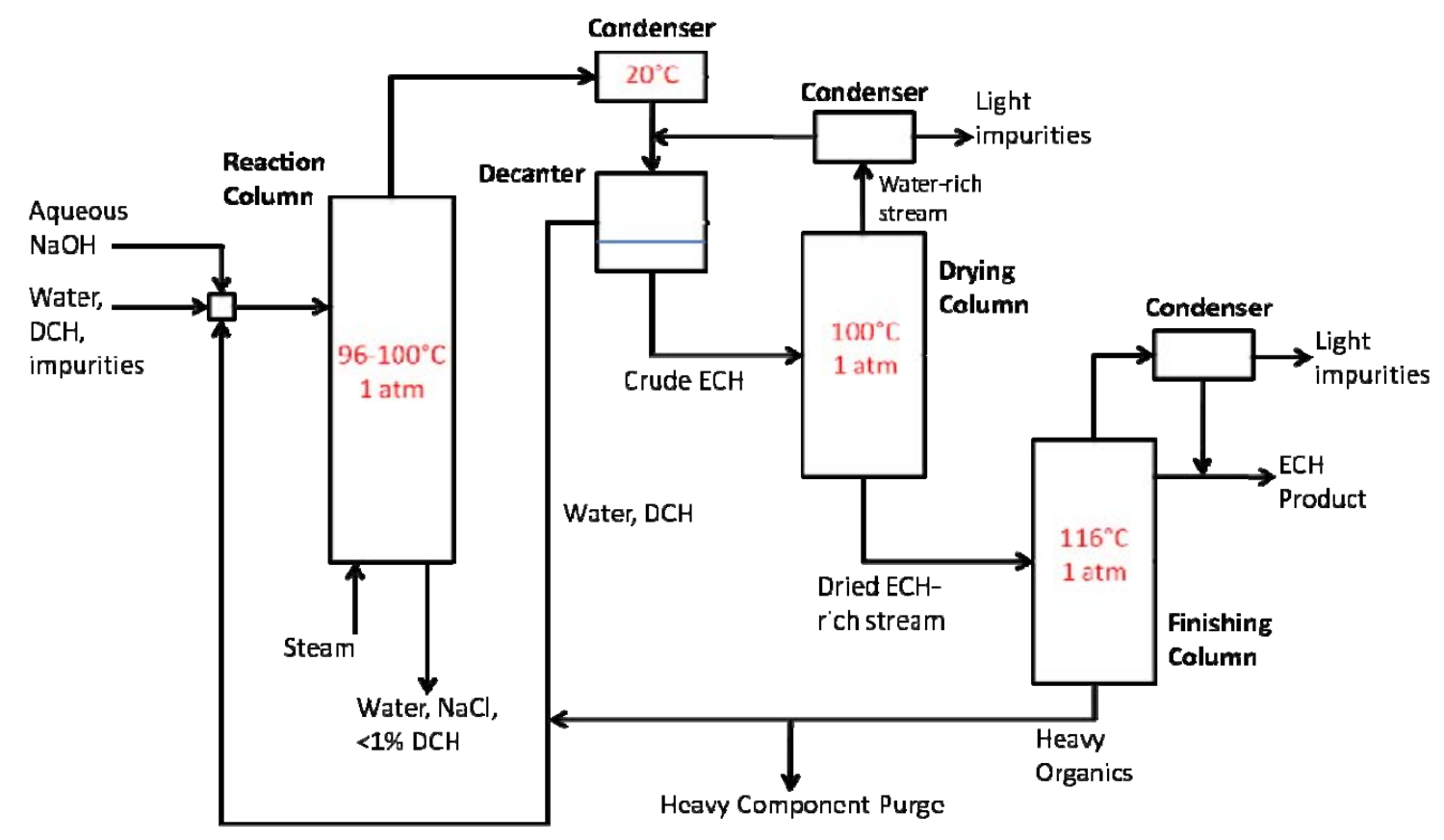

Figure 5. Epoxidation Reactor Assembly 


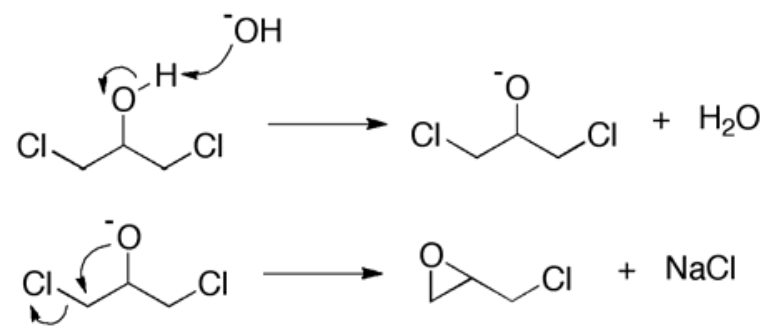

Figure 6. Mechanism for Epoxidation Reaction

The gaseous product and steam mixture is condensed, allowed to separate into a biphasic mixture, decanted, and distilled twice more to obtain the final product.

\begin{tabular}{|l|l|}
\hline Reactor Type: Distillation/stripping column & Base Feed Rate: 1.2 equiv/mol DCH \\
\hline Reactor Feed Temperature: $25^{\circ} \mathrm{C}$ & Product Concentration in Effluent: $4 \% \mathrm{wt}$ \\
\hline Reactor Temperature: $97^{\circ} \mathrm{C}$ & Epichlorohydrin Yield: $93 \%$ \\
\hline Reactor Pressure: $1 \mathrm{~atm}$ & Base Storage Conditions: $25^{\circ} \mathrm{C}, 1 \mathrm{~atm}$ \\
\hline Reactor Residence Time: 20 minutes & \multicolumn{2}{|l}{} \\
\cline { 1 - 2 } &
\end{tabular}

Table 3. Epoxidation Data

\subsubsection{Glycerol-based Epichlorohydrin Production}

Between 1.7 and 2.3 billion pounds of soybean oil are used for the production of biodiesel in the U.S. each year. ${ }^{1}$ Glycerol is a major byproduct of this process, and it has flooded the market and made synthetic glycerol production less profitable. In point of fact, Dow Chemical Company recently ended their synthetic glycerol production in the U.S. ${ }^{6}$ That volume of biodiesel equates to approximately 150-250 million pounds of glycerol produced each year.

In response to this change in the market, glycerol utilization is an active area of research in industry and academia, especially in the area of epichlorohydrin production. ${ }^{8-15}$ Dow Chemical Company currently operates two glycerol-to-epichlorohydrin plants: a pilot-scale plant in Germany, and a 150,000 metric ton per year plant in Shanghai. Solvay S. A. operates two facilities in France and Thailand at 15,000 metric tons and 100,000 metric tons respectively. Spolchemie operates a single facility in the Czech Republic at 15,000 metric tons per day.

The glycerol-based production of epichlorohydrin removes the need for $\mathrm{Cl}_{2}$ by supplanting two initial reaction steps with one single step and maintains the known technology for Dichlorohydrin-to-Epichlorohydrin (Figure 7). This technology was published by Dow Chemical Company in a recent issue of Clean. ${ }^{8}$ Dozens of patents by various authors have been added to the literature with variants and improvements to this process ${ }^{9-15}$. Because the second step of this process is essentially the same as the previous method, it will not be discussed at length. 


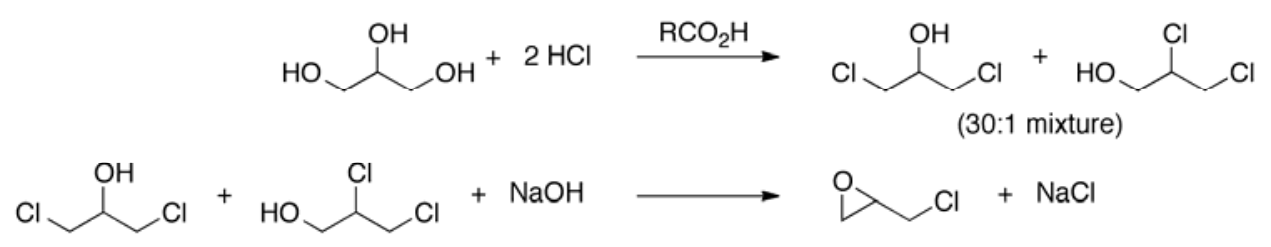

Figure 7. Epichlorohydrin from Glycerol

\subsubsection{Glycerol to Dichlorohydrin Reaction}

Dow and Solvay differ in their approaches to this process, so each will be discussed concurrently to highlight the differences.

Both processes make use of a CSTR as the reactor assembly. The content is predominantly glycerol and dichlorohydrin product with an added carboxylic acid (e.g. acetic acid, adipic acid) used as a catalyst. The function of the catalyst is shown in Figure 8. The Dow process uses anhydrous/gaseous hydrochloric acid pressurized over the liquid phase of the reaction medium. Solvay uses diluted aqueous hydrochloric acid to aid mixing with the glycerol. In both cases, the reaction takes place in the liquid phase.

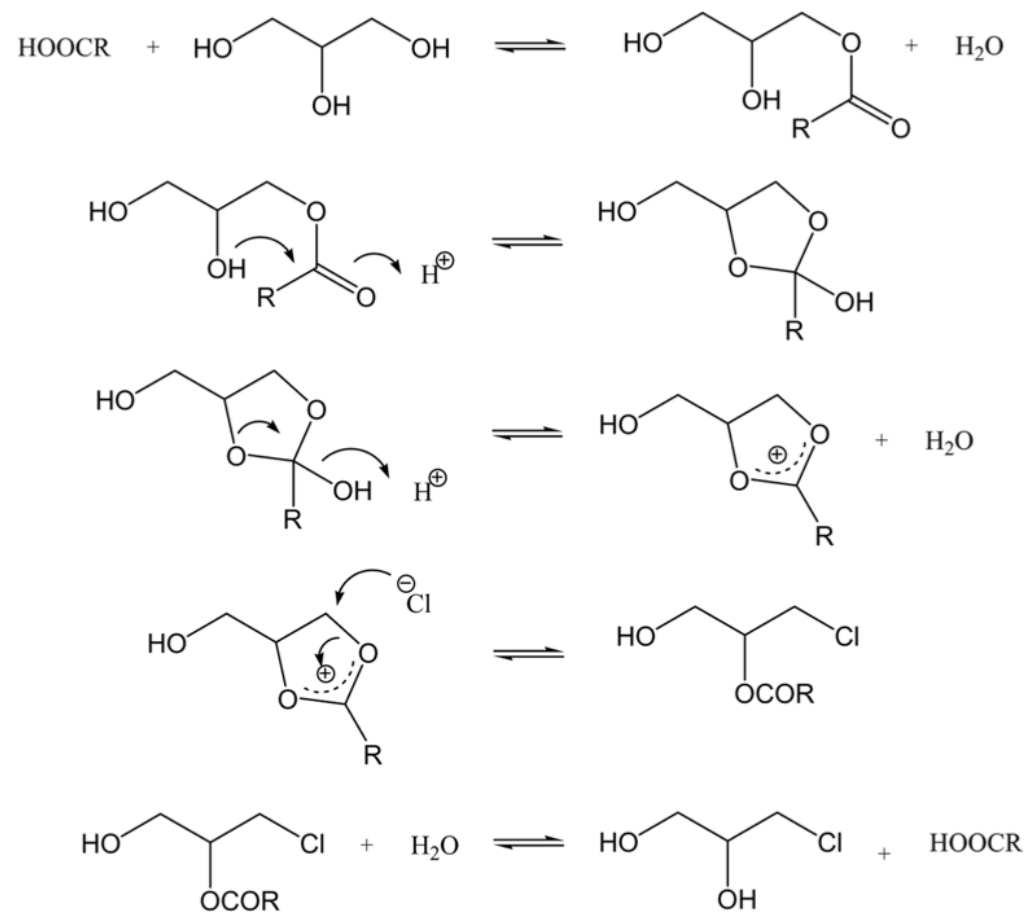

Figure 8. Mechanism of Catalyst Action on Glycerol

As one might assume, pressure of $\mathrm{HCl}$ in the Dow process will play a significant role in the rate of reaction. Residence times are on the order of 2 hours. In the Solvay process, a decreased rate of reaction is seen based on dilution of the acid leading to a residence time on the order of 20 hours. The mixture in both cases is taken on directly to the epoxidation reaction that is described 
in section 5.3.1.3.

\begin{tabular}{|l|l|}
\hline Reactor Temperature: 90-120 C & Reactor Temperature: $90-120$ C \\
\hline Reactor Pressure: $90-120$ psi & Reactor Pressure: ambient \\
\hline Reactor Residence Time: 2 hours or less & Reactor Residence Time: 20 hours \\
\hline Anhydrous HCl Feed Rate: 1-25 mol\% & Aqueous HCl Feed Rate: Stoichiometric \\
\hline Dichlorohydrin Yield from Glycerol: $93 \%$ & Dichlorohydrin Yield from Glycerol: $93 \%$ \\
\hline HCl Storage Temperature: ambient & HCl Storage Temperature: ambient \\
\hline HCl Storage Pressure: & HCl Storage Pressure: ambient \\
\hline
\end{tabular}

Table 4. Glycerol Conversion Data

\subsection{Comparison of Technologies}

\subsubsection{Summary}

This change in epichlorohydrin production technology is an interesting example of market evolution driving innovation. And more specifically for this study, it shows a clear benefit in safety and security. Our team has come to this conclusion by comparing the two production methods and semiquantitatively examining the toxicology, chemical properties, scale, and other relevant data contained in this document, the cited references, and the attached supplementary information. This was also checked using the CSAC/ABS Consulting Metrics to verify that there was indeed a decrease in the hazard by moving to a glycerol-based process (see section 5.4.2).

As a qualitative summary, a comparison of propylene and glycerol shows volatility and combustibility are drastically reduced. Waste streams containing chlorine are reduced from three equivalents to one equivalent per equivalent of product formed. Fewer steps for the glycerol process allow for a smaller facility footprint with fewer components decreasing the potential for accidental release points.

5.4.2. CSAC/ABS Consulting Star Charts 


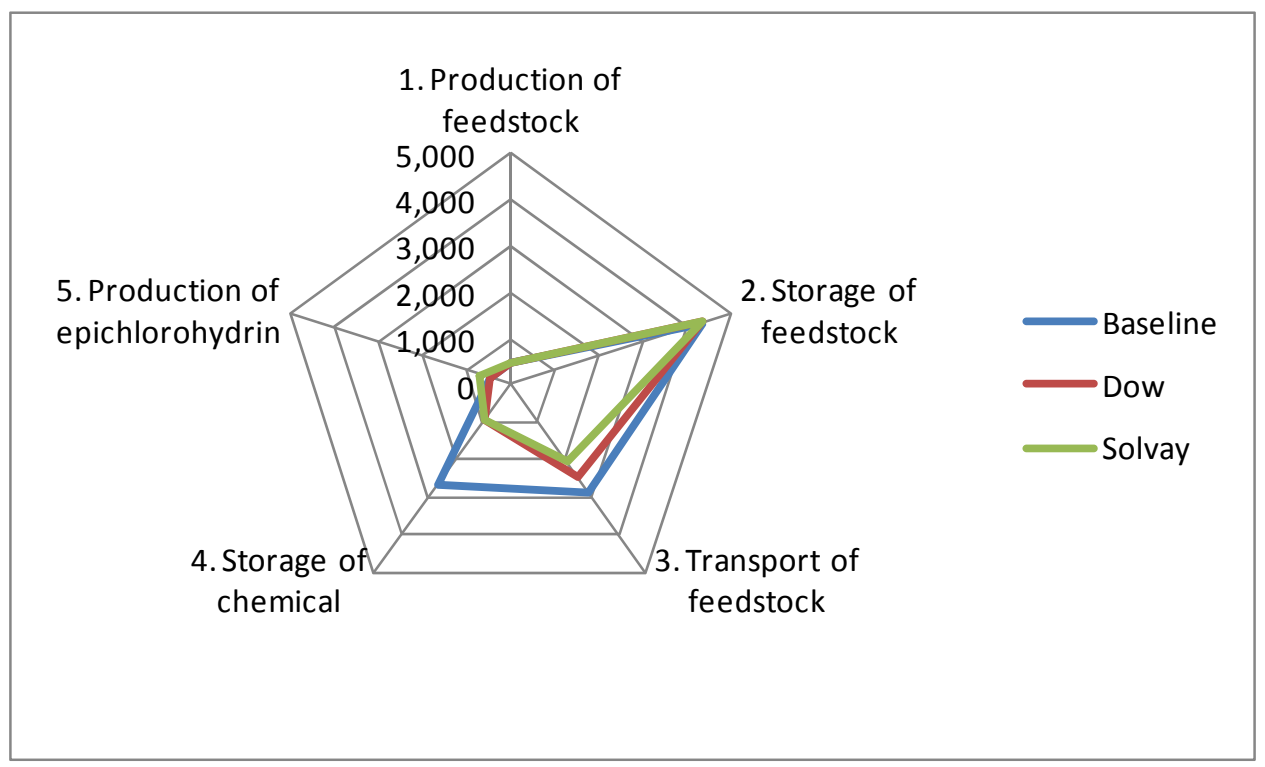

Chart 1. Epichlorohydrin Star Chart

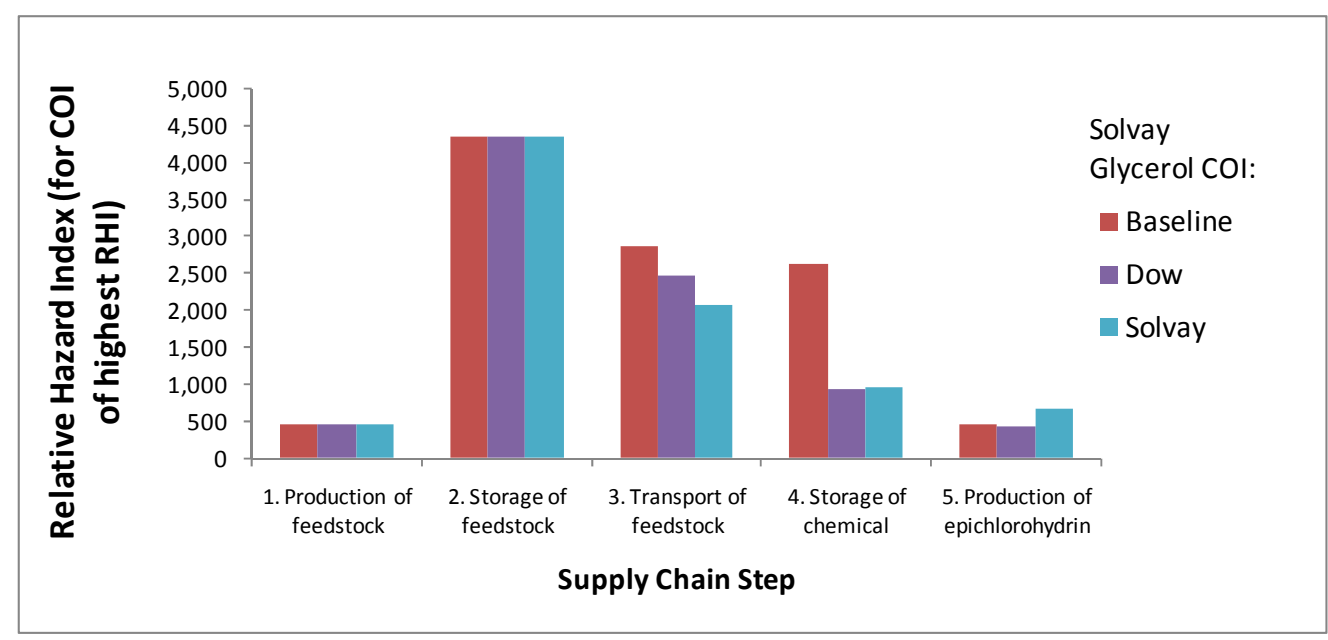

Chart 2. Epichlorohydrin Bar Chart

\subsection{References}

1. SRIC Chemical Economic Handbook, 2010.

2. Guenter Sienel, Robert Rieth, Kenneth T. Rowbottom. "Epoxides". Ullmann's Encyclopedia of Industrial Chemistry, 2005. Wiley-VCH.

3. Ludger Krahling, Jurgen Krey, Gerald Jakobson, Johann Grolig, Leopold Miksche. "Allyl Compounds". Ullmann's Encyclopedia of Industrial Chemistry, 2005. Wiley-VCH.

4. “Epichlorohydrin.” Wikipedia. 20 March 2011. Web. 21 April 2011. $<$ http://en.wikipedia.org/wiki/Epichlorohydrin>.

5. “Epoxy Resin.” Wikipedia. 12 April 2011. Web. 15 March 2011. $<$ http://en.wikipedia.org/wiki/Epoxy_resin>.

6. Dow Epichlorohydrin Product Stewardship Manual, Dow Chemical Company, 2007.

7. “Chlorohydrins.” W. Frank Richey. Kirk-Othmer Encyclopedia of Chemical Technology, 2000. Wiley-Interscience. 
8. "Glycerin as a Renewable Feedstock for Epichlorohydrin Production. The GTE Process." Bruce M. Bell, John R. Briggs, Robert M. Campbell, Susanne M. Chambers, Phil D. Gaarenstroom, Jeffrey G. Hippler, Bruce D. Hook, Kenneth Kearns, John M. Kenney, William J. Kruper, D. James Schreck, Curt N. Theriault, Charles P. Wolfe. Clean 2008, 36, 657.

9. British Patent 974,164.

10. US Patent Application 2010/0331555 A1

11. US Patent $2,177,419$

12. Arceo, E.; Marsden, P.; Bergman, R. G.; Ellman, J. A. Chem. Commun. 2009, 3357.

13. Corma, A.; Iborra, S.; Velty, A. Chem. Rev. 2007, 107, 2411-2502.

14. Arceo, E.; Ellman, J. A.; Bergman, R. G. J. Am. Chem. Soc. 2010, 132, 11408-11409.

15. Nagato, N.; Mori, H.; Maki, K.; Ishioka, R. US Patent 4,634,784; 1987. 
[Blank page following section.] 


\section{IST SEARCH IN HYDROGEN CYANIDE-DERIVED CHEMICALS}

\subsection{Introduction}

The nitrile (CN) functional group is a versatile moiety for synthetic chemistry. It is easily installed from sources such as hydrogen cyanide, cyanide salts, or ammoxidation processes and transformed into other valuable functional groups such as carboxylic acids $(\mathrm{COOH})$, esters (COOR), ketones, aldehydes, and amides. In this way, the nitrile group is used as a single carbon atom source and the nitrogen atom is disposed of as waste. While this is a convenient way of obtaining a single carbon atom, it necessitates the use of toxic CN-containing molecules, introduces the possibility of explosive "runaway" reactions, involves energy intensive processes, and creates nitrogenous waste streams.

For these reasons, CSAC directed our team to explore IST alternatives in chemistries that employ hydrogen cyanide. Within the cyanide supply chain, our analysis highlighted large-scale chemical production methods for methyl methacrylate and methionine that could benefit from the adoption of IST alternatives. This chapter will discuss the current technology associated with each of these chemicals and hydrogen cyanide followed by a detailed discussion of the IST alternatives and why they are improvements on the previous processes.

\subsection{Hydrogen Cyanide Classical Production}

Domestically, hydrogen cyanide is made by two related methods. Both of these methods are grouped together as ammoxidation processes: the production of nitriles using ammonia and oxygen. A carbon source is subjected to these compounds in the presence of a catalyst at high temperature to induce the ammoxidation of the carbon substrate.

To directly form hydrogen cyanide, methane is the carbon substrate, and it is subjected to temperatures as high as $1200{ }^{\circ} \mathrm{C}$ at one atmosphere in the presence of ammonia and oxygen. This process is also known as the Andrussow process and uses a platinum mesh catalyst. Yields of $70 \%$ are typical for this process based on methane. See Figure 1 for a depiction of the Andrussow process components. 


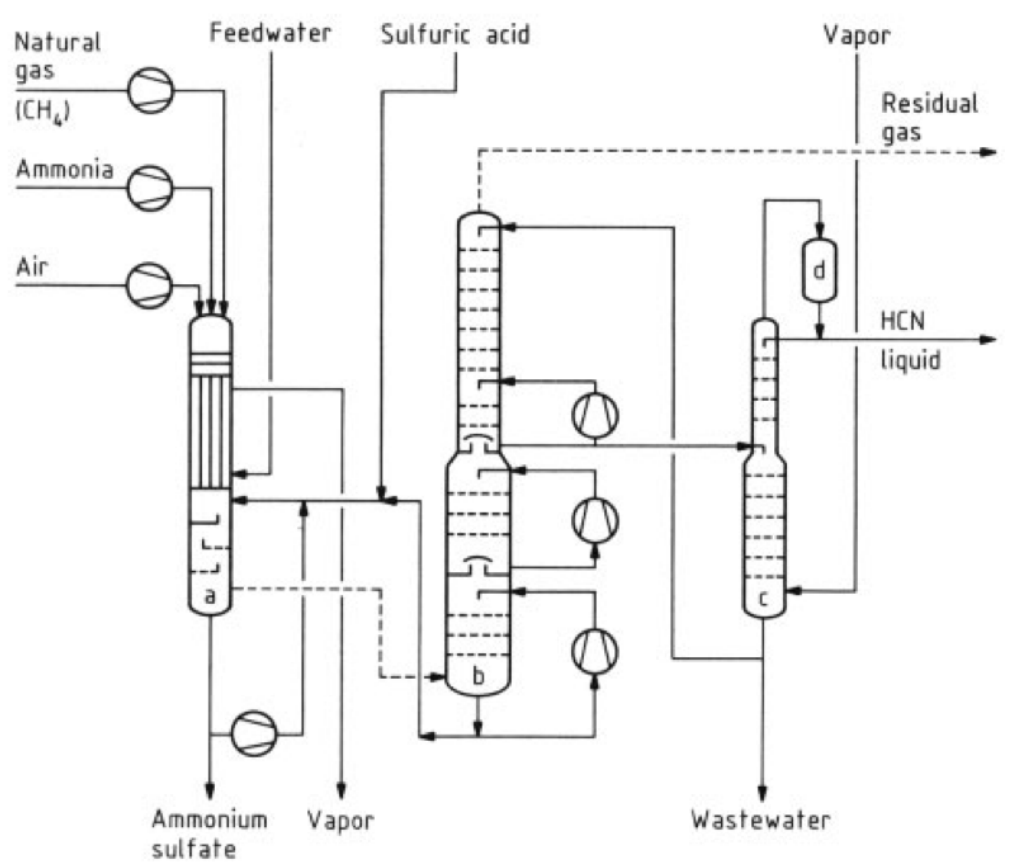

Figure 1. Andrussow Process Diagram

Another important source of hydrogen cyanide is generated by the ammoxidation of propylene to form acrylonitrile. Approximately $10 \%$ of the propylene is cleaved to yield one equivalent each of acetonitrile and hydrogen cyanide. The conditions in this process are less severe than the methane-based process because the hydrogen bonds adjacent to the $\pi$-bond are activated. This also leads to the decomposition pathway that generates acetonitrile and hydrogen cyanide. The conditions are specifically $450{ }^{\circ} \mathrm{C}$ and one atmosphere, and a molybdate-based catalyst is used.

Both methods purify the hydrogen cyanide using standard industrial methods: absorption tower, distillation, and condensation. The purified product is then piped into the desired process directly. Storage is normally avoided when possible.

\subsection{Methyl Methacrylate Classical Production}

\subsubsection{Overview of $M M A$}

Methyl Methacrylate (MMA) is an important chemical in plastics manufacturing. It is typically thought of as a monomer for polymerization with itself or co-monomers to generate copolymers. Some general applications include cast and extruded acrylic sheet (Plexiglas); surface coatings such as paints, urethanes water-based and solvent-based dispersions; and copolymers with styrene and other monomers.

The current market for methyl methacrylate operates at a scale of approximately six billion pounds. The United States is the largest consumer (20.5\%) with Europe (17.8\%), China (15.5\%), and Japan (11.7\%) as the next top consumers. Domestically, the United States is home to four production facilities operated by three companies. Evonik CYRO (Waggaman, LA) and Dow Chemical Company (Deer Park, TX) produce methyl methacrylate for polymethyl methacrylate 
(PMMA). Dow produces approximately 460,000 tonnes and Evonik produces 149,000 tonnes. Lucite International produces a total of 333,000 tonnes between its two facilities in Beaumont, TX and Memphis, TN. This methyl methyacrylate is sold to other consumers as the monomer. Approximately $25 \%$ of this MMA is exported to countries such as Mexico, Taiwan, Belgium, and Canada.

\subsubsection{Acetone Cyanohydrin Method}

There are three commercially viable methods operating globally, but only the Acetone Cyanohydrin (ACH) method is used domestically. The acetone cyanohydrin process is so named because that chemical is an important intermediate in the synthetic scheme (Figure 2). Acetone cyanohydrin is synthesized by the base-catalyzed condensation of HCN with acetone. The base is typically an alkali hydroxide. The reactor is a series of continuously stirred tank vessels kept at a temperature of $5-10{ }^{\circ} \mathrm{C}$ and one atmosphere with a residence time of one and a half hours. The effluent from the reactor is piped directly into the next step where sulfuric acid is used to transform the nitrile into an amide functional group.

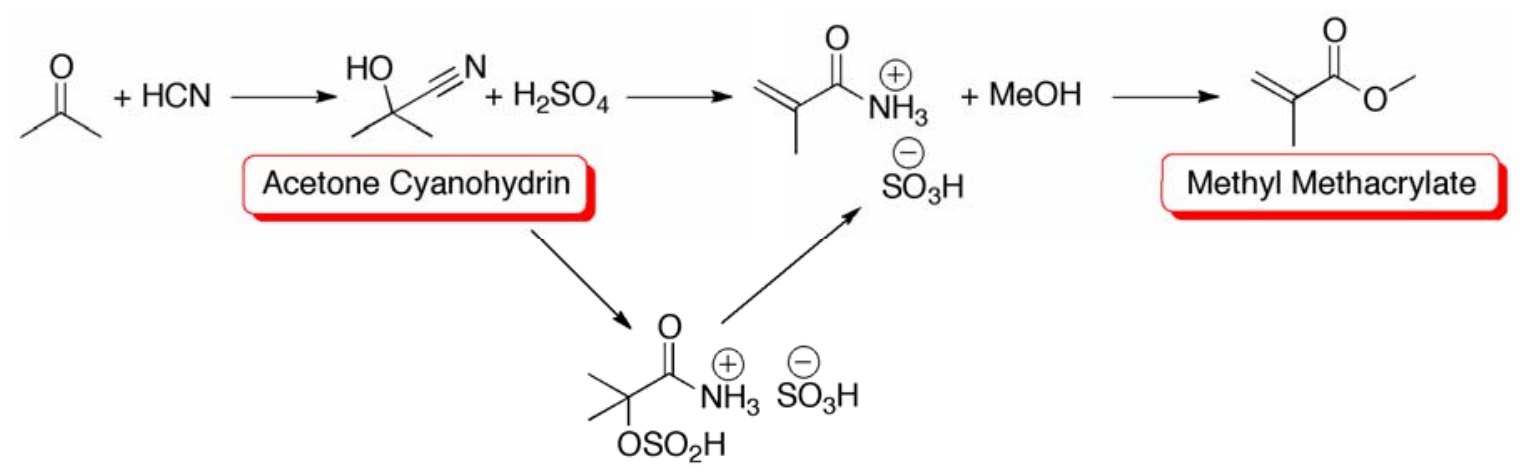

Figure 2. Acetone Cyanohydrin Method

Acetone cyanohydrin in a mixture of water is combined with excess sulfuric acid to hydrolyze the nitrile down to the amide functional group. This reaction is performed in a series of CSTRs at $150{ }^{\circ} \mathrm{C}$ and one atmosphere. A residence time of one hour is typical, and the methacrylamide sulfate product is piped directly to the next stage of the reactor.

Methacrylamide sulfate is combined with a four-fold excess of methanol at $100{ }^{\circ} \mathrm{C}$ and one atmosphere to generate the final product (Figure 3). Residence times are slightly longer in this stage at four hours, and the product is purified using standard methods such as stripping and distillation columns. 


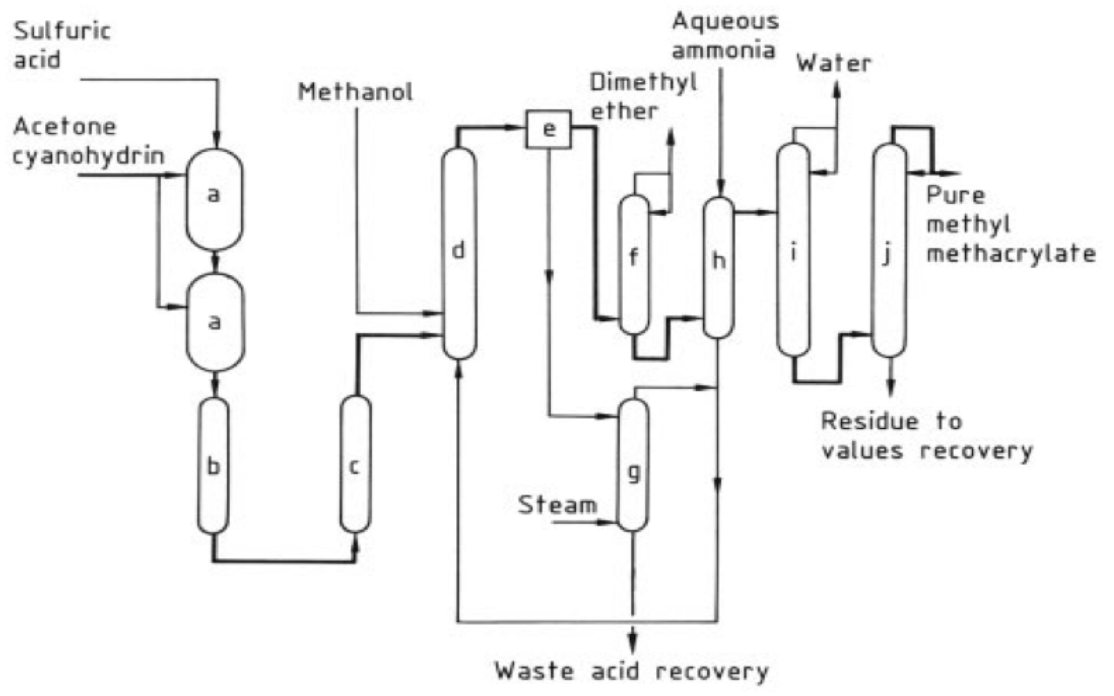

Figure 3. ACH to MMA Reactor Components

Based on a facility of 20,000 tons per year production, our team has calculated the necessary quantities of starting materials on a daily basis.

$\begin{array}{ll}\text { Methane: } & 35,300 \text { pounds } \\ \text { Ammonia: } & \text { 37,500 pounds } \\ \text { Acetone: } & 90,200 \text { pounds } \\ \text { Sulfuric Acid: } & \text { 222,800 pounds } \\ \text { Methanol: } & 173,400 \text { pounds } \\ \text { HCN: } & \text { 42,000 pounds (intermediate) } \\ \text { ACH: } & 130,000 \text { pounds (intermediate) }\end{array}$

Reactor quantities are also included, along with the calculations, in the electronic supplementary information; filename "MMA-HCN Synthesis v2.xlsx".

The domestic facilities that operate using this method are completely integrated except for the elements of HCN generation. In regards to HCN generation, the economics of acrylonitrile can affect the supply chain forcing the purchase of HCN from off-site necessitating shipping. If this is the case, it has been determined that several days of operating inventory would likely be stored. In the normal operating conditions, interim storage within the process is constantly fluctuating, but the quantity is on the order of several hours of inventory at full capacity.

\subsubsection{Mitsubishi Gas Company Method}

The production of ammonium bisulfate and necessary acid inventories has fueled development of new methods that use solid catalysts and recycle waste products. One method that has been adopted is the Mitsubishi Gas Company (MGC) method. This process replaces sulfuric acid with a solid acid catalyst and reforms HCN from the waste stream.

The MGC method borrows the initial HCN production and ACH formation technology from the classical ACH method. Three new steps are needed convert the ACH to MMA and one 
additional step to reform HCN (Figure 4). The recycle step here is not quantitative, and replenishment of virgin hydrogen cyanide is still needed. That quantity has not been determined and most likely varies by plant-to-plant based on reactor design, age, and size.

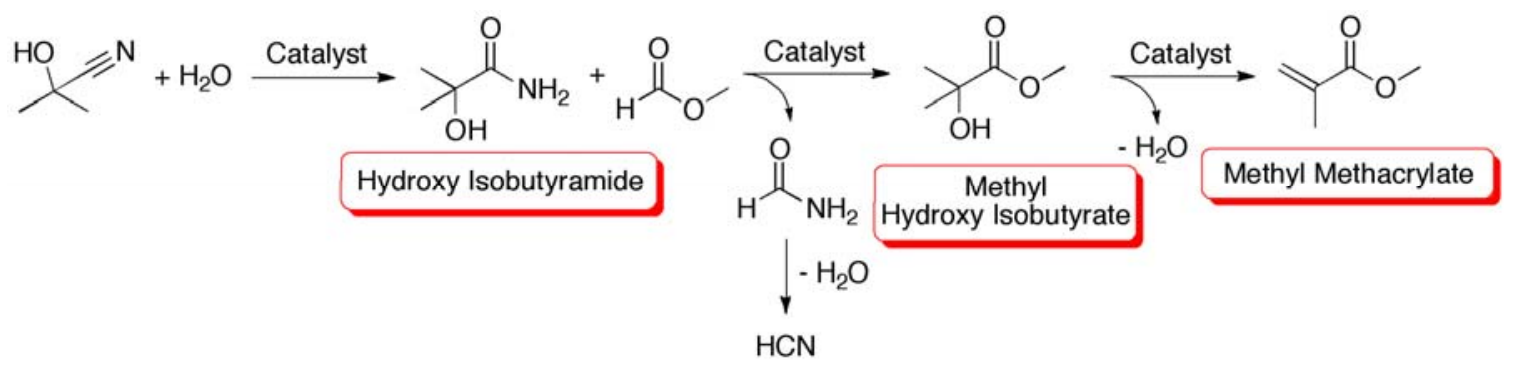

Figure 4. Mitsubishi Gas Company MMA Production

For details of the acetone cyanohydrin production, see section 6.3.2. "Acetone Cyanohydrin Method". Once ACH has been produced, it is taken on to a liquid-phase CSTR vessel stirred over a bed of $\mathrm{MnO}_{2}$ to achieve hydrolysis. The reactor is set to $60{ }^{\circ} \mathrm{C}$ and one atmosphere. The majority of this reaction mixture is water (10-fold excess) with added acetone to reduce any decomposition pathways of ACH. This hydrolysis forms the neutral amide Hydroxy Isobutyramide (Figure 5).

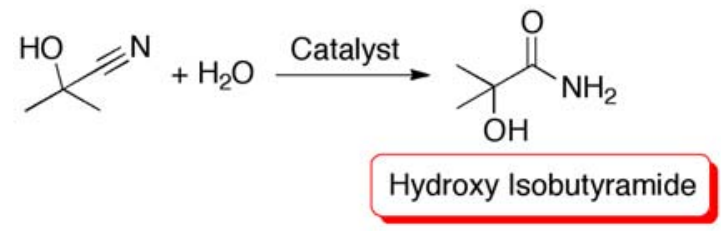

Figure 5. ACH to Hydroxy Isobutyramide

The aqueous product mixture from this reactor is sent to a $60{ }^{\circ} \mathrm{C}$ pressurized vessel $(40$ atmospheres) where it is mixed with carbon dioxide gas, a metal oxide or alkoxide catalyst, and methanol. The methanol and carbon dioxide form methyl formate that serves to transform the hydroxy isobutyramide into an ester (Figure 6). The reactor operates at such high pressures to ensure a large quantity of carbon dioxide is dissolved in the aqueous solution. The pressure here has a direct positive correlation to the kinetics of product formation.

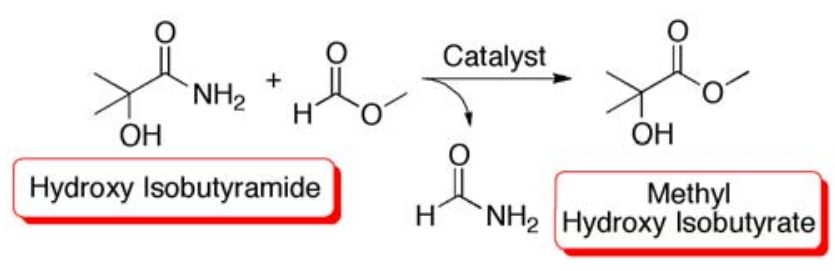

Figure 6. Methyl Hydroxy Isobutyrate Formation

After the methyl hydroxy isobutyrate has been formed, the product is separated by distillation and stripping columns. It is then passed over a zeolite catalyst in the gas phase at $260{ }^{\circ} \mathrm{C}$ and one atmosphere to give methyl methacrylate in $90 \%$ yield (Figure 7). A co-feed of methanol is 
necessary in this step to prevent carboxylic acid formation and a reduction in the yield.

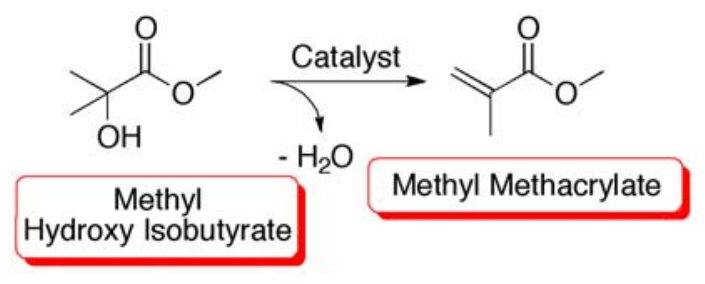

Figure 7. Gas-phase Formation of MMA

The key step in this process that differentiates it from other solid acid catalyst methods is the HCN recycle. During the amide-to-ester step where methyl hydroxy isobutyrate is formed, a waste stream of formamide is generated. This formamide can be dehydrated over a zeolite catalyst in the gas phase at 0.1 atmospheres and $520^{\circ} \mathrm{C}$ with a small co-feed of air (Figure 8). This regenerates hydrogen cyanide that can then be dried and pulled back into the acetone cyanohydrin formation process.

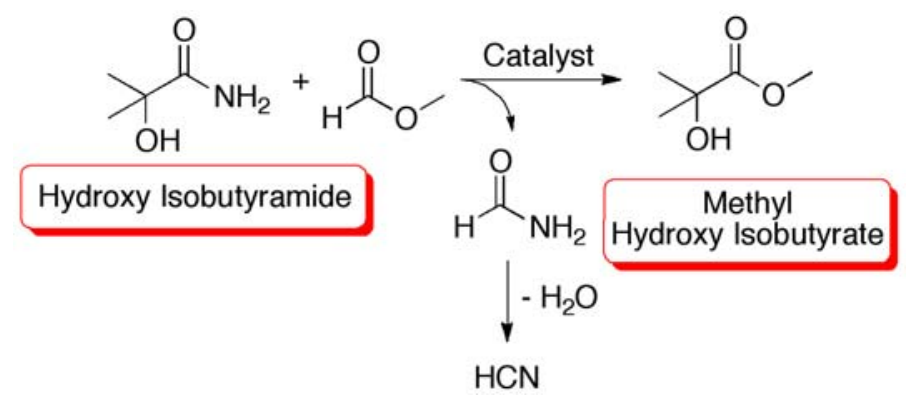

Figure 8. HCN Recycle by Decomposition of Formamide Waste

The necessary daily amounts for this process for a 20,000 ton per year MMA process are listed below.

$\begin{array}{ll}\text { Methane: } & 35,300 \text { pounds } \\ \text { Ammonia: } & 37,500 \text { pounds } \\ \text { Acetone: } & 168,700 \text { pounds } \\ \text { Methanol: } & 200,700 \text { pounds } \\ \mathrm{CO}_{2}: & 175,400 \text { pounds } \\ \mathrm{HCN}: & 42,000 \text { pounds (intermediate) } \\ \text { ACH: } & 130,000 \text { pounds (intermediate) } \\ \text { Isobutyramide: } & 161,600 \text { pounds (intermediate) } \\ \text { Isobutyrate: } & 155,900 \text { pounds (intermediate) } \\ \text { Formamide: } & 74,900 \text { pounds }\end{array}$

Reactor quantities are also included, along with the calculations, in the electronic supplementary information; filename "MMA-Mitsubishi Synthesis.xlsx".

The Mitsubishi Gas Company method achieves its goals of reducing acid and waste inventories 
by using a solid acid catalyst and a recycle loop. However, the complexity of the process has increased with the addition of new steps in the synthetic scheme as compared to the classical ACH method.

\subsubsection{C-4 Method}

Alternative methods for making methyl methacrylate without the need for hydrogen cyanide are driven by alternative sources of carbon. Ethylene and butylene are two sources that have been exploited on a commercial scale. Currently, the method using isobutene/isobutanol is viewed by some as the safest route to methyl methacrylate. Four commercial facilities are operating in japan (Mitsui Chemicals, Mitsubishi Rayon, and Sumitomo Chemical).

This method involves two basic steps: oxidation of the carbon source and esterification to give the final product, methyl methacrylate (Figure 9, Figure 10).

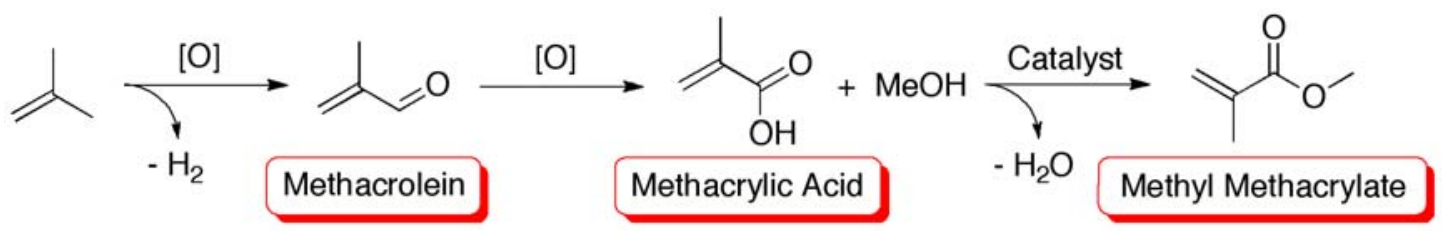

Figure 9. Isobutene to Methyl Methacrylate Scheme

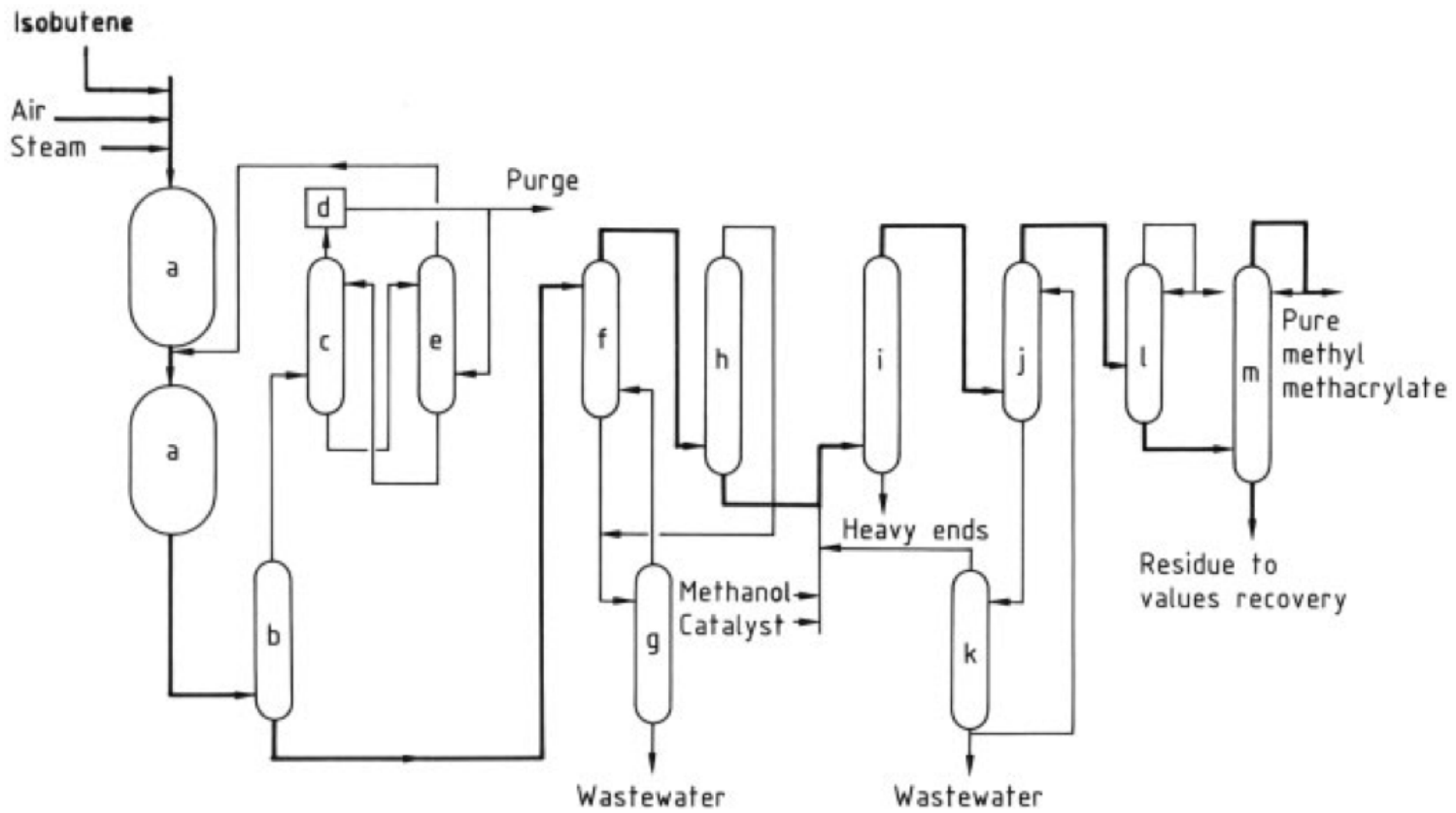

Figure 10. Isobutene to MMA Process Components

The process for oxidation of hydrocarbons of all types is a gas-phase high temperature $\left(357^{\circ} \mathrm{C}\right)$ reaction at 1-2 atmospheres. The isobutene or isobutanol, a co-feed of air, and a co-feed of water are introduced to the reactor with a bed of molybdenum oxide/alkali salt catalyst capable of 
oxidizing to methacrolein. The methacrolein proceeds directly to the next flow reactor where it is further oxidized by a phosphorus/molybdenum/alkali salt catalyst to methacrylic acid. There is no holdover inventory between these processes, and purification is performed before taking on to the esterification reactor.

The esterification takes place in a CSTR-type assembly. The condensed and purified methacrylic acid is combined with a four-fold excess of methanol and a mineral acid at approximately $100{ }^{\circ} \mathrm{C}$ and 1 atmosphere. A four-hour residence time is typical of this step.

A fully integrated 20,000 ton per year MMA facility would need to operate with these daily inventories:

$\begin{array}{ll}\text { Isobutene: } & 105,800 \text { pounds } \\ \text { Methanol: } & 160,700 \text { pounds } \\ \text { Methacrylic Acid: } & 108,000 \text { pounds }\end{array}$

Reactor quantities are also included, along with the calculations, in the electronic supplementary information; filename "MMA-Butylene Synthesis.xlsx".

\subsubsection{Final Comments on MMA Processes}

Compared to the two previous methods, the C-4 process has fewer steps, fewer chemicals, less intermediate storage, and less waste. Qualitatively, we believe that this method represents an improvement in safety that should be considered when new facilities for MMA are being developed. Economics of this process and availability of isobutene are the limiting factors that prevent adoption by the industry, and it is not clear at this point why isobutene production and availability is different between Japan and the United States.

\subsubsection{CSAC/ABS Consulting Charts}




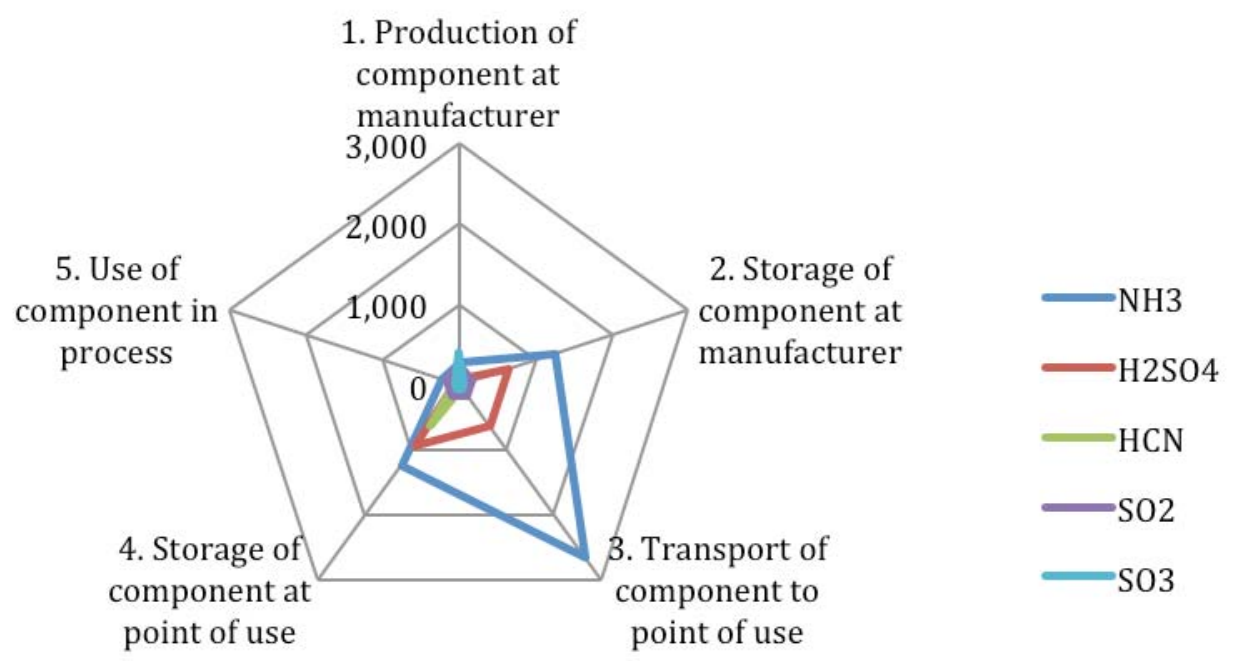

Figure 11. Classical MMA Production Star Chart

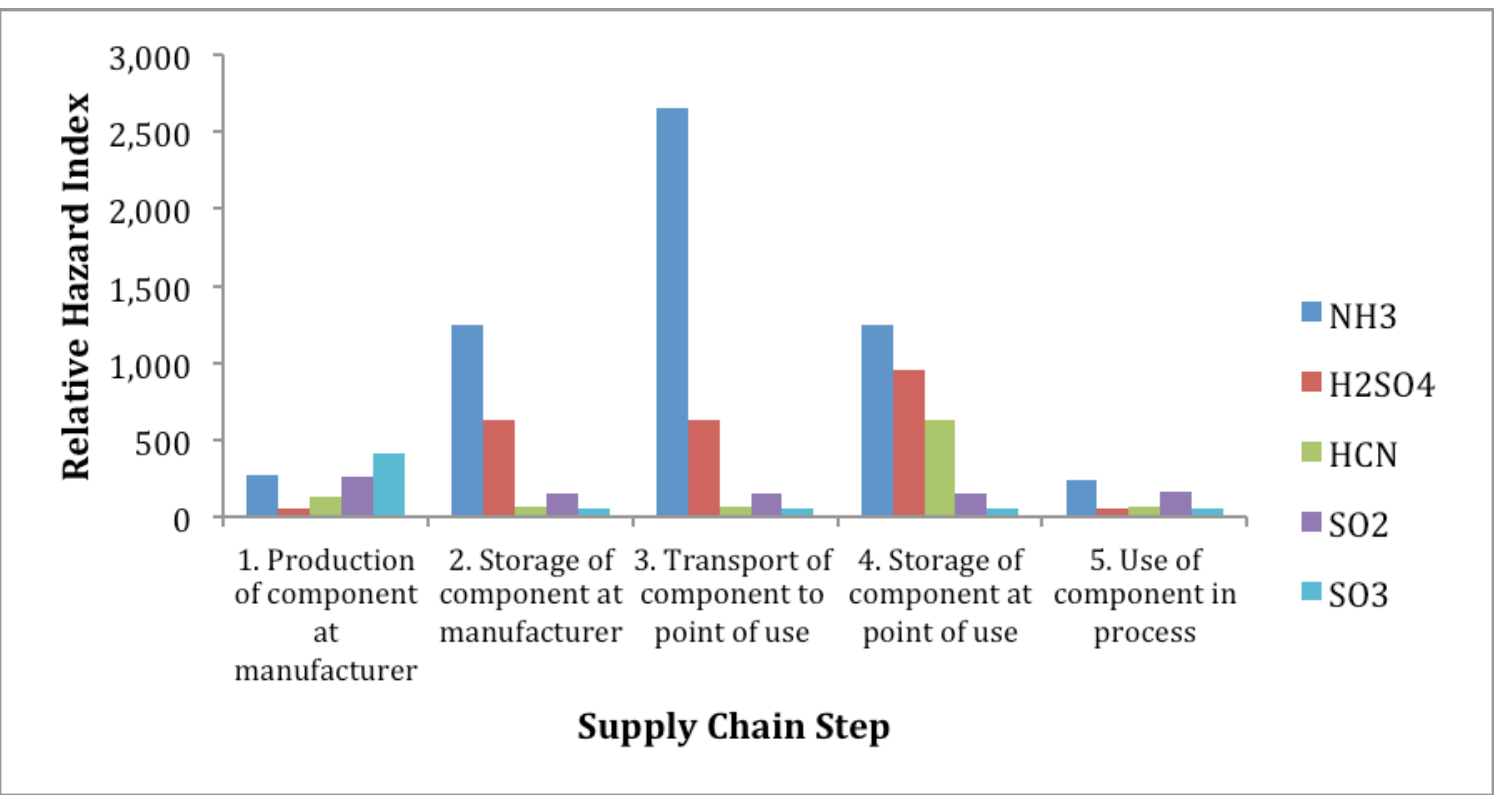

Figure 12. Classical MMA Production Bar Chart 


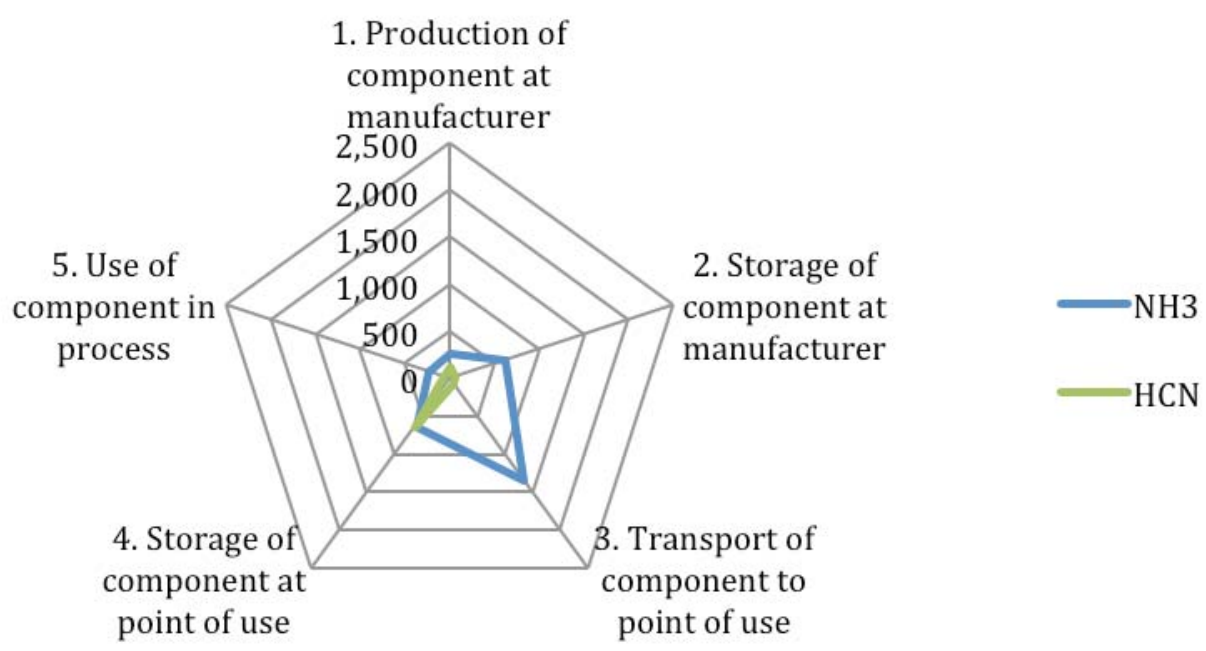

Figure 13. MGC MMA Production Star Chart

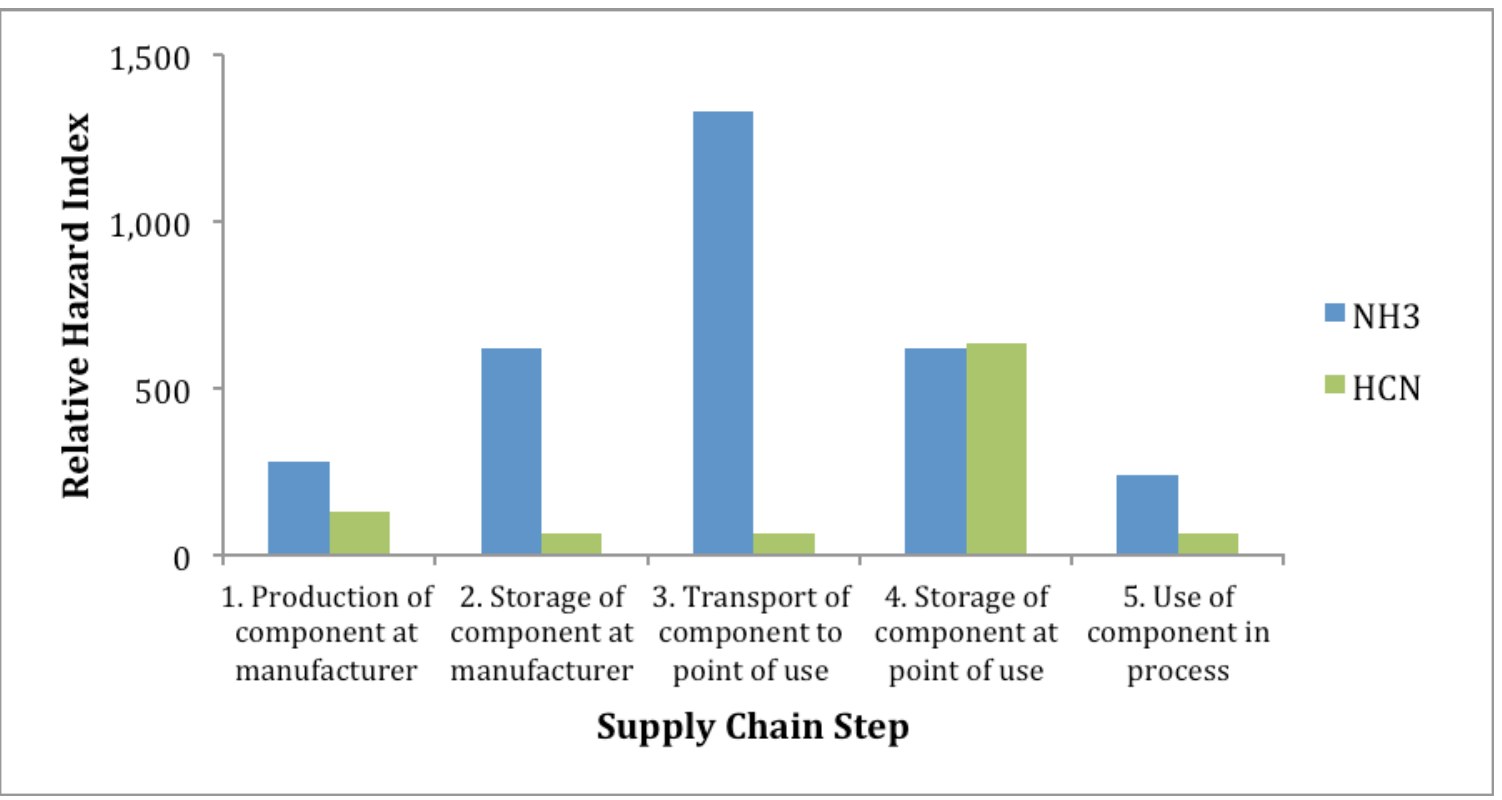

Figure 14. MGC MMA Production Bar Chart 


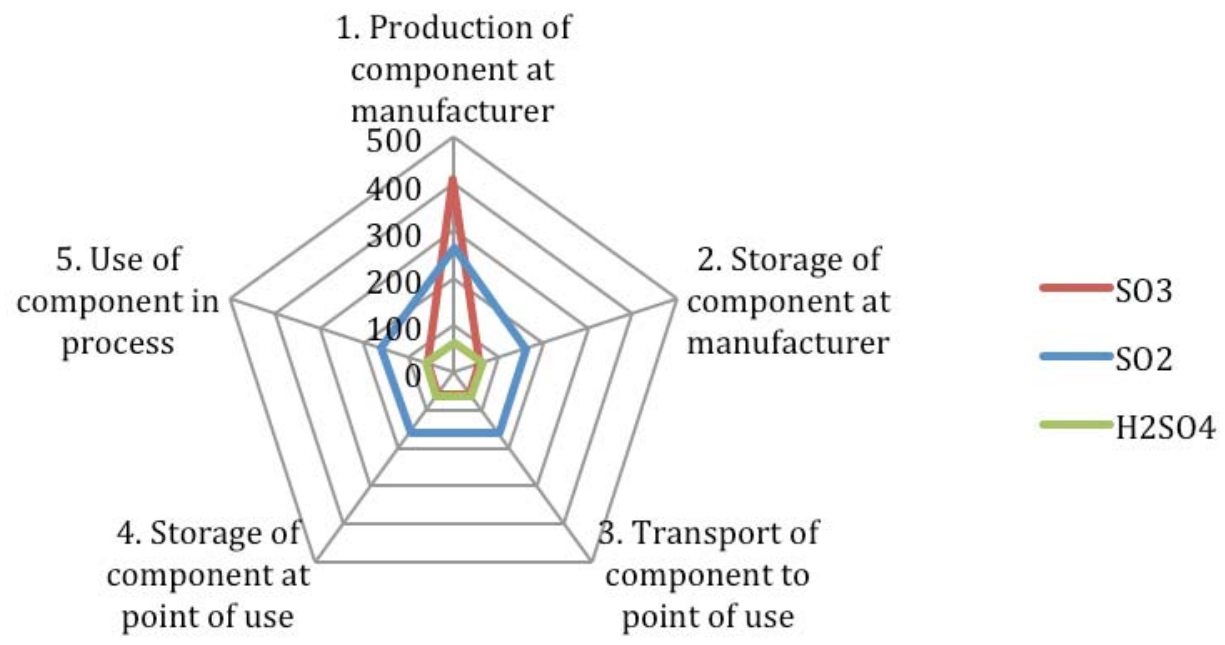

Figure 15. C-4 MMA Production Star Chart

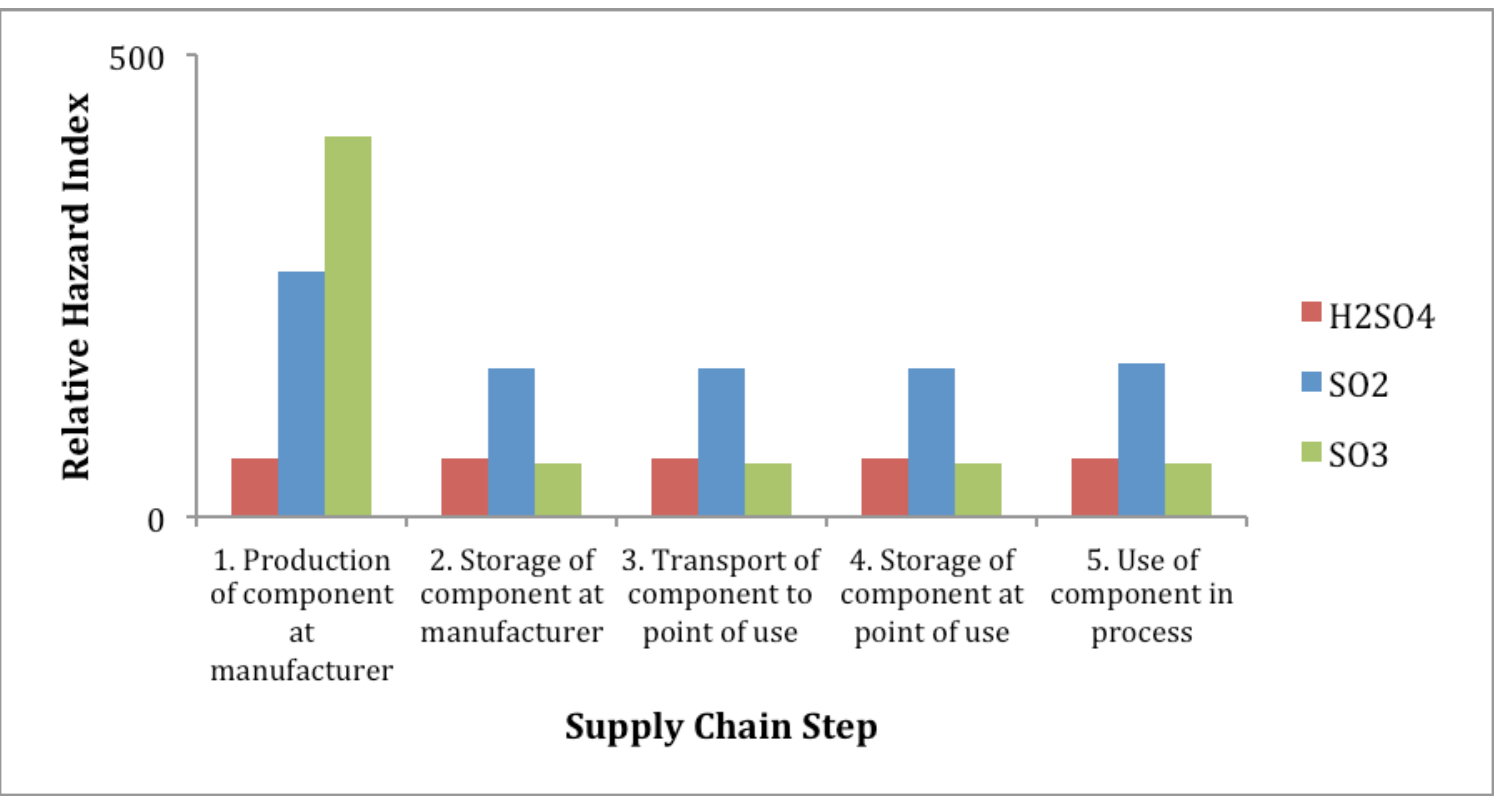

Figure 16. C-4 MMA Production Bar Chart

\subsection{Methionine Production Processes}

\subsubsection{Overview}

Methionine is the second highest produced amino acid in the world and the largest produced domestically. The United States is one of the world's top exporters. Global production of this 
chemical is approximately 700,000 metric tons with the United States producing 287,000 metric tons and exporting 146,000 metric tons. The reason for this large production volume comes from its use an animal feed supplement. It is mostly used for poultry and is formed into tablets, slowrelease formulas, aqueous solutions, or 99\% pure powders.

The chemical structure is important for chemical syntheses. Naturally occurring amino acids are produced enantiomerically pure as the L-isomer. However, the racemic ( L and R enantiomers in an equal mixture) compound is perfectly acceptable in this application, and this allows for simpler chemistries in synthesis. The hydroxy analog of methionine is also tolerated as a food supplement, and it has now become a key component of the market (Figure 17).

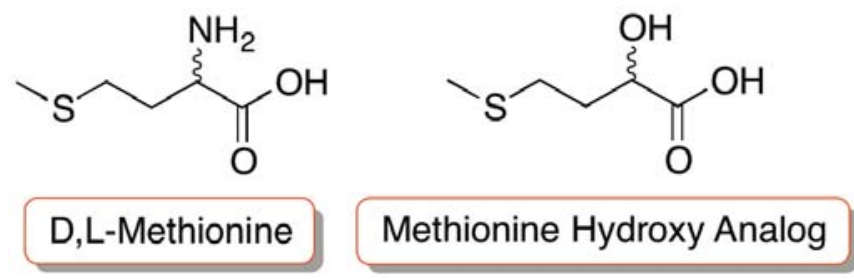

\section{Figure 17. D,L-Methionine and D,L-Methionine Hydroxy Analog}

Three major suppliers of methionine and derivatives operate in the United States. Evonik Degussa operates a 175,000 ton D,L-Methionine process in Theodore, AL. Adisseo USA has a facility in Institute, WV producing 23,000 tons of D,L-Methionine Hydroxy Analog (MHA). MHA is also made by Novus International in Alvin, TX at a 285,000 ton scale plant.

\subsubsection{Petrochemical Methionine Production}

The traditional production of methionine, and the process that is performed domestically, is a multistep operation utilizing many petrochemical feedstocks (Figure 18). The key feedstock that CSAC is concerned with here is the use of hydrogen cyanide. This chemical is consumed in an intermediate step, and the synthesis of HCN is the same as in section 6.2. This section will walk through the process from elementary building blocks to the final D,L-Methionine product.

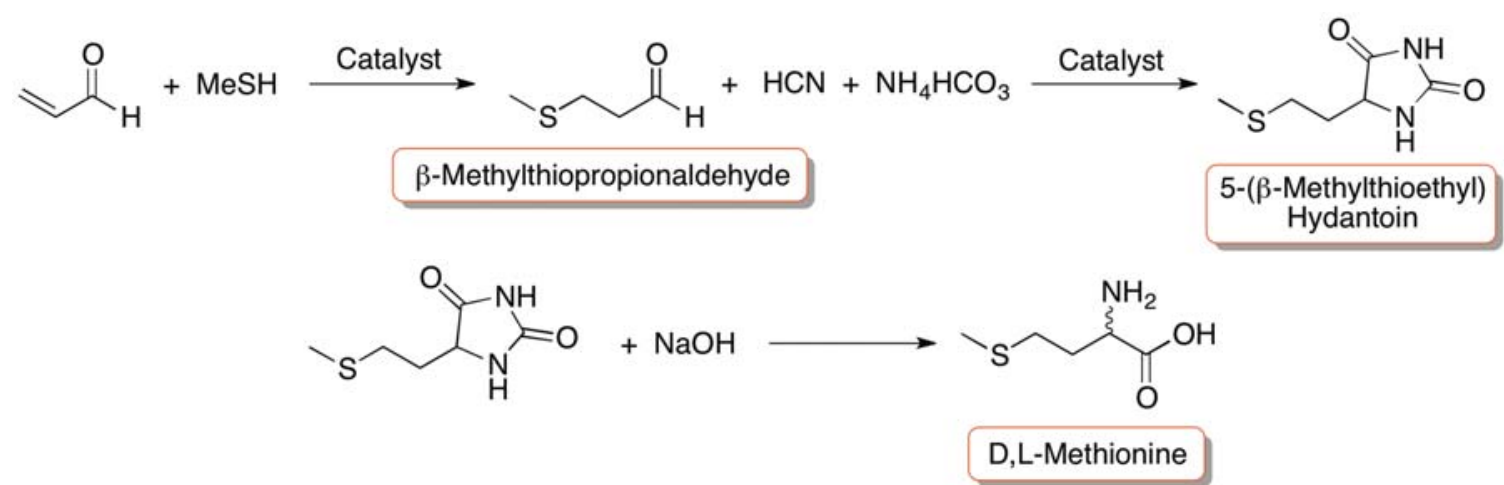

Figure 18. Classical Methionine Production

This process begins with the generation of methanethiol from methanol and hydrogen sulfide. 
Most methanethiol is generated solely for the production of methionine, and production facilities are co-located. This chemical is synthesized by a gas-phase reaction of methanol and hydrogen sulfide using a base catalyst (Figure 19). The reaction conditions here can vary considerably, but one to seven atmospheres and $300-400{ }^{\circ} \mathrm{C}$ are representative conditions (Figure 20). A residence time in the reactor of 10 seconds and a final yield of $90 \%$ are typical. The product is delivered directly to the next step.

$$
\mathrm{MeOH}+\mathrm{H}_{2} \mathrm{~S} \longrightarrow \mathrm{MeSH}+\mathrm{H}_{2} \mathrm{O}
$$

Figure 19. Methanethiol Production

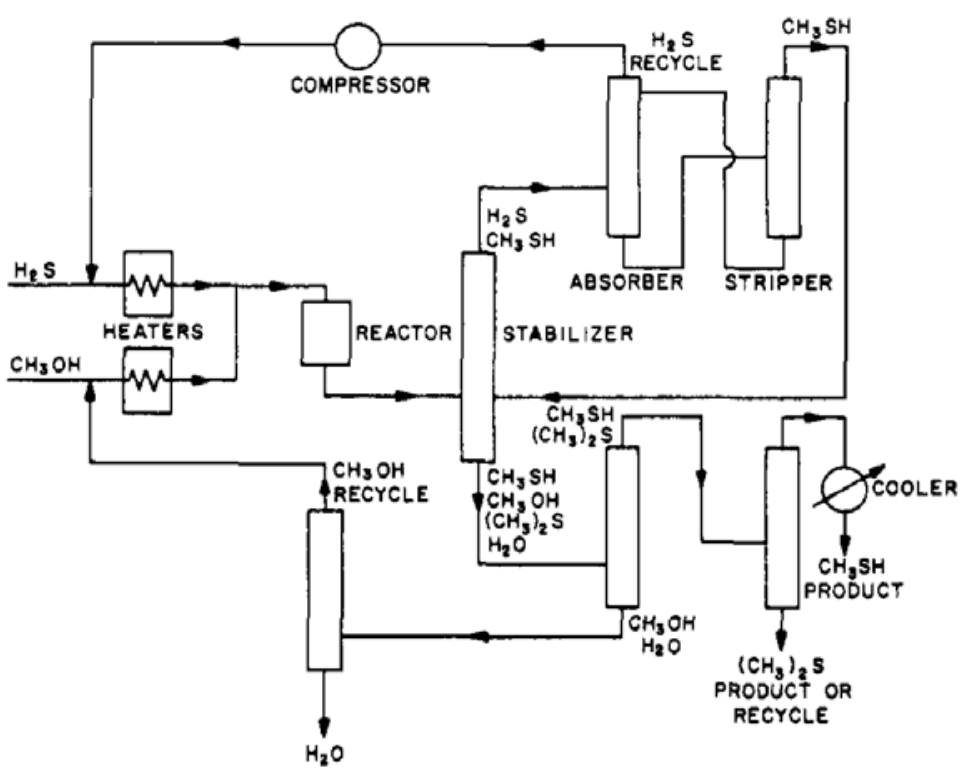

Figure 20. Methanethiol Production Components

The next step consumes the methanethiol and an equivalent of acrolein to form $\beta$ methylthiopropionaldehyde. The reactor is usually a gas/liquid contact reactor with the liquid being mostly product (Figure 21, Figure 22.). Methanethiol and acrolein in an equal molar ratio are introduced as gases with an amine catalyst (less than $1 \%$ by mole). A two to four hour residence time at $40{ }^{\circ} \mathrm{C}$ and 1.5 atmospheres are necessary conditions for full consumption of starting materials. The product yield is normally $95 \%$ at $99 \%$ consumption of acrolein. 


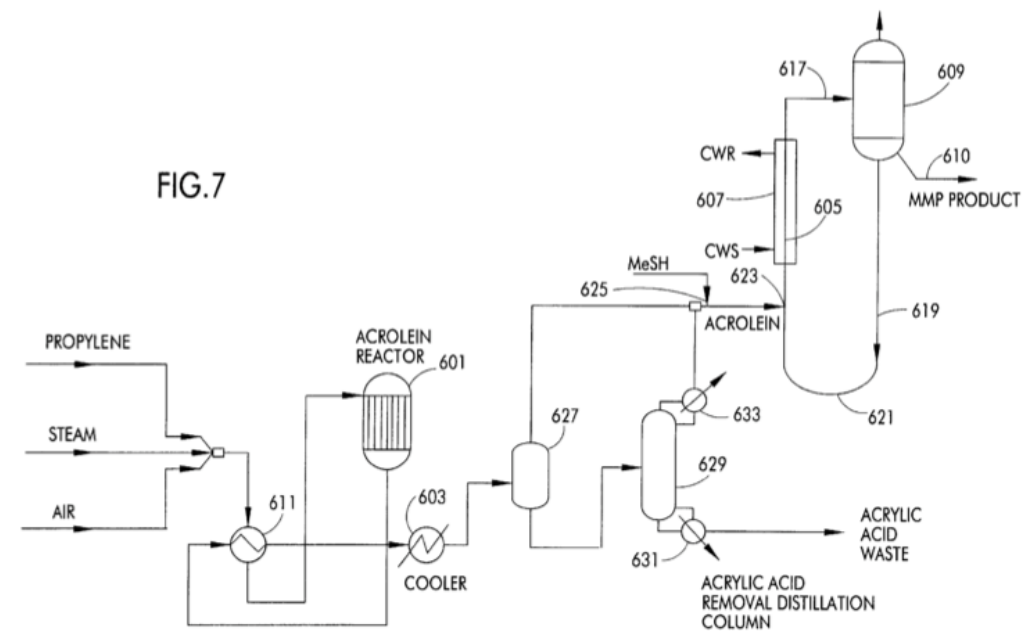

Figure 21. Reactor Components to Form $\beta$-Methylthiopropionaldehyde

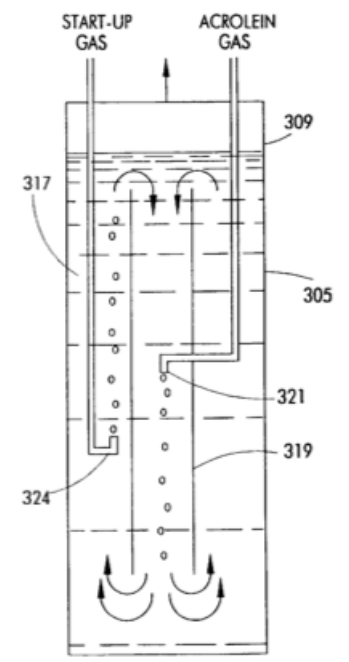

Figure 22. Gas/Liquid Contact Reactor

At this stage, the product is ready for treatment with hydrogen cyanide. The hydrogen cyanide is necessary here to introduce a single carbon atom into the molecule and facilitate the formation of a carboxylic acid moiety. HCN in the gas phase (1.1 equivalents), aqueous ammonium bicarbonate (formed from ammonia, water, and carbon dioxide), and $\beta$ methylthiopropionaldehyde effluent with the amine catalyst from the previous stage are mixed in a second gas/liquid contact reactor. Reaction conditions are $70^{\circ} \mathrm{C}$, one atmosphere, and a residence time of two to four hours. The desired product is 5 -( $\beta$-methylthioethyl)hydantoin, and it is made in $95 \%$ yield.

The liquid effluent from this step is taken on to the hydrolysis stage to form the carboxylic acid. A base catalyst, normally an alkali salt such as sodium hydroxide, is used to break apart the hydantoin ring structure. This reaction also releases carbon dioxide and ammonia, and these chemicals can be recycled back into the previous stage of the process. After acidification of the reaction mixture using sulfuric acid, the product precipitates from the solution and can be 
reclaimed. This process is performed at $180{ }^{\circ} \mathrm{C}$ and three to five atmospheres with a residence time of approximately 4 hours. The yield is typically $97 \%$.

If a process were to operate on a scale of 20,000 tons per year, we estimate the following quantities that would be needed on a daily basis.

$\begin{array}{ll}\mathrm{H}_{2} \mathrm{~S}: & 40,700 \text { pounds } \\ \text { Acrolein: } & 57,600 \text { pounds } \\ \text { Methanethiol: } & 49,400 \text { pounds } \\ \text { Hydrogen Cyanide: } & 27,800 \text { pounds } \\ \text { Ammonia: } & 52,500 \text { pounds } \\ \text { Carbon Dioxide: } & 135,600 \text { pounds } \\ \text { Sodium Hydroxide: } & 40,300 \text { pounds } \\ \text { Sulfuric Acid: } & 98,600 \text { pounds }\end{array}$

Reactor quantities are also included, along with the calculations, in the electronic supplementary information; filename "Methionine synthesis.xlsx".

\subsubsection{Biochemical Production of Methionine}

Fermentation technology has quickly developed over the past decade to the point of full commercialization. Methionine is one of many chemicals now being produced in this way, and this section will explore how this technology can be seen as an IST alternative to the classical petrochemical methionine production process.

Cheiljedang Corporation and Arkema Incorporated announced a joint project in April of 2011 to produce L-methionine via a combined biochemical and petrochemical process. The scale of the plant will approach 80,000 tons per year and will be built in location in Southeast Asia by the end of 2013. This technology removes the need for HCN by supplanting petrochemical reaction steps with a single fermentation step to produce the precursor molecule O-Acetylhomoserine. Methionine is produced by an enzymatic reaction of the precursor molecule with methanethiol (Figure 23).

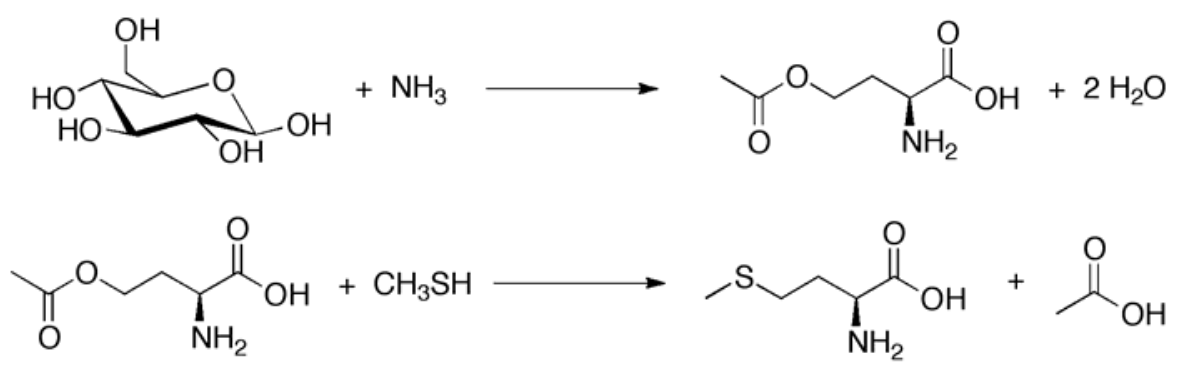

Figure 23. Fermentation and Enzymatic Production of L-Methionine

To produce O-acetylehomoserine, an aerobic fermentation of glucose sugars with a nitrogen source in an aqueous medium. Fermentors are normally operated at one atmosphere and 25-40 ${ }^{\circ} \mathrm{C}$. The aqueous solution is greater than $90 \%$ water with residence times of $10-160$ hours. The 
nitrogen source can be any number of ammonium salts of dissolve ammonia, and other minor components such as metal salts, amino acids, and pH buffers can be added as well.

The enzymatic portion of this synthetic scheme is performed in CSTR vessels with similar reaction conditions $\left(25-40{ }^{\circ} \mathrm{C}\right.$, one atmosphere), but this reaction has a much shorter residence time of two hours. The enzyme catalyst is produced on-site in similar fermentation vessels with sugar and nitrogen sources as the main inputs. Methanethiol is produced in a petrochemical process as described in section 6.4.2. Methanethiol and O-acetylhomoserine are combined, and the product is separated from the broth using standard biochemical processing steps: crystallization, evaporation, spray drying, and filtration.

If a process were to operate on a scale of 20,000 tons per year, we estimate the following quantities that would be needed on a daily basis. Note: there are chemicals in this list that were not detailed in this discussion. This was part of a more detailed discussion and analysis outside the scope of this work that included pesticide use and crop-growing. Details can be found in the electronic supplementary information, filename "Methionine - Fermentation - SNL IST Gaps Study 10-19-2011.pptx”.

$\begin{array}{ll}\mathrm{H}_{2} \mathrm{~S}: & 40,700 \text { pounds } \\ \text { Ammonia: } & 37,000 \text { pounds } \\ \text { Chlorine: } & 121 \text { pounds } \\ \text { Hydrogen Cyanide: } & 17 \text { pounds } \\ \text { Cyanogen Chloride: } & 40 \text { pounds } \\ \text { Phosphorus Trichloride: } & 47 \text { pounds } \\ \text { Hydrogen Chloride: } & 94 \text { pounds }\end{array}$

Reactor quantities are also included, along with the calculations, in the electronic supplementary information; filename "Methionine - Fermentation.xlsx".

\subsubsection{Final Comparison of Methionine Technologies}

Once the tally of chemicals, final storage numbers, and reaction conditions are shown for facilities of comparable size, it becomes apparent that fermentation technologies represent a significant improvement in safety from the perspective of IST. While the list of chemicals compiled for the petrochemical and biochemical processes do not completely overlap, it is plain to see that the quantities in the biochemical process are very small compared to the tens of thousands of pounds in the petrochemical processes. The conclusion our team has drawn is that biochemical and fermentation technologies should be adopted when it is of importance to include IST in the design. The following section shows the analysis done by our team using the CSAC and ABS Consulting Metrics.

\subsubsection{CSAC/ABS Consulting Charts}




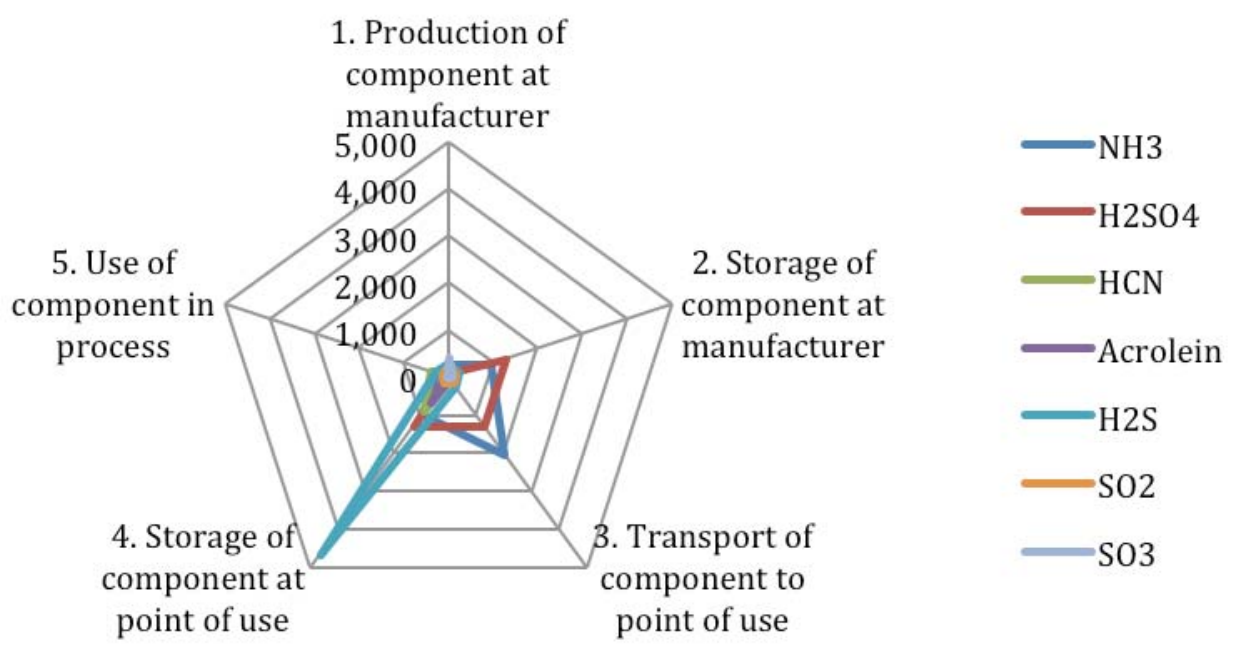

Figure 24. Petrochemical Methionine Star Chart

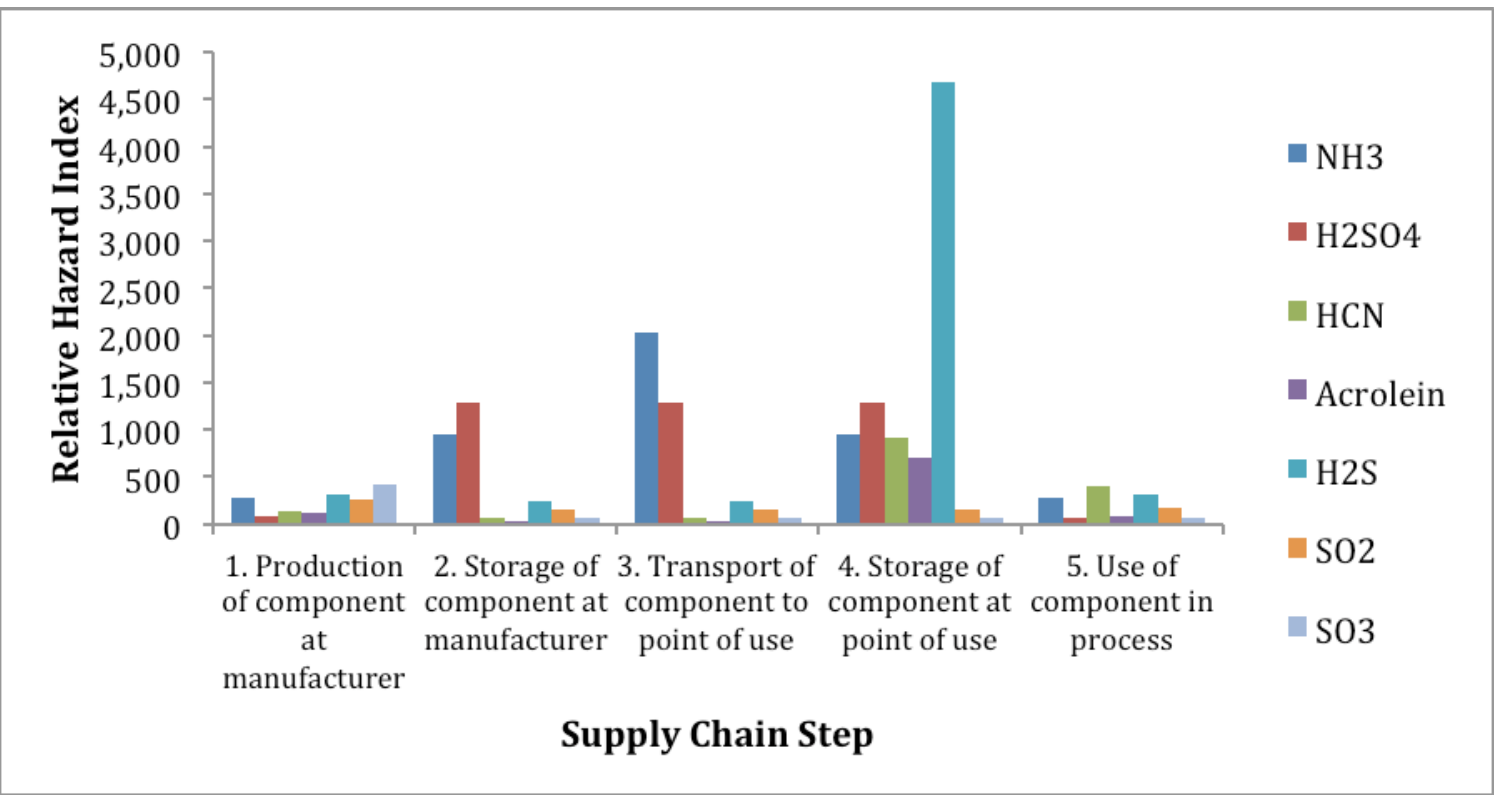

Figure 25. Petrochemical Methionine Bar Chart 


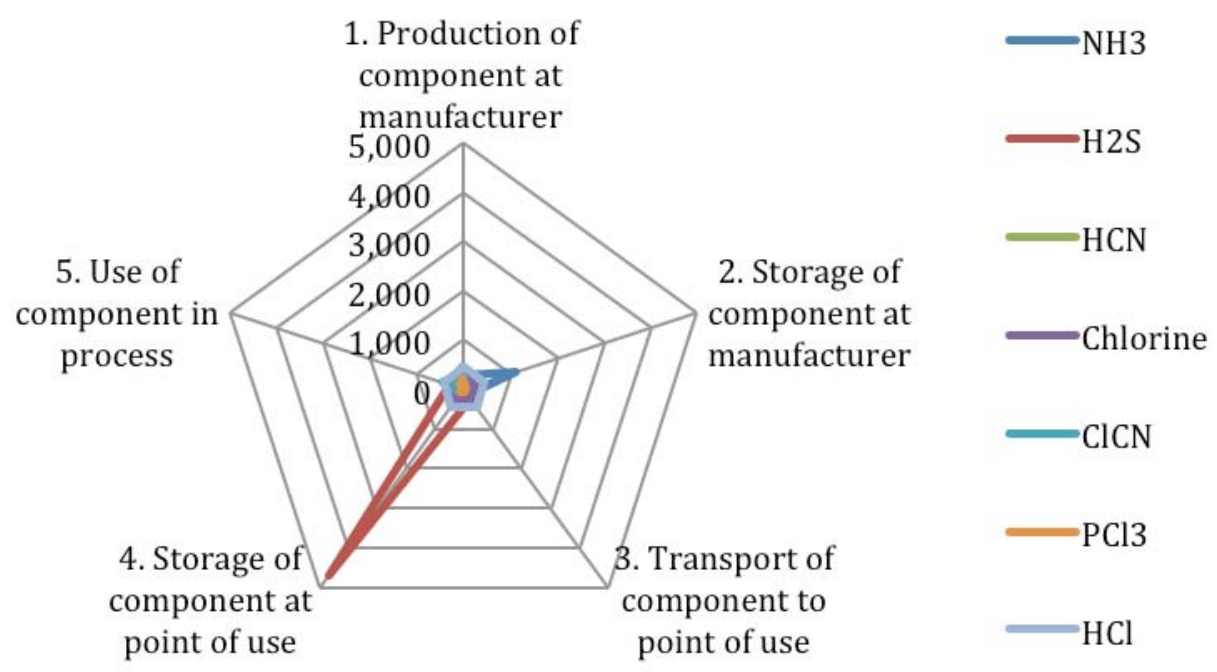

Figure 26. Biochemical Methionine Star Chart

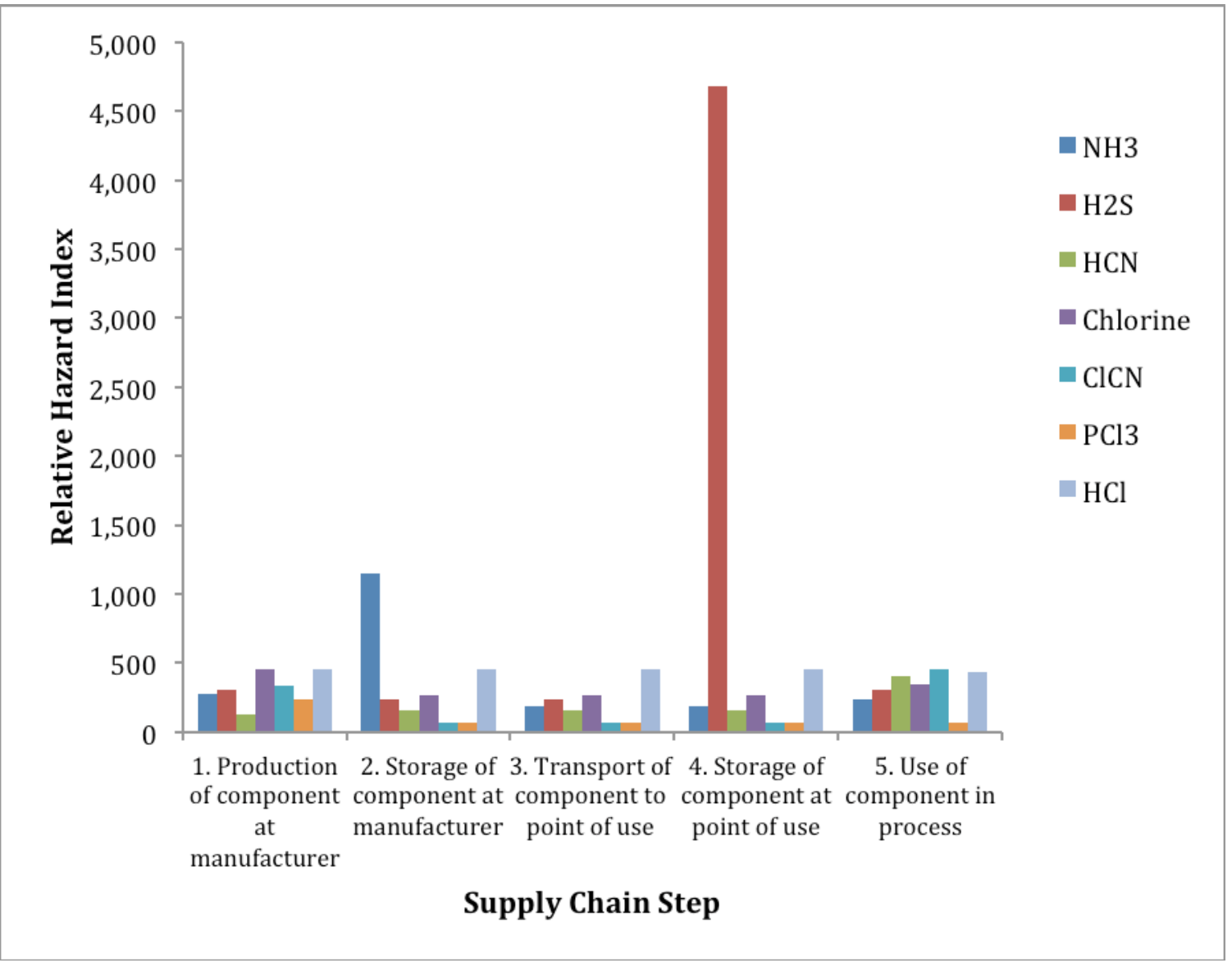




\section{Figure 27. Biochemical Methionine Bar Chart}

\subsection{References}

1. Ullmann's, Cyano Compounds-Inorganic, 2007

2. Ullmann's, Acrylonitrile, 2005

3. Satterfield, C. N. Catalytic Oxidation: Heterogeneous Catalysis in Industrial Practice; McGraw Hill: New York, 1991.

4. Toxicological Profile for Cyanide, U.S. Department of Health and Human Services, 2006

5. SRIC Report on Hydrogen Cyanide, 2010

6. International Patent published under PCT, WO 2009/111605 A1, Improved Process to Co-Manufacture Acrylonitrile and Hydrogen Cyanide

7. Edwards, D. W.; Rushton, A. G.; Lawrence, D. $5^{\text {th }}$ World Congress of Chemical Engineering, 1996, 2, 1113-1118.

8. Ullmann's, Acetone, 2009

9. SRIC Report on Methyl Methacrylate, 2009

10. US Patent 2,731,490, G. Barksy, 1953, Method of Making Cyanohydrins

11. European Patent 1,371,632 A1, Rohm and Haas, 2003, Process for Producing Acetone Cyanohydrin

12. European Patent 0,206,230, "Methyl Methacrylate Production."

13. US Patent 2,416,756, "Continuous Production of Esters of Methacrylic Acid."

14. US Patent 5,393,918, "High Yield Process for the Production of Methacrylic Acid Esters."

15. Ullmann's, “Methacrylic Acid and Derivatives,” 2005.

16. Kirk-Othmer, Methacrylic Acid and Derivatives

17. US Patent 4,987,256, Ebata et. Al. "Process for production of alpha-hydroxycarboxylic acid amide."

18. US Patent 5,225,594, Shima et. al. "Process for producing methacrylic acid."

19. Abe, T. "New Process for Methylmethacrylate MGC's New ACH Process for MMA." Sci. Technol. Cat. 1998, 81.

20. US Patent 4,983,757, Ishikawa et. Al. "Process for production of carboxylic acid esters and formamide."

21. US Patent 4,216,339, Couteau et. Al. "Process for the production of methyl formate.”

22. US Patent 4,319,037, Yoneoka "Process for producing methyl formate."

23. US Patent 5,225,594, Shima et. al. "Process for producing methacrylic acid.”

24. Abe, T. "New Process for Methylmethacrylate MGC's New ACH Process for MMA." Sci. Technol. Cat. 1998, 81.

25. US Patent 5,225,594, Shima et. al. "Process for producing methacrylic acid.”

26. European Patent 0429800 A2, Naito et. al. "Process for preparing unsaturated carboxylic acid ester.”

27. European Patent 0446446 A2, Shima et. al. "Process for preparing alpha, betaunsaturated carboxylic acid ester."

28. Balkus, K. J. Jr.; Khanmamedova, A. K. "Dehydration of Methyl alphaHydroxyisobutyrate Catalyzed by Zeolites." J. Catal. 1995, 151, 10.

29. Abe, T. "New Process for Methylmethacrylate MGC's New ACH Process for MMA." Sci. Technol. Cat. 1998, 81. 
30. US Patent 5,225,594, Shima et. al. "Process for producing methacrylic acid."

31. US Patent 4,693,877, Oehsen et. al. "Cleavage of formamide to give hydrocyanic acid and water."

32. Abe, T. "New Process for Methylmethacrylate MGC's New ACH Process for MMA." Sci. Technol. Cat. 1998, 81.

33. Song, N. et. al. Journal of Catalysis 2005, 236, 282-291.

34. US Patent 2005/0159621 A1, "Mixed Metal Oxide Catalysts for the Production of Usaturated Aldehydes from Olefins."

35. US Patent 7,015,354 B2, "Preparation of (Meth)acrolein and/or (Meth)acrylic Acid.”

36. Folkins \& Miller, Ind Eng Chem Prod Res Dev 1 (1962) 271

37. US Patent 4,225,516 "Process for the manufacture of $\beta$-methylthiopropionaldehyde."

38. US Patent 5,352,837 "Process for the Preparation of 3-(methylthio)propanal."

39. US Patent 5,744,647 "Process for the Preparation of 3-(methylthio)propanal."

40. US Patent 6,320,076 "Process for the preparation of 3-(methylthio) propanal."

41. US Patent 5,973,200 "Process for the preparation of 2-hydroxy-4-(methylthio)butanoic acid or methionine by mercaptan addition."

42. US Patent 4,319,044 "Process for recovering useful components from waste gas of methionine synthesis."

43. US Patent 2,717,253 "Preparation of methionine hydantoin."

44. US Patent 4,069,251 "Continuous process for the manufacture of methionine."

45. US Patent 3,917,683 "Process for the preparation of DL-methionine."

46. SRI report on Amino Acids, 2009.

47. US Patent Application US 2011/0053253 A1

48. International Patent Application WO 2008/013432 


\section{CHEMICAL RELEASE PREVENTION AND MITIGATION, METRICS EFFORT}

\subsection{Introduction}

A significant effort both domestically and globally is the development of safe handling procedures for industrial chemical compounds. From the intended purpose to the unintentional release, all scenarios must be considered and mitigated in one fashion or another. Considering that chemicals can exist in several different states of matter (gas, liquid, and solid) and each of these can lead to new avenues for reactivity, the usage and subsequent plans for containment can be complicated and wide-ranging. This fact has led to the development of numerous countermeasures for release prevention and mitigation. This chapter will discuss those methods along with Sandia National Laboratories' preliminary efforts to provide a quantifiable release prevention and mitigation index that complements the current CSAC IST Metrics.

\subsection{Chemical Release Prevention and Mitigation Countermeasures}

\subsubsection{Countermeasures}

Release prevention and mitigation is governed by simple principles applied to various scenarios depending on the chemical, the use, the location, and the perceived efficacy. This discussion will begin with a description of the countermeasures that are most widely used in the domestic production industry and the principles they rely on for effectiveness.

\subsubsection{Primary Containment}

Containment of a chemical is an obvious need to prevent a release but the considerations begin at the use stage of an industrial process. Primary containment includes the reactors, transfer pipes, distillation and separation apparatus, and storage vessels necessary to operate a process. Materials, wall thickness, operating temperature, and pressure are taken into account when making choices on the construction of the primary containment to reduce the likelihood of a release.

\subsubsection{Emergency Containment}

Emergency containment is a form of secondary containment, but it is being called out here separately from other secondary containment such as dikes, berms, and enclosures (discussed below). Emergency containment can be operated actively or it can be a passive countermeasure. Valves or sumps will redirect the chemical to a holding tank or pit in an active mode of mitigation. This can happen either before or after a release has occurred depending on where the item is placed. In a passive mode, a drain of burst disc-type relief valve could be used as the mechanism for emergency secondary containment. This passive measure for containment usually ties in to a dike or enclosure for optimal effectiveness.

\subsubsection{Dikes and Berms}


Dikes, also called berms or bunds, are low walls or curbs constructed around hazardous chemical vessels to "catch" a chemical agent if the primary and/or secondary vessel fails. Diking can be used indoors and outdoors and is most often implemented for liquid agents, although it can also be effective for dense gases. There are two key parameters considered in the design of a dike: the total volume and the surface area. A dike should be able to contain $110 \%$ of the volume of the hazard vessel (or vessels, if there are several within one dike). The dike should also be designed to minimize the surface area of spilled chemical in order to reduce the rate at which the hazard evaporates. Other factors that impact the rate of evaporation include the heat of the containment vessel, solar radiation, residual water in the dike (e.g., rain water), and airflow over the spilled hazard agent. There are many options for dike materials and designs to address these factors. For example, dikes constructed with refrigeration or low-conductivity materials can reduce the volatilization of agents like condensed chlorine. While dikes can be effective at mitigating the initial transport of hazard, subsequent measures such as foam blankets, sumps and collection pits, are needed to prevent further dispersion and to remediate the agent collected in the secondary containment.

\subsubsection{Barriers and Enclosures}

Secondary enclosures completely surround vessels containing volatile liquids and gaseous agents in order to prevent dispersion. For example, a building housing a multi-vessel process can serve as a secondary enclosure to prevent exposure of the nearby public in the event of a gaseous release. There are negative impacts to be considered in implementing enclosures for gas releases. Low minimum ignition energies for flammable substances, for instance, may be an indication that open-air storage is a better option. Similarly, enclosures can result in the concentration of asphyxiating gases putting plant workers in danger. In this case, venting and scrubbing systems are critical subsequent mitigation measures.

In addition to buildings enclosing chemical process and storage vessels, other features of the site layout can serve as vapor barriers. Trees, buildings, terrain obstacles (e.g., hills) and other structures (e.g., fences) in and around the plant site can contain or cause dilution of gas plumes, especially dense gases. In fact, trees and vegetation are known to have a scrubbing effect on gas plumes. All these measures serve to minimize the impact of accidental chemical releases on the surrounding environment and nearby population.

\subsubsection{Valves and Flow-Limiting Devices}

Devices such as valves are used to redirect or impede a chemical agent from reaching a point of potential release. There are two general cases where this would be necessary: (1) a vessel has been compromised or (2) conditions within a vessel are approaching its operating limits, increasing the likelihood of a release. In the first scenario, a release already exists and a valve or flow-limiting device is now functioning as a mitigation countermeasure. A flow-limiting device will only slow the release, but a valve can stop any additional release from occurring (usually paired together).

The case of a potential release occurs in situations where a runaway reaction is likely or external environmental changes exist (temperature, pressure). In these cases, primary containment is still 
intact but may fail if action is not taken. Valves may redirect or stop the flow of reagents, and flow-limiting devices can be used in process elements to passively control reaction rates and prevent runaway reactions.

\subsubsection{Quench Systems}

Chemical quench systems use the inherent chemical reactivity of an agent to eliminate the risk of a toxic inhalation hazard. They are used on area gas releases and in chemical reactors and containers. A quench system is comprised of a tank filled with a chemical reagent such as a caustic solution of sodium hydroxide but is normally tailored to react with the specific release agent. The product(s) of this reaction are usually well known, and these products are designed to be less hazardous than the starting materials. The chemical reagent is present in sufficient amounts to fully react with a worst-case release (entire contents of vessel). Effectiveness might be assumed to be $100 \%$ when built and run appropriately, but is not a continuous method and therefore, might suffer from "instant on" problems. Chemicals that are commonly quenched and their associated quenching agent: $\mathrm{HCl}(\mathrm{NaOH}), \mathrm{H}_{2} \mathrm{~S}(\mathrm{NaOH}), \mathrm{Cl}_{2}(\mathrm{NaOH}), \mathrm{SO}_{2}(\mathrm{NaOH})$, Phosgene $(\mathrm{NaOH}), \mathrm{HCN}(\mathrm{NaOH}), \mathrm{NO}_{\mathrm{x}}(\mathrm{NaOH}), \mathrm{HF}(\mathrm{KOH}), \mathrm{NH}_{3}\left(\mathrm{H}_{2} \mathrm{SO}_{4}\right)$.

The only differences in the implementation for an area gas release and a failure of a reactor or container are in the method of introduction to the quench tank. An area gas leak necessitates a ventilation system pulling the gas into the tank liquid. If a liquid spill has occurred, this method will only be effective for the evaporative portion or the release, and the spill must be contained in an enclosure for the quench system to work properly. To tie into a primary container, a relief valve or burst disk leads to the tank liquid. The only concern in this scenario is the problem of scale in regards to static chemical storage. Most industrial chemical producers will not implement quench systems for their largest quantities of chemicals.

An example of a chlorine quenching system is pictured below in Figure 1. This demonstrates the knowledge of the quenching systems and the complexity that is associated with controlling chemical reactions. 


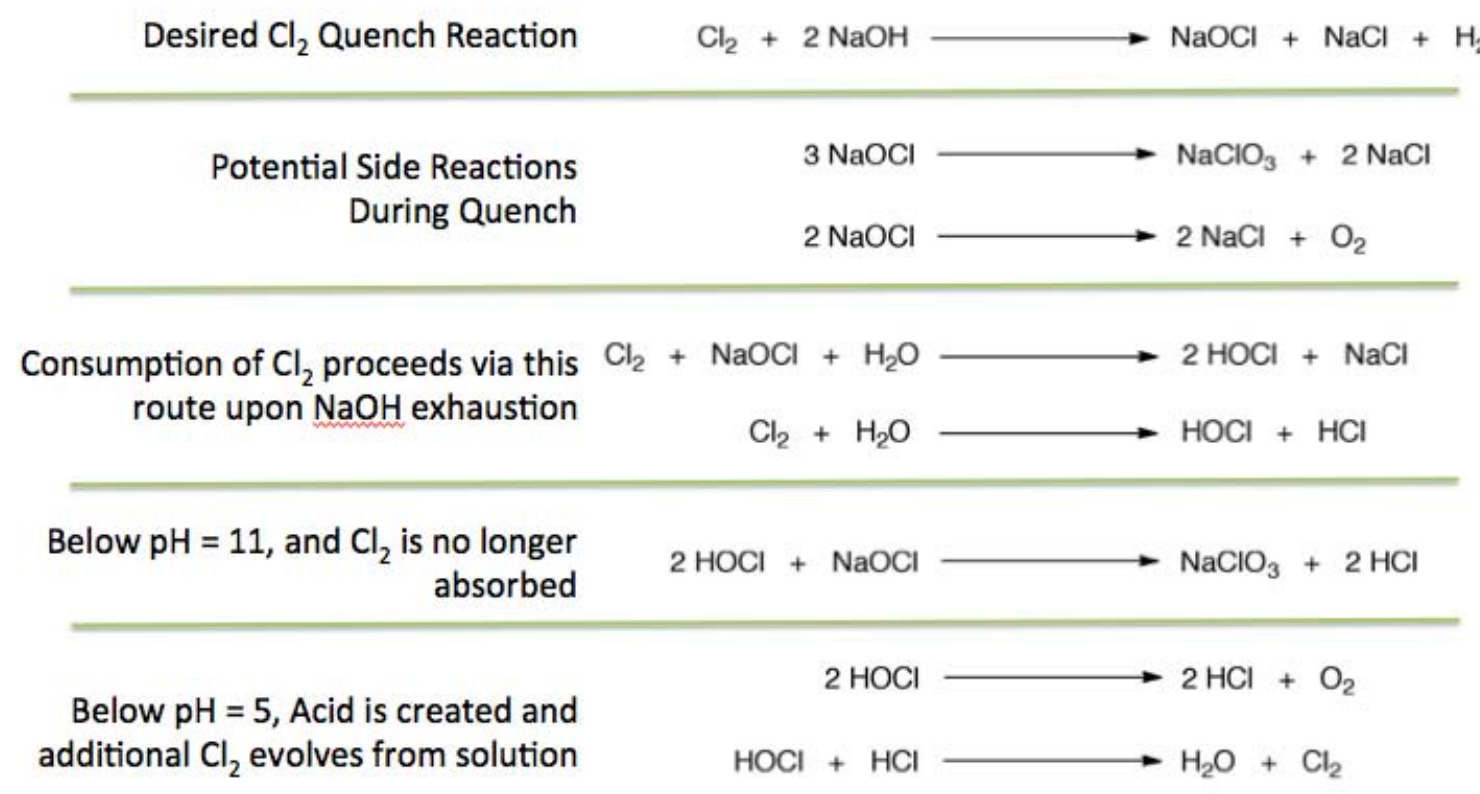

Figure 1. Chlorine Quenching Reactions and Potential Side Products.

\subsubsection{Water Deluge Systems}

Water curtains and deluge systems can be used to solubilize a gas and return the mixture to the ground. This can be used in cases where there is a gas leak or a highly volatile liquid. Various designs exist and have been optimized for the potential release scenario. Some can even be portable and are used by emergency crews to respond to unexpected releases. Nozzle type, water capacity, droplet size, $\mathrm{pH}$, and environmental conditions are all variables that have to be optimized for maximum effectiveness. Additionally, chemical properties alter effectiveness. Hydrofluoric acid, hydrochloric acid, and ammonia have been studied extensively and give mitigation percentages up to $99 \%$ in controlled settings. Modeling has shown effectiveness follows solubility (Henry’s Law constant). However, reactivity with water or additives can also aid the capture of gases such as carbon dioxide, phosphine, and sulfur trioxide.

\subsubsection{Foam Blanketing}

Foam blanketing is a method used on a wide variety of chemical liquid spills but is most commonly used on flammable hydrocarbon liquid spills. The method of action is to prevent evaporation and combustion or other reactions. It is deemed a temporary solution to any chemical spill since a foam will degrade over time. It is not a clean up tool and must be used in conjunction with other methods (e.g. burn off or quenching).

Chemical identity has strong effect on foam effectiveness, and only a few chemicals and chemical classes can be mitigated using foams. Chemicals are grouped into five categories:

1. Hydrocarbon Liquids (water-immiscible volatile organics) — very effective; fluoropolymer based foams 
2. Liquefied Hydrocarbon Gases (methane, ethane, ethylene) - a limited number of hydrocarbons can benefit from blanketing; not an effective strategy across the board

3. Polar Compounds (water-soluble organic compounds) — foam creates a gel or precipitate layer on contact with chemical; uses stearates or polysaccharides to separate the foam and seal the spill

4. Water Reactives (silanes, phosgene, $\mathrm{NO}_{\mathrm{x}}, \mathrm{SO}_{\mathrm{x}}$ ) - controllable using similar foams as polar compounds; problems with reactivity and creation of byproducts exist

5. Liquefied Inorganic Gases $\left(\mathrm{NH}_{3}\right.$ and $\left.\mathrm{Cl}_{2}\right)$ - category includes many more chemicals but only two have been investigated sufficiently; chlorine effectively blanketed using category 1 foams; ammonia is too water-soluble and heat of solvation is too high to be effectively blanketed

\subsubsection{Foam Scrubbing}

Foam scrubbing is the entrainment of gaseous releases into a foam containing reactive additives. This encases the gaseous agent inside the bubbles of the foam, and this is the distinguishing characteristic that separates it from foam blankets. It is essentially a casing around the chemical. If a scrubbing, or quenching, agent is available and can be used with a foam, this is a much more effective approach. In common industrial practices, is it mainly used to capture particulate matter from combustion exhaust feeds. It is an expensive method and is not commonly used where other methods of exhaust mitigation are available. Chemicals that are currently mitigated using foam scrubbing systems are as follows: Formaldehyde, Acetaldehyde, Hydrogen Sulfide, Ammonia, Chlorine, $\mathrm{NO}_{\mathrm{x}}$, and $\mathrm{CO}_{2}$.

\subsubsection{Flare Stacks}

Exhaust systems in chemical facilities can be fitted with flare stacks to combust harmful emissions. They are typically used at oil and natural gas refineries, and they serve to mitigate hydrogen sulfide releases. Method suffers from a limited number of combustible chemicals that would not generate additional harmful combustion products. Reduction in flare stack usage continues due to external pressures, and is it not likely to be used for other chemicals outside of pure hydrocarbons in the future.

\subsubsection{Passive and Active Countermeasures}

\subsubsection{Definition of Passive and Active Countermeasures}

FEMA has defined passive mitigation countermeasures as "mitigation measures that require not human intervention [or power] to be effective and are usually more effective than active mitigation measures." An active mitigation countermeasure is one that "requires human intervention [or power] to operate properly and are usually less effective than passive mitigation measures." With these two definitions in hand, the countermeasures that are described above can now be categorized. (Note: Due to differences in implementation, some countermeasures can be 
passive or active. The specific situation should be examined carefully on a process-by-process basis.)

\subsubsection{Passive Mitigation}

Passive mitigation countermeasures work in conjunction with active measures to provide containment for hazardous chemicals prior to, during, and after a release event. Unlike active measures, passive mitigation measures do not require human intervention or power to be effective. Most passive mitigation measures can be categorized as either primary or secondary containment structures. Structures such as reaction and process vessels, above- and underground storage tanks, piping, transfer and transport containers prevent the loss of containment of chemical hazards on a day-to-day basis. As a result, primary containment structures are designed with material compatibility and robustness as the key design features.

On the other hand, the goal of passive secondary containment is to hasten the transport of liquid and/or vapor hazards released during the loss of primary containment. Therefore, multiple design features must be considered when putting secondary containment measures into place. In addition to material compatibility and robustness, the plant layout and environmental conditions (temperature, airflow) must also be considered. Secondary containment structures can be implemented at the point of potential release (e.g., dikes), while other measures such as secondary enclosures provide more remote and general barriers.

What follows is a listing of the passive countermeasures (determined based on input from our team and subject matter experts).

Primary Containment
Secondary Containment
Dike
Berm
Enclosure
Perimeter
Drain
Flow Limiting Devices
Rupture Valve
Grounding
Fire Wall
Blast Wall
Reaction Inhibitor

\subsubsection{Active Mitigation}

As stated above, active mitigation countermeasures have some external element needed to allow them to function. That element can be human interaction or a power source. In addition to the factors that affect efficacy for a passive countermeasure, active countermeasures' likelihood for failure increase due to operator error, loss of power, and mechanical or electrical malfunction. It should be noted here that the "operator" in question could be a computer system or other type of 
automatic activation system. Active countermeasures are used in conjunction with passive countermeasures to provide a wide-ranging safety net for any hazardous release, but they are both subject to the environmental conditions at the time of the release event.

Active Countermeasures (determined based on input from our team and subject matter experts):

\author{
Sump \\ Quench System \\ Manual Shutoff \\ Auto Shutoff \\ Emergency Power \\ Chemical Scrubber \\ Flare Stack \\ Chemical Purge System \\ Sprinkler (Fire Fighting) \\ Deluge System \\ Water Curtain \\ Foam Blanket \\ Foam Scrubbing \\ Emergency Storage \\ Vent/Relief Valve \\ Interlock \\ Alarm \\ Keyed Bypass \\ Emergency Air
}

\title{
7.2.3. Countermeasures in Process Elements
}

Because industrial chemical processes are complex and varied in their implementation, it is helpful to distill the general process elements down to a set of categories for the purposes of appropriate countermeasure installation. As was done in CSAC's IST Metrics, our team has taken the three general categories of Process, Transportation, and Storage to represent any and all elements possible in an industrial chemical process. The Process elements include but are not limited to reactors, piping (where applicable), distillation towers, and settling tanks. Storage elements mostly comprise the on-site vessels that hold the precursor, intermediate, and final products of a process. If the material leaves the confines of the chemical facility, the vessels (tank cars, barges, cylinders, etc.) would be sorted into Transportation.

Due to factors such as cost, infrastructure, and feasibility, it is not possible to use all of the previously discussed countermeasures in each of the three categories. For example, a dike could not be set up to surround a barge or tank car, although emergency responders might be armed with a portable version (this would not necessarily be the responsibility of the chemical facility and therefore, outside the scope of the facility's planning phase). Figure 2 shows the most common prevention and mitigation countermeasures sorted among the three industrial elements. 

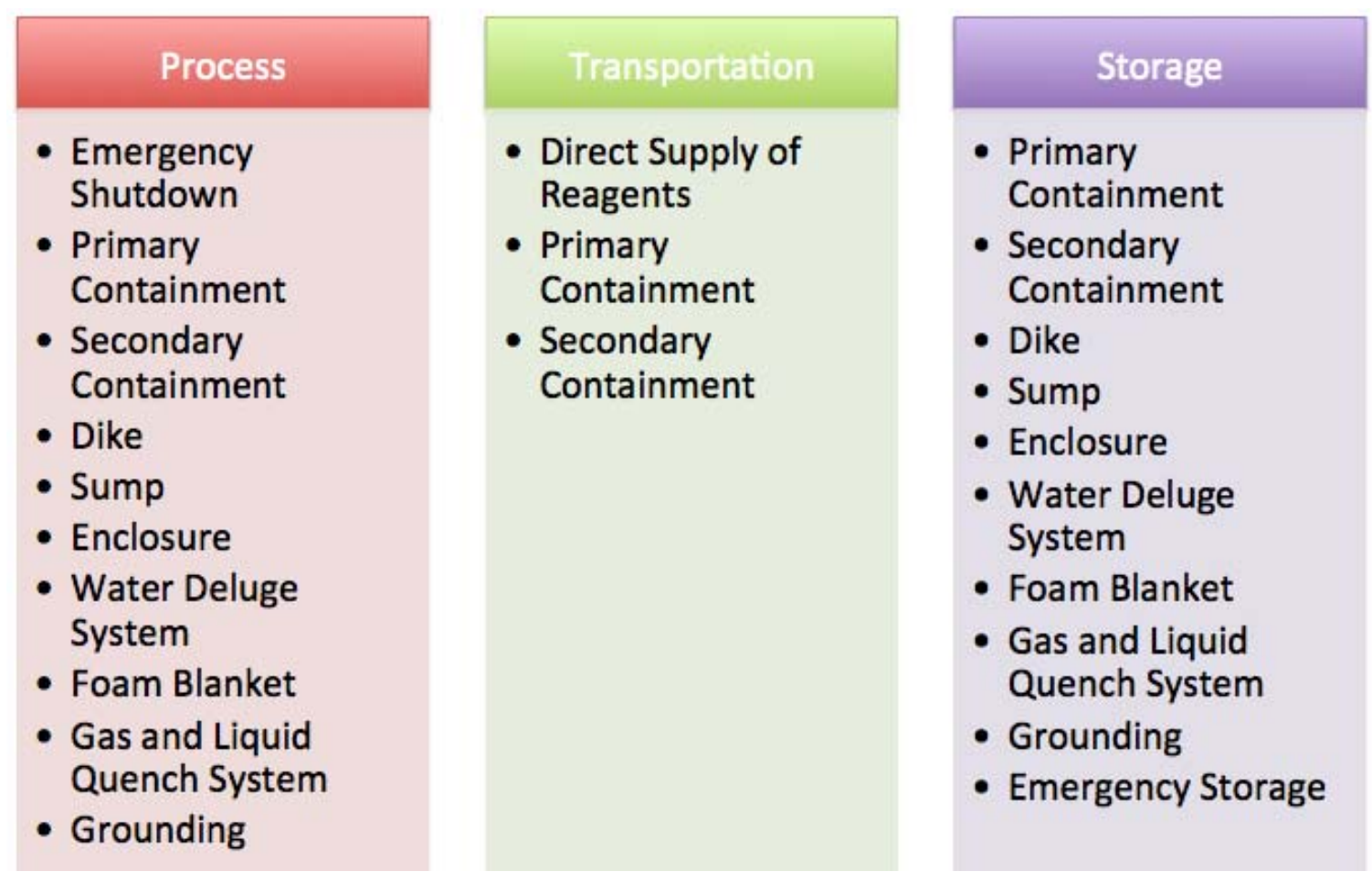

\section{Figure 2. Release Prevention and Mitigation Countermeasures According to Industrial Elements}

\subsubsection{Countermeasures on a Timeline of a Release Event}

For the purposes of this study, an organization of the countermeasures along a release event timeline is a useful classification. A release event timeline has been discussed in some texts and studies, but the nomenclature here was borrowed from V. Fthenakis' "Prevention and Control of Accidental Releases of Hazardous Gases" and subsequently augmented by our team to fit our study. In Figure 3, the arrow represents time and the five items along the timeline are the proposed events that occur during a release event. Those events are Prerelease, Release, Liquid Transport, Vapor Transport, and Exposure. During each of these events, countermeasures can be more or less effective to prevent or mitigate the release of the chemical agent. In the release timeline, exposure is reached when all countermeasures have failed (and no countermeasures technically "act" during this phase of the release). 


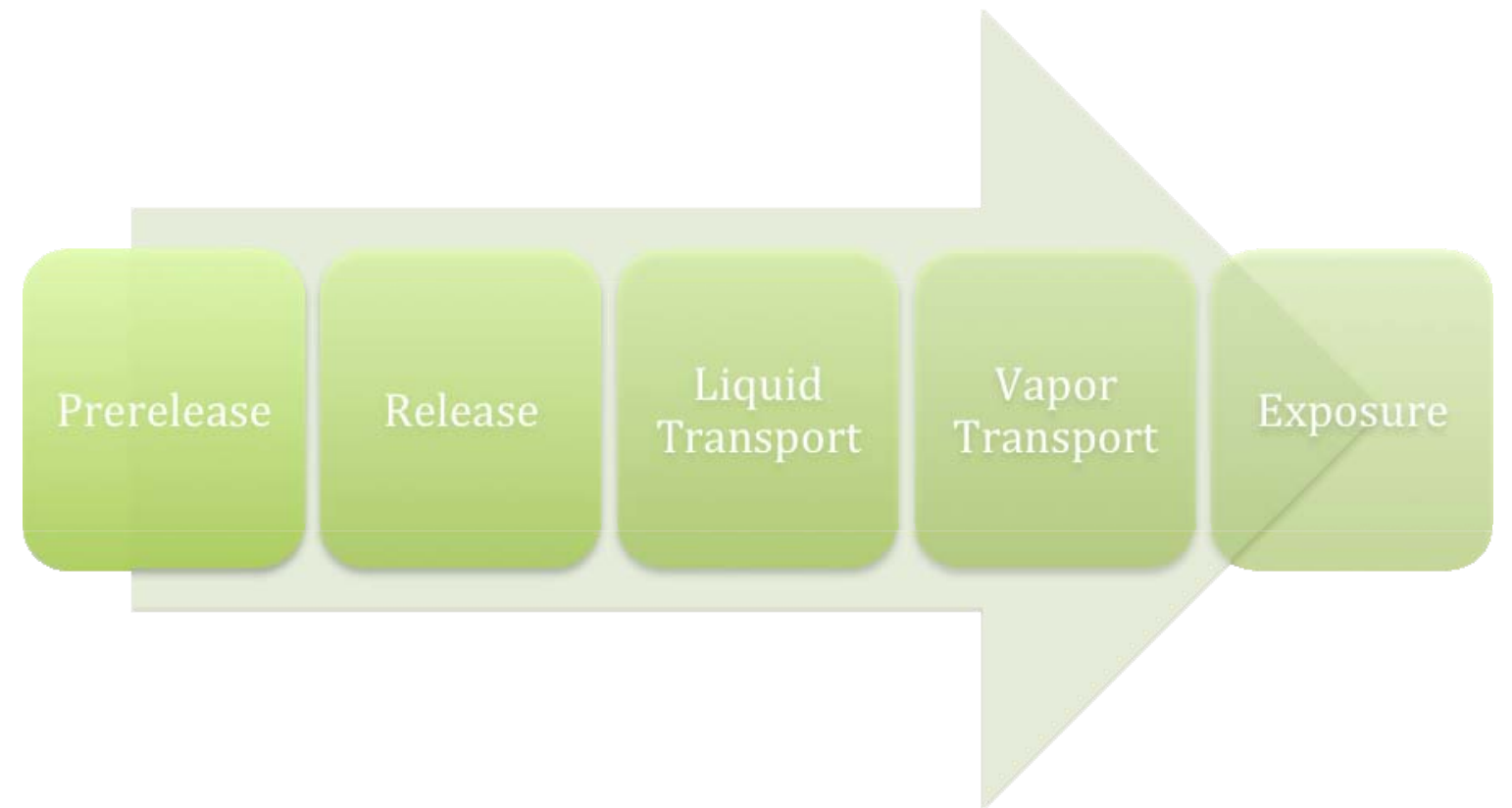

Figure 3. Release Event Timeline.

All the previously described countermeasures can be found organized in the timeline in Figure 4. Our team has found this categorization to be helpful in clarifying efficacy of countermeasures since it leads to a larger and more detailed discussion of the release. Organizing the countermeasures along a timeline more easily shows how they function during an event and can be used to explore their interplay as an event progresses. Additionally, this is relevant from the standpoint of emergency responders since it addresses their use of available countermeasures relative to the progression of a release. I should be noted here that including the concepts of prerelease and prevention bring in "likelihood", and countermeasures acting on a system before a release has occurred are working to decrease the probability of release and not the extent of release. In the end, one establishes success of these prevention countermeasures as a yes/no determination and not a determination of "percent saved" as most mitigation measures would be. This was not a part of the discussion for CSAC IST Metrics but is a key part of chemical production safety engineering and is the reason for its use in our study. 

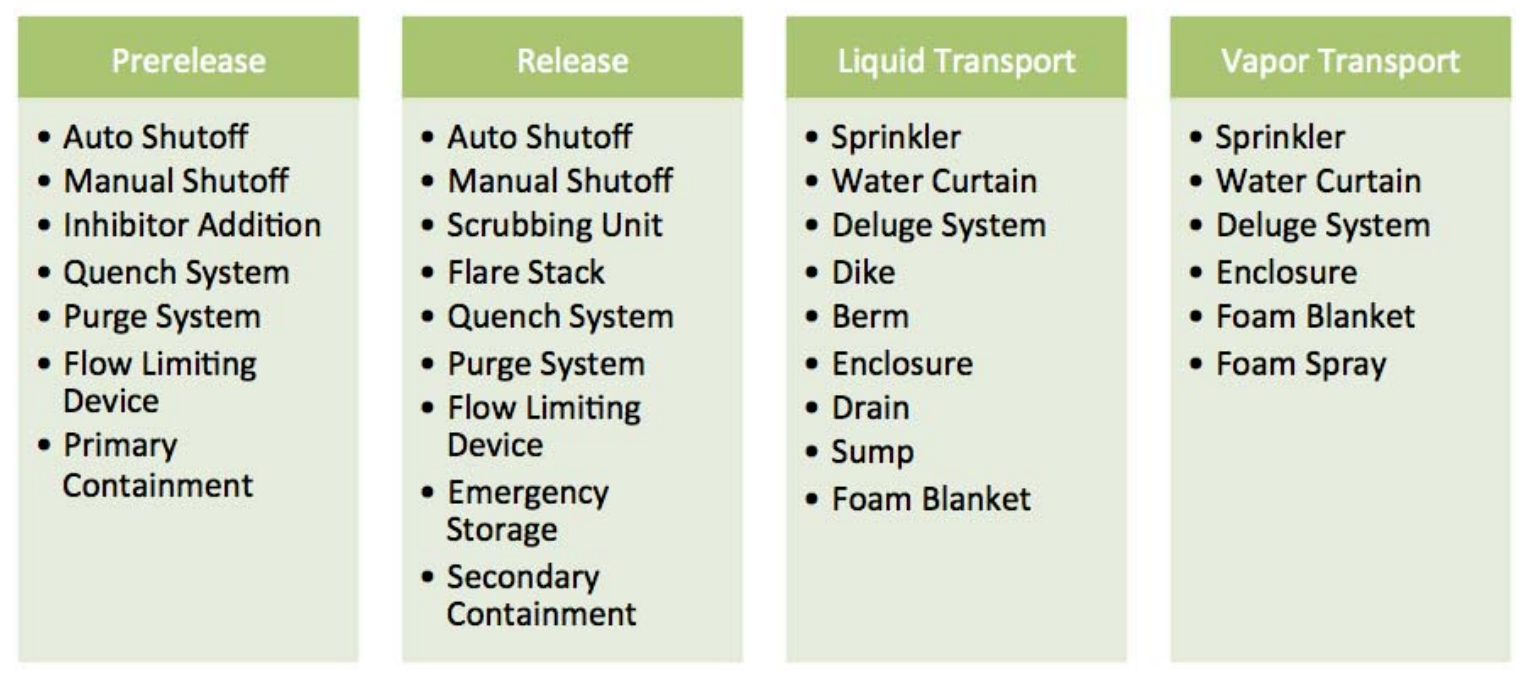

Figure 4. Countermeasures Organized by Timeline.

\subsection{Chemical Release Countermeasures Reduction Modifier Architecture}

\subsubsection{Introduction}

CSAC has invested in IST/ISHC by seeking to develop a set of metrics that can guide decisionmaking at various levels of government and industry. The result has been an innovative effort that spans the supply chain from chemical precursor production to final usage and storage. However, this methodology was meant for a direct comparison of chemical processes that produce the same final product and were not strictly developed to assess countermeasure effectiveness on the release scenarios that are commonly accounted for at chemical production facilities. This focus on chemical properties and process and storage conditions meant that there could theoretically be instances where a chemical process might be ruled less safe despite a robust safety net of release prevention and mitigation countermeasures.

ABS Consulting was the author of the initial IST Metrics, and a "release quantity reduction modifier" was included in this work.

$$
F_{\text {red }}=10\left(1-A_{\text {red }}\right)
$$

- "Metric input: $\mathrm{A}_{\text {red }}$ : Estimated fraction of largest quantity that could be released from single vessel/container in catastrophic release that would be avoided by these measures

- Minimal-hazard input value: 1 (100\% reduction of release mass)

- Maximal-hazard input value: 10 (no reduction of release mass)”

This term would be multiplicatively applied to the "Relative Hazard Index" or RHI for each node in the supply chain.

$$
R H I=R_{t o x} R_{q t y} R_{T P V} R_{p o p} F_{\text {red }}
$$




$$
\begin{aligned}
& R_{t o x}=\text { Toxicity } \\
& R_{q t y}=\text { Quantity in use, storage, or transportation } \\
& R_{T P V}=\text { Processing or storage conditions } \\
& R_{p o p}=\text { Effected population } \\
& F_{\text {red }}=\text { Reduction quantity }
\end{aligned}
$$

However, it was determined that this reduction factor did not adequately account for the benefits of release prevention and mitigation countermeasures. Because of these concerns, Sandia was asked to contribute to this IST Metrics effort by fleshing out the methodology for a more detailed countermeasure reduction modifier.

The Sandia team has identified several previous methods for quantifying countermeasure effectiveness. RMP*Comp Tool is a freeware program developed by the EPA and NOAA to predict the endpoint of a chemical release based on the chemical type and properties. It accounts for crude environmental conditions, mitigation countermeasures such as dikes and enclosures, and uses a similar methodology as ABS Consulting for assessing "active" mitigation methods (an estimate of fraction of total quantity released). ALOHA and CAMEO are more sophisticated models developed by NOAA that track chemical releases based on environmental conditions, types of releases, changes over time (release rate, evaporation, etc.), but does not address mitigation specifically. PHAST is a private software suite developed by DNV and is similar to ALOHA but includes the added benefit of chemical plant layout and some mitigation and release prevention.

\subsubsection{Sandia Countermeasure Reduction Modifier Development}

After examining the comparable methods currently used by government and industry, six specific qualities were identified that needed to be addressed for a successful countermeasure reduction modifier.

First, the countermeasures must be the centerpiece of the modifier. This entails making a clear delineation between prevention and mitigation, active and passive. The modifier must also allow the countermeasures to function as fail-safes, work against one another, or create synergy. Presentation in a visual format and by category will demonstrate the countermeasures in action.

Secondly, the interaction of countermeasures with a chemical is an important concept in that must be grounded in a scientific understanding. Hard data from testing, modeling, and incident reports should be gathered and accounted for to give legitimacy to the modifier. This is a key concept that some of the aforementioned models lack.

The third desirable quality is numerical representation. The CSAC IST Metrics is a numerical rating system, and the additional modifiers must easily integrate into it. This can either be addressed at the RHI level as is already done in the ABS Consulting version or can be put in at the Quantity level. 
Multiple release events are possible in highly complex facilities and systems. Certain countermeasures have been developed with specific release scenarios in mind and only function properly in those scenarios. Therefore, various release scenarios should be integrated into the rating system for this modifier to work properly. This mimics the preparation that an industrial chemical facility takes to prevent releases, and this might allow the Metrics to be integrated into future facility plans. The addition of intentional release scenarios should also be considered. Cascading scenarios are also a potential concern in the development of this modifier.

Because CSAC seeks to use this modifier across the supply chain of chemical production, it must be applied uniformly across the Process, Transportation, and Storage nodes of the Index. We view this as being agnostic of the location, state, and conditions of the hazard.

Finally, the Metrics gives a top-level view of the chemical supply chain hazard and therefore, the modifier must be accessible and comprehensible to the untrained personnel that might use it. This is certainly one of the major drawbacks for the previously reported IST hazard programs.

\subsubsection{Timeline-based Architecture}

As was discussed in section 7.2.4, a timeline has the potential to organize countermeasures among a prerelease and release scenario and allow them to act at specific points where they can be most effective. The timeline also achieves the goal of using a visual aid for the modifier.

\subsubsection{Chemical, Incidents, and Scenarios}

To begin the timeline of a release event, some "ground rules" must be set with regards to the chemical of interest. This means that any eventual scenario, incidents, and countermeasures must act upon the chemical hazard. Toxicity, boiling point, vapor pressure, solubility, and other essential data must be gathered so that the efficacy of a countermeasure can be assessed. This parallels the Metrics and should integrate well with the relevant data needed there.

Another set of "ground rules" is the incidents and scenarios that could exist for a chemical facility. These serve several functions: highlight varying degrees of severity of release, differentiate between states of matter of the chemical during release, alter efficacy of certain countermeasures, and represents an "impact" that will be acted upon by countermeasures. Currently, our team has identified two incidents and five release scenarios that could serve in these categories (Figure 5). Incidents are categorized as accidental or intentional, and scenarios can be slow liquid leak, two-phase leak, slow gas leak, violent gas leak, and catastrophic release. 


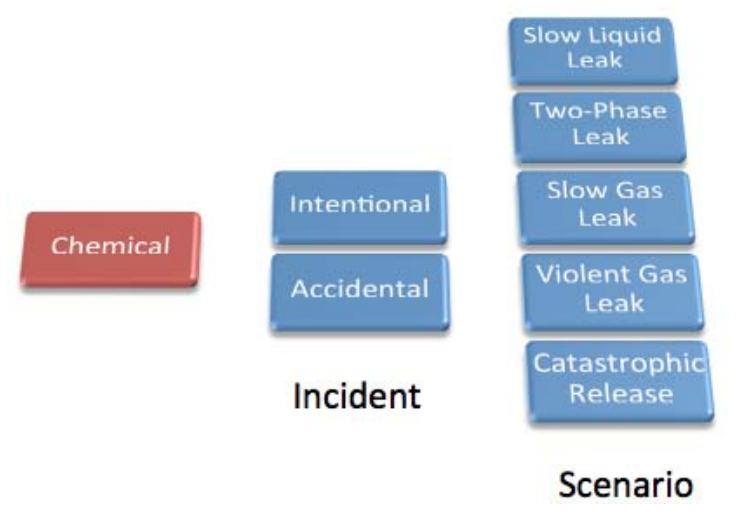

Figure 5. Incidents and Scenarios.

This list of incidents and scenarios is based on categories that are typically investigated by modeling and safety literature, but it is subject to change based on sensitivity studies and new or more descriptive terminology.

\subsubsection{2. $\quad$ Event Progression}

The keystone to this modifier is the progression of a release event from prerelease to exposure (Figure 6). A release has several stages that are commonly described in relevant literature with "prerelease" being added as a first stage for the purposes of this study. Again, the timeline is used to visually and categorically organize countermeasures within the event progression.

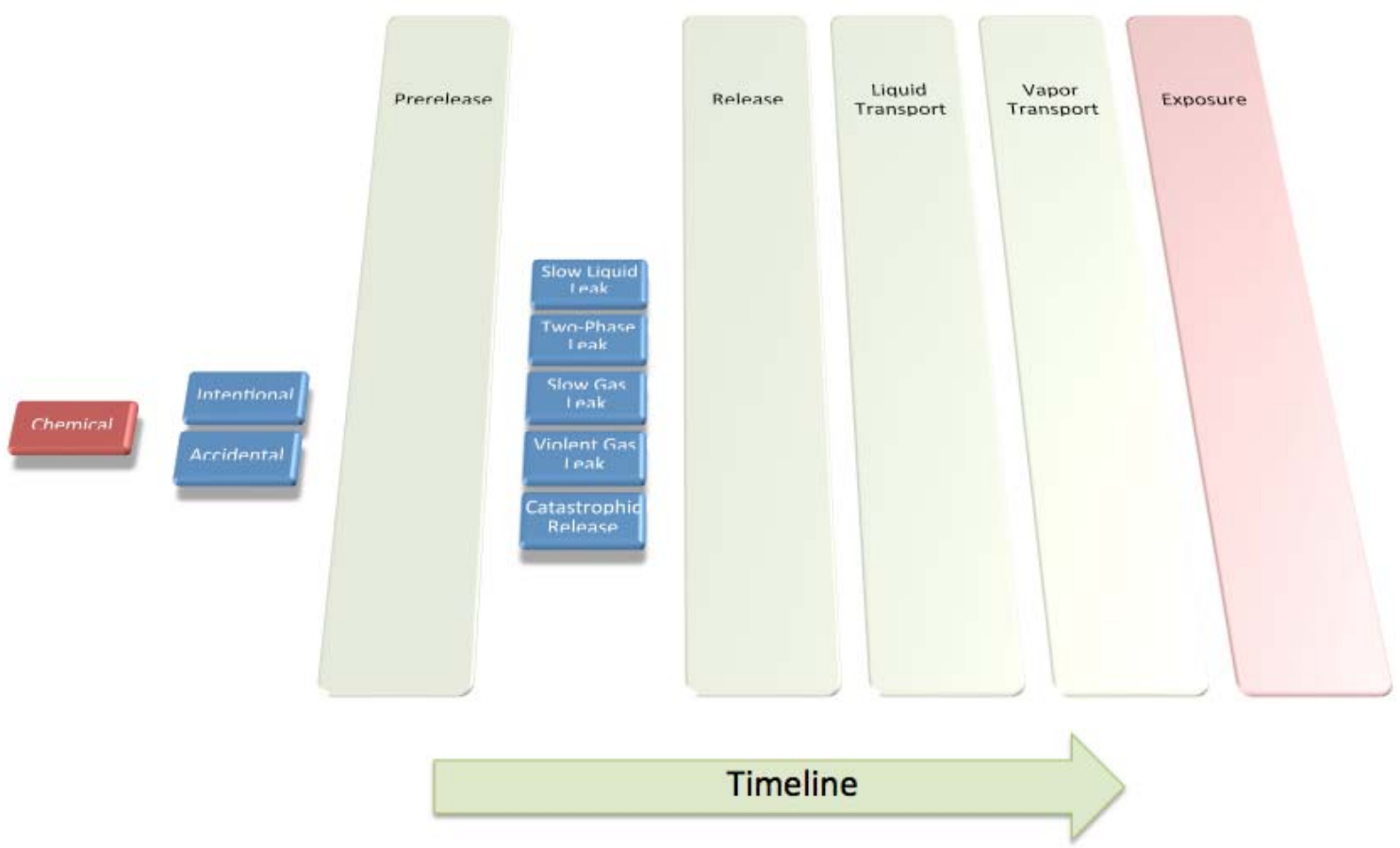

Figure 6. Event Progression on a Timeline (includes Chemical, Scenarios, and Incidents). 
Prerelease is the first stage of a scenario before containment has been lost. This includes both normal operating conditions and potential "loss of containment" conditions. In this section, determinations are made by assessing preventative measures and probabilities. Release is the second stage of the progression, and this is the point where containment of the chemical has been compromised and will progress without intervention. Liquid Transport is the stage where a liquid chemical is mobile outside of containment. Gaseous chemicals would not proceed through this time point, and therefore, any countermeasures that act on that time point would not act upon a gaseous chemical. Vapor Transport is the stage where a liquid chemical is evaporating or is highly volatile or a gaseous chemical is directly released into the atmosphere. This can occur simultaneously with Liquid Transport. The final time point in the event is Exposure, which we have defined to be a chemical leaving the confines of the facility.

\subsubsection{Countermeasures on the Timeline}

Within each stage of the release event, certain countermeasures can be applied (Figure 7). Efficacy of a countermeasure is directly affected by both the chemical and the way in which is it used. This is also where the numerical goal can be met. An "impact factor" can be generated for each countermeasure once it goes into the event progression, which is a combination of the chemical's properties and the state it is in. In Prerelease one would find countermeasures that prevent or inhibit the root cause of a potential loss of containment (relief valves, inhibitor addition, or emergency power). During Release, countermeasures can be employed to reduce the amount that can be lost from containment (emergency storage, quench or purge systems). At the Liquid Transport stage, a chemical can only be recaptured or quenched, and countermeasures such as dikes, berms, foam blankets, and water sprays are used here. In Vapor Transport, the same is true regarding capture or quenching, but only certain countermeasures are applicable such as water sprays, enclosures, and foam sprays. Once Exposure has been reached, it has been determined that the system of countermeasures present at the facility has failed or is inadequate.

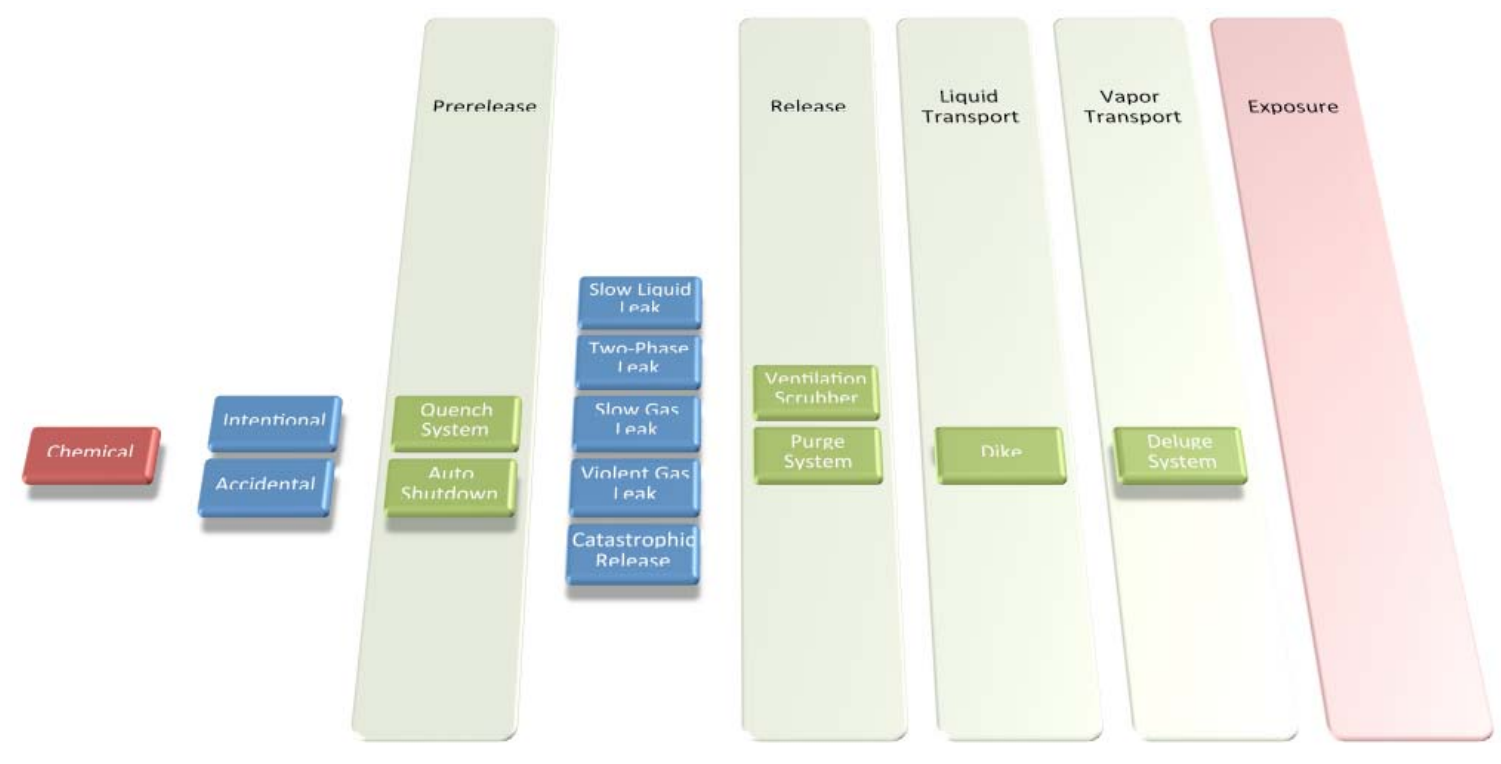

Figure 7. Countermeasures Placed on the Timeline. 
As was stated above, a countermeasure's efficacy is directed affected by the chemical and the environmental conditions that are present. If this effort proceeds beyond the conceptual stage, this would be the bulk of the work. Two examples of an efficacy determination are included below along with the reasoning behind these values.

\section{Example: Water Curtain with Hydrochloric Acid, Sulfur Dioxide, and Hydrogen} Sulfide

- In modeling scenarios, water sprays can be expected to have a decreasing effectiveness for $\mathrm{HCl}(100 \%), \mathrm{SO}_{2}(20 \%)$, and $\mathrm{H}_{2} \mathrm{~S}(0 \%)$ at a vapor to air concentration of $~ 3 \%$

- Ammonia at a vapor concentration of $1.5 \%$, can be $95 \%$ mitigated using a water spray

- These percentages are based on solubility of the gas in water (Henry's Law constant), modeling using Henry’s Law constant predicts 100-90\% mitigation for ammonia

- Most compounds have measured constants; solubilities can be generalized

- We will be able to slot in other chemicals into this effectiveness chart to yield a final mitigated amount

\section{Example: Foam Scrubbing with Formaldehyde}

- Foam Scrubbing mitigates 99\% of formaldehyde vapor

- Experiments were conducted with gas concentrations of $0.017 \%$ to $0.36 \%$ were used with low expansion foam containing $\mathrm{Na}_{2} \mathrm{~S}_{2} \mathrm{O}_{5}$, achieved 99\% mitigation

- Foam scrubbing used with the appropriate reactive agent is commonly viewed as having 100\% mitigation efficiency

- For known pairings of reactive agent and chemical of interest, we can slot those values into the efficacy chart

\subsubsection{Outcome of Release Event Timeline}

Generally, the reduction factor of overall hazard for the IST Metrics will be the outcome (Figure 8). More specifically, a determination of the likelihood of incidents and scenarios combined with a chemical's ability to bypass countermeasures will be given a numerical value that can be applied in several ways to reduce the RHI value of the IST Metrics. 


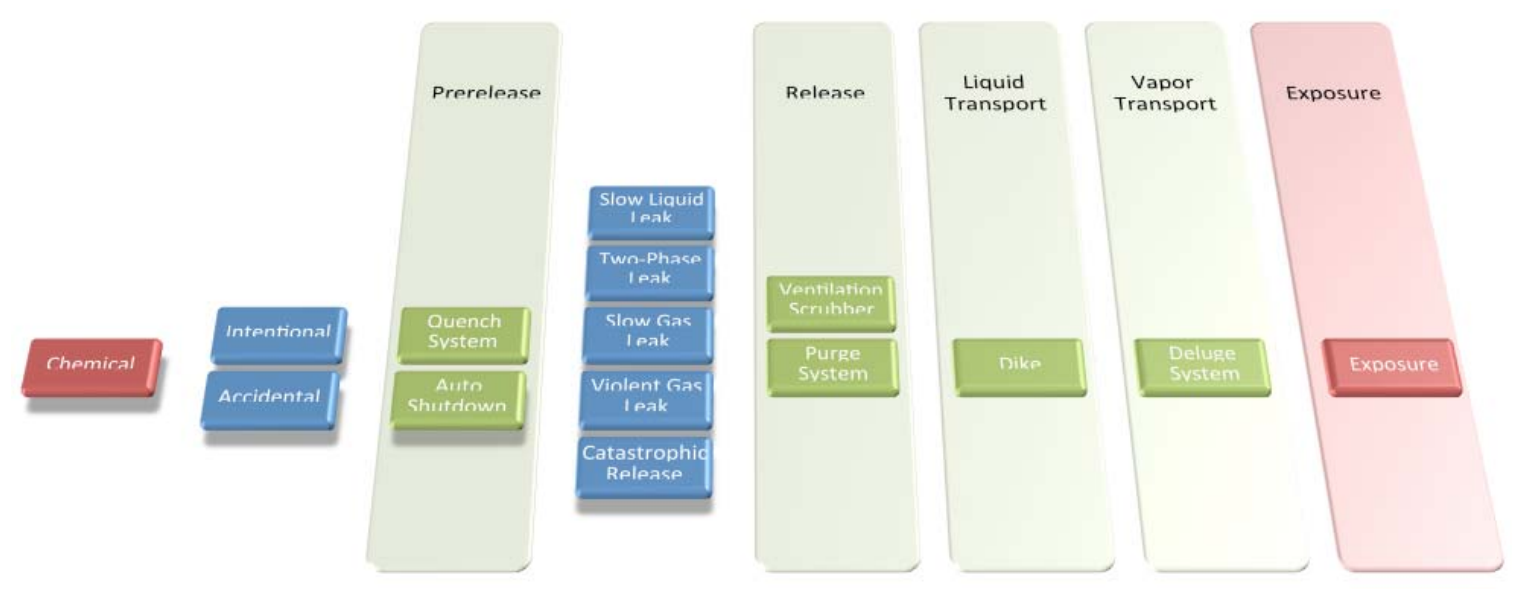

Figure 8. Outcome of the Release Event Timeline.

Again, this is a concept that has not yet been tested fully. It is one solution to the problem of applying a reduction factor to a mixed Metrics where both probabilities and concrete mitigation factors are unknown. Future work, especially in the areas of efficacy values and outcome integration is needed.

\subsection{References}

1. World Chlorine Council, “Chlorine Safety Scrubbing Systems.” Edition 1, 2011.

2. EPA CFR Title 40

3. OSHA CFR 29 Part 1910

4. Vasukus M. Fthenakis. Prevention and Control of Accidental Releases of Hazardous Gases. New York: Wiley, 1993.

5. Inherently Safer Chemical Processes A Life Cycle Approach, $2^{\text {nd }}$ Edition. Center for Chemical Process Safety. Hoboken: Wiley, 2009.

6. Fthenakis, Vasilis. M. Prevention and Control of Accidental Releases of Hazardous Gases. New York: Wiley, 1993. Print.

7. Prevention and Control of Accidental Releases of Hazardous Gases. Vasilis M. Fthenakis, Wiley, 1993.

8. Mitigation of Vapor Cloud Hazards Part II. Limiting The Quantity Released and Countermeasures for Releases Richard W. Prugh, Plant/Operations Progress 5, 3, 1986.

9. Chlorine Safety Scrubbing Systems, World Chlorine Council, April 2011, Edition 1.

10. “Chemical Switch Cuts Costs, Improves Safety.” Products Finishing Magazine, 2005, Bionomic Industries. 


\section{SAFETY AND SECURITY}

The overlap of chemical safety practices and chemical security is often assumed, however this interaction has not been well characterized (Figure 1). Chemical industry is motivated to utilize safe practices in order to protect their workers and surrounding populations in the event of accidental chemical releases. In addition, consumer interests in environmental and public health issues also drive chemical industry to use of safer materials and processes. For these reasons, safety design and engineering have progressed in parallel with the emergence of chemical industry.

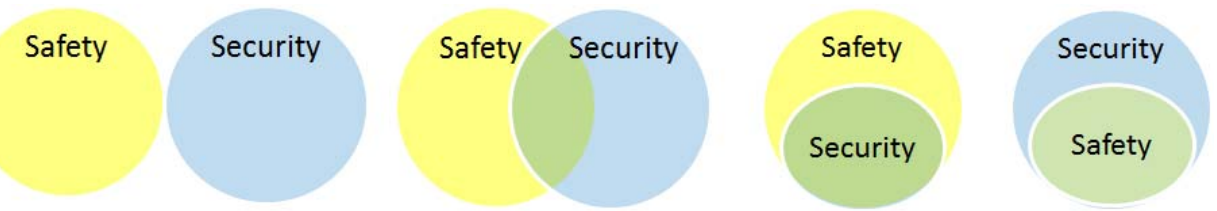

Figure 1. Potential relationships of safety and security in chemical industry. The overlap between these domains is not well defined.

Increasingly, chemical facilities also consider security concerns within their hazard assessments. Security measures are implemented in chemical industry to minimize the risk of harm resulting from intentional acts against a facility, and to protect assets within the facility from theft, diversion or sabotage. Because there are protection measures that address both safety and security concerns for a single hazard, it seems feasible that safety and security could be designed and engineered together. However, this mutual benefit for both safety and security may not always be the case. Table 1 provides examples of protection measures and their impact on safety and security.

Table 1. Examples of protection measures and their respective impacts on safety and security. Impacts are rated as positive (green), negative (red), and mixed (yellow). These are just a few examples to highlight the complex relationship between safety and security in chemical industry.

\begin{tabular}{|l|l|l|}
\hline \multicolumn{1}{|c|}{ Measure } & \multicolumn{1}{|c|}{ Safety Impact } & \multicolumn{1}{c|}{ Security Impact } \\
\hline Labeling HF tankers & $\begin{array}{l}\text { Facilitates hazard } \\
\text { identification in HAZMAT } \\
\text { response }\end{array}$ & $\begin{array}{l}\text { Notifies an adversary of } \\
\text { potential target }\end{array}$ \\
\hline $\begin{array}{l}\text { Transporting } \mathrm{Cl}_{2} \text { in multiple 1- } \\
\text { ton cylinders rather than 90- } \\
\text { ton railcars to eliminate a } \\
\text { catastrophic release scenario }\end{array}$ & $\begin{array}{l}\text { Requires additional } \\
\text { connection and transfer } \\
\text { processes which increases } \\
\text { chance of accidents due to } \\
\text { human error }\end{array}$ & $\begin{array}{l}\text { Small tanks may provide more } \\
\text { opportunity for theft and } \\
\text { diversion }\end{array}$ \\
\hline $\begin{array}{l}\text { Physical security measures } \\
\text { such as barriers and access } \\
\text { controls (e.g., locked doors) }\end{array}$ & $\begin{array}{l}\text { Hinders evacuation in an } \\
\text { emergency } \\
\text { Increased complexity of plant } \\
\text { layout }\end{array}$ & $\begin{array}{l}\text { Delays access to intruder } \\
\text { Knowledge partitioning so that } \\
\text { operators only know one } \\
\text { piece of process }\end{array}$ \\
\hline $\begin{array}{l}\text { Substituting NaClO for } \mathrm{Cl}_{2} \text { in } \\
\text { water treatment }\end{array}$ & $\begin{array}{l}\text { Inherently safer due to } \\
\text { elimination of hazard }\end{array}$ & $\begin{array}{l}\text { Inherently more secure due to } \\
\text { elimination of toxic inhalation } \\
\text { hazard }\end{array}$ \\
\hline
\end{tabular}


Based on this handful of examples, it appears that safety and security measures overlap in some cases, are independent in others, and actually conflict with each other in selected cases. Therefore, we are left with a complex engineering challenge: to develop an approach for process/facility design that addresses both safety and security objectives, leveraging one another when possible, and accommodating conflicts if they exist. The first step in developing a concerted approach is to fully characterize the intersection of safety and security. Here we will discuss a few important analysis considerations for this characterization effort, specifically focusing on the differences in risk of accidental versus intentional chemical incidents.

\subsection{Risk Triplets for Accidental vs. Intentional Scenarios}

Risk is commonly understood as a product of probability and consequence. Kaplin and Garrick further developed this concept by proposing that a risk curve $(R)$ could be calculated based on a complementary cumulative distribution function (CCDF) using a set of triplets described in equation 1.

$$
R_{\text {safety }}=<s_{i}, p_{i}, x_{i}>
$$

Where...

- $s_{i}$ is the scenario,

- $p_{i}$ is the probability of that scenario, and

- $x_{i}$ is the consequences of that scenario

Safety risks, or the risk of harm resulting from an accidental chemical release, can be effectively calculated using this definition. In this calculation, probability of an incident is based on historical data, experimental data, fault trees, or other quantitative assessment techniques. However calculating security risk, or the risk of harm from an intentional scenario, is more complex. The probability term in a security risk calculation is now dependent on an adversary's perceptions of the scenario and the potential consequences. Because of this, $p$ is interdependent on $s$ and $x$ and therefore no longer satisfies the definition of a CCDF. Furthermore, statistical estimates of probability are susceptible to considerable uncertainty. To address these weaknesses in security risk calculations, Wyss and coworkers proposed a new triplet using "difficulty" in place of probability (equation 2).

$R_{\text {security }}=<s_{i}, d_{i}, x_{i}>$

Where...

- $d_{i}$ is the degree of difficulty to successfully accomplish a scenario

The difficulty term represents the challenges that an adversary would encounter in gathering and employing resources such as personnel, material, and knowledge, to successfully execute a specified scenario. In developing a chemical attack scenario, an adversary will weigh his objectives against his resources and capabilities in order to select what he perceives to be his best scenario option. Conversely, defense investments often aim to increase the difficulty to the adversary or reduce the consequences of a chemical attack. In this respect, the new risk triplet is much more transparent for security applications than the general risk triplet based on probability. 


\subsection{Assessing difficulty of CSC versus traditional chemical scenarios}

The Chemical Defense Systems Model was utilized to qualitatively evaluate the relative difficulty of a scenario targeting the chemical supply chain (CSC) compared to a traditional chemical attack scenario (e.g., Aum Shinrikyo's sarin attack on the Tokyo subway is a "traditional" attack). Once an adversary conceives of a chemical attack he will undertake a number of activities and decisions to develop his attack. The "path" an adversary takes to develop an attack is influenced by their objectives, capabilities and resources, as well as their perceptions of our defenses and vulnerabilities.

To execute a chemical attack an adversary prepares three elements of an attack scenario: the chemical agent, the dissemination strategy and the target. Developing the agent may involve activities such as buying, stealing and/or synthesizing chemicals, storing or stockpiling prepared chemical agents, developing formulations, testing the toxicity, etc. An adversary also develops a dissemination strategy to release the agent and expose the target. A dissemination strategy may be as simple as uncapping a chemical container, or may be more sophisticated by using an aerosolization, sprayer or explosive device. Attack targets can be roughly categorized into five venue types: indoor, outdoor, food/beverage, CSC and water supply. To prepare for an attack on a specific target, an adversary may learn the schedule or operations of their target, identify vulnerabilities or ways to overcome security features, perform walk-throughs or test runs, and subsequently develop a procedure to execute an attack based on the information they have gathered.

In a for a traditional attack scenario, such as those considered for defense planning, the preparation activities for a set of scenario elements may occur relatively independently. To prepare an indoor inhalation scenario, for example, an adversary would undertake a number of steps to synthesize sarin, to build a backpack sprayer and to stake out a transit facility. These preparation activities are represented by a multistep pathway (Figure 2a). In contrast, while attack on the CSC is defined by the same set of scenario elements, the preparation pathway is

a)

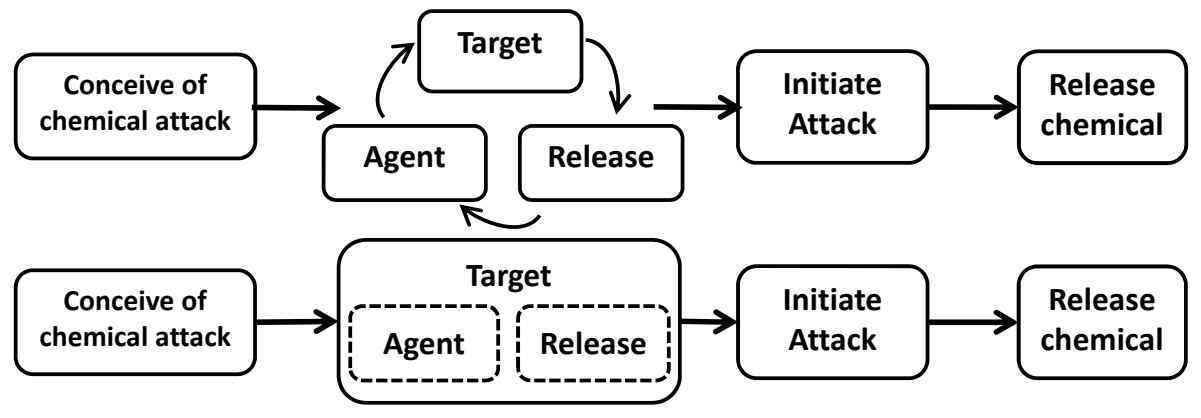

Figure 2. High-level outline of the adversary's chemical attack pathways based on the Chemical Defense Systems Model. In the traditional attack path (a) the scenario elements (target, agent and release) are prepared relatively independently. In a CSC attack path (b) the scenario elements are aggregated which reduces the total number of steps in the path. 
condensed compared to the traditional attack (Figure 2b). This is because the chemical agent is intrinsic to the attack target in a CSC scenario. For example, an adversary may sabotage a process at a chemical plant that utilizes significant quantities of hydrochloric acid, releasing the hazardous chemical onto the surrounding population. In this example, preparation activities are focused primarily on disrupting the target.

The structures of a CSC attack paths and traditional attack paths are fundamentally different (Figure 2). This indicates that there may also be a corresponding difference in the level of difficulty to execute each type of attack successfully. Therefore, we would expect that risk calculations for a CSC attacks will be distinct from that of traditional chemical attacks. At a high level, we can hypothesize that the consolidated scenario path for CSC attacks may reduce the difficulty to an adversary to prepare and execute an attack. However, the overall risk of a CSC attack is influenced by many factors. A full analysis of efficacy of safety and security measures would be required to accurately assess their impact on the scenario difficulty and the consequences.

\subsection{Conclusion}

Security measures in chemical industry influence chemical terrorism scenarios on many levels; a chemical attack may be deterred, delayed, detected, or mitigated through response. In many cases safety measures implemented in the CSC to prevent and mitigate accidental releases can be leveraged for security objectives. In general, protection measures that reduce or eliminate a hazard (as opposed to measures that control a hazard) tend to benefit both safety and security objectives. However, as discussed, safety and security are not always synchronous. Therefore, an approach for integrated safety and security risk assessments is needed in order to set appropriate objectives for each, and to build a protection architecture that addresses both. 


\section{DISTRIBUTION}

1 Chemical Security and Analysis Center

Attn: Adolfo R. Negron

adolfo.negron@st.dhs.gov

$\begin{array}{llll}1 & \text { MS0734 } & \text { Margaret Ochs } & 6124 \text { (electronic copy) } \\ 1 & \text { MS0734 } & \text { J. Bruce Kelly } & 6632 \text { (electronic copy) } \\ 1 & \text { MS0899 } & \text { RIM-Reports Management } & 9532 \text { (electronic copy) } \\ 1 & \text { MS1361 } & \text { Calvin Jaeger } & 6833 \text { (electronic copy) } \\ 1 & \text { MS1411 } & \text { Amy Sun } & 1814 \text { (electronic copy) } \\ 1 & \text { MS9004 } & \text { Peter Davies } & 8100 \text { (electronic copy) } \\ 1 & \text { MS9004 } & \text { Nathaniel Gleason } & 8101 \text { (electronic copy) } \\ 1 & \text { MS9004 } & \text { Duane Lindner } & 8120 \text { (electronic copy) } \\ 1 & \text { MS9004 } & \text { Howard Hirano } & 8110 \text { (electronic copy) } \\ 1 & \text { MS9291 } & \text { Trisha Hoette } & 8114 \text { (electronic copy) } \\ 1 & \text { MS9291 } & \text { Mitchell Anstey } & 8125 \text { (electronic copy) } \\ 1 & \text { MS9292 } & \text { Kamlesh Patel } & 8125 \text { (electronic copy) } \\ 1 & \text { MS9292 } & \text { Benjamin Wu } & 9634 \text { (electronic copy) } \\ 1 & \text { MS9406 } & \text { Scott Paap } & 8114 \text { (electronic copy) } \\ 1 & \text { MS9406 } & \text { Todd West } & 8114 \text { (electronic copy) }\end{array}$




\section{S. Sandia National Laboratories}

